\title{
Learning to Listen to Place:
}

Beyond Restoration at the Former Royal Alberta Museum

by

\begin{abstract}
Nastassia Usenka
A thesis submitted to the Faculty of Graduate and Postdoctoral Affairs in partial

fulfilment of the requirements for the degree of
\end{abstract}

Master of Architecture

in

Azrieli School of Architecture \& Urbanism

\author{
Carleton University \\ Ottawa, Ontario \\ (C) 2021 \\ Nastassia Usenka
}




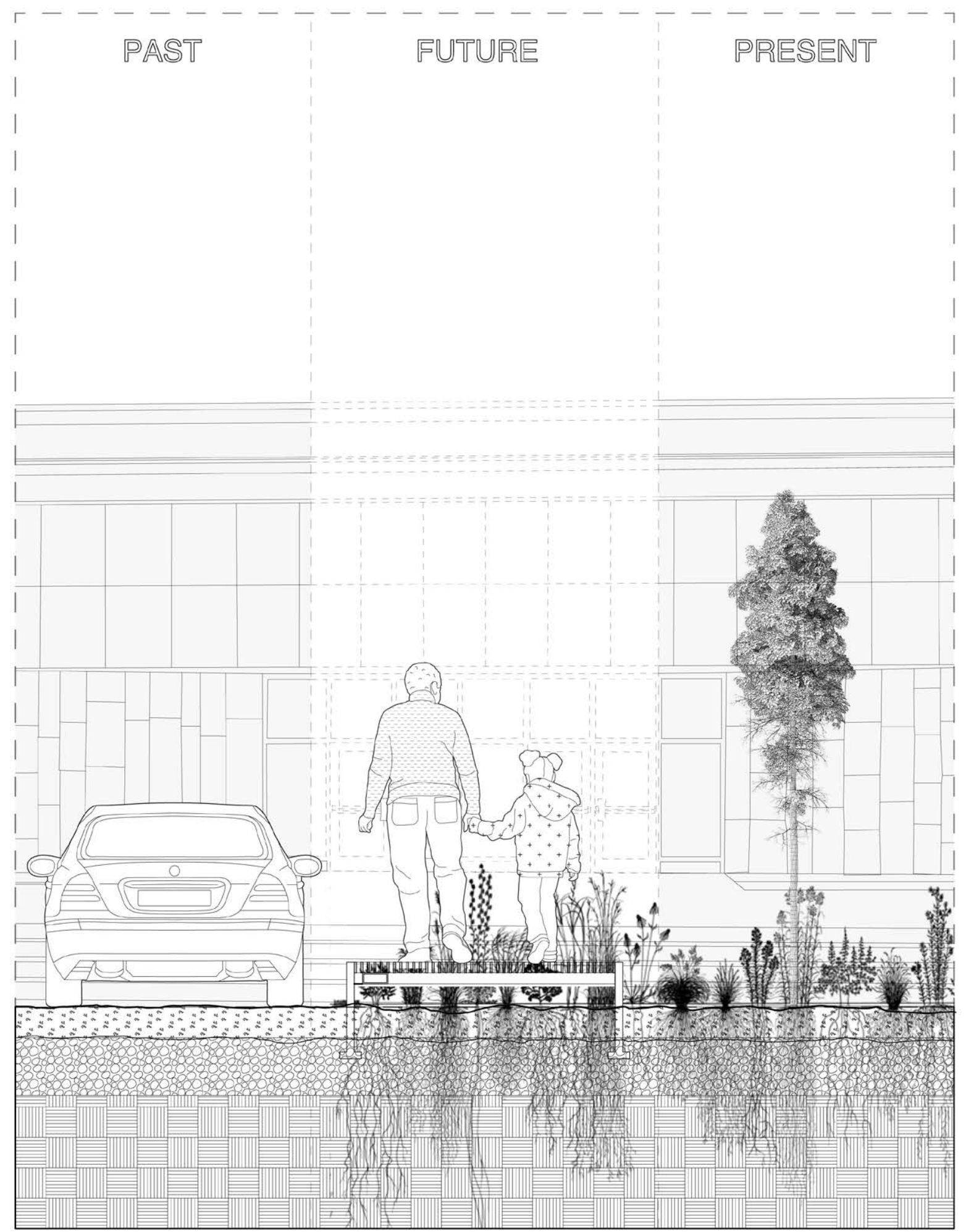

Fig. 0.1: A New Connection 


\section{ABSTRACT}

In light of the climate crises of the 21 st century, the need for the conservation, restoration and adaptive reuse of existing buildings is crucial to meeting Canadian and global ecological sustainability goals. Focusing on the adaptive reuse of the building and site of the former Royal Alberta Museum in Edmonton, Alberta, this project promotes a holistic approach to sustainability that equally recognizes societal, ecological and economic considerations.

This thesis argues that a material and conceptual methodology of critical questioning, disassembly, evaluation, and reassembly can create a culture of renewal and repair in which architecture consistently adapts to our future needs. By listening to Indigenous ways of knowing and by framing time through the seven generations model, the thesis places itself in opposition to current, fast-paced building methodology. It suggests a future that moves towards conciliation through a multi-generational process to create new, heartfelt and lasting connections to people and place. 


\section{ACKNOWLEDGMENTS}

Thank you Sheryl, for your joyful guiding presence, and for creating a sense of normalcy this year. Thanks to Ben, Robin and Sinan for being the greatest thesis group, a wonderful sounding board for ideas.

Thank you Andrei and Alina, for always laughing at me, and, most importantly, for making me laugh at myself.

Thank you to my parents, for steadfastly believing in the importance of education, and for your unending support.

Thank you to Barry, Chris and Patrick, for helping navigate conversations of reconciliation, for sharing a database of Centennial projects, and for sharing plans of the museum.

Thank you Erin, for always being one step ahead, but right by my side. Thank you Tasia, for your unending support and guidance along the way. I honestly could not have done this without you both.

Thank you Camille and Melissa, for your friendship and support, for the wine nights, and for the high-pitched shrieking which started on day one of the M.Arch 1 program, and which has now echoed across oceans and continents.

Thank you Jan, for everything.

Thank you to all the other countless studio friends, family members, professors and contributors who have helped and shared in this experience along the way.

And lastly, thank you for reading. 


\section{TABLE OF CONTENTS}

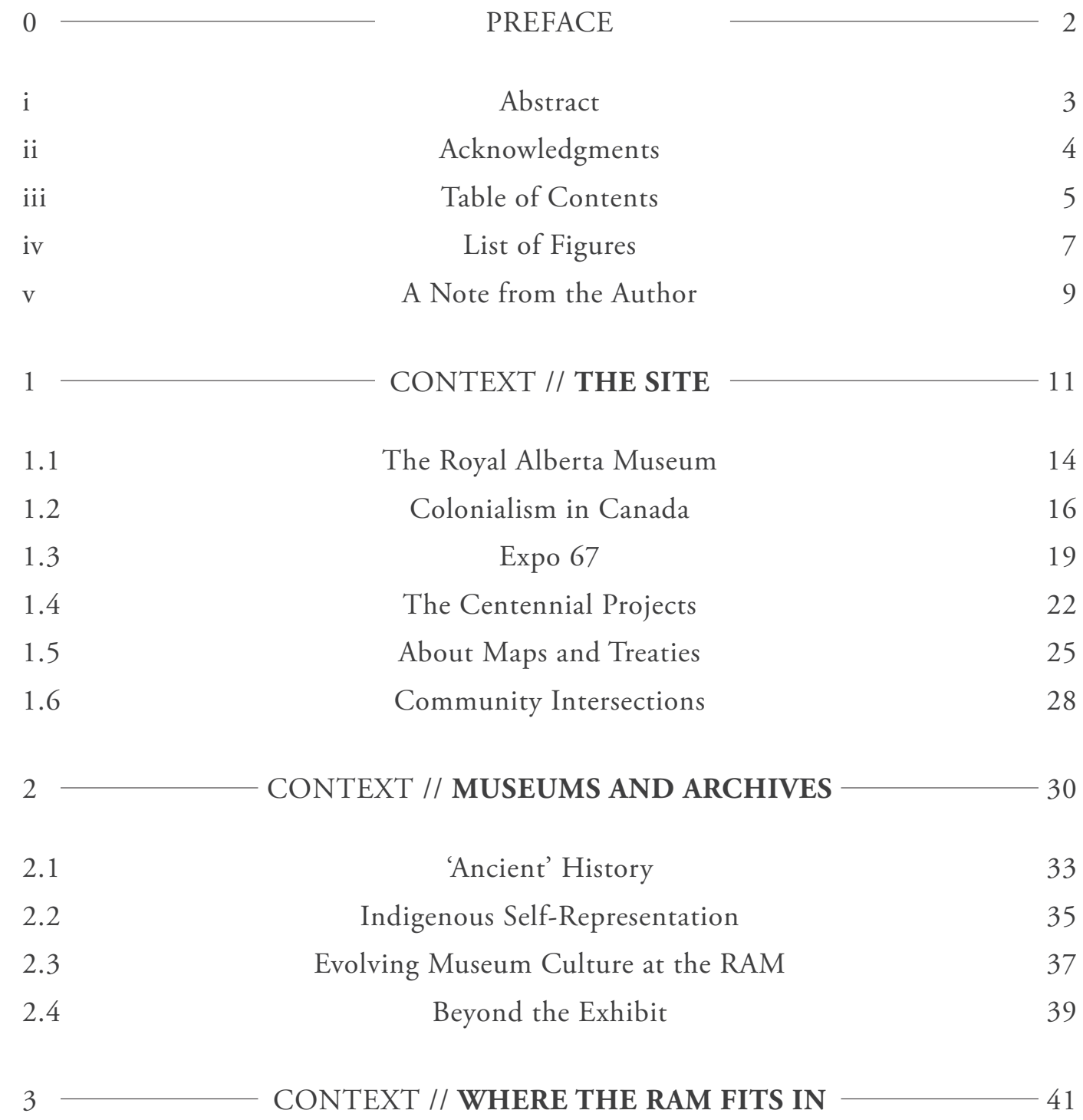




\section{TABLE OF CONTENTS}

4 FOUNDATIONS // VERNACULAR ARCHITECTURE 49

4.1

4.2

4.3

5 -FOUNDATIONS // SUSTAINABILITY

5.1

5.2

5.3

6 FOUNDATIONS // TAKING STOCK

7 INTENTIONS // THREE INTERVENTIONS

7.1

7.2

7.3

7.4

7.5

8 INTENTIONS // THE PROCESS OF TIME

9 INTENTIONS // REFLECTION

11

12 64 72 86 133 $-136$

BIBLIOGRAPHY 139 APPENDIX 


\section{LIST OF FIGURES}

\begin{tabular}{|c|c|}
\hline Fig. 0.1: & A New Connection \\
\hline Fig. 1.1: & The (former) Royal Alberta Museum \\
\hline Fig. 1.2: & Observing Government House \\
\hline Fig. 1.3: & (Top) Partial Image of the Expo Grounds \\
\hline Fig. 1.4: & (Bottom) Indians of Canada Pavilion \\
\hline Fig. 1.5: & Centennial Project Map \\
\hline Fig. 1.6: & Overlapping Mappings \\
\hline Fig. 1.7: & Community Feedback \\
\hline Fig. 2.1: & (Above) North Wall Frieze \\
\hline Fig. 2.2: & (Bottom) Writing-on-Wall Glyphs \\
\hline Fig. 3.1: & Contenxtualizing the Site \\
\hline Fig. 3.2: & Site Plan \\
\hline Fig. 3.3: & Main Entrance \\
\hline Fig. 3.4: & (Right) Key Plan \\
\hline Fig. 3.5: & (Top) Government House \\
\hline Fig. 3.6: & (Bottom) Korean Pavilion \\
\hline Fig. 3.7: & (Right) Key Plan \\
\hline Fig. 3.8: & (Above) Ksan Totem Pole \\
\hline Fig. 4.1: & Current Köppen-Geiger Map \\
\hline Fig. 4.2: & Sketchbook Notes: The North \\
\hline Fig. 4.3: & Sketchbook Notes: South Korea \\
\hline Fig. 4.4: & Sketchbook Notes: Pacific Northwest \\
\hline Fig. 5.1: & The Three Tiers \\
\hline Fig. 5.2: & Guiding Questions \\
\hline Fig. 5.3: & The Seven Generations Model \\
\hline Fig. 6.1: & The Royal Alberta Museum Entrance \\
\hline Fig. 6.2: & Site Photos Contact Sheet 1 \\
\hline Fig. 6.3: & The 'Sculpture Garden' \\
\hline Fig. 6.4: & Site Photos Contact Sheet 2 \\
\hline Fig. 6.5: & Observing Government House \\
\hline Fig. 6.6: & Site Photos Contact Sheet 3 \\
\hline Fig. 6.7: & Connection to the River Valley \\
\hline Fig. 6.8: & Site Photos Contact Sheet 4 \\
\hline Fig. 6.9: & New Possibilities for Occupation \\
\hline Fig. 6.10: & Site Photos Contact Sheet 5 \\
\hline Fig. 6.11: & Taking Stock \\
\hline Fig. 6.12: & Mapping Materiality \\
\hline
\end{tabular}




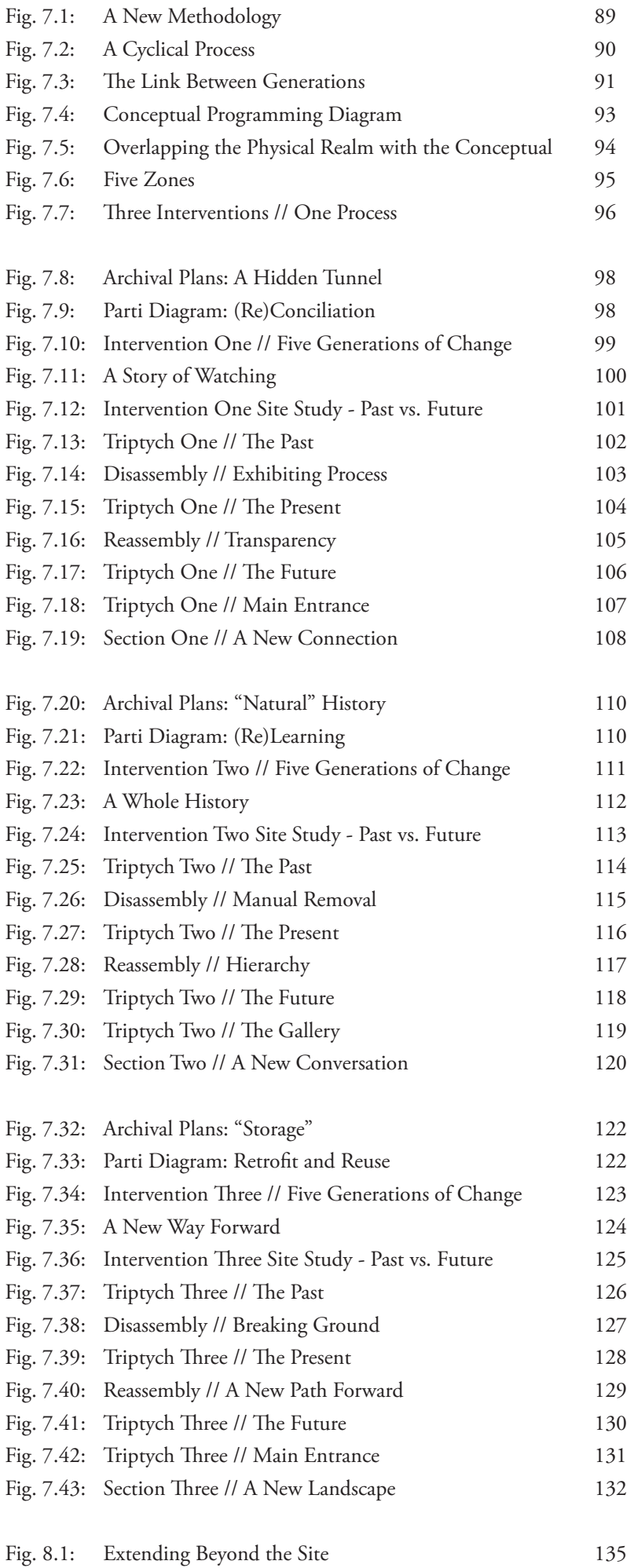

Fig. 0.2 - Fig. 0.9: Alberta Public Works Plans $\quad$ 144-150

*All images by author unless otherwise stated in the accompanying citation. 


\section{A NOTE FROM THE AUTHOR}

I would like to reiterate the following statement, beautifully said by Beatrice Harris in an article titled Indigenous Representation in the 'Moral Museum':

"As a non-Indigenous researcher attempting to work within a decolonizing framework, I am aware that I embody a privileged position in this particular academic space. Further, I am not equipped to comprehensively understand and explain Indigenous experiences, values and knowledges." ${ }^{1}$

This statement applies to me and this research as well.

I am not an expert in Indigeneity, I am not Indigenous. But I am trying to make sense of the colonial implications of the Anthropocene and trying to find my place in the world today. I am learning to listen, learning to open my values and beliefs to criticisms in the pursuit of healing. I sincerely hope that I can continue to learn, to find ways to define safe spaces, and to look for difficult and uncomfortable questions in the search of a path forward, a path towards mutual understanding and open conversations.

This thesis relies on the term "Indigenous" throughout the writing whenever possible, but in some cases other terminology is used in direct quotations, or when incorporated in the official names and titles of past events, legislations or publications. For anyone struggling to understand correct terminology and word usage, I highly recommend the definitions in Appendix I of Indigenous Relations by Bob Joseph.
1 Beatrice Harris, "Indigenous Representation in the 'Moral Museum': Perspectives from Classical Ethical Theory," Museum Management and Curatorship 33 no. 2 (March 4, 2018): 203, https://doi.org/ 10.1080/09647775.2018.1442738. 


\section{To those of us:}

who seek to communicate the intent of our souls through movement as the words do not yet exist in the spoken language 


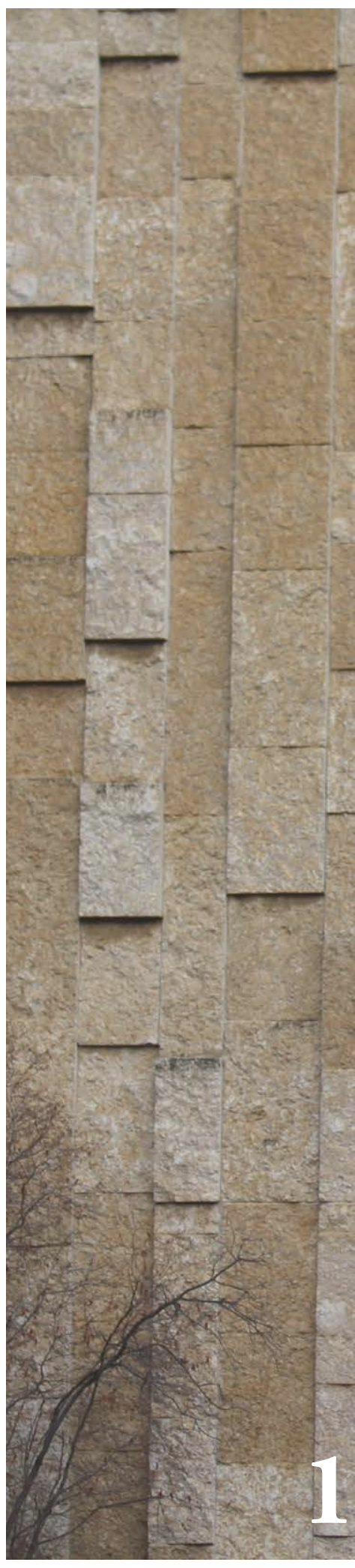

CONTEXT 


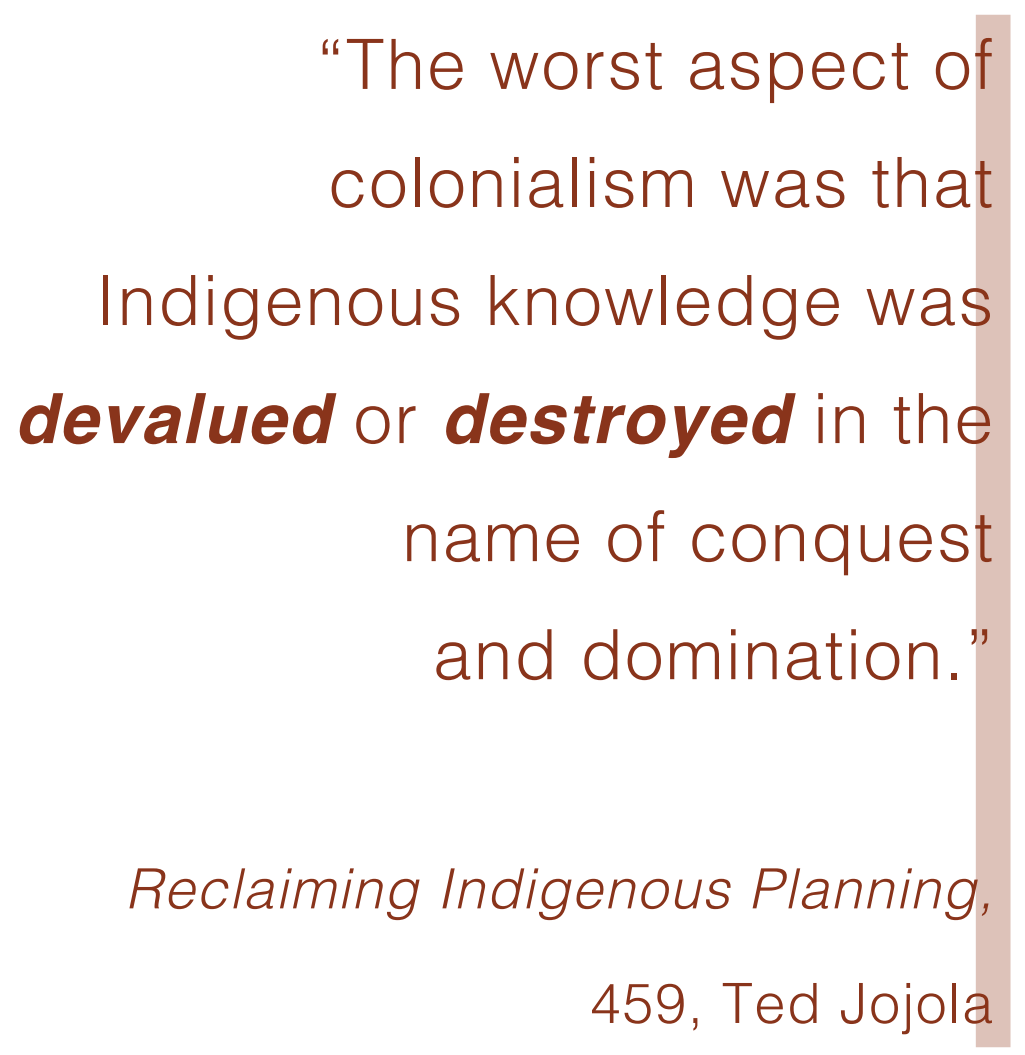



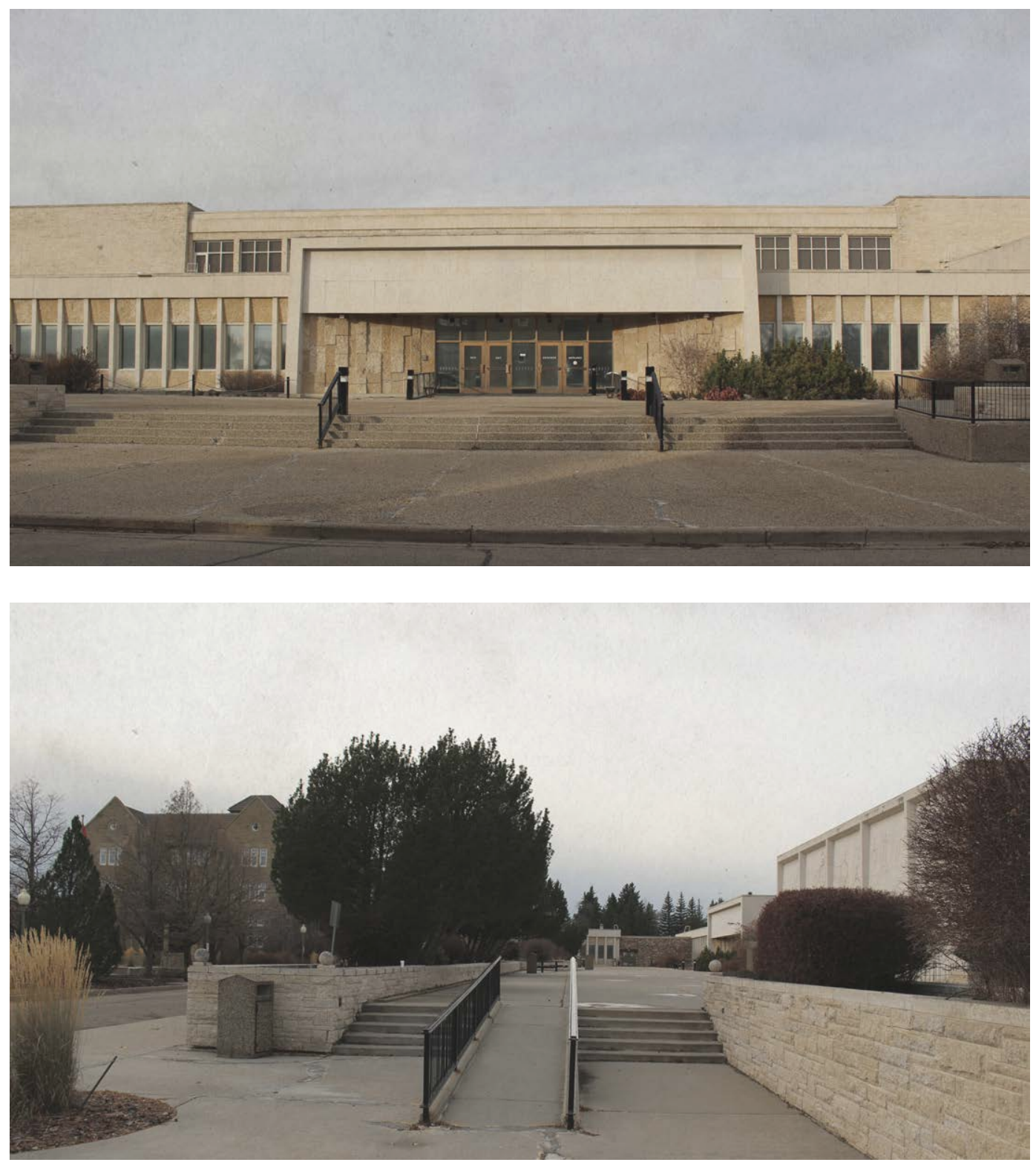

Fig. 1.1: The (former) Royal Alberta Museum 


\subsection{THE ROYAL ALBERTA MUSEUM}

The former Royal Alberta Museum, now dubbed the Glenora Building, is a museum in Edmonton, Alberta built as a part of Canada's Centennial Projects in the 1960s. There are roughly 800-900 of these buildings across the country, buildings designed to forge a Canadian identity through the federal support of arts and culture. ${ }^{1}$ The site is nestled between the affluent neighbourhood of Glenora, the downtown core, the prominent North Saskatchewan River Valley, and sits on 'provincial' land.

Funding for a new, larger building was announced by the provincial government in 2011, which resulted in the building closing its doors to the public in 2015 and continuing to move archives and galleries to the new facility until $2019 .^{2}$ As of 2020, the building will soon stand empty. In 2016, shortly after the official closure, the province put out a call through Alberta Infrastructure for proposals "to examine the potential development of the Royal Alberta Museum (commonly abbreviated as the RAM) into a public green space." ${ }^{3}$ Development, in this case, meant demolition and deconstruction of the building, with no consideration for adaptive reuse or rehabilitation of the site. ${ }^{4}$

\section{Province seeks ideas on how to redevelop Royal Alberta Museum site}

A By Julia Wong · Global News

1 Posted March 5, 2016 5:04 pm . Updated March 5, 2016 9:08 pm

\footnotetext{
New plans for historic Royal Alberta Museum site

f $(1)$ in

Province considering a public green space to fill empty lot

Zoe Todd · CBC News · Posted: Mar 04, 2016 6:00 AM MT | Last Updated: March 4, 2016
}

1 Marco Polo and Colin Ripley, Architecture and National Identity / Architecture et Identite Natioinal: The Centennial Projects 50 Years On / Les Projets Du Centenaire 50 Ans plus Tard, Bilingual edition (Halifax, Nova Scotia, Canada: Dalhousie Art Gallery, 2014).

2 Cook, Dustin, "What's next for the Old Royal Alberta Museum? Concerned Residents Make Plea for Repurposing the Site," News, Edmonton Journal, May 5, 2019, https://edmontonjournal.com/news/ local-news/whats-next-for-the-old-royalalberta-museum-concerned-residentsmake-plea-for-repurposing-the-site-withits-future-up-in-the-air

3 Wong, Julia, "Province Seeks Ideas on How to Redevelop Royal Alberta Museum Site," News, Global News, March 5, 2016, https://globalnews.ca/news/2559879/province-seeks-ideas-on-how-to-redeveloproyal-alberta-museum-site/.

4 Cook, Dustin, "What's next for the Old Royal Alberta Museum? Concerned Residents Make Plea for Repurposing the Site." 
Sharing the site and sitting opposite the museum, but apparently saved the same fate of the RAM, is the Government House, a former official residence of the Lieutenant Governor of Alberta and a listed provincial historic resource. ${ }^{5}$ The juxtaposition highlights the willingness of the province to destroy a cultural landmark without community consultation ${ }^{6}$, while explicitly stating protection for a symbol of provincial governmental power. ${ }^{7}$ This thesis explores an alternative future for the former Royal Alberta Museum through adaptive reuse of the building, and rehabilitation of the site it stands on with consideration of its contested history.
5 Wong, Julia, "Province Seeks Ideas on

How to Redevelop Royal Alberta Museum Site."

6 Simons, Paula, "Wanted: An Idea Good Enough to Save the Historic RAM," News, Edmonton Journal, December 20, 2017, https://edmontonjournal.com/ opinion/columnists/paula-simons-wantedan-idea-good-enough-to-save-the-historic-ram.

7 Todd, Zoe, "New Plans for Historic Royal Alberta Museum Site," News, CBC News, March 4, 2016, https:// www.cbc.ca/news/canada/edmonton/ new-plans-for-historic-royal-alberta-museum-site-1.3475299.

EDMONTON JOURNAL

\section{Local News \\ What's next for the old Royal Alberta Museum? Concerned residents make plea for repurposing the site}

May 05, 2019 - Last Updated 1 year ago $\cdot 3$ minute read

\section{Residents fret over fate of former Royal Alberta Museum}

Bill Mah

Oct 27, 2016 - Last Updated 4 years ago $\cdot 3$ minute read

Politics / Local News / Local Arts / Commercial Real Estate / Columnists

\section{Paula Simons: Edmonton, we can't lose the RAM to the wrecking ball}




\subsection{COLONIALISM IN CANADA}

The creation of museums, and the forging of a uniform national culture, are complex political moves purposely carried out to subjugate and suppress the Indigenous peoples in Canada. Museums which focus on the "history of man" are rooted in anthropological and ethnographic traditions of the 1700 s-1800s, in which the study of other cultures became a political tool that contributed to the creation of the 'other' in collective Western consciousness. ${ }^{8}$ This was done in order to justify aggressive expansion into occupied lands.

The history of Canada as a country is tied to a system in which Indigenous peoples were forced onto reserves that were too small for self-sufficiency, ill-suited for agriculture, and detached from traditional ways of life and from their surroundings. ${ }^{9}$ The creation of a reserve system politicized and divided space, resulting in "[the definition of] two primal spaces, one for [Indigenous peoples] and one for virtually everyone else." 10 This also resulted in a Foucaultian system of surveillance in which the eyes of official government agents as well as landowners were "embedded in the land system" and "defined where [Indigenous people] could and could not go" within this dual system. ${ }^{11}$ Indigenous people had to find ways to survive in these racialized spaces, also being simultaneously subjected to genocide and human rights injustices through the residential school system.
8 Joy Hendry, "Chapter 1: Museums Are Transformed Test," in Reclaiming Culture: Indigenous Peoples and Self Representation (New York: Palgrave Macmillan, 2005), 30.

9 R. Cole Harris, "Native Space," in Making Native Space: Colonialism, Resistance, and Reserves in British Columbia (Vancouver, B.C: University of British Columbia Press, 2002), 265-92.

10 Harris, 265

11 Harris, 271 
These were infrastructures and systems specifically designed to break down Indigenous ways of life, routine and social structures, and constitute a direct attack not only on Indigenous rights but also fundamental human rights. Far from being isolated incidents, these structures of systematic racism and colonialism work together and continue to be perpetuated today. As is neatly summarized by Ted Jojola, a distinguished Indigenous professor from the University of New Mexico: "Although assimilative policies may no longer be overt, leaders still continue to force decisions that do not have the benefit of a collective understanding." 12

Centuries of generational trauma and attacks on cultural continuity have created a legacy of subjugation within Canada's history. Concrete examples of systemic inequity are complex and often range from interpersonal relations and extend as far as government negligence. One well-publicized example from late 2020 involves a scandal between the Nova Scotia fishing industry and Sipekne'katik First Nation, in which commercial fishers have been using violence and arson to prevent Indigenous peoples from exercising their "constitutionally protected treaty right to earn a moderate living from fishing" while the RCMP and Government continue to fail to put in place sufficient measures to protect the nation from physical and property harm. ${ }^{13}$
12 Jojola, "Indigenous Planning: Towards a Seven Generations Model," 469.

13 Maan Alhmidi, "The RCMP Have "let down' Indigenous Fishers Facing Violence in Nova Scotia: Minister," News, CTV News, October 19, 2020, https://atlantic. ctvnews.ca/the-rcmp-have-let-down-indigenous-fishers-facing-violence-in-nova-scotia-minister-1.5151182. 


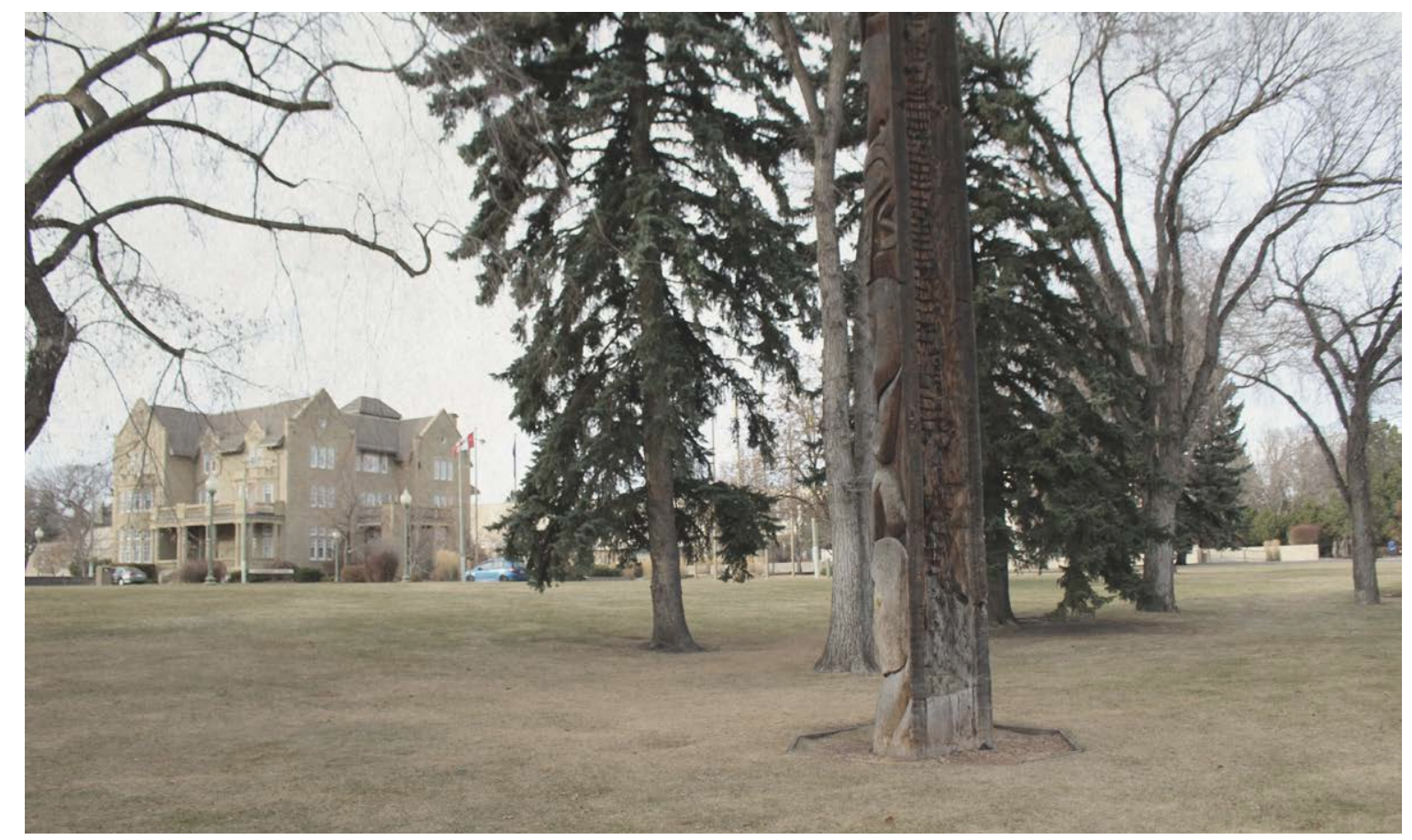

Fig. 1.2: Observing Government House

Buildings, such as the former Royal Alberta Museum, were not complacent in the creation of this violence. Discussed in further detail in Chapter 2, the museum opened in 1967 to exhibits on Indigenous culture using stolen items to perpetuate stereotypes of a singular 'authentic' and 'traditional' Indigenous culture. Even the title of the museum refers to a history of British Imperialism. It was originally titled the Provincial Museum and Archives of Alberta but was later designated the Royal Alberta Museum after a visit by Queen Elizabeth II in 2005. ${ }^{14}$ It has since been renamed as the 'Glenora Building' by the provincial government, its designation and title passed to a new building located in Edmonton's downtown core. This thesis uses the title of the former Royal Alberta Museum (or RAM) to more acutely contextualize it within its euro-centric past.

By choosing to tear it down, rather than confront its contested history, the Alberta provincial government refuses to recognize former and current injustices towards Indigenous peoples and surrenders an opportunity for conciliation. 


\subsection{EXPO 67}

At the time that the former Royal Alberta Museum was built, the lived experiences of Indigenous Peoples in Canada were brought to the forefront of Canadian and International attention through the Indians of Canada Pavilion at Expo 67 in Montreal. Expositions are rooted in a European tradition of "the world's fair as an encyclopedic expression of faith in the pacific harmonies alleged to be implicit in technology, world trade, and "enlightened" nationalism [that] dates back to the great London Exhibition of 1851." ${ }^{5}$ The Expo, "the most significant event in Canada of that year," ${ }^{16}$ had the official theme of Terre des Hommes, or Man and His World, ${ }^{17}$ and was visited by millions of Canadians, international tourists, and more than 90 heads of state, including Her Majesty Queen Elizabeth II. ${ }^{18}$

The choice to hold the Expo in Montreal was a politically motivated one, meant to "aggressively oppose" "destructive forces"19 that existed in the form of Quebecois Nationalism. However, the real force that "threatened to puncture the projected images of nationhood, unity, and peace at many turns... included the Indians of Canada Pavilion.... an Indigenous-led celebration of survival and a mounted critique of historical and present-day settler colonialism nested within the Centennial's unabashed patriotism." ${ }^{20}$ This was achieved through a critical exhibit in which Indigenous leaders exposed the systems they had been living under to bring awareness to their experience of history under Canada's regime. ${ }^{21}$ Jane Griffith argues that it may be inaccurate to place Expo 67 as an epochal moment in Indigenous activism, as the pavilion "existed before, after, and during...changing contexts of history classrooms, Indian Affairs policy, Indigenous resistance, and residential schooling
15 Neil Compton, "Expo 67," Commentary 44, no. 1 (July 1, 1967): 32.

16 Polo and Ripley, Architecture and National Identity / Architecture et Identite Natioinal, 13.

17 Peter H. Aykroyd, The Anniversary Compulsion: Canada's Centennial Celebration, a Model Mega-Anniversary (Toronto, Ontario: Dundurn, 1992), 165.

18 Aykroyd, 168.

19 Aykroyd, 11

20 Jane Griffith, "One Little, Two Little, Three Canadians: The Indians of Canada Pavilion and Public Pedagogy, Expo 1967," Journal of Canadian Studies 49, no. 2 (2015): 172, https://doi.org/10.3138/ jcs.49.2.171

21 Myra Rutherdale and Jim Miller, "'It's Our Country': First Nations' Participation in the Indian Pavilion at Expo 67," Journal of the Canadian Historical Association / Revue de La Société Historique Du Canada 17, no. 2 (2006): 148-73, https://doi.org/10.7202/016594ar. 
throughout the 1960s." 22 However, the pavilion left "a legacy of self-confidence and a sense of possibility" for many people. ${ }^{23}$

The exhibit was a form of public pedagogy that "offered an education from an Indigenous perspective and also critiqued colonial education." ${ }^{24}$ In contrast, the colonial underpinnings of the Canadian Pavilion provided examples of typical narratives of Indigeneity that the Indians of Canada Pavilion was contending. There, "Indigenous references were abundant" but "located...only in the past," and the future of Canada represented as one of conquering resources, environment and land. ${ }^{25}$

The exhibit sent ripples throughout North America, widely covered in the media for "bracing realism," ${ }^{26}$ and its "bitter indictment of the white man - his deceit, treachery, and lasting injustice against the Indian..." ${ }^{27}$ While initially, planning officials wanted the Indians of Canada Pavilion "to modify its negative tone," ${ }^{28}$ most Indigenous visitors were left unsurprised by the exhibits, and some "wanted the pavilion's displays to confront the issues more aggressively." ${ }^{29}$ The intentions of the pavilion were not to "induce guilt," but to "[curate] difficult knowledge... a pedagogical intention to open the public's eyes and expose injustice." 30 For non-Indigenous visitors who were open to listening to the true stories being shared, "as examples of survival and strength," there can be no doubt that the exhibits would stimulate them to "[investigate] their own subject positions and implications as benefactors of colonialism." ${ }^{31}$ That investigation is a crucial part of conciliation, and has to be the first step taken in order to create lasting change.

Indigenous "resistance to European education... is centuries old" and did not begin at Expo 67, but the pavilion "called attention to the violence of colonization in ways that were muted or flat-out erased in colonial pedagogies of the centennial year." ${ }^{2}$ This set the stage for understanding Indigenous right to self-determination and self-governance for the coming decades.
22 Griffith, "One Little, Two Little, Three

Canadians," 174.

23 Philips, Ruth B., Anderson, Janice, and Brydon, Sherry, "Arrow of Truth: The Indians of Canada Pavilion at Expo 67," in Museum Pieces (McGill-Queen's University Press, 2011), 29

24 Griffith, "One Little, Two Little, Three Canadians," 179.

25 Griffith, 187

26 Compton, "Expo 67," 38

27 Jay Walz, "Canadian Indians' Expo Exhibit Indicts White Man," New York Times, July 16, 1967

28 Philips, Ruth B., Anderson, Janice, and Brydon, Sherry, "Arrow of Truth," 45

29 Rutherdale and Miller, "'It's Our Country,"' 166

30 Griffith, "One Little, Two Little, Three Canadians," 180.

31 Griffith, 197.

32 Griffith, 198 

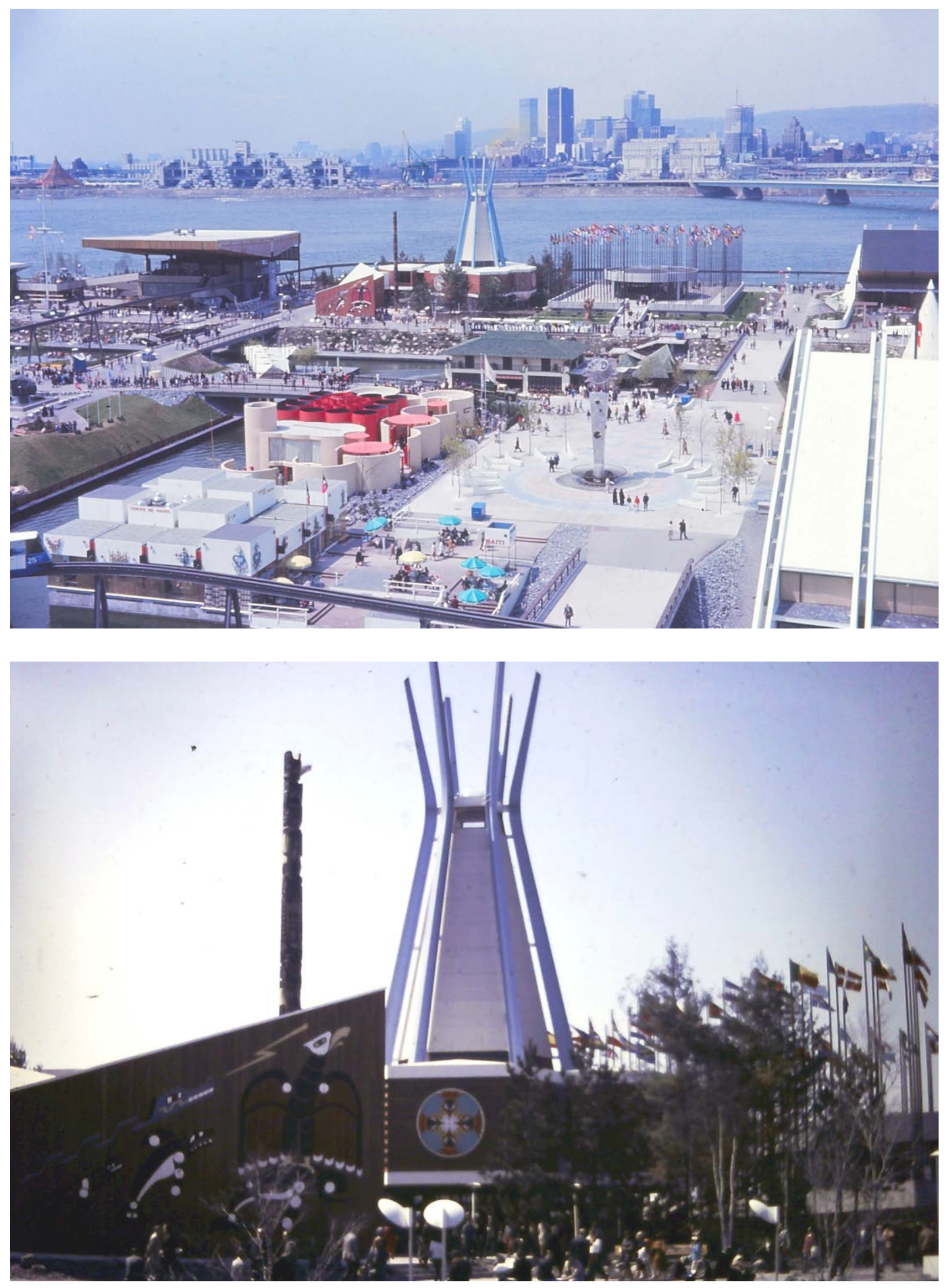

Fig. 1.3: (Top) Partial image of the Expo Grounds

Bélanger, Laurent, Pavillons Haïti, Monaco, Jamaïque, Les Provinces de l'Atlantique, Les Indiens du Canada, ONU, Place des ingénieurs, Colonne spatiale du sculpteur Gerald Gladstone. May 1967, Expo 67, île Notre-Dame, Montréal, Québec, Canada. Creative Commons, Wikimedia

Fig. 1.4: (Bottom) Indians of Canada Pavilion Nystrand, Shawn, Expo 67 - Indians of Canada Pavilion. 1967, Expo 67, île Notre-Dame, Montréal, Québec, Canada. https://www.flickr.com/photos/the_webhamster/5338250048/ 


\subsection{THE CENTENNIAL PROJECTS}

The legacy of buildings such as the RAM, built around the same time frame as Expo 67, furthermore show the vast difference between the cries of injustice put forward by Indigenous peoples, and the official centennial story being broadcast and supported by the Canadian government. As seen in the previous chapter, "The Centennial's explicit program of promoting unity also drew criticism from Canada's First Nations, for whom the 1867 Confederation was seen as part of a long history of betrayal and subjugation." ${ }^{3}$

However, the pedagogy of unity during a time of globalization and modernization was widely promoted throughout the country with both the Centennial Grants Program and the Confederation Memorial Program - the "most ambitious architectural, political, economic, and social project of the $20^{\text {th }}$ century ... undertaken collaboratively by federal, provincial, and municipal governments and aimed at enhancing public life across the nation with large-scale arts, cultural, recreational and educational facilities." 34 Aimed at national identity building en masse, ${ }^{35}$ celebrations of this scale are "organized to reaffirm the social structure of the country." ${ }^{36}$
33 Polo and Ripley, Architecture and National

Identity / Architecture et Identite Natioinal, 25.

34 Polo and Ripley, 4.

35 Polo and Ripley, 12.

36 Aykroyd, The Anniversary Compulsion, 6. 


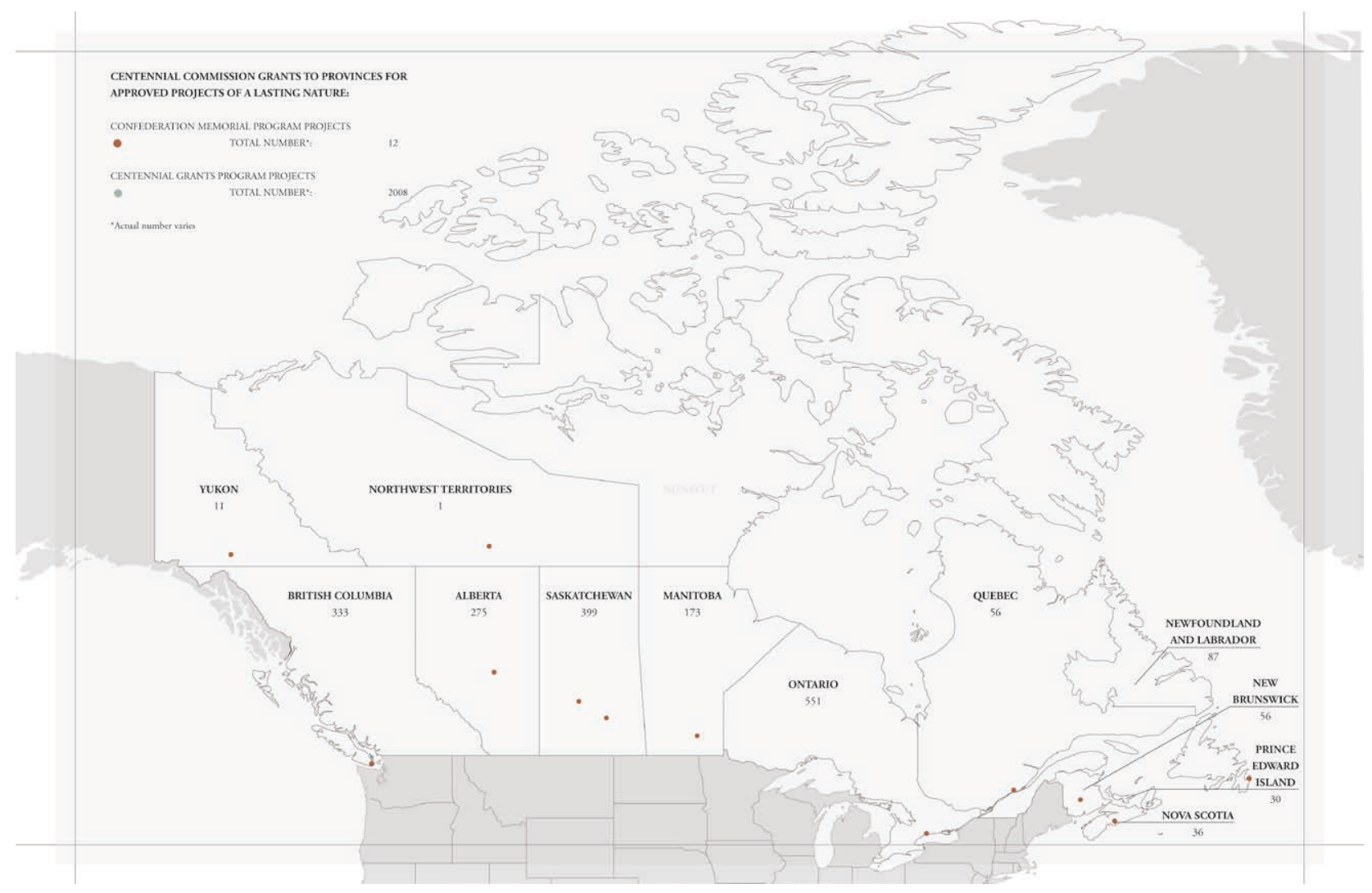

Fig. 1.5: Centennial Project Map

Approximately 2,301 projects were funded and produced through the dual programs, of which around 860 were buildings, and about 520 were recreational structures. ${ }^{37}$ These projects can be considered a network of micro and macro-memorials to the Centennial year, scattered across Canada. ${ }^{38}$ Of the over 2,301 projects, only 61 were from municipalities on reserves. ${ }^{39}$ As these projects were partially federally and provincially funded, the proposals had to be approved at each level, with the Centennial Commission overseeing the proposals for one last final approval. ${ }^{40}$ This series of checks and balances ensured that the projects were in keeping with guidelines of uniformity, "criteria of a positive nature," 41 and that they fulfilled requirements of celebrating the centennial "in a manner in keeping with its national and historical significance." ${ }^{42}$ This exclusive interest undoubtedly influenced a communities decision to apply for funding. The application process itself would have been a politically charged one for communities which were negatively affected by colonial expansion.
37 Aykroyd, 11
38 Aykroyd, 84
39 Aykroyd, 113
40 Aykroyd, 79
41 Aykroyd, 79
42 Aykroyd, 75 
Following celebrations, such as Canada 150, have been markedly different than the Centennial. The "emphasis has been on events rather than legacy projects," which "speaks to a different attitude towards the role of architecture in representing national ambition." ${ }^{43}$ This shifting attitude may partially be attributed to wide-spread awareness of the negative implications of colonialism, raised through interventions like the Indians of Canada pavilion at Expo 67. There has been acknowledgement that solely celebrating the Confederation "[disregards] the contribution of Aboriginal cultures and societies that lived in Canada before 1867," that "Canada cannot divest itself of the roles and places that Aboriginal peoples have played in the history [of Canada]," and that future celebrations "must be inclusive of [rich Indigenous cultures], traditions, and societies." ${ }^{44}$

Although a full final list of Centennial projects does not exist, unofficial partial records portray where the majority of projects are located within Canada. A partial list of projects exists publicly available on http://www.thecentennialproject. net/. In order to visualize the proliferation of centennial projects throughout Canada, I have used the above resource to create an open source google map available for anyone to view and edit, accessed through the map link and QR-code in the sidenotes. In respect to this thesis, I see the relevance of this data as situating the RAM within the large network of 'nation-building' projects to which it belongs. I also suggest that as the built-projects come to the end of their life cycles, they are evaluated to reassess how they can be best re-adapted to better meet the reconciliatory efforts of Canada today.
43 Britten, Liam, "Canada 150 Won't Leave Much of a 'concrete' Legacy, Architects Say," News, CBC News, July 3, 2017, https://www.cbc.ca/news/canada/ british-columbia/canada-150-centennial-projects-1.4188658

44 "Canada's 150th Anniversary in 2017" (House of Commons, Canada: Parliament of Canada, September 2012), 17-18, https://www.ourcommons.ca/DocumentViewer/en/41-1/CHPC/report-4/page-45

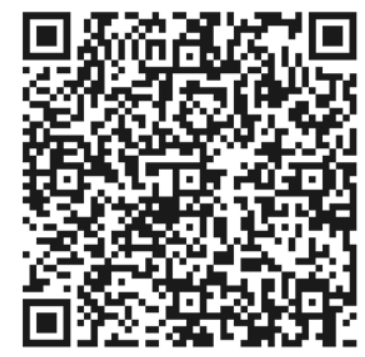

Open Source Centennial Projects Map: https://www.google.com/maps/d/u/0/viewer?hl=en\&hl=en\&mid=1sXfah-bbhlzlwVXhsoY8z1Ctsh9aE-o_\& $\|=56.208709268134$ $88 \% 2 C-86.28436396042656 \& z=3$ 


\subsection{ABOUT MAPS AND TREATIES}

Edmonton, the site of the RAM, is located within Treaty 6 territory, which is a traditional meeting ground, gathering place, and traveling route of the Nêhiyawak (Cree), Anishinaabe (Saulteaux), Niitsitapi (Blackfoot), Métis, Dene, and Nakota Sioux. For thousands of years prior to the last few centuries, the history of the land was not inscribed on a Western cartographic axis.

Western colonial expansion and concepts of land ownership resulted in a parceling of land around the mid-1800s. The RAM stands on a site that was parceled out to a man named Malcolm Groat, who was stationed in Fort Edmonton by the Hudson's Bay company. ${ }^{45}$ Although much of his 900 acres was annexed by Edmonton in early 1900's, ${ }^{46}$ his name is still acknowledged near the site through Groat Road, which connects the two sides of Edmonton over the North Saskatchewan River through Groat Road Bridge. This arbitrary delineation of space is a rather new mark on the landscape of Edmonton, that was only possible due to the dispossession of Indigenous people "of most of their land" through a reserve system that was borne of "pervasive settler assumptions, backed by the colonial state, that most of the land they encountered... was waste, waiting to be put to productive use." ${ }^{47}$

The intentional creation of a reserve system was meant to break down Indigenous ways of life, routine and social structures and was a direct aggression on Indigenous rights, "and would today be categorized as cultural genocide." ${ }^{48}$ The eyes of official government agents as well as landowners were
45 Edmonton Historical Board, "Westmount," accessed January 10, 2021, https://www.edmontonsarchitecturalheritage.ca/index.cfm/neighbourhoods/ westmount/.

46 Edmonton Historical Board.

47 Harris, "Native Space," 265.

48 Rob Shields, Kieran Moran, and Dianne Gillespie, "Edmonton, Amiskwaciy Wâskahikan, and a Papaschase Suburb for Settlers," The Canadian Geographer / Le Géographe Canadien 64, no. 1 (March 2020): 112, https://doi.org/10.1111/cag. 12562. 
"embedded in the land system" and "defined where [Indigenous people] could and could not go" and therefore "the management of movement associated with property rights was the most essential discipline imposed on [Indigenous people].”49

Given the multitude of failings of the reserve system, the one important thing to come out of it is that "it had left [Indigenous Peoples] toeholds in their ancestral territories." ${ }^{50}$ However, even these small toeholds are increasingly slipping away due to the continued forced displacement of people. As recently as 2007, a UN Special Rapporteur stated "The continuing trend is towards a decline in the resources of Indigenous people, reduction of their land and territorial base, and progressive and accelerated loss of control over their natural resources, in particular their forests. ... The growing incidence of migration among Indigenous people is one of the expressions of globalization and of the inequality and poverty it engenders." 51

Due to Canada's stated goals of reconciliation, most provinces require basic education on the history and implications of the 11 numbered Treaties in grade school. Acknowledgement of Treaty territory goes a long way to create deeper understanding of Canada's colonial roots and assists Canadians in learning the extent of the abuse that has been carried out against Indigenous peoples, to help find a way forward beyond perpetuating racial biases, towards conciliatory practices, and most importantly, to learn about the traditional caretakers of the land we find ourselves on.
49 Harris, "Native Space," 271

50 Harris, 285

51 Miranda J. Brady, "Mediating Indigenous Voice in the Museum: Narratives of Place, Land, and Environment in New Exhibition Practice," Environmental Communi cation 5, no. 2 (May 19, 2011): 204, https:// doi.org/10.1080/17524032.2011.562649. 


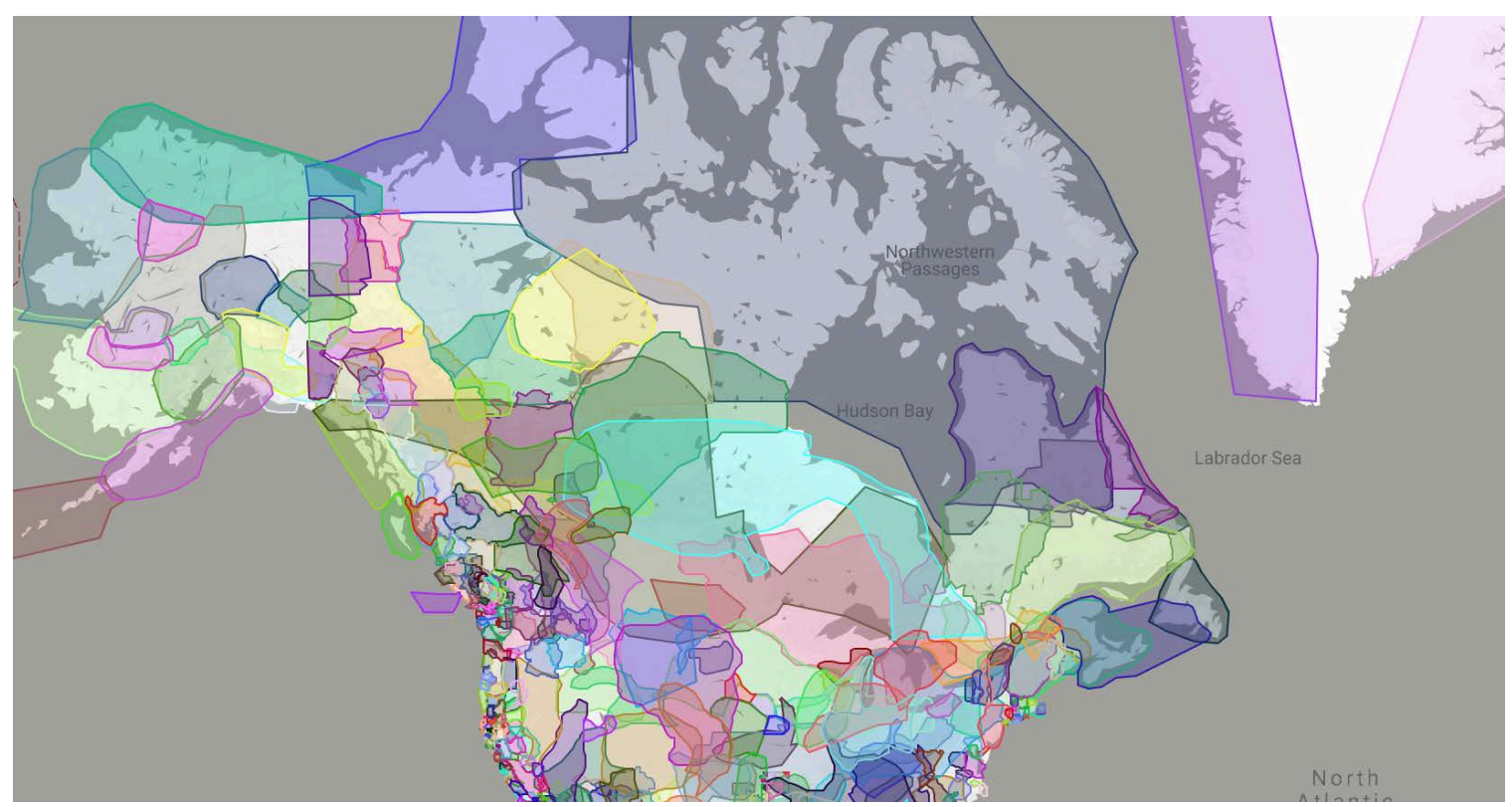

Fig. 1.6: Overlapping Mappings

Territories by Land, Whose Land?, Google Maps, INEGI,

Less formal and highly accessible websites and mobile applications like "Whose Land?" and "https://native-land.ca/" seek to make the information about traditional landholders, treaties and steps towards reconciliation widely available to the general public. ${ }^{52}$ These maps counteract the dominant practice of Cartesian mapping by depicting the multi-layered realities of place that co-exist in time. They also simplify the process of understanding the history of the land on which you find yourself, and remove barriers for acknowledgement, which is a sign of respect and recognition for the specific Indigenous groups that have "had a relationship with the land you're standing on since time immemorial." ${ }^{53}$

Despite these steps forward, I still see a need for the continued and widespread education of the settler on the systemic injustices carried out towards Indigenous peoples throughout the last few centuries. There exists the possibility for a more cohesive and nuanced understanding of history. As seen in Chapter 7, this thesis positions itself in regard to that need by suggesting that portions of the former RAM be used for cultural competency training and for settler re-education. 


\subsection{COMMUNITY INTERSECTIONS}

Having overgrown the museum facility, the RAM built a new building more centrally in Edmonton. The move was completed in 2020, and the Glenora building now stands empty. Almost 2 years after already putting forward a request for proposals for the demolition of the building, it was only due to community push back and a petition started by a Glenora resident advocating for saving the building that the provincial government reluctantly put forward a poll asking for alternate suggestions for what should be done with the building. ${ }^{54}$ As seen in the following image on the next page, $96 \%$ of responses came back advocating for preserving or re-purposing the building in various ways. The Mayor of Edmonton, Don Iveson, has also voiced his support for re-purposing the building, stating "If there's an option to adapt and reuse the building, that's usually better and a better use of energy and resources than pulverizing it. I hope that option will be explored." 55 Ultimately though, the building stands on provincially designated lands within Edmonton's boundaries, and the provincial government will make the final decision on the fate of the building and the site.

When taking into consideration community interest, the opinions of Glenora residents have been expressed through community consultations and publicized media statements. However, the opinions of the Enoch Cree, Papaschase Cree, and other Indigenous peoples who call the Edmonton area home have not been sought - or have even been actively ignored - although $12 \%$ of poll responses indicated that the participants would like to see the building put to Indigenous
54 Simons, Paula, "Wanted: An Idea Good Enough to Save the Historic RAM."

55 Wong, Julia, "Province Seeks Ideas on How to Redevelop Royal Alberta Museum Site." 


\section{The Responses}

In our review of the submissions, we separated the feedback received into three categories: "Preserve Architectural Heritage \& Repurpose Site", "Demolish Building" and "Sell Building/Site". $95 \%$ of the suggestions were to preserve/repurpose, $4 \%$ to demolish, and $1 \%$ to sell. We then separated the preserve/repurpose responses (95\% of responses) into 7 themes of uses:

- Museum or Gallery $20 \%$

- Indigenous Community $12 \%$

- Arts, Culture or Community Hub

- Entertainment/Event Space $7 \%$

$20 \%$

- Social Services $7 \%$

- Educational Facility $12 \%$

- Other $24 \%$

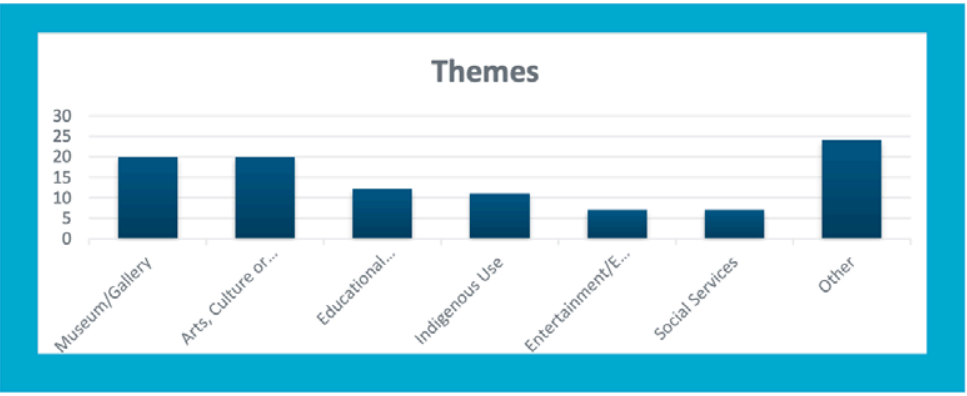

The category "Other" denotes ideas that were unique, hence not fitting other categories, or did not specify use but reaffirmed preserving/repurposing the site.

\section{Community Uses. ${ }^{56}$}

This thesis explores the possibilities of how a heavily politicized centennial building, once a tool of Indigenous subjugation, can be re-adapted to instead become a space of conciliation. In responding to the colonial nature of the museum, I believe it is important to include and amplify the voices of Indigenous people in deciding on the future of spaces which were traditionally built to subjugate them. It is often assumed that it should be the job of Indigenous peoples to tell us how to right these wrongs, but that ignores our own individual responsibility to commit to the learning process. As "understanding local history (particularly regarding settlement, government policy, and First Nation loss of land) is essential in initiating discussions," and collaboration can only proceed "once historic relations are understood and properly acknowledged," ${ }^{57}$ I see a need for the future of the site to be adapted for the promotion of a new public pedagogy. One that educates the settler on alternate modes of land stewardship, a more extensive view of history, and Indigenous ways of knowing.
Fig. 1.7: Community Feedback Government of Alberta, Glenora Building - Former Royal Alberta Building, June 2020, https://www. alberta.ca/glenora-building.aspx

56 Government of Alberta, "Glenora Building - Former Royal Alberta Museum," Government, Alberta.ca, June 23, 2020, https://www.alberta.ca/glenora-building. aspx.

57 Tota, Kasia, "The Old/New Neighbours - Breaking Ground in Collaborative Land Use Planning between First Nations and Local Governments," in Plan Canada, 3rd ed., vol. 4, n.d., 31-33. 


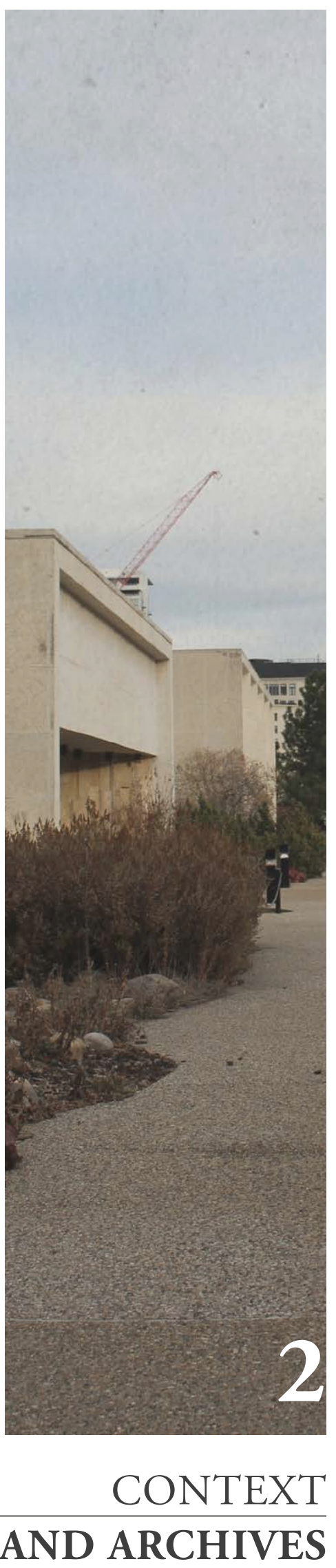


"Museums create knowledge about the objects on display by selectively presenting information they think is relevant and omitting that which they determine unnecessary. While at any one time the museum visitor might assume this interpretation represents the "truth" about the object, it is, in reality, only one element in its ongoing history."

Museums and Northwest Coast Art, 758, Aldona Jonaitis 

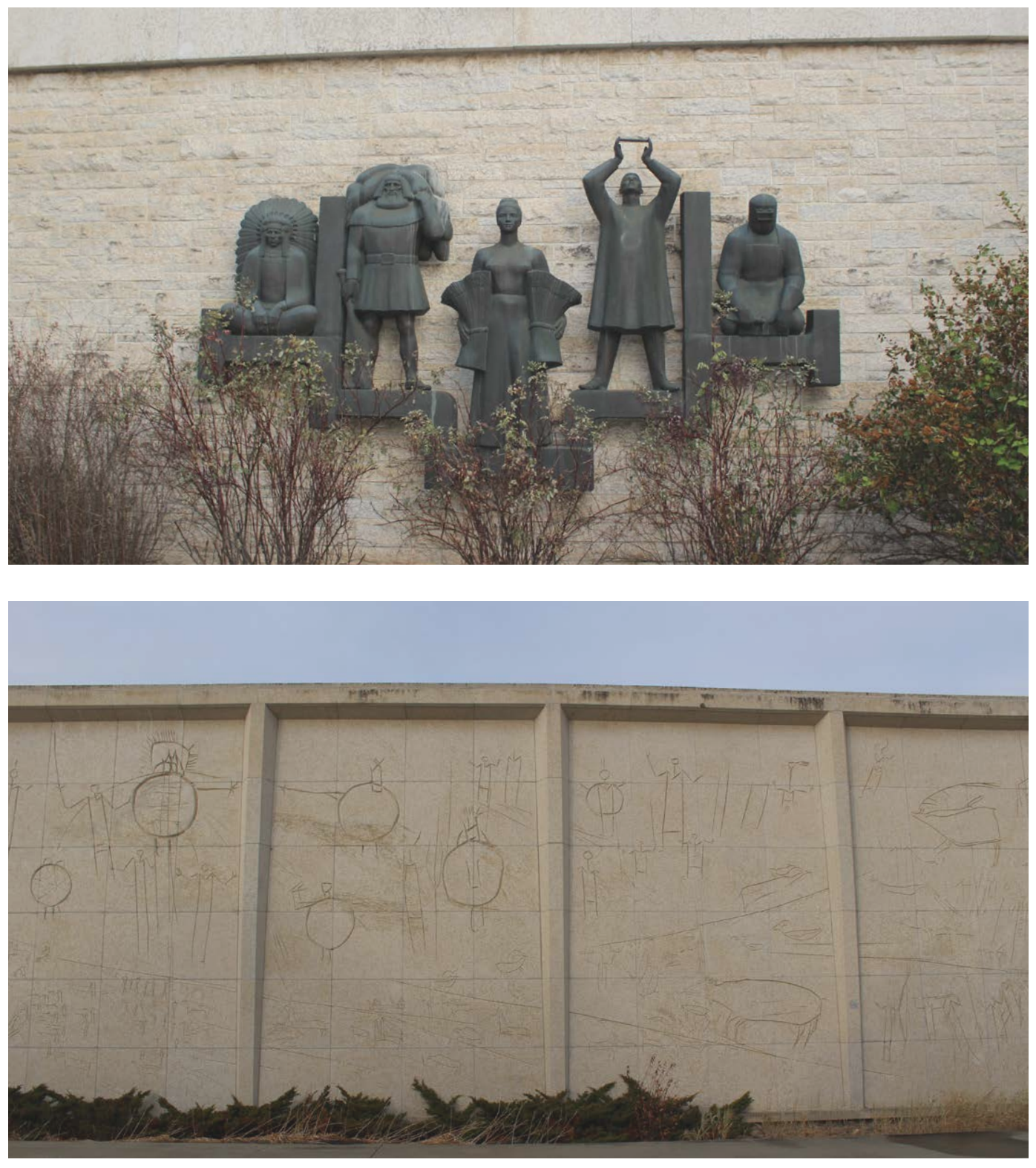

Fig. 2.1: (Above) North Wall Frieze

Fig. 2.2: (Bottom) Writing-on-Wall Glyphs 


\section{1 'ANCIENT' HISTORY}

As early as the 1800s Missionaries and early 'explorers' of North America began to collect Indigenous objects for personal collections and for cultural displays in international expositions. ${ }^{58}$ It is important to note that these people were not 'professionals' in collecting, nor were they experts on the Indigenous cultures they were taking objects from. ${ }^{59}$ At best and most optimistic, they were enthusiasts which enjoyed the objects Indigenous peoples were creating - unfortunately more commonly they were stealing and banning objects from Indigenous peoples. They thus attacked Indigenous social, cultural and religious systems, all while profiting off the sale of these items to private collectors and using these objects in international expositions to create racial division that justified aggressive expansion into foreign, occupied lands. ${ }^{60}$

Stolen sacred objects, tools, and sometimes even human remains were put on display in an attempt to create one pan-Indigenous, pre-contact identity that was 'authentic' or 'true'. These objects were removed from their context and their holders, while the people themselves were also forbidden from practicing cultural ceremonies and spiritual beliefs. ${ }^{61}$ This "commodification and appropriation of images and symbols of cultural difference" 62 aimed to fix ethnographic racial biases in the Western psyche by controlling the discourse on history, and by "[undermining] the cultural identity" of Indigenous peoples. ${ }^{63}$

In discussions of museums throughout this thesis, I must define that my default use of the word 'museum' refers specifically to ones based on ethnographic and anthropological traditions and is not as predominantly focused on museums
58 Jacknis, Ira, "From Explorers to Ethnographers, 1770-1870," in Native Art of the Northwest Coast: A History of Changing Ideas, ed. Charlotte Townsend-Gault, Jennifer Kramer, and Ki-ḳe-in (Vancouver: UBC Press, 2013), 90.

59 Jacknis, Ira, 52. 60 Jacknis, Ira, "From Explorers to Ethnographers, 1770-1870."

61 Barker, John, "Going by the Book: Missionary Perspectives," in Native Art of the Northwest Coast: A History of Changing Ideas, ed. Charlotte Townsend-Gault, Jennifer Kramer, and Ki-ke-in (Vancouver: UBC Press, 2013), 234-64. 234

62 Caitlin Gordon-Walker, Exhibiting Nation: Multicultural Nationalism (And Its Limits) in Canada's Museums (Vancouver, Canada: UBC Press, 2016), 106-7.

63 Jojola, "Indigenous Planning: Towards a Seven Generations Model," 461. 
which deal with the creation and curation of art - although these have been known to contribute to systemic injustice as well. As Harris argues, "traditional anthropological museums are inherently political in their role in legitimizing colonial structures and national narratives," ${ }^{64}$ often portraying cultures in the past tense to suggest that they are no longer a part of the contemporary realm. More specifically, museums function as "a cartographic tool that establishes relationships between objects and carefully selected narratives that forge a strategic historical and cultural memory that aligns with a particular construction of an imagined community." ${ }^{65}$ It is worth emphasizing that this strategic creation of memory is just that - imagined and constructed. It does not accurately represent the lives of the communities, especially when displays are put together without the direct input of the communities themselves.

While museums have begun to move away from these practices, some of these traditions continue today and create barriers to the repatriation of objects and reconciliation of peoples. Understanding the history of museum culture in the last 200 years places the Royal Alberta Museum and its exhibits within a longer narrative that is connected to a Western control of the representation of historical experience, a position that it must respond to.
64 Harris, "Indigenous Representation in the 'Moral Museum,'” 206.

65 Talia Weltman-Cisneros, "'From Objects to Subjects: The Museumification of Blackness in Mexico,'" African and Black Diaspora: An International Journal 13, no. 1 (January 2, 2020): 81, https://doi.org/10.10 80/17528631.2019.1637604. 


\subsection{INDIGENOUS SELF-REPRESENTATION}

Around the mid 1900s, "First Nations people began challenging the ways in which they have been represented in museums, objecting to the "museumification" of their cultures and insisting that museums convey the message "we are still here." ${ }^{66}$ This was a stark contrast to previous exhibits which had attempted to exhibit Indigenous peoples "as they had lived prior to Euroamerican contact," and by doing so simultaneously portrayed contemporary Indigenous cultures as inauthentic and historic cultures as extinct. ${ }^{67}$ While it took a few more decades, and much more than just the pavilion at Expo 67 to invoke change, eventually "the issue of museum representation would be addressed seriously on a national scale. ${ }^{68}$ By the first decade of the twenty-first century, the inclusion of Native voices had become "de rigeur" for any exhibit of Native art." ${ }^{69}$ The abundance of new museums is a sign that they are still an in-demand cultural institution, ${ }^{70}$ and "the question of "voice" has become as important as the question of "truth."”71 Self-representation exists on a spectrum, with varying modes of inclusion and exclusion.

It has become unthinkable to create an exhibit on Indigenous culture without first consulting someone from the culture you wish to showcase. New, "collaborative models between museums and Indigenous people are now normative in the curatorial process." 72 These models and displays "appear to empower local people, but we must be cautious, before we describe such schemes as 'self-representation' because the tribal people in this case are again being 'consulted' and 'invited' rather than initiating their own forms of display." ${ }^{73}$ Including Indigenous voices within a Western framework asks for a level
66 Jonaitis, Aldona, "Museums of the Northwest Coast," 758.

67 Jonaitis, Aldona, 757

68 Philips, Ruth B., Anderson, Janice, and Brydon, Sherry, "Arrow of Truth," 46.

69 Jonaitis, Aldona, "Museums of the Northwest Coast," 760

70 Hendry, "Chapter 1: Museums Are Transformed," 38.

71 Brady, "Mediating Indigenous Voice in the Museum," 202

72 Brady, 203.

73 Hendry, "Chapter 1: Museums Are Transformed," 44. 
of conformity and presents a layer of control over the final exhibit. As well, certain standardized methods of exhibition such as the 'glass box' are counterintuitive to objects which wish to be handled or where tactile experience is important.

Museums created by Indigenous People have the potential for self-representation, especially in regard to "the respect accorded to [sacred objects]," because "people can [decide whether to display objects relating to the spiritual or not] for themselves." ${ }^{74}$ This level of control over the exhibit means "...exhibitions...transmit different levels of information to different groups of people." 75

Varying levels of understanding are directly related to someone's familiarity with the culture and objects displayed. It is possible that through a single exhibit, one group of people can gain cultural knowledge, while another group of people may only able to appreciate the formal or artistic components of the display. Far from deterring exhibits and displays with different levels of information meant for different groups of visitors, the resulting multiple layers and depth of understanding present an opportunity for cross-referencing knowledge and building a comprehensive critical understanding of history. As Aldona Jonaitis states, "It is not a matter of either or, an insider versus an outsider monopoly on truth...It is, rather, a question of how the insider and outsider perspectives might interact and build upon one another in the process of truth-seeking and understanding." 76

However, if building the museum was a condition for an Indigenous group to be able to repatriate their own objects, ${ }^{77}$ then it is unlikely that it can ever be a completely truthful model of self-representation. Only if a museum is free of the obligations and restrictions placed by external modes of Western value-thinking, can it truly become "[a place] of shared experience" and "provide' a platform for dialogue, be a place where people can express difference peacefully... and... bring knowledge of the past to educate for future social interaction." 78
74 Hendry, 43.

75 Joy Hendry, "Chapter 5: Arts, Archcitecture and Native Creativity," in Reclaiming Culture: Indigenous Peoples and Self Representation (New York: Palgrave Macmillan, 2005), 154.

76 Jonaitis, Aldona, "Museums of the Northwest Coast," 766.

77 Hendry, "Chapter 1: Museums Are Transformed," 46.

78 Hendry, 44 


\subsection{EVOLVING MUSEUM CULTURE AT THE RAM}

The former RAM opened in 1967 to an inaugural exhibit on Indigenous culture which was very much in keeping with the colonial museum practices of the time, utilizing both the museumification of Indigenous peoples and iconographic totemism to divide history. "The original museum... galleries featured Fur Trade, Native Peoples of Alberta, Agriculture, Pioneer Life, and Industry \& Commerce," 79 and "Aboriginal artifacts were curated separately from other objects of human history and culture." ${ }^{80}$ Even today, Indigenous objects and icons are woven in amongst other cultural symbols and buildings on site to display a tone of cultural ambiguity. A Ksan totem pole on site is from the Gitskin Band - a Pacific Northwest Tribe, not located in Alberta - and the sculptures on the museum depict Indigenous people next to pioneers and farmers. The placement of these objects next to other statues and a gifted Korean pavilion make it seem as though "Indigenous" identity is just another part of Canadian multiculturalism. These objects are a form of tokenism that introduces Indigeneity as a side conversation to be sought out, rather than including Canadian-Indigenous relations as a main conversation on site.

The new facility opened in 2016 to an exhibit which was developed in conjunction with Indigenous community leaders and acknowledged the history of the residential school system. ${ }^{81}$ However, in spite of its apparent progressive steps forward, it is still an institution built on a stolen and contentious archive, with scandals surrounding the treatment of members of its Indigenous Advisory Panel, and sacred objects such as the Manitou Asinîy meteorite. ${ }^{82}$
79 City of Edmonton, "Public Buildings," Government, Edmonton.ca (The City of Edmonton, March 24, 2021), Edmonton, Alberta, Canada, https://www.edmonton. ca/city_government/edmonton_archives/ public-buildings.aspx.

80 Gordon-Walker, Exhibiting Nation, 114. 81 Hampshire, Gareth, "Indigenous History Prominent at New Royal Alberta Museum," News, CBC News, December 26, 2017, https://www.cbc.ca/news/canada/edmonton/edmonton-indigenous-history-royal-alberta-museum-1.4449069.

82 Omar Mosleh, "'I'm Not Your Token': Indigenous Employee Accuses Alberta Museum of Systemic Racism," News, The Toronto Star, June 27, 2020, https://www. thestar.com/news/canada/2020/06/27/ im-not-your-token-indigenous-employee-accuses-alberta-museum-of-systemic-racism.html. 
Additionally, the built fabric of the former Royal

Alberta Museum still exists, and the statues on the exterior of the building place Indigenous peoples next to imagery of mammoths and pioneers, still perpetuating the subconscious impression that they are a relic of the past that no longer exists within the fabric of Edmonton's contemporary timeframe. This ignores the that Edmonton has the second-largest metropolitan Indigenous population in Canada, and that the population is relatively young in comparison to the Canadian population at large. ${ }^{83}$

In the same way that an archive has a history and a pre-context, ${ }^{84}$ the Glenora building also has an embodied history that it has to address to move forward. As the former Royal Alberta hopes to be rebuilt, it is important to address its past as a museum. Its proximity to downtown Edmonton and connection to the River Valley has the potential for higher foot traffic, and $102^{\text {nd }}$ Avenue is one of the busiest roadways in and out of the city center. Embodied memories in the museum can be reconciled with the present and move towards a more understanding future by creating a few key moments on site that juxtapose settler passerby with the history of colonialism in Canada. This could counter a history of complacency, and instead intentionally ask Glenora residents and Edmontonians alike to reflect on their history on the land while accessing the River Valley or trying to find a picturesque outlook onto the city.
83 Shields, Moran, and Gillespie, "Edmonton, Amiskwaciy Wâskahikan, and a Papaschase Suburb for Settlers," 114.

84 Stuart Hall, "Constituting an Archive," Third Text 15, no. 54 (2001): 89-92, https:// doi.org/10.1080/09528820108576903. 


\subsection{BEYOND THE EXHIBIT}

In order to honestly confront history in which anthropological museums have "supported oppressive colonial processes, which in some cases have led to policies of extermination against indigenous peoples," 85 the repatriation of objects and material culture must be carried out. That leaves the question of the purpose of museums - if their archives are emptied, what is left to salvage?

The International Council of Museums has been periodically redefining the concept of a museum, slowly steering away from solely focusing on "material evidence" until it included the "intangible heritage of humanity and its environment" in 2007. ${ }^{86}$ This inclusion signifies a break from their typical "embodiments... of a power to 'show and tell' which [seek] rhetorically to incorporate the people within the processes of the state." ${ }^{87}$ This inclusion likely followed UNESCO, which in 2003 also chose to include Intangible Cultural Heritage as a "mainspring of cultural diversity and a guarantee of sustainable development." ${ }^{88}$ The designation emphasizes the value of cultural skills, knowledge and practices. Intangible cultural heritage "cannot last without the direct intervention and transmission of human beings, such as an individual act or a collective custom," ${ }^{89}$ as it goes beyond knowledge that can be written down and recorded, but can encompass entire cultural worldviews. There are currently five categories of heritage that can be classified as intangible cultural heritage: “(a) oral traditions and expressions; (b) performing arts; (c) social practices, rituals, and festive events; (d) knowledge and practices concerning nature and the universe; and (e) traditional craftsmanship." 90
85 Harris, "Indigenous Representation in

the 'Moral Museum," 196.

86 Seulah Kim et al., "Utility of Digital Technologies for the Sustainability of Intangible Cultural Heritage (ICH) in Korea," Sustainability 11, no. 21 (November 2019): 5-6, https://doi.org/10.3390/su11216117.

87 Tony Bennett, "The Exhibitionary Complex," New Formations, no. 4 (1988): 99.

88 Kim et al., "Utility of Digital Technologies for the Sustainability of Intangible Cultural Heritage $(\mathrm{ICH})$ in Korea," 3.

89 Kim et al., 1.

90 Kim et al., 3 
Through these designations, a "living archive" ${ }^{11}$ becomes more than an ever growing collection of material culture, but instead becomes a process of teaching and learning aimed at passing down the knowledge that contemporary cultures hold. As Beatrice Harris argues, "there may still be the potential for museums to engage with such material and culture that does not require active acquisition or display, through the development of community education programs that facilitate the passing of traditional knowledge, heritage and practice, in their original setting and context." ${ }^{92}$ Rather than continuing to "[construct] cultural difference within Alberta as a spectacle of cultural diversity... a commodity... that... might be offered as a replacement for intercultural engagement," ${ }^{93}$ it is through the facilitation of cross-cultural interaction and communication that the former Royal Alberta Museum, and centennial buildings or museums like it, could begin to confront their muddied pasts.

I see three unique opportunites at the former Royal Alberta Museum which could help to deconstruct the spectacle of cultural difference, and to reinvent the museum as a place of community education. The first is to give space back to the Enoch Cree, the Papaschase Cree, and the Indigenous peoples of Edmonton, to use as artist/creator spaces, Treaty 6 meeting grounds, as a space to cultivate knowledge, to deconstruct, or to do with as they wish. The second is to use a portion of the museum as a cultural competency learning center for Western settlers to learn about the legacy of systemic racism and oppression that existed and continues to exist at varying scales within Edmonton, Alberta, and Canada. And the third is to curate accidental moments of interaction between both groups of people, in the hopes that it cultivates an understanding through small and personal connections to individual people.
91 Hall, "Constituting an Archive," 89

92 Harris, "Indigenous Representation in the 'Moral Museum,"' 203

93 Gordon-Walker, Exhibiting Nation, 116. 


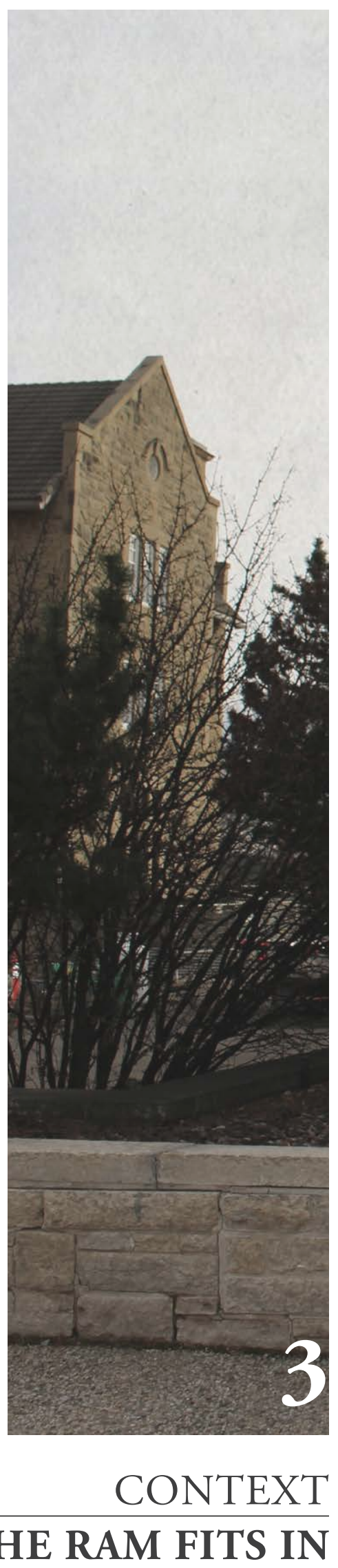

WHERE THE RAM FITS IN 
"As an authoritative state-sponsored institution, the RAM is clearly not a neutral space of encounter. It exists within, and maintains, certain structures of power and hierarchy. Through its mandate, and in its collections and exhibitions, it establishes a clear relationship between viewers and viewed." Exhibiting Nation, 129, Caitlin Gordon-Walker 


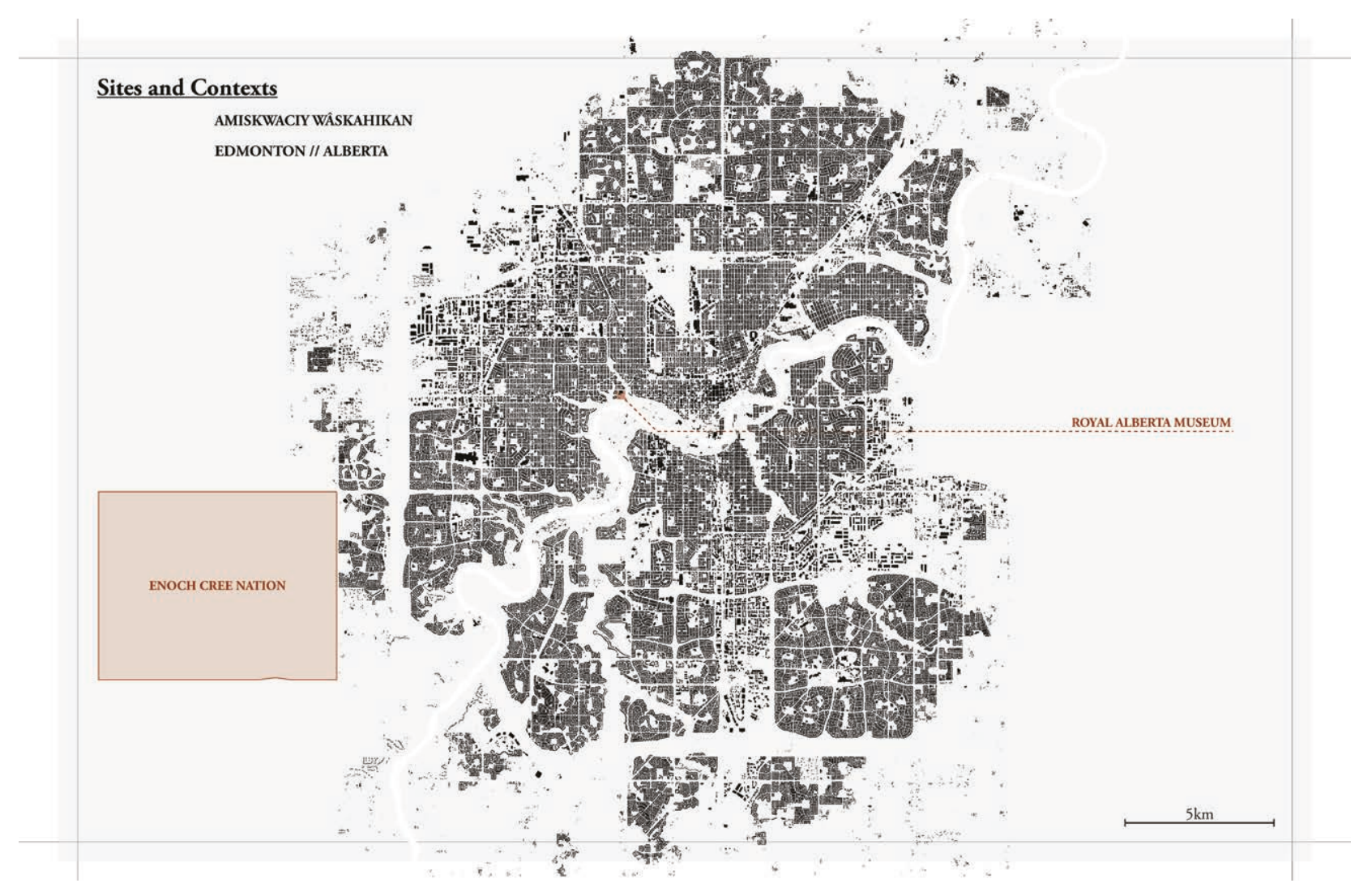

Fig. 3.1: Contextualizing the Site

The former Royal Alberta Museum, "was built to

house the archival and province-specific museum material the province had...collected to commemorate its less-than-hundred-year history." ${ }^{94}$ While problems with museum collections have been covered in Chapter 2, the fact remains that the building is "welcoming, filled with light... built with the kind of materials and craftsmanship you just don't find in public buildings these days: terrazzo and granite flooring; solid oak doors and banisters, trimmed with brass; marble walls..." 95 A Centennial project, it was meant to celebrate cultural achievements, and serve as a reminder of "Canada's year of celebration and as hope for the continuing development of Canadian culture." ${ }^{96}$ But looking forward, what do we want for the development of 'Canadian' culture? The provincial government is proposing finding a public-private partnership, to repurpose the building and site to be as profitable as possible for private land developers. ${ }^{97}$ But is privatized economic security the future of Canadian culture?
94 Peter H. Aykroyd, The Anniversary Compulsion: Canada's Centennial Celebration, a Model Mega-Anniversary (Toronto, Ontario: Dundurn, 1992), 85-86.

95 Simons, Paula, "Edmonton, We Can't Lose the RAM to the Wrecking Ball," News, Edmonton Journal, March 8, 2016, https:// edmontonjournal.com/entertainment/local-arts/paula-simons-edmonton-we-cantlose-the-ram-to-the-wrecking-ball.

96 Aykroyd, The Anniversary Compulsion, 86. 97 Wyton, Moira, "Province Mulls Private Sector Help to Repurpose Former RAM, Remand Centre Sites," News, Edmonton Journal, January 19, 2020, https://edmontonjournal.com/news/local-news/provincemulls-private-sector-help-to-repurpose-former-ram-remand-centre-sites. 
Kasia Tota wrote the following in regards to land planning between Indigenous groups and local governments: it is possible to "realize the potential of long-term vision as a catalyst for pragmatic action. Vision has a potent quality. Fundamentally oral, it speaks of where the community has come from and where it would like to go in the future ... A successful community plan can thus be a symbol of renewal, hope, and... determination to ensure that development takes place on the community's terms and according to the... values as articulated by elders, parents, and leaders." 98 The advice was written for Indigenous land planning, but perhaps settlers could gain from heading the advice as well - albiet in a different way.

Through a questioning of community values, of future possibilities, and understanding the importance of decolonizing spaces, it is possible to create a new vision of Canada's future. Shields argues that breaking the cycle of the "colonial processes of erasure and spatialized oppressions" requires understanding that "Places... do not have agreed-upon boundaries. They are not fixed... places have practices. In some definitions, places are practices." 99 What is the unique practice of this place, this city, this country?

On the following pages, the varied and patchworked remnants of the cultural artifacts in the built environment on the site are documented and examined.
98 Tota, Kasia, "The Old/New Neighbours - Breaking Ground in Collaborative Land Use Planning between First Nations and Local Governments," in Plan Canada, 3rd ed., vol. 4, 2003, 334 .

99 Rob Shields, Kieran Moran, and Dianne Gillespie, "Edmonton, Amiskwaciy Wâskahikan, and a Papaschase Suburb for Settlers," The Canadian Geographer / Le Géographe Canadien 64, no. 1 (March 2020): 108, https://doi.org/10.1111/cag.12562. 


\section{FORMER ROYAL ALBERTA MUSEUM}

SITE PLAN // LAND USE // OVERVIEW

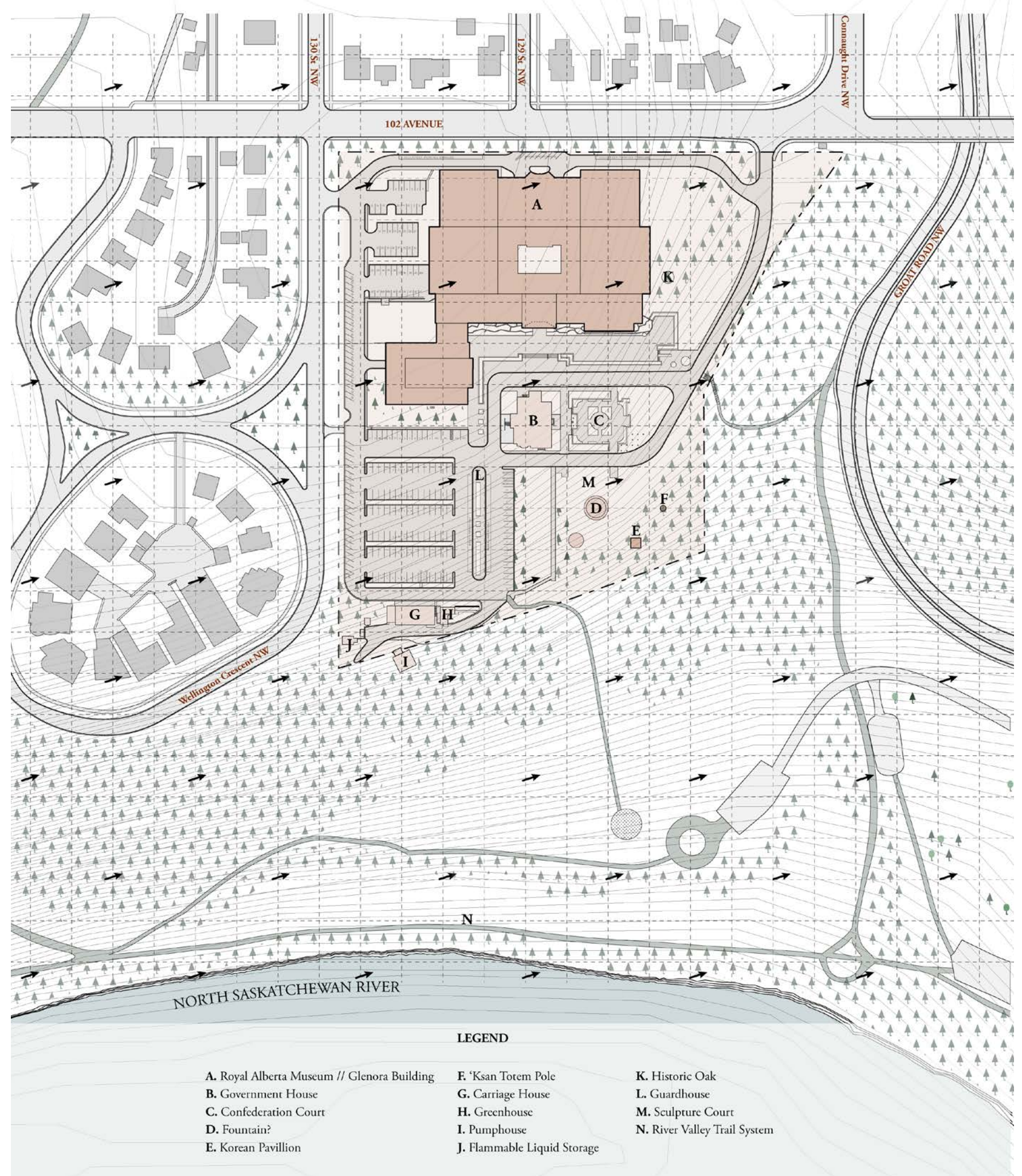

Fig. 3.2: Site Plan 


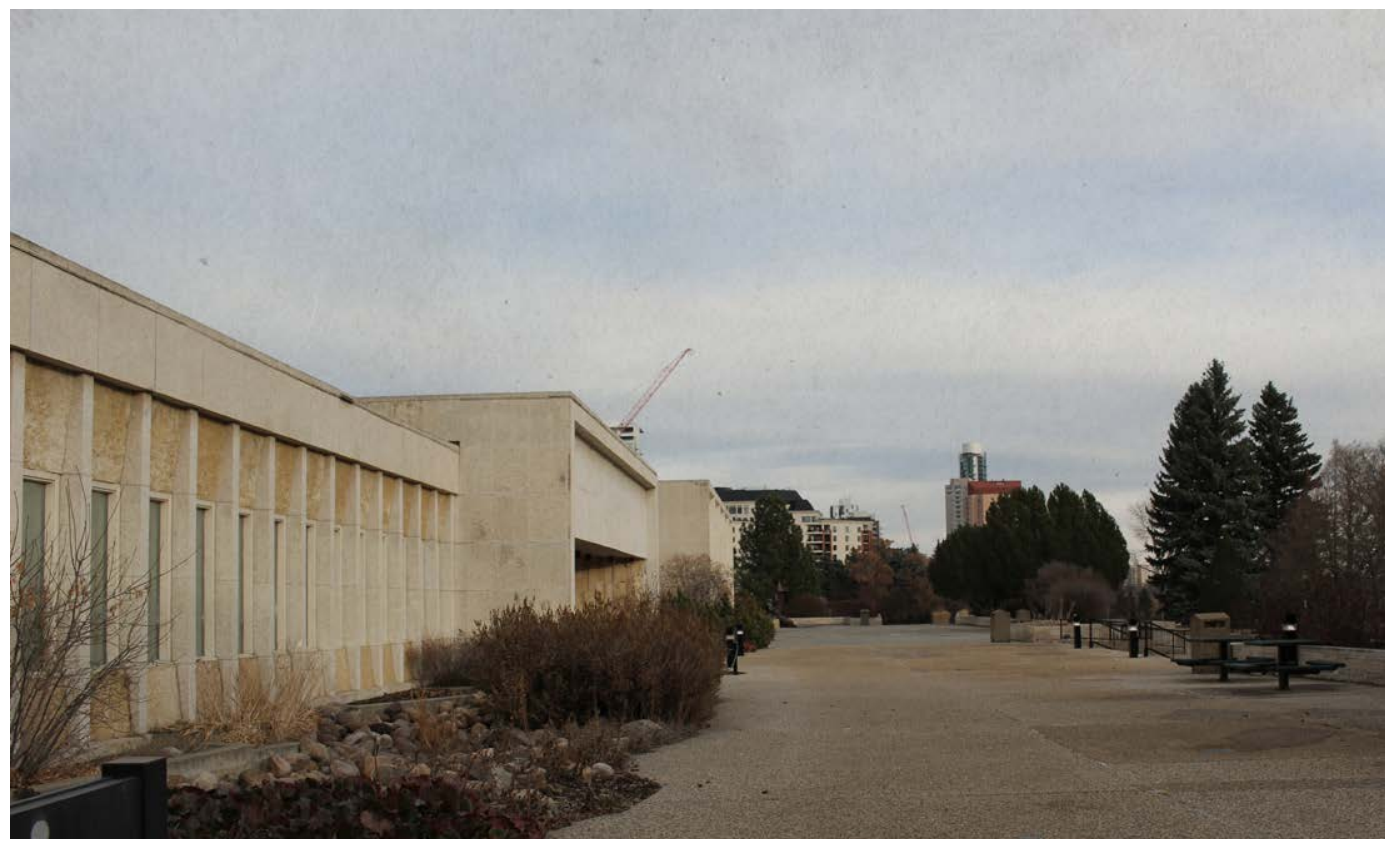

BUILT // 1965

ARCHITECT // Raymond O. Harrison

OPEN TO PUBLIC // 1967

CLOSED TO PUBLIC // 2015

CONSTRUCTION // Tyndall Stone, Marble, Black Granite, Brass Fittings Oak ADDITIONAL NOTES //

- Built as a part of the federal government's Confederation Memorial Centennial Program

- New facilities built for the Royal Alberta Museum in 2015

- Replacement value of the building (2016): 156 million dollars

- Annual operations costs (20016): 2 million dollars

- Total cost of deferred maintenance costs (2016): 50 million dollars

- Government House, Carriage House, and the associated nearby lands are a Provincial Historic Resource

- Includes: 420 seat theatre

Offices for 100 people

Commercial catering kitchen

Classrooms

Storage Facilities

Reception Space

Boardrooms

Galleries

- Problems: mold, lead, asbestos, faulty HVAC, elevators need replacement

Fig. 3.3: Main Entrance

CONTEXTS represents the base of thematic research in investigating the specific spatial and political implications created by a single building, looking for a way forward beyond it's past. 

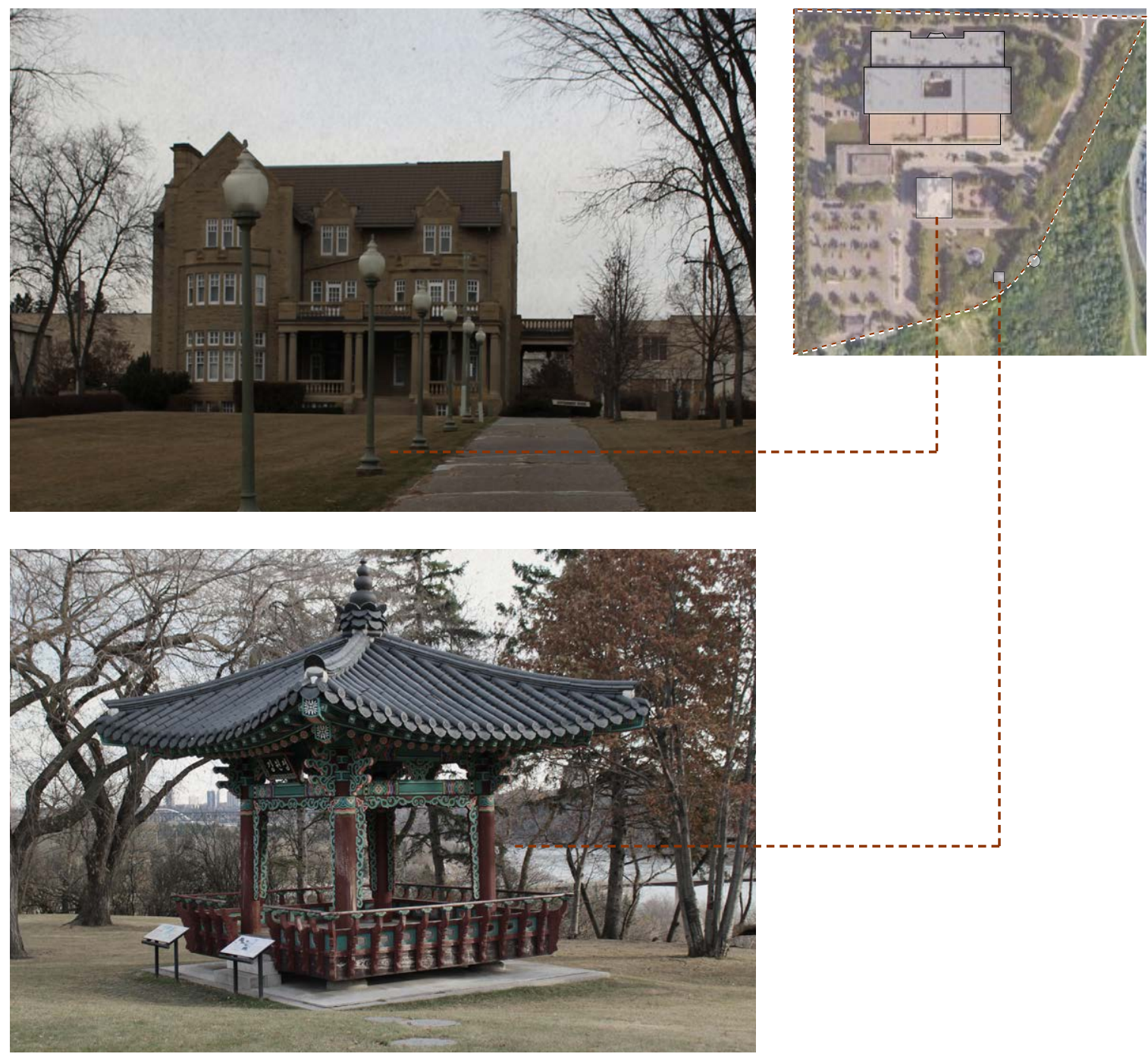

Fig. 3.4: (Right) Key Plan

Google Maps, January 2021, https://www.google.ca/maps/@53.5411701,-113.544945,17z

Fig. 3.5: (Top) Government House

BUILT // 1913

ARCHITECTS // Richard Palin Blakey

CONSTRUCTION // Sandstone Building (Quarried near Calgary)

ADDITIONAL NOTES //

Served as the official residence of Alberta's Lieutenant Governor for 25 years, used for various uses from 1938-1966, then re-established as a center for government meetings.

Fig. 3.6: (Bottom) Korean Pavilion

BUILT // 2005

CONSTRUCTION // Wood and Stone

ADDITIONAL NOTES //

Gifted to Alberta for the celebration of it's centennial and of 30 years of friendship by Gangwon province in South Korea. A traditional Jeongja, built without nails or screws, usually placed in areas with a commanding view or as a threshold to a city. 

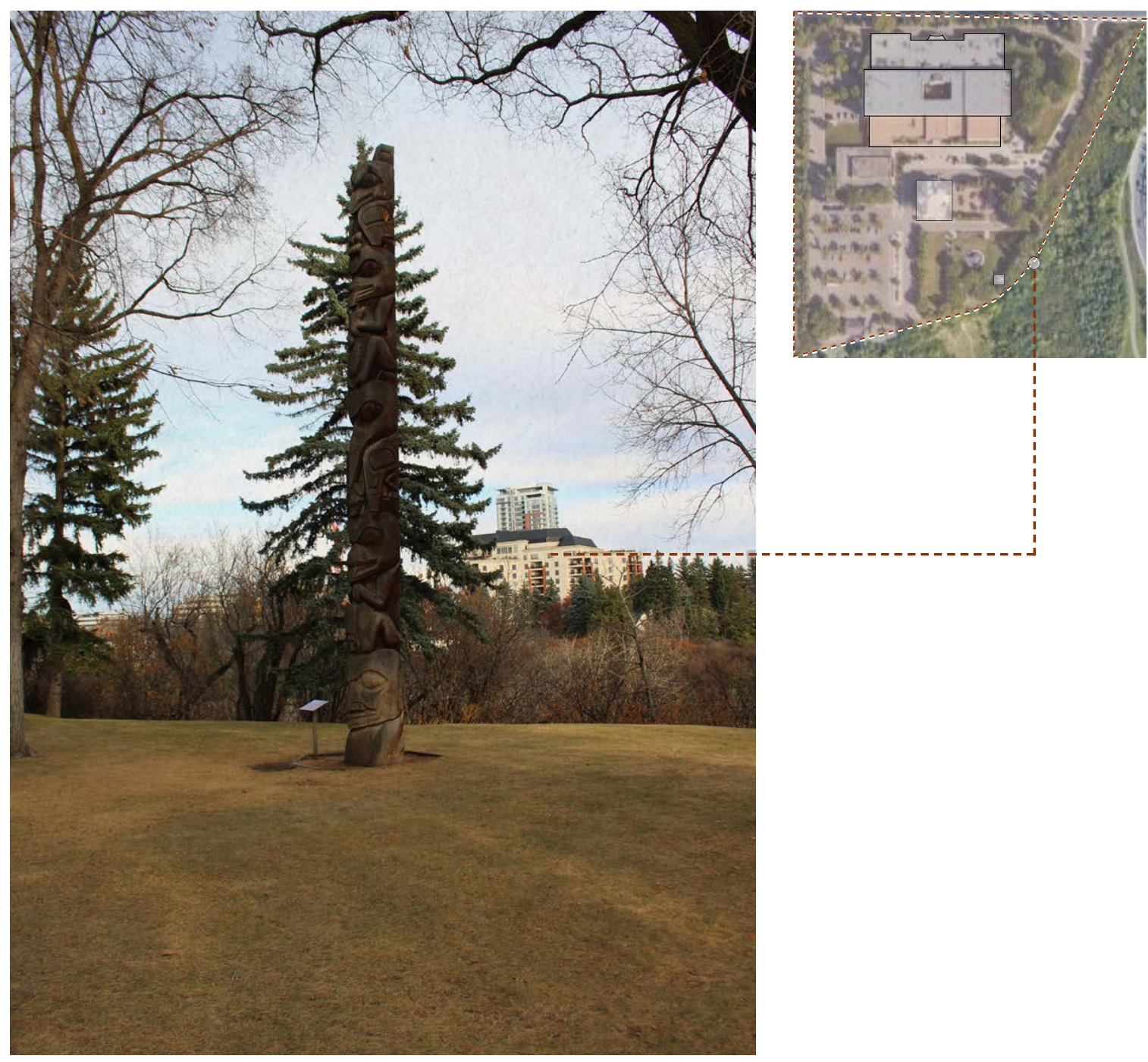

Fig. 3.7: (Right) Key Plan

Google Maps, January 2021, https://www.google.ca/maps/@53.5411701,-113.544945,17z

Fig. 3.8: (Above) Ksan Totem Pole

RAISED // 1983

CARVERS // Earl Muldoe, Chester MacLean, Victor Mowat

CONSTRUCTION // Red Cedar Log

ADDITIONAL NOTES /

37-foot high pole, carved by Earl Muldoe of the Gitskan in a distinctive Northwest Coast

Indigenous art style. 


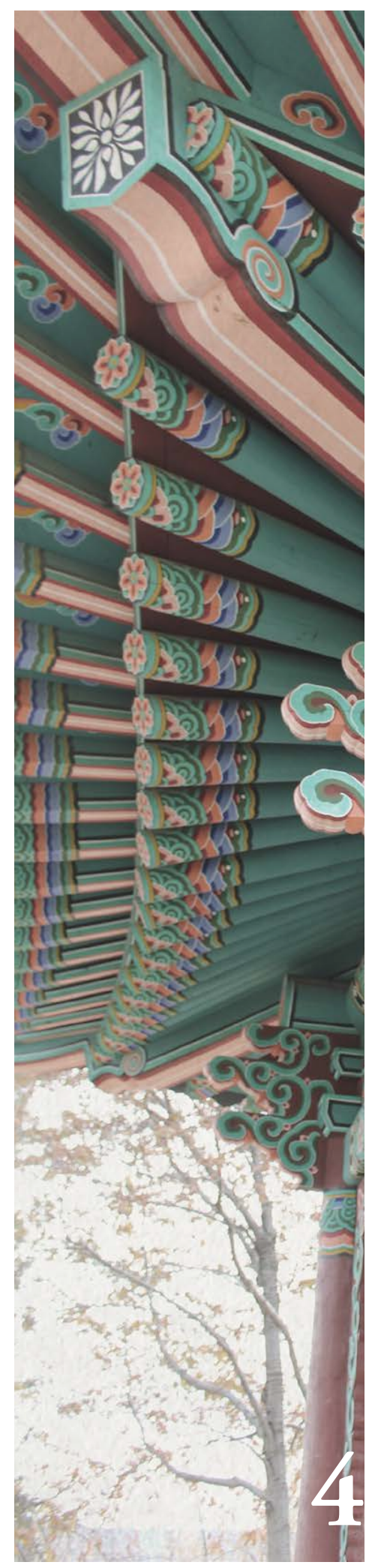

FOUNDATIONS 


\section{"...the evolution of}

architecture is usually dealt with only in its late phases.

Skipping the first fifty centuries, chroniclers present us with a full-dress pageant of "formal" architecture, as arbitrary a way of introducing the art of building as, say, dating the birth of music with the advent of the symphony orchestra. ."

Architecture without Architects,

1, Bernard Rudofsky 


\subsection{DEFINING BOUNDARIES}

In 1964, Bernard Rudofsky organized an exhibit on vernacular architecture in New York City, at the Museum of Modern Art. Of the exhibition, he stated: "Architecture without Architects attempts to break down our narrow concepts of the art of building by introducing the unfamiliar world of non-pedigreed architecture. It is so little known that we don't even have a name for it. For want of a generic label, we shall call it vernacular, anonymous, spontaneous, indigenous, rural, as the case may be." ${ }^{100}$ The exhibit was not merely about creating a typology of non-pedigreed architecture, but also to "free ourselves from our narrow world of official and commercial architecture," ${ }^{101}$ which often focuses on a brief western history of the built environment made by individuals in positions of privilege, wealth and power. ${ }^{102}$

An interest in the vernacular started well before the 1960 's, and the first usages of the word in relation to a local architecture can be traced back to the $19^{\text {th }}$ century ${ }^{103}$ - tied into the history of colonialism and conquest that was explored earlier in this thesis in Chapter 1. Initially, the term was parochially defined to mean "primitive" modes of architecture, ${ }^{104}$ falsely associating the building typologies labeled as 'vernacular' with a rudimentary, outdated, or otherwise unsophisticated quality. However, these traditional modes of building have proved to be "the largest untapped source of architectural inspiration... The wisdom to be derived goes beyond economic and esthetic considerations, for it touches the far tougher and increasingly troublesome problem of how to live and let live, and how to keep peace with one's neighbours, both in the parochial and universal sense." 105
100 Rudofsky.

101 Rudofsky, 15

102 Rudofsky, 13

103 Nezar Alsayyad, "Foreward," in Vernacular Architecture in the Twenty-First Century: Theory, Education and Practice (London: Taylor and Francis, 2006), xvii-xviii, https:// www-taylorfrancis-com. proxy.library. carleton.ca/books/vernacular-architecture-21st-century-lindsay-asquith-marcel-vellinga/e/10.4324/9780203003862. xvii

104 Rudofsky, Architecture without Architects, 15.

105 Rudofsky, 19 
Not limited to just one geographical area, a single

material, or a building type, each form of vernacular architecture evolved in response to its unique region, culture, climate, available materiality, and therefore "serves its purpose to perfection." ${ }^{106}$ Can the same be said of current building typologies, with their focus on energy performance and complete separation of interior environment from exterior?

The driving question of this thesis has been "how can the past inform the current relationship between ecological and social sustainability, and influence current modes of building?" Vernacular architecture was a key starting point, exemplifying how society has been building for eons, in an environmentally sustainable, regionally specific way. 'Vernacular architecture' is used in the scope of this thesis to refer to a localized style of architecture particular to a specific geographical area, built from temporal and regionally available materials and ways of making by local people. ${ }^{107}$
106 Rudofsky, 12.

107 "Vernacular, Adj. and n.," in $O E D$ Online (Oxford University Press), accessed January 11, 2021, http://www.oed.com/ view/Entry/222608. 


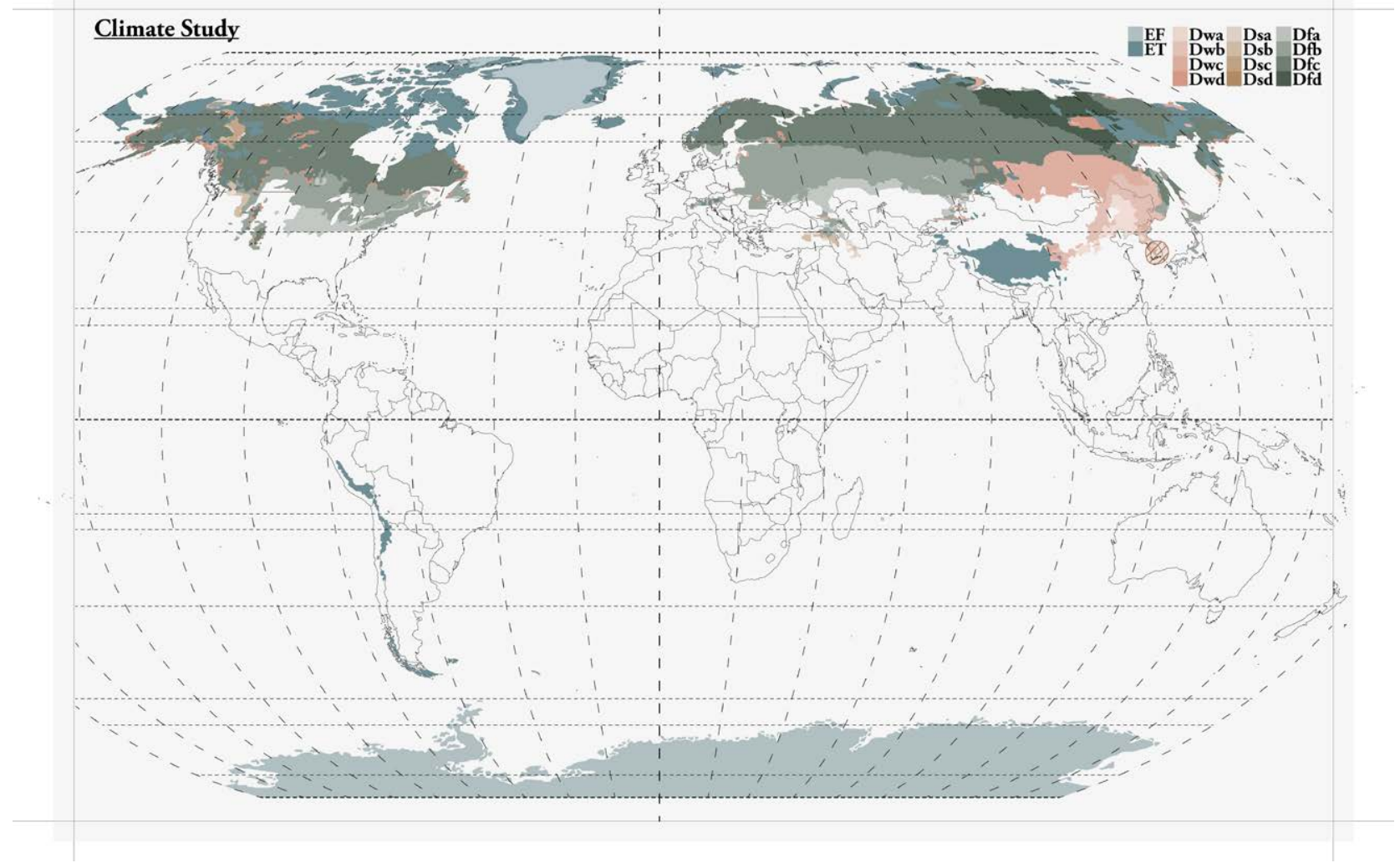

As the process of building is increasingly digitized and separated from specific geographies, the realities of a shifting landscape become more difficult to visualize. Climate change is expediting that process, resulting in changing weather patterns and more instances of extreme weather. Some of these effects are measurable and quantifiable, such as "plant hardiness zones [in North America] moving north at 13 miles per decade..." or "the permafrost line in Canada moving 80 miles north in just 50 years." ${ }^{108}$ Köppen-Geiger maps are

Fig. 4.1: Current Partial Köppen-Geiger Map; Showing Cold-Weather Climates 108 Nicola Jones, "Redrawing the Map: How the World's Climate Zones Are Shifting - Yale E360," Yale Environment 360, October 2018, https://e360.yale.edu/ features/redrawing-the-map-how-theworlds-climate-zones-are-shifting.

109 Franz Rubel and Markus Kottek, "Observed and Projected Climate Shifts 1901-2100 Depicted by World Maps of the Köppen-Geiger Climate Classification," Meteorologische Zeitschrift 19, no. 2 (April 1, 2010): 136-37, https://doi. org/10.1127/0941-2948/2010/0430

being consistently recreated and redrawn, taking into account new climate data and evidence to predict Earth's changing climate zones, even up to the year $2100 .{ }^{109}$ The ongoing changes demand us to reconsider the environment we assume we are building for, redrawing climactic and political lines on the map. Climate change will be felt by people in all corners of the world and our built environment will have to adapt as well. While climate crises we are about to face are unprecedented, it may be a return to vernacular architectures that can aid us in adapting architecture moving forward. 


\subsection{LEARNING FROM THE PAST // CASE STUDIES}

The following 3 case studies are a testimony to the amazing features, technology, and uniquely sustainable thinking that are characteristic of traditional forms of vernacular architecture. They were initial points of inquiry due to their location in cold-weather climates and their reliance on materials that are widely available in Canada. They represent early research that contributed towards a shift in ideology about a buildings ability to adapt with its surroundings, which is reflected through a later interest in the existing materiality on the site of the former Royal Alberta Museum. 


\subsubsection{THE NORTH}

As climactic conditions led my exploration of vernac-

ular typologies, igloos, located in some of the harshest winter climates in the world, seemed like a natural starting point.

Because "Arctic lands were visibly distinct from their adjacent waters" 110 in the summer, and "land and sea gave the appearance of a continuous frozen landmass" ${ }^{111}$ in the winter, both seasons required unique structural responses. Winter opened up possibilities of living along the edges of ice floes, travelling lightly over a frozen landscape, ${ }^{112}$ and building temporary structures with the most abundant material in the North ice. In the Central Arctic, "wood was a rare and precious raw material," 113 not often used in architecture. Instead, winter dwellings were built of ice, and "[Inuit] families would lay a circular foundation from eight to fifteen feet in diameter, adding spiraling tiers of snow slabs until a complete dome was formed" 114 This creates a "surprisingly warm shelter" 115 in which the "high insulation value of the snow... enabled people to live comfortably with only their body heat and the small flame of a seal oil lamp." 116

Perhaps the most striking characteristic of igloos is that because they embrace the transient nature of ice, they are built to be relatively temporary. They anticipate the spring and summer melts and accept the cyclical nature of the seasons. It is therefore the culturally passed down knowledge of how to build which enables the architectural typology to last year to year. "[Arctic peoples] valued knowledge as a source of personal power, but they also recognized that the stories a community holds in common are a fundamental source of knowledge." ${ }^{117}$ The buildings and objects created "were merely
110 Ridington, Robin, "Northern Hunters,"

in America in 1492: The World of the Indian Peoples before the Arrival of Columbus., ed. Josephy, Alvin M. Jr. (New York: Vintage Books, a Division of Random House, Inc., 1991), 28

111 Ridington, Robin, 28.

112 Ridington, Robin, 28.

113 Ridington, Robin, "Northern Hunters." 42

114 Ridington, Robin. 29

115 Allen Noble, Vernacular Buildings: A Global Survey (Bloomsbury Publishing, 2013), 236.

116 Ridington, Robin, "Northern Hunters." 42

117 Ridington, Robin. 26 
Inuit Igloos

NORTHERN CANADA // GREENLAND
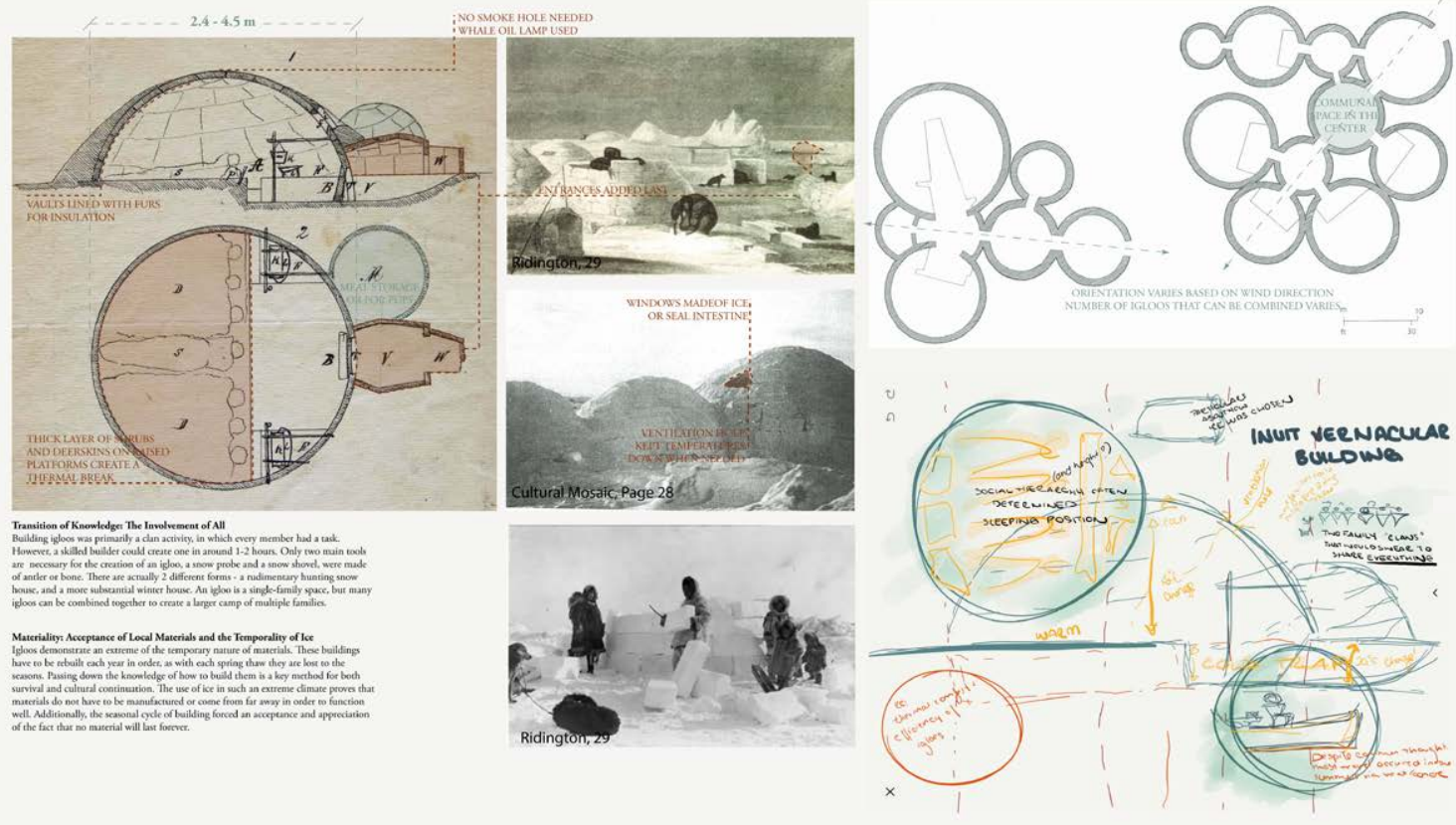

the manifestations of empowering ideas they held in mind." 118

Fig. 4.2: Sketchbook Notes: The North with images from referenced readings 118 Ridington, Robin. pg.45-46.

Modern forms of building and materials that claim

to be 'sustainable' or 'long lasting' often are speaking of a timeline of several decades. By contrast, igloos cyclical nature of existence has ensured their relevance as a built form for thousands of years. This study has relevance to my thesis because it is a temporary and transient architectural typology in which the building materials are uniquely local, and where cultural knowledge contributes to the built form. The focus on the continuity of community knowledge of how to build, and responsiveness to existing local materiality will resurface in the interventions proposed for the site and building of the former Royal Alberta Museum in Chapter 7. 


\subsubsection{SOUTH KOREA}

In the search of further vernacular forms of architecture which had endured the test of time but were located in cold-weather climates, Gyeongbokgung Palace in Seoul, South Korea, became a point of study. Gyeongbokgung Palace was originally built in the $1300 \mathrm{~s} .{ }^{119}$ Unlike the last precedent, Gyeongbokgung palace is not a generalized form of an architectural typology, but a monument which has undergone various preservation and rebuilding efforts, which were aimed at keeping the resulting structure as closely aligned with the 'original' form as possible. A symbol of national identity, it has been almost completely destroyed twice, and has gone through numerous periods of rebuilding and restoration, each time overseen by a Daemokjang - a word reserved for traditional wood buildings, and for the people who build them. ${ }^{120}$

A Daemokjang is a traditional role, responsible for the entire construction process; from choosing the wood, through planning and construction, to maintaining and restoring the buildings over time, and for passing on this knowledge to their apprentices, and is therefore in some regards, similar to an architect. ${ }^{121}$ A key difference, however, is the emphasis on maintenance and restoration of buildings over time. Their knowledge is classified as Intangible Cultural Heritage, and the emphasis on prolonged maintenance reaffirms the tie between sustained cultural knowledge, site specificity and a uniquely South Korean vernacular method of building.

The official acknowledgement and recognition of individuals for their ability to combine "artistic creativity with scientific knowledge on nature and technological abilities" to successfully construct Daemokjang is an important
119 Jong-Deok Choi, "The Palace, the City and the Past: Controversies Surrounding the Rebuilding of the Gyeongbok Palace in Seoul, 1990-2010," Planning Perspectives 25, no. 2 (2010): 193, https://doi. org/10.1080/02665431003613014.

120 Choi, 193

$121 \mathrm{Kim}$ et al., "Utility of Digital Technologies for the Sustainability of Intangible Cultural Heritage (ICH) in Korea," 13-14. 


\section{Gyeonbokgung Palace}

SEOUL // SOUTH KOREA

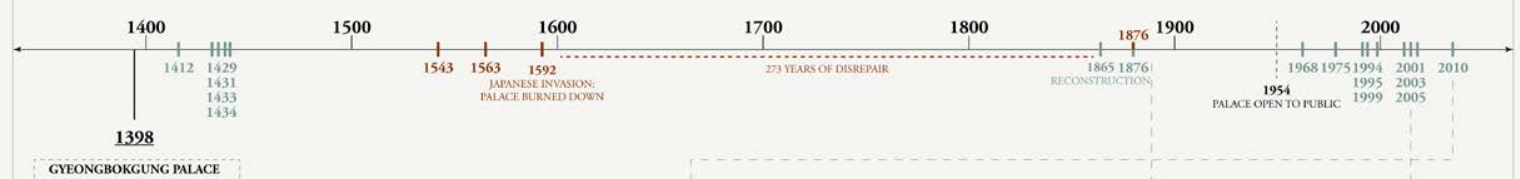

GYEONGBOKGUNG PALACE
ESTABLISHED: WALIS ARE BUIIT
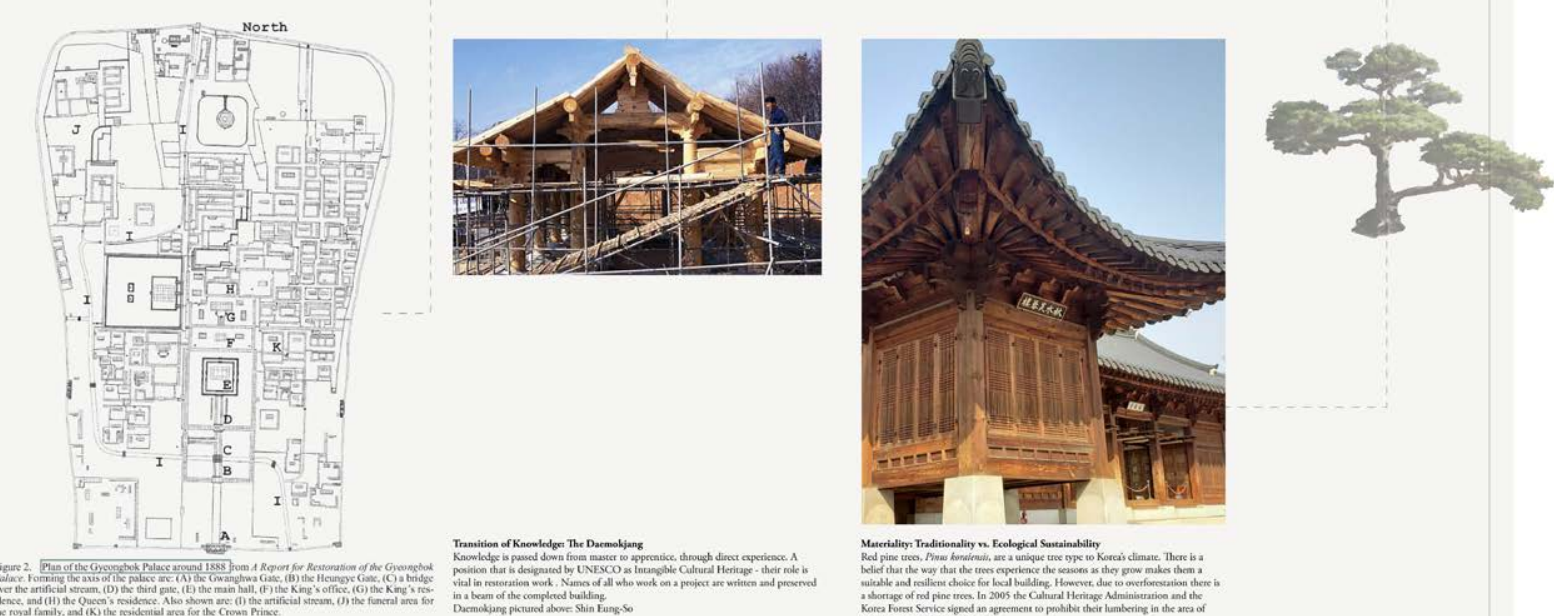

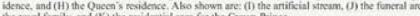

Fig. 4.3: Sketchbook Notes: South Korea

step in bringing cultural knowledge into current construction methodology. ${ }^{122}$ Daemokjang understand and pass down the knowledge of how to work with, assemble, and maintain wood to their apprentices. ${ }^{123}$ By accepting the impermanence and the natural lifecycle of wood, the role of the Daemokjang becomes not only to safeguard the building, but more importantly to preserve the knowledge of how to build. This research proposes a cultural shift, in which buildings themselves are not as important as the knowledge of how to build them. Choosing to strengthen the link between community held knowledge and material knowledge is a more "holistic and inclusive understanding of heritage" which has led to this building standing the test of time for over 700 years.
$122 \mathrm{Kim}$ et al., 14.

123 Choi, "The Palace, the City and the Past." 


\subsubsection{PACIFIC NORTHWEST}

Long before wood became heralded as a 'green' building material, it was commonly used along the Pacific Northwest Coast. It would be narrow-minded to assume that every Indigenous group along the coast stretching from "Yakutat Bay in Alaska to northern California" ${ }^{124}$ had an identical approach to building. There were, however, some similarities apparent in the architectural typologies of pit houses. This study focused on lessons learned from pit house buildings - which rely on wood as a predominant structural material. This does not include the full variety of structures built by Indigenous peoples along the coast, nor the wide range of the materials used, but is one general vernacular typology investigated due to its reliance on wood as a building material.

Pit house structures require first digging down into the ground before assembling the frame around the perimeter, and fastening regionally varied exterior facing in place to keep the weather out. ${ }^{125}$ Along the Pacific Northwest Coast, western red cedar was often used due to "its straight grain, ease of splitting, workability, and resistance to decay." 126 The most common point of failure was "the rotting of the base of the posts from ground moisture." ${ }^{127}$ As that occurred, or if the group chose to move to another location, the buildings were disassembled, all parts re-evaluated, and the larger pieces trimmed down for reuse as smaller components in a new structure. ${ }^{128}$ These structures, often kept water-tight with earth or reed mats, were "very warm structures and admirably suited for winter use when the temperatures drop well below freezing." 129 The wide use of a range of similar pit house structures, the "cross-continental and trans-temporal nature
124 Daugherty, Richard D., "People of the Salmon," in America in 1492: The World of the Indian Peoples before the Arrival of Columbus., ed. Josephy, Alvin M. Jr. (New York: Vintage Books, a Division of Random House, Inc., 1991), 48-83. 51

125 Daugherty, Richard D., 57-58. 63-64, 75-76.

126 Daugherty, Richard D., "People of the Salmon." 62

127 Mark Jarzombek, "The Great Northern Continuum - Part I," in Architecture of First Societies: A Global Perspective (Hoboken, New Jersey: Wiley, 2013), 121.

128 Jarzombek, 121.

129 Daugherty, Richard D., "People of the Salmon," 76 


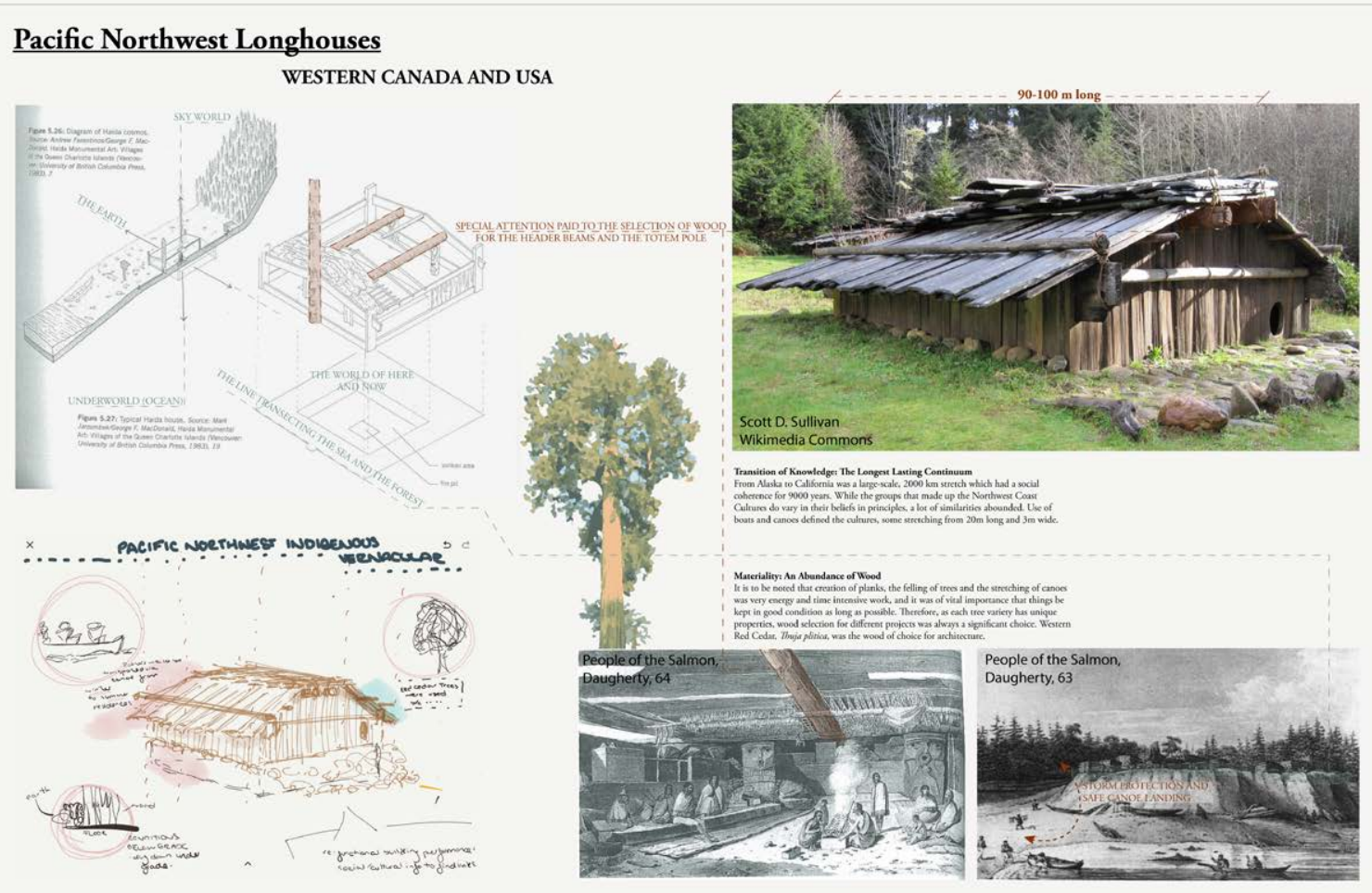

Fig. 4.4: Sketchbook Notes: PNW

of this house form, adapted to cold climates as well as to desert, and adapted to riverine as well as agricultural communities, is a testament to its astonishing versatility." ${ }^{130}$

Perhaps one factor even more astonishing than their versatility is the longevity of the building tradition. "The pit house and cone house tradition - lasting over 30,000 years - are the most fundamentally successful examples of architecture in human history." ${ }^{131}$

In their book, "New Architecture on Indigenous Lands," Malnar and Vodvarka use the example of a Big House, the U'mista Centre in Albert Bay, British Columbia, to depict how a traditional Indigenous building typology can be adapted over time and incorporated into contemporary culture. The building retains connections to traditions through the cultural activities it facilitates, the reliance on a wood structure, and the community involved in the design process, ${ }^{132}$ although the scale increased and the use changed from residential to ceremonial. ${ }^{133}$ As they point out, there
130 Jarzombek, "The Great Northern Continuum - Part I,” 121

131 Jarzombek, 119

132 Joy Monice Malnar and Frank Vodvarka, New Architecture on Indigenous Lands (Minneapolis: University of Minnesota Press, 2013), 47-48

133 Malnar and Vodvarka, 43. 
often exists the fallacy to see traditional vernacular building types "as frozen in time - static artifacts for unchanging functions. This has tended to discourage - though not eliminate evolutionary growth in an indigenous architecture responsive to changing building usage." ${ }^{134}$ Seeing vernacular traditions as fixed in a time hinders the capabilities of the modern building industry to find value in traditional modes of building. In the scope of this thesis, the realization of that fallacy spurs the re-investigation of the word 'vernacular,' causing us to question how contemporary building practice can re-embrace vernacular traditions to become more rooted in their unique place. The tradition of disassembly, evaluation, re-use and reassembly is a methodology that can be incorporated in this thesis. 


\subsection{RE-DEFINING BUILDING}

The need for a Canadian regional architecture was expressed as early as the 1950s in the Massey Lévesque report, "[noting] that "there is increasing consciousness of the need in Canada for the development of a regional architecture adapted to the landscape and climate and also to the materials typical of the area," already recognizing at this early date that the geographic vastness, climatic variation and different cultural traditions across the country would inevitably require architectural responses specific to local contexts." 135 This was, of course, ignoring the regionally adapted architecture that already existed in Indigenous forms of building.

"[While] the Provincial Museum in Edmonton displays a monolithic, sparsely glazed form of Brutalism, it communicates its regional identity through a cladding of Tyndall limestone, typical of major public buildings in the Prairie Provinces." 136

The RAM, built in a brutalist, modernist style, brings together local Canadian materials through the Tyndall Stone it is faced with, and oak and marble finishes on the interior, in an attempt to create a new Canadian vernacular of the 1960s. Ironically, Canada's commitment to its own arbitrary self-representation is shown by the fact that as of this year, the building stands empty. This can be explained by a short-sighted interpretation of vernacular, one which did not "[study] the vernacular within its historic and cultural context," ${ }^{137}$ and was too focused on formal representation.
135 Polo and Ripley, Architecture and National Identity / Architecture et Identite Natioinal, 27.

136 Polo and Ripley, 28.

137 Lindsay Asquith and Vellinga, Marcel, "Introduction," in Vernacular Architecture in the Twenty-First Century: Theory, Education and Practice (London: Taylor and Francis, 2006), 4, https://www-taylorfrancis-com. proxy. library.carleton.ca/books/vernacular-architecture-21st-century-lindsay-asquith-marcel-vellinga/e/10.4324/9780203003862. 
As AlSayyad argues, the hope for vernacular lies in its place "as a political project, a project whose principle mission is the dynamic interpretation and re-interpretation of this past in an ever-changing present." 138 The materials which exist on site today are now a part of the landscape and utilizing them in the remaking of the museum and the grounds is part of a process of 'dynamic reinterpretation.' However, "vernacular architecture should be explicitly treated as a cultural process rather than as merely a material product," 139 and the outdated ideologies and biases that came out of a museum context will similarly have to be critically examined and reinterpreted. This must be done so they can once again "fit within their cultural and ecological contexts," such that "a truly sustainable future built environment can be achieved." 140
138 Alsayyad, "Foreward."

139 Asquith and Vellinga, Marcel, "Introduction," 19

140 Asquith and Vellinga, Marcel, 19. 


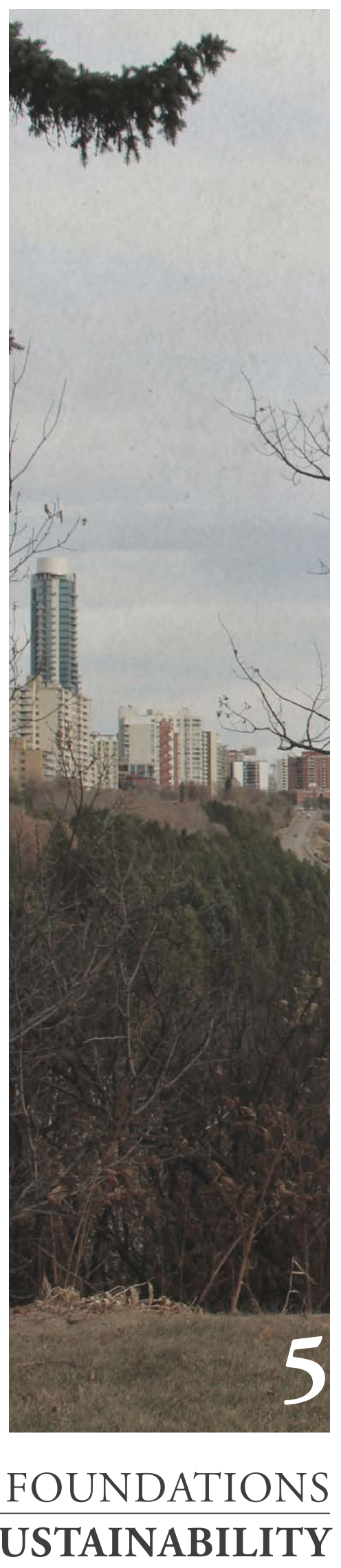


"...we are well overdue for a paradigm shift: one that will finally allow us to reconcile our commoditised present with the many lessons afforded by pre-industrial and vernacular construction."

The Road Not Taken,

14, Pender and Liemieux 


\subsection{THE THREE TIERS}

Jean Carroon states 3 pillars for sustainability in her book - Sustainable Preservation: Greening Existing Buildings. The 3 pillars are societal, ecological or environmental, and economic - or more colloquially - people, planet, and profit. ${ }^{141}$ This definition of sustainability is undoubtedly more holistic than focusing solely on economic considerations.

In 2019, as sustainability and climate change rose to the forefront of the collective mind, countries began to investigate the key players in climate change. In Canada, the building industry accounts for the consumption of almost $50 \%$ of natural resources and over $30 \%$ of energy use and the production of almost $40 \%$ of $\mathrm{CO}_{2}$ emissions and $25 \%$ of landfill waste. ${ }^{142}$ In architecture, the materials we use and the way in which we build is innately tied to the environment.

The 17 Sustainable Development Goals put forward by the United Nations similarly depict a holistic approach to sustainability, with energy and economics situated amongst other aims of sustainability, such as well-being, clean water, and responsible consumption and production. ${ }^{143}$ They are just one example of a framework that uses all 3 pillars to judge sustainability.

Jean Carroon argues, through research and an extensive number of case studies, that the preservation and restoration of existing buildings is crucial to addressing the climate emergency, and for achieving true sustainability. Some key environmental sustainability outcomes are substantial improvement in Life Cycle Assessments, as seen through the continued use and repair of heritage buildings when compared to newer builds, the regional specificity of local
141 Jean Carroon, Sustainable Preservation: Greening Existing Buildings, 1. Aufl., 1st ed. (Hoboken, N.J: Wiley, John Wiley \& Sons, Incorporated, Wiley-Blackwell, 2010).2010 142 Mark Thompson Brandt, "Buildings and Stories: Mindset, Climate Change and Mid-Century Modern," Journal of Architectural Conservation 23, no. 1-2 (2017): 40, https:// doi.org/10.1080/13556207.2017.1327195. 143 United Nations, "THE 17 GOALS | Department of Economic and Social Affairs," un.org, accessed October 5, 2020, https:// sdgs.un.org/goals. 2020 . 
material use, and the production of less $\mathrm{CO} 2$ overall. ${ }^{144}$ Economic factors are broken down and show that the continued maintenance and repair of buildings, compared to new builds, actually create more spending and subsequent job growth in the local labour market as opposed to money spent on new builds. ${ }^{145}$ And lastly, social outcomes are noted in the regional specificity of historic buildings and in how the revitalization of buildings positively impacts the communities surrounding them. ${ }^{146}$

This all combines to conclusively show that not every "new discovery or refinement" brings us closer to "higher values or greater happiness," and that the key to "real and tangible progress" may well lie in looking back and readapting what we already have. ${ }^{147}$
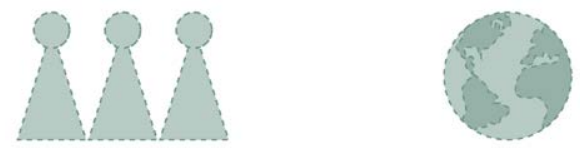

ECOLOGICAL // PLANET

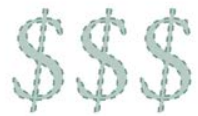

ECONOMIC // PROFIT

Fig. 5.1: The Three Tiers
144 Carroon, Sustainable Preservation, 49 145 Carroon, 50

146 Carroon, 53-54.

147 Rudofsky, Architecture without Architects, 19 


\subsection{RE-FOCUSING THE DIRECTION}

Typically 'green' solutions such as Passive House Standards, LEED accreditation and similar rating systems focus on new buildings, rather than on the reuse of current building stock. Additionally, they often rely on proprietary innovative products, the long-term effects of which are not known. In one published example, the maintenance requirements of an English thatched cob cottage was compared to a LEED certified building. The comparison of the two juxtaposes their age and relative sustainability - the cob cottage served over sixty years, while decay was found in the structural members of the LEED certified building after only ten years. ${ }^{148}$

It is clear that "A global attitude adjustment that strongly prioritizes sustainable rehabilitation of our existing resources over new creation is required in order to meet critical climate change and other environmental targets." ${ }^{149}$ This rehabilitation must be understood as starkly distinct from preservation. While preservation involves "designation [as] a form of legal protection that helps to recognize and protect historic places," ${ }^{150}$ this cannot be applied to the building stock en masse. It is inadequate to simply create a list of buildings that are worth saving and to consider the rest as disposable. The major critique here is that "merely conserving designated buildings... helps to define waste, or that which does not have value," and ignores the building stock as a whole, and is thus not in keeping with larger sustainability goals. ${ }^{151}$ In some instances, historical preservation also raises the questions about original building use and intent. In the case of the former Royal Alberta Museum, which contributed to racial biases, what does keeping it intact mean?
148 Pender and Lemieux, "The Road Not Taken."

149 Brandt, "Buildings and Stories," 37. 150 Government of Alberta, "Designation of Provincial Historic Resources," Government, Alberta.ca, 2021, https://www. alberta.ca/designation-provincial-historic-resources.aspx.

151 Susan M. Ross, "Re-Evaluating Heritage Waste: Sustaining Material Values through Deconstruction and Reuse," The Historic Environment: Policy \& Practice 11, no. 2-3 (July 2, 2020): 382-408, https://doi.org /10.1080/17567505.2020.1723259.pg.382 


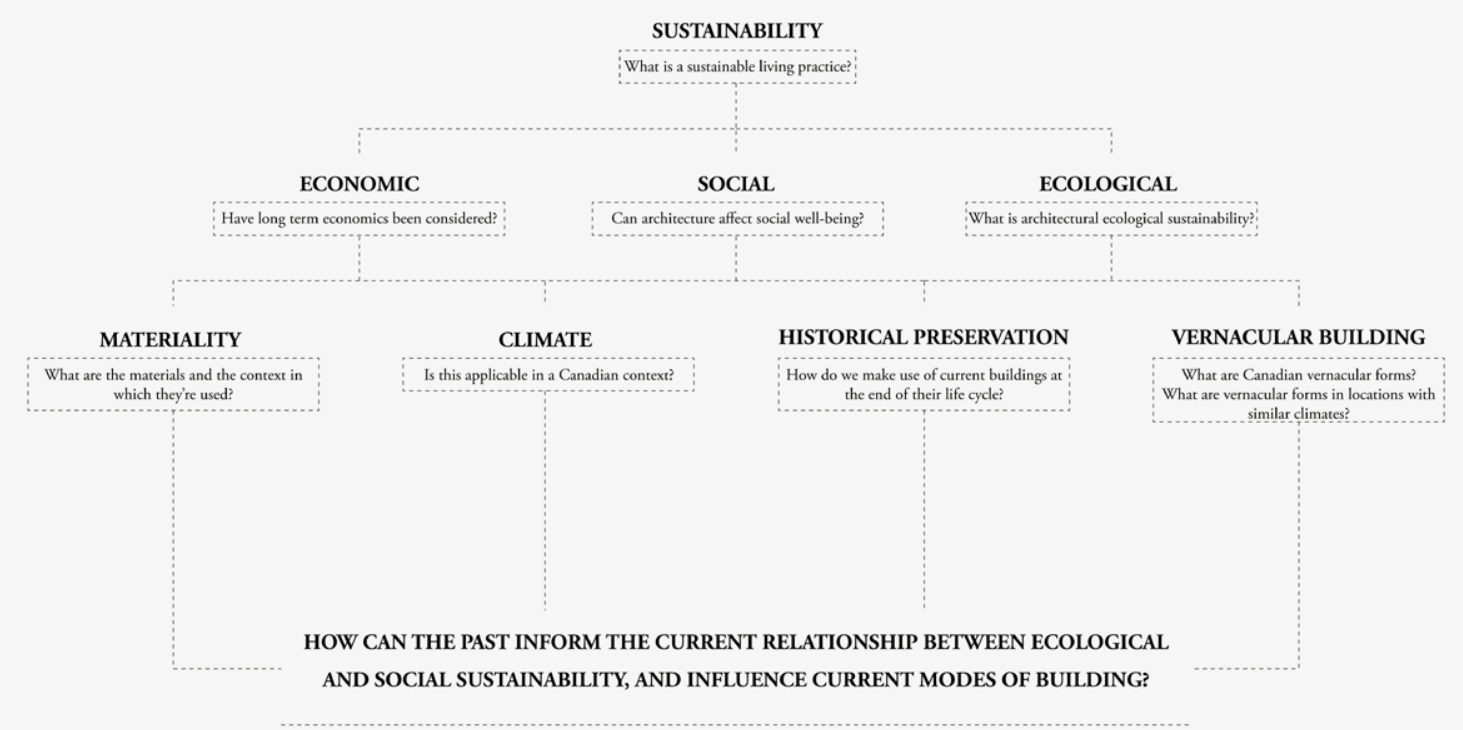

Fig. 5.2: Guiding Questions

A reiterative rehabilitation in which "each alteration is a 'retelling' of the building" can help us to reframe our questions of sustainability, so that "when the changes are complete, it becomes the existing building for the next retelling. In this way the life of the building is both perpetuated and transformed by the repeated act of alteration and reuse."152 This can open up more possibilities for cradle-to-cradle thinking and a transition to a circular economy in which existing buildings and sites undergo a process of 'urban mining' to further reuse available materials, to "prevent the extraction of new resources" ${ }^{153}$ and to decrease the amount of material that ends up in landfill. ${ }^{154}$ Susan Ross argues for a "slower [process] of building deconstruction, followed by reuse of the reclaimed components and materials" 155 as "a key strategy for implementing [a] continued economy of materials." 156

This thesis chooses to title the reiterative processes of deconstruction instead as processes of disassembly and reassembly, and to combine them with the seven generations model and reconciliatory goals to create a sustainable, multi-generational construction methodology.
152 Brandt, "Buildings and Stories," 37.including existing and heritage buildings, is required to meet critical climate change and other environmental targets. This is

153 Ross. pg.384

154 Ross. pg.386

155 Ross, "Re-Evaluating Heritage Waste." pg.382

156 Ross. pg.386 


\subsection{THE SEVEN GENERATIONS MODEL}

"Within an individual's lifetime, it is not unusual that an extended family consists not only of oneself, but those that are three generations before and three generations after. This is the intergenerational family - great-grandparents, grandparents, parents, "you", children, grandchildren, and great-grandchildren. Fundamentally, the middle generation - you - represents the center point of a bridge that spans the past and the future. The knowledge of the past informs the present and, together, it builds a vision towards the future. This is known as the seven generations model." 157

The concept of the seven generations model is an Indigenous way of knowing that proposes an alternative way of thinking about time, space, and the cultural implications of the built environment. Integrating this concept into the thesis moving forward creates an entirely new understanding of buildings and cultures, as it extends to questions of societal change as well as the built environment. It can be used as a way to move towards reconciliation and towards increasing the understanding of interconnectedness between all people and all things. Combined with the practices of disassembly and reassembly, it can start to become the basis of a new construction methodology.

The seven generations model can assist us to move away from "measures of success...based on Western measures of attainment," and to move towards measures of success based on "community values." ${ }^{158}$ By incorporating a longer time
157 Jojola, "Indigenous Planning: Towards a Seven Generations Model."

158 Jojola, 465. 
frame within a culture of adaptive reuse, we can "[move] from a culture of repair and renewal [which is] essential for reducing our environmental impact and becoming a regenerative society, rather than one that is merely doing less harm." 159 A simple concept that can help to frame the question of the former RAM in a different way, within a different time scale. One that doesn't ask 'What do we do with the RAM today,' but instead, 'how can I create a building system and culture so that my great-grandchildren will be proud of the values I hold?'

A limitation of this research is that, as a westerner, my understanding and explanation of the seven generations model is innately limited, and cannot be as comprehensive or accurate as when it is presented by an Indigenous knowledge holder. This limitation in the research amplifies the existing need to create space for Indigenous voices and knowledge to be shared across all aspects of society in order to move towards sustainability.
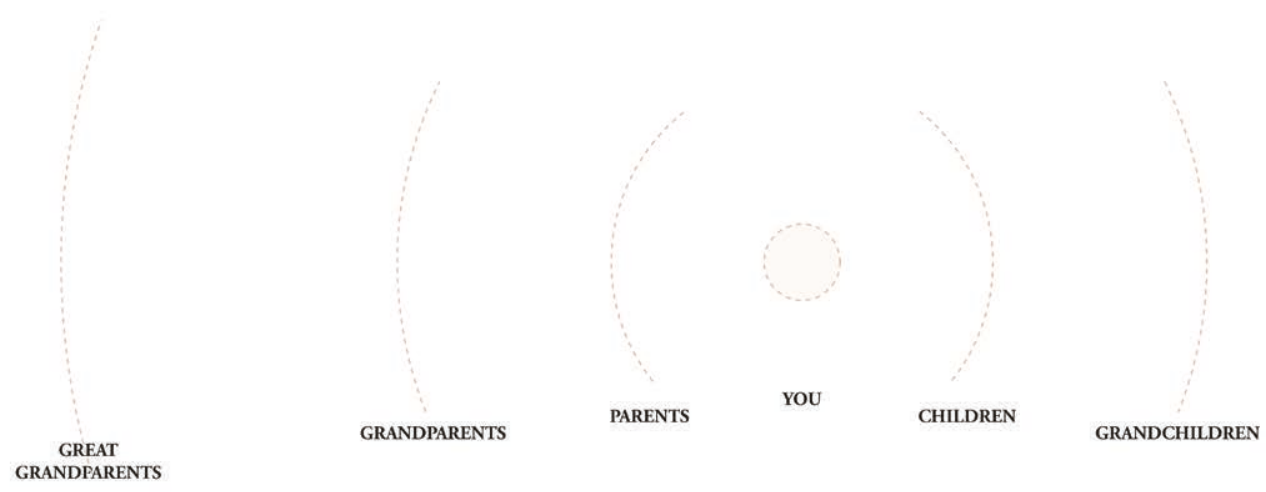


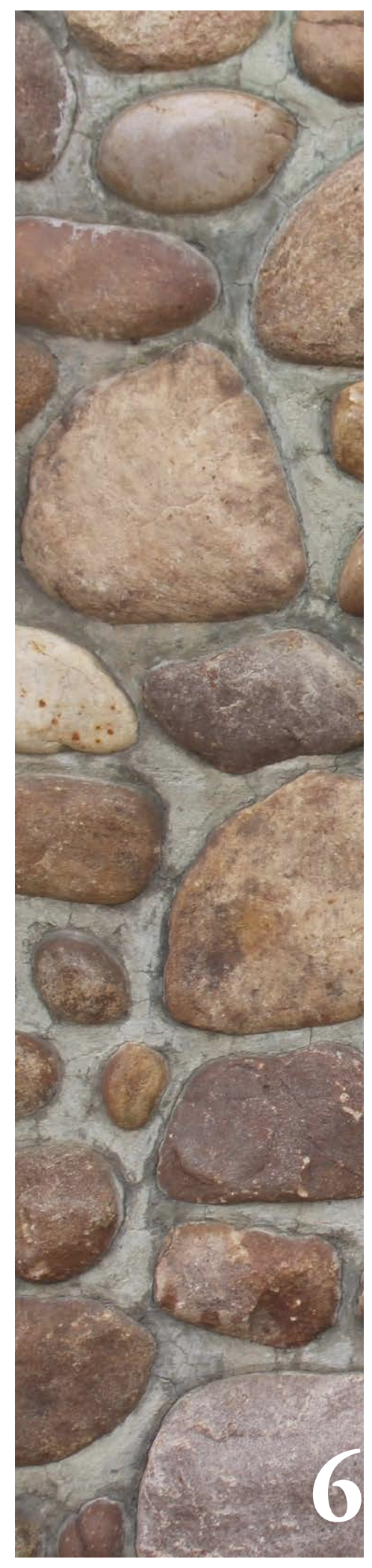

FOUNDATIONS TAKING STOCK 


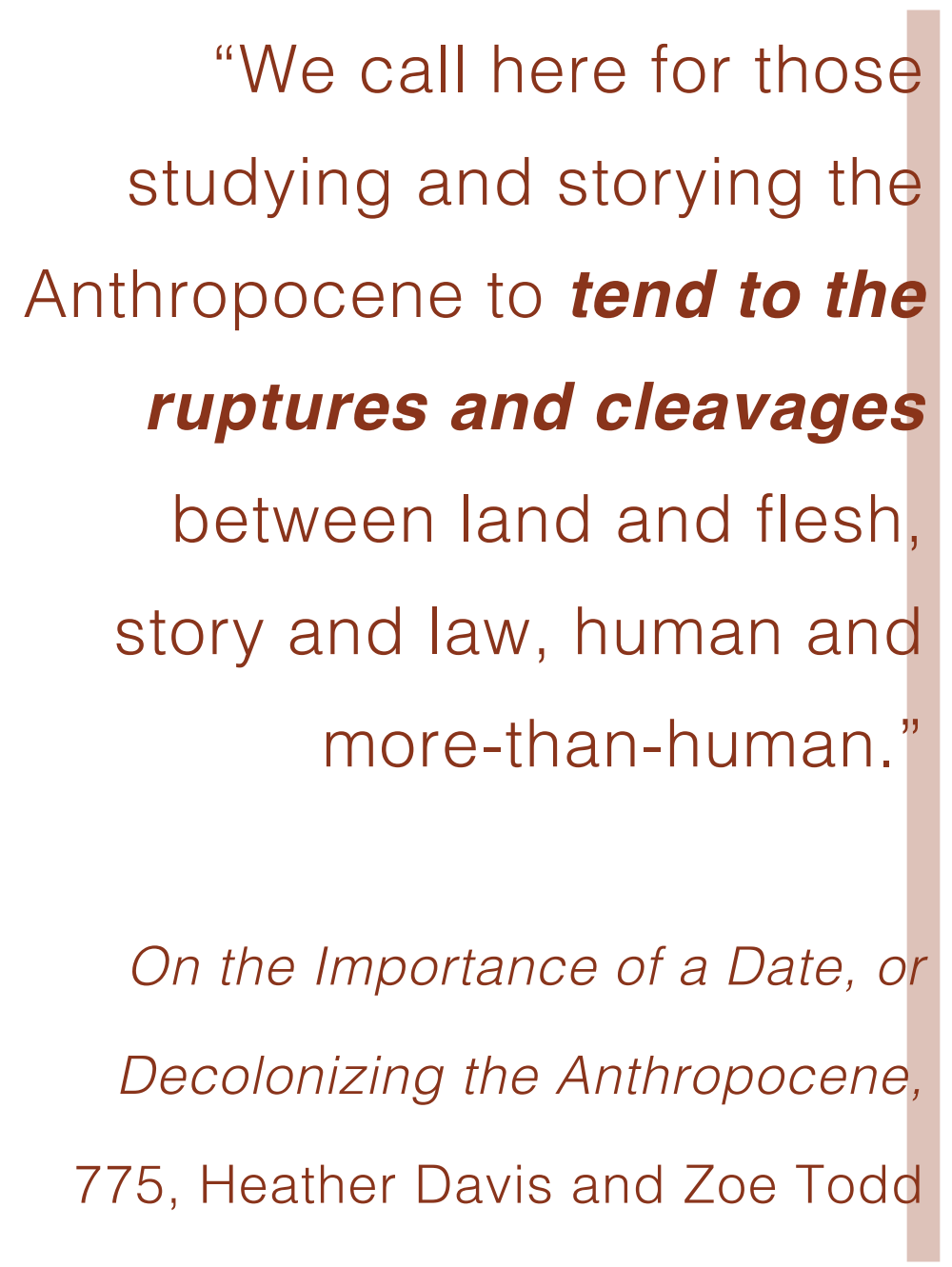




\section{$\underline{\text { Royal Alberta Museum }}$}

\section{THE BUILDING ITSELF}

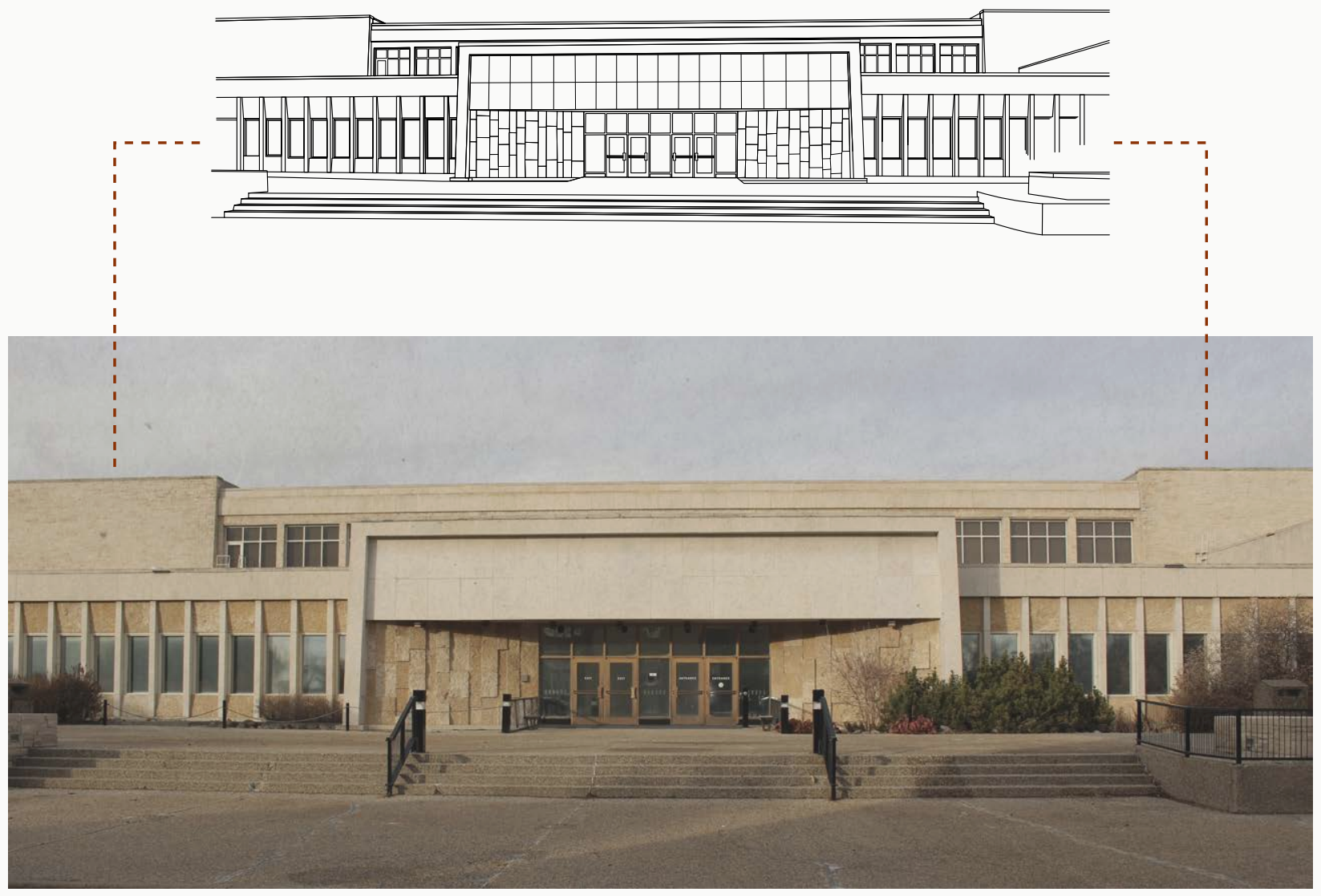

Fig. 6.1: The Royal Alberta Museum Entrance

FOUNDATIONS represents a process of understanding what is present on the site and researching potential methodologies of reuse and adaptation. 


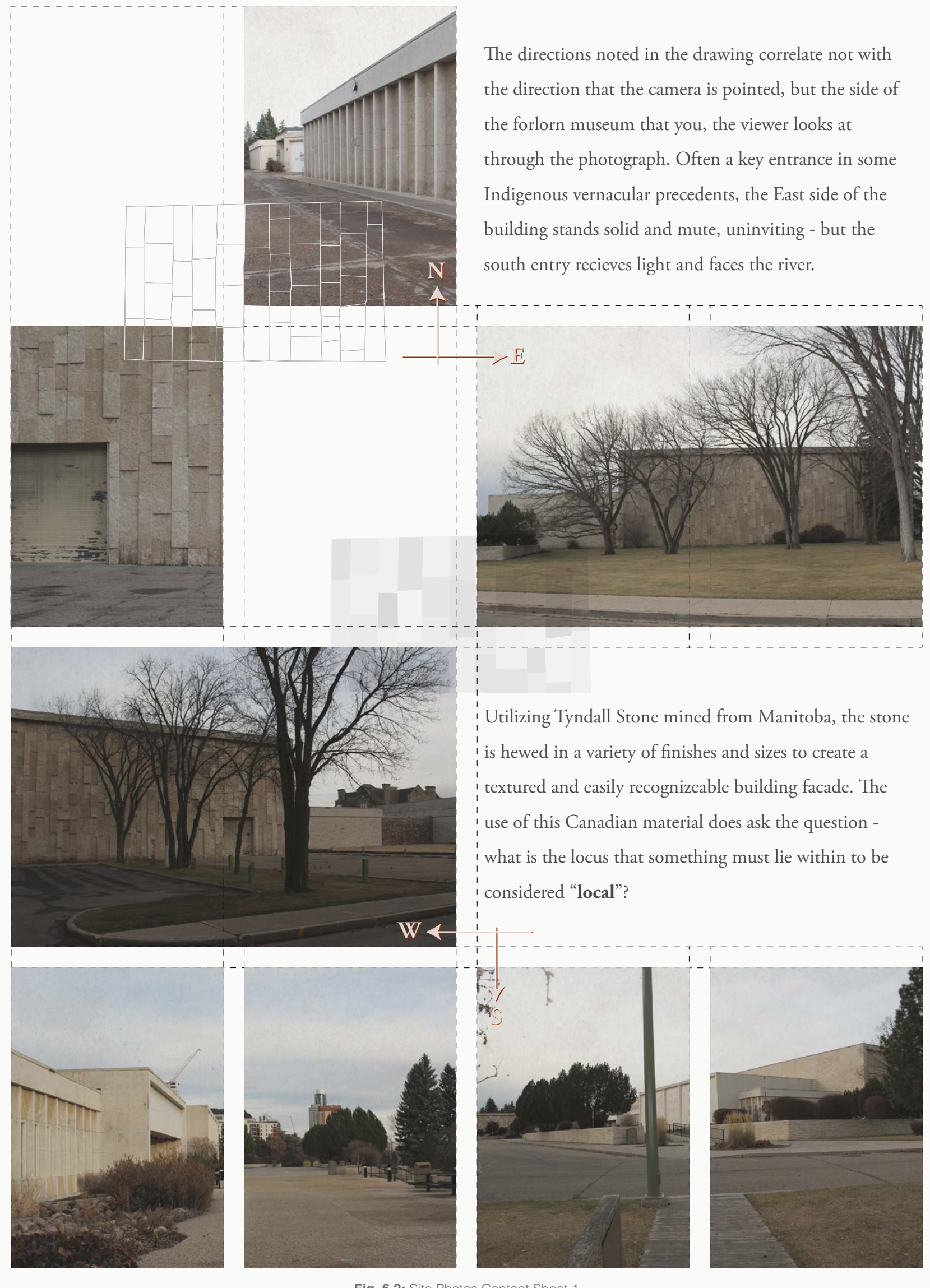

Fig. 6.2: Site Photos Contact Sheet 1 


\section{$\underline{\text { Royal Alberta Museum }}$}

\section{CULTURAL OBJECTS}

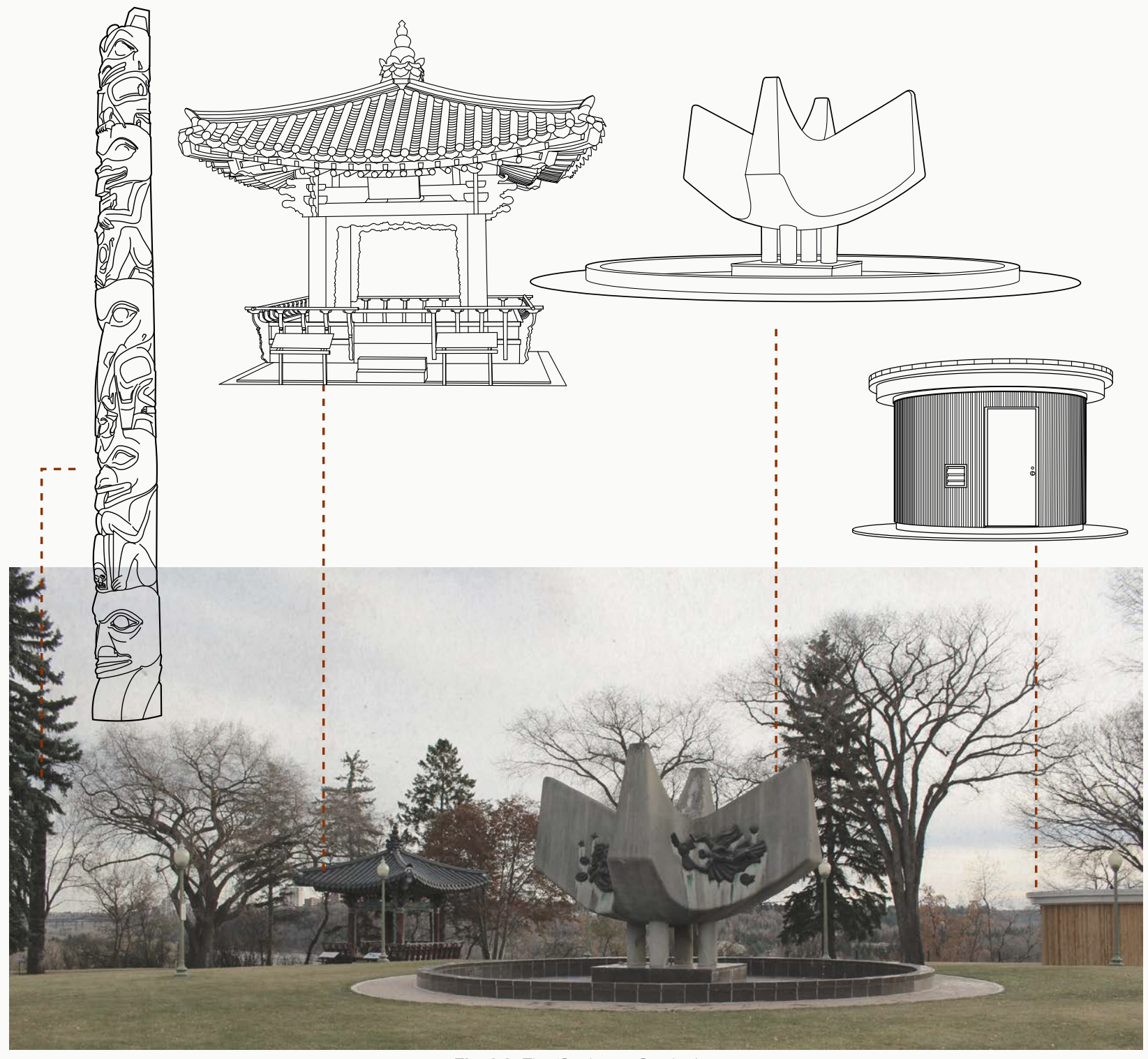

Fig. 6.3: The 'Sculpture Garden' 

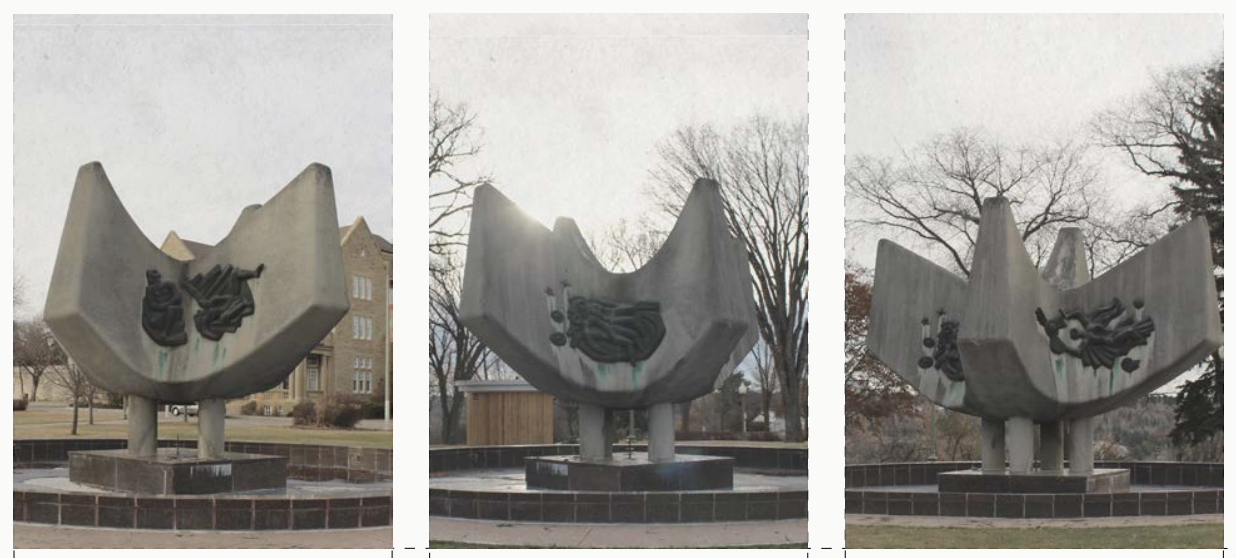

Dubbed "cultural objects" -

these items share a space

called the Sculpture Court,

and yet the prominence that

a mechanical tool shed has

on the landscape makes it

share equal prominence

with the other objects.
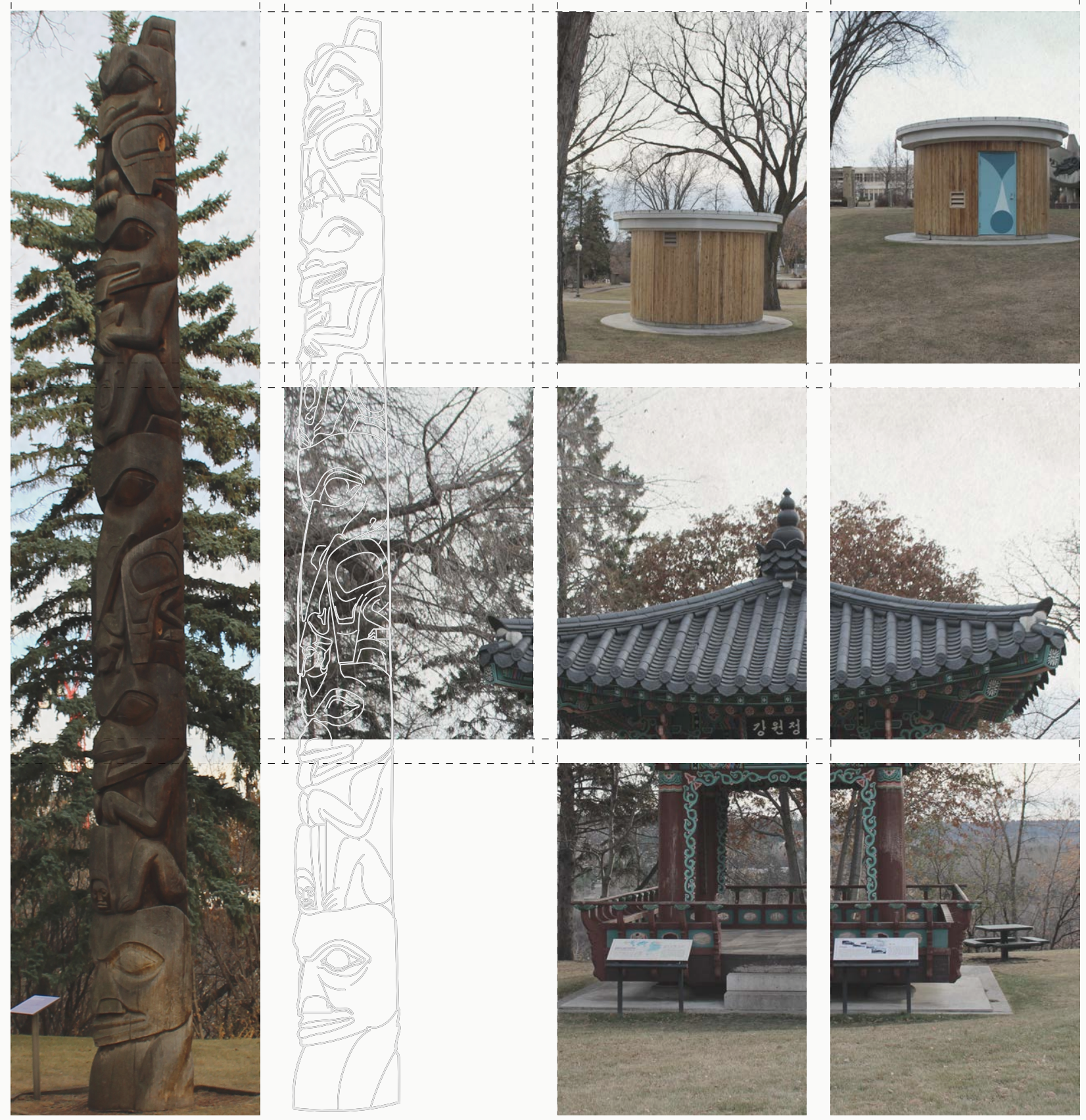

Fig. 6.4: Site Photos Contact Sheet 2 


\section{Royal Alberta Museum}

\section{GOVERNMENT INTERVENTION}

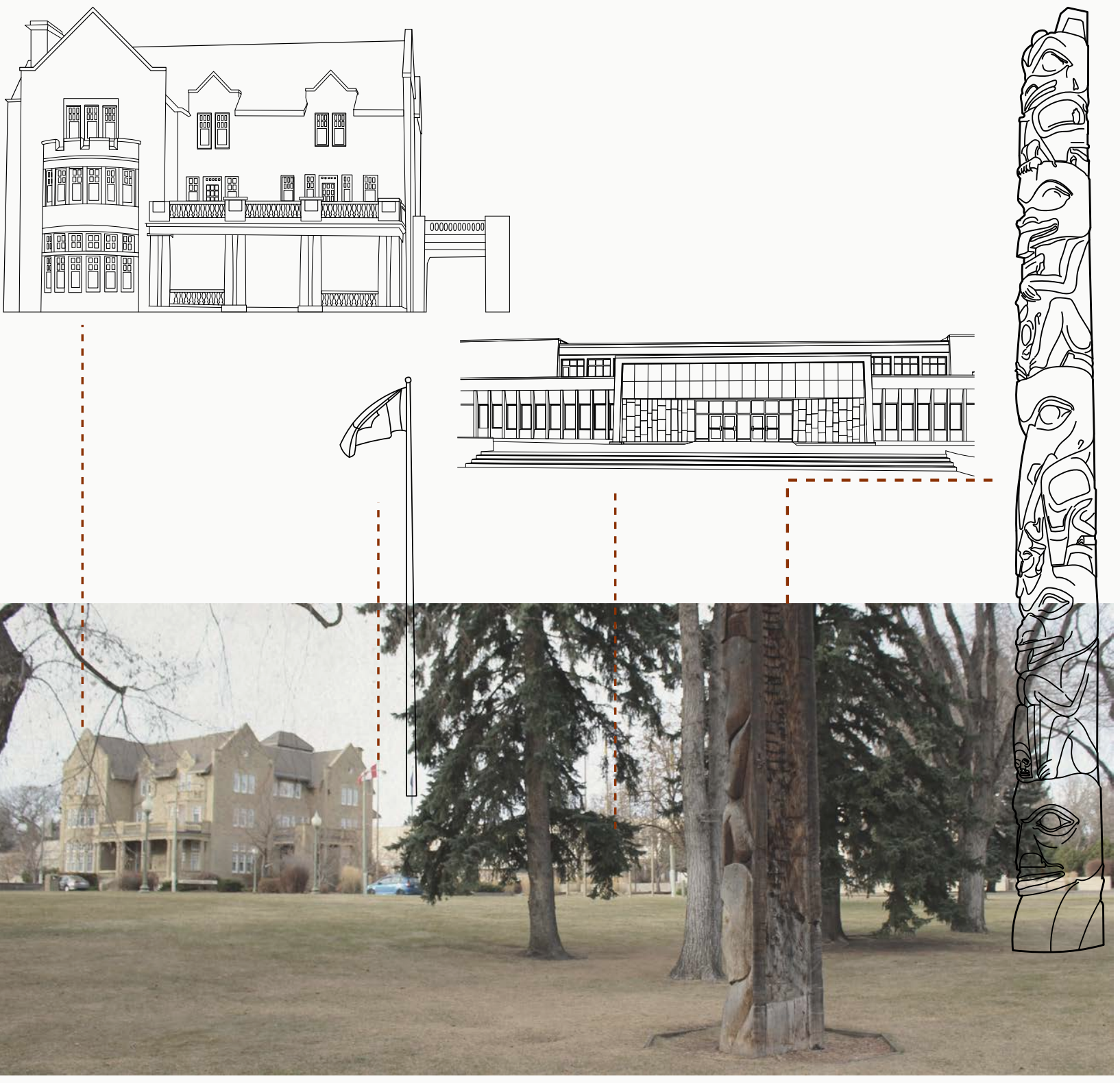

Fig. 6.5: Observing Government House 
In the Canadian narrative, outward displays of national pride are paired with a specific Indigenous narrative. On the museum grounds, this includes the placement of a totem pole in an area titled a "Sculpture Court" - actively under-representing the value of totem poles as historical tools and as a means of knowledge sharing, suggesting that they find use only as art objects. As well, the placement of both the totem pole and a replication of the "Writing on the Wall" are
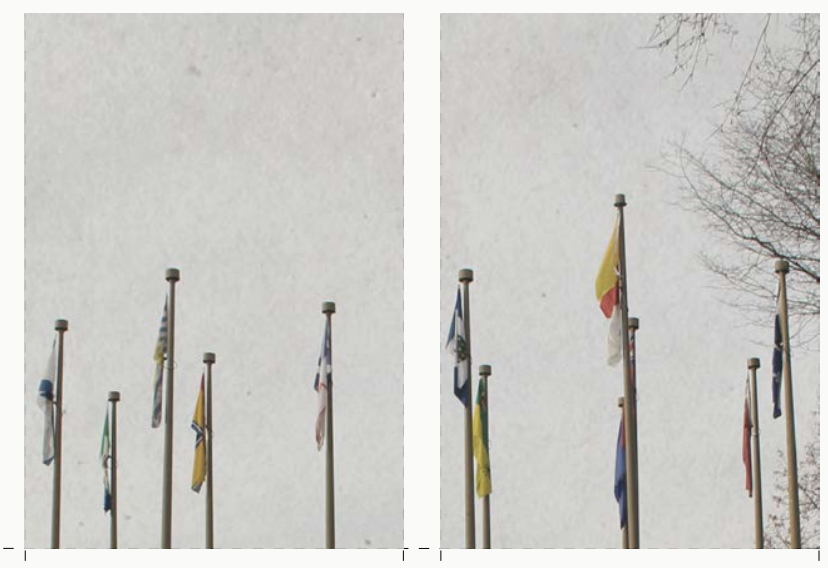
within the controlling view of the "Government House" and "Confederation Court" - consistently subject to obsesrvation.
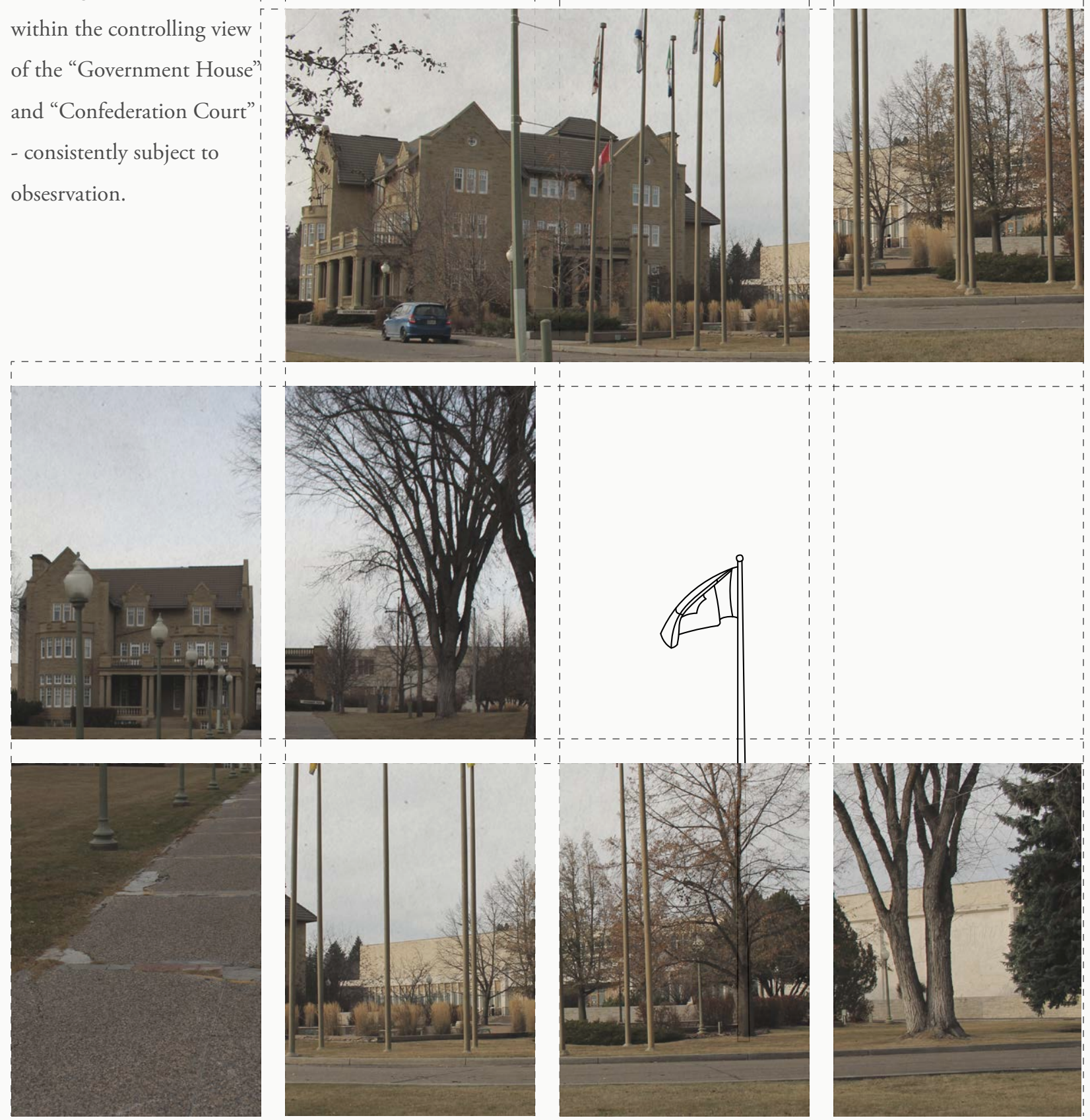

Fig. 6.6: Site Photos Contact Sheet 3 


\section{$\underline{\text { Royal Alberta Museum }}$}

\section{RIVER VALLEY CONNECTION}
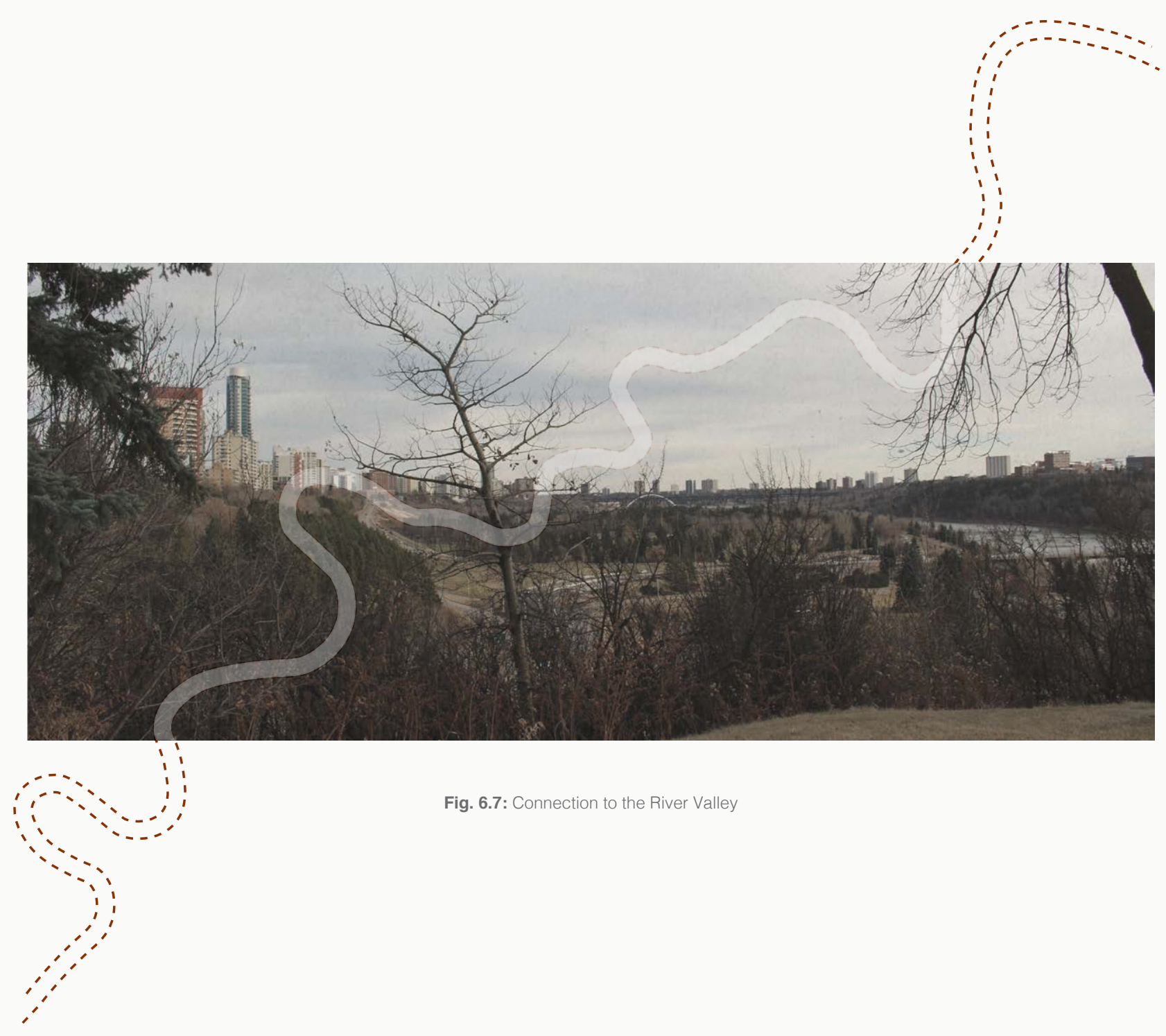

Fig. 6.7: Connection to the River Valley 

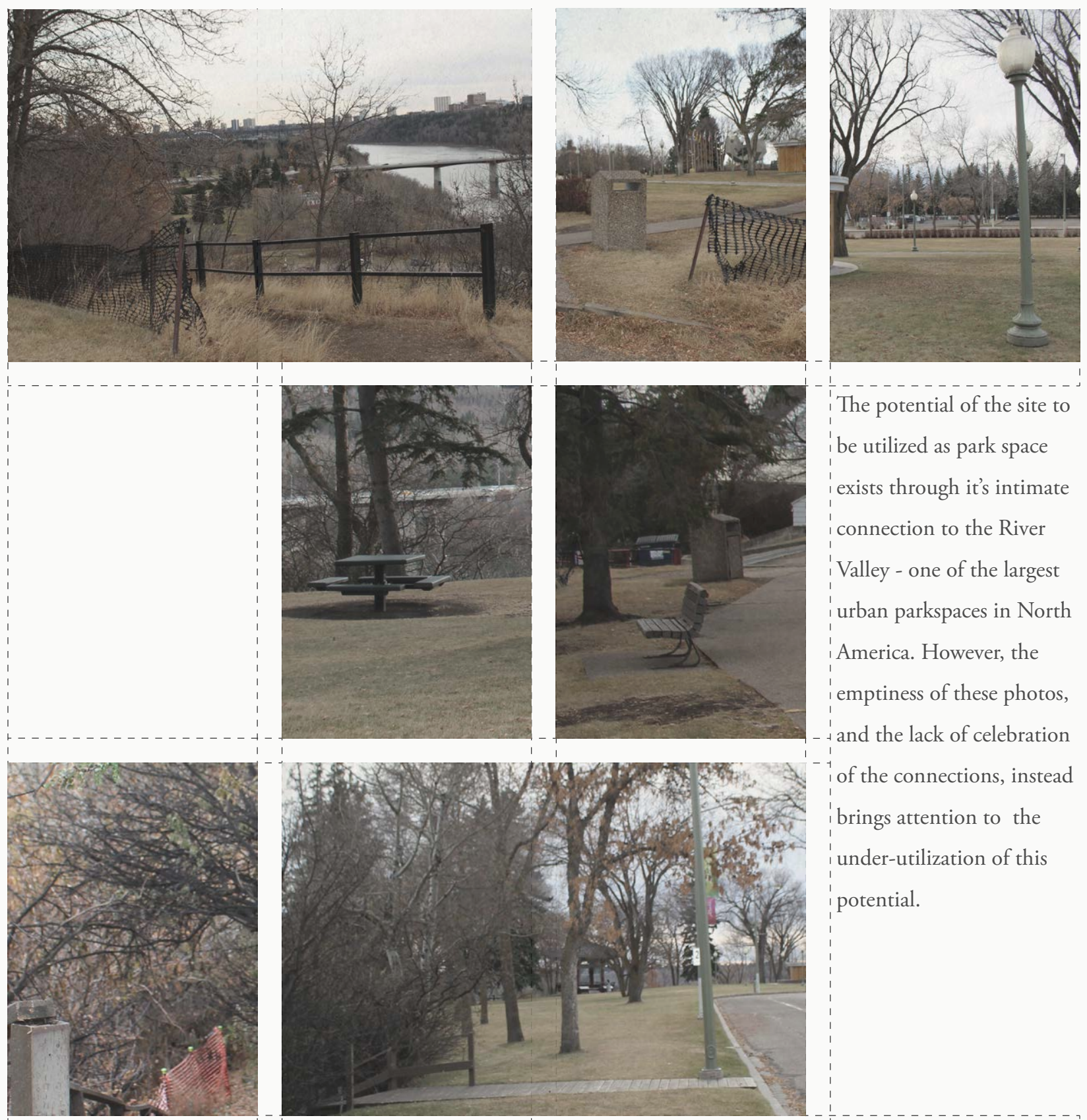

The potential of the site to

be utilized as park space

exists through it's intimate

connection to the River

Valley - one of the largest urban parkspaces in North America. However, the emptiness of these photos, and the lack of celebration

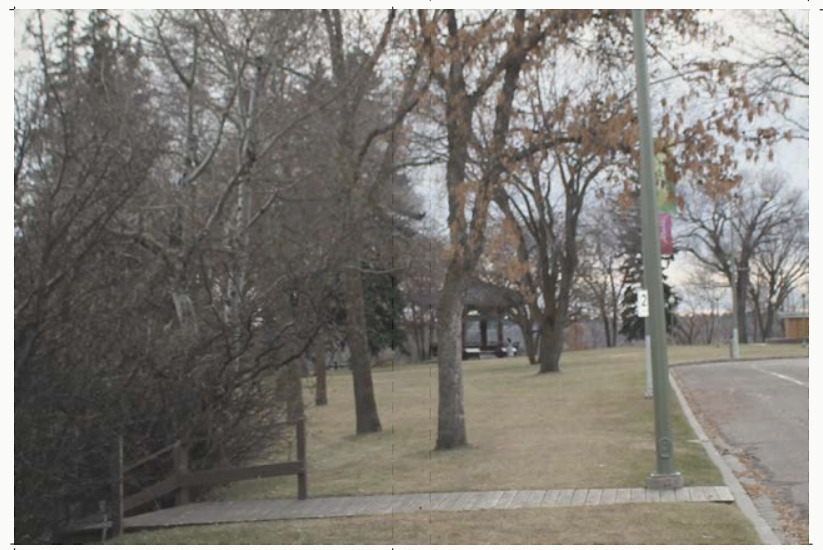

i of the connections, instead brings attention to the under-utilization of this potential.
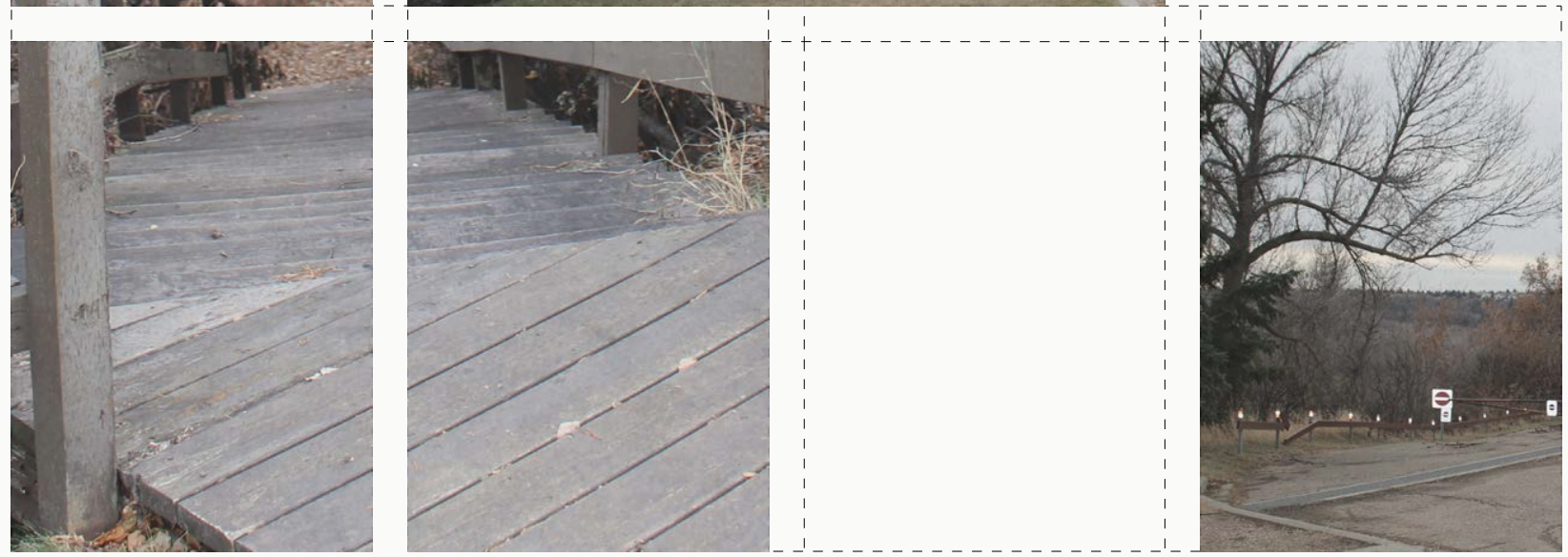

Fig. 6.8: Site Photos Contact Sheet 4 


\section{$\underline{\text { Royal Alberta Museum }}$}

LANDSCAPE vs. HARDSCAPE

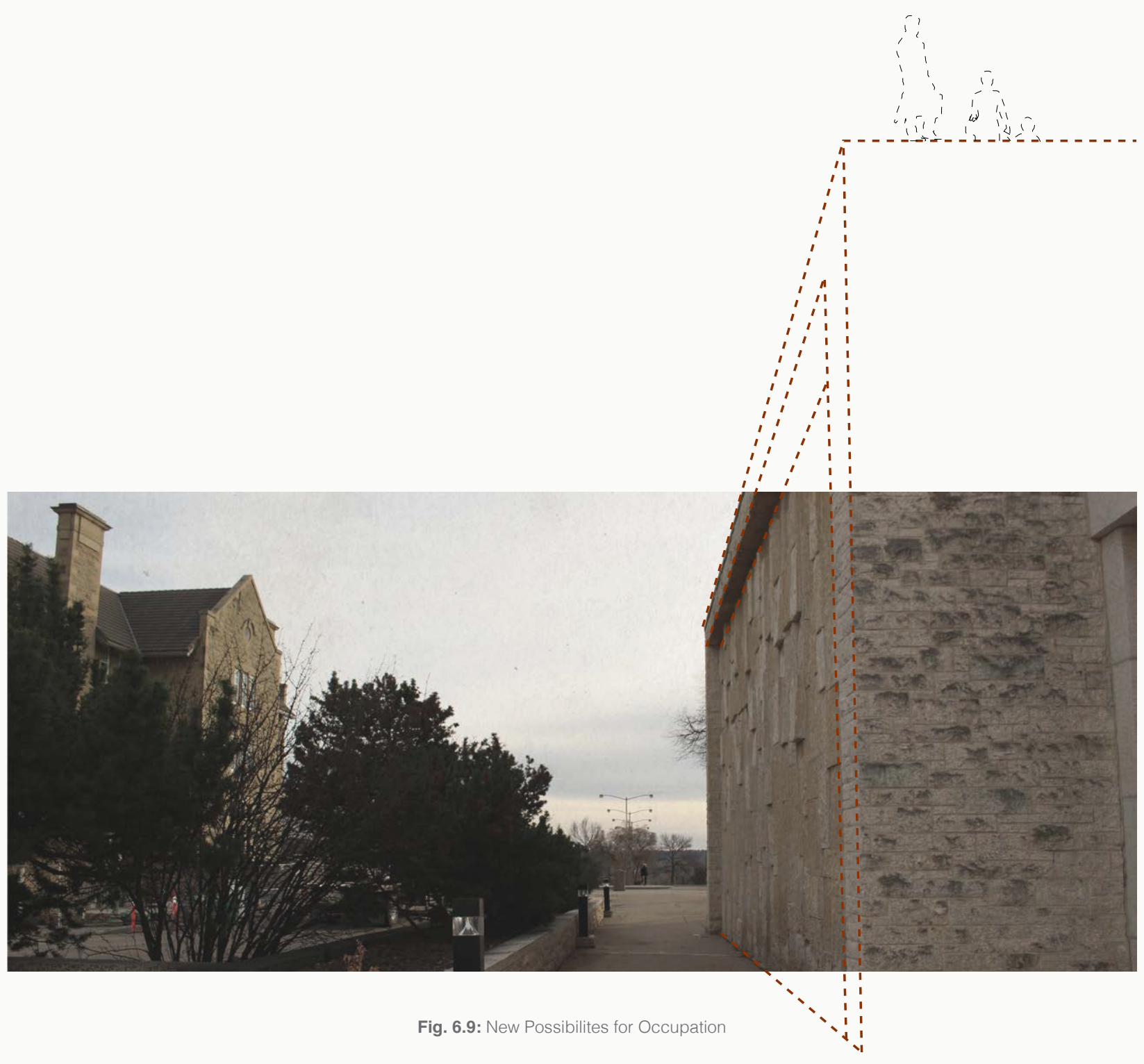


The vast amount of

hardscaping not only

prevents the site itself from breathing, but contributes to problems like acid shock syndrome in the North

Saskatchewan River in the spring. The evident failures in the hardscape show how unsustainable vast asphalt surfaces are - to break this up, reuse the aggragate in new building materials and bring more greenery into the site would enliven the space and remediate the environment.
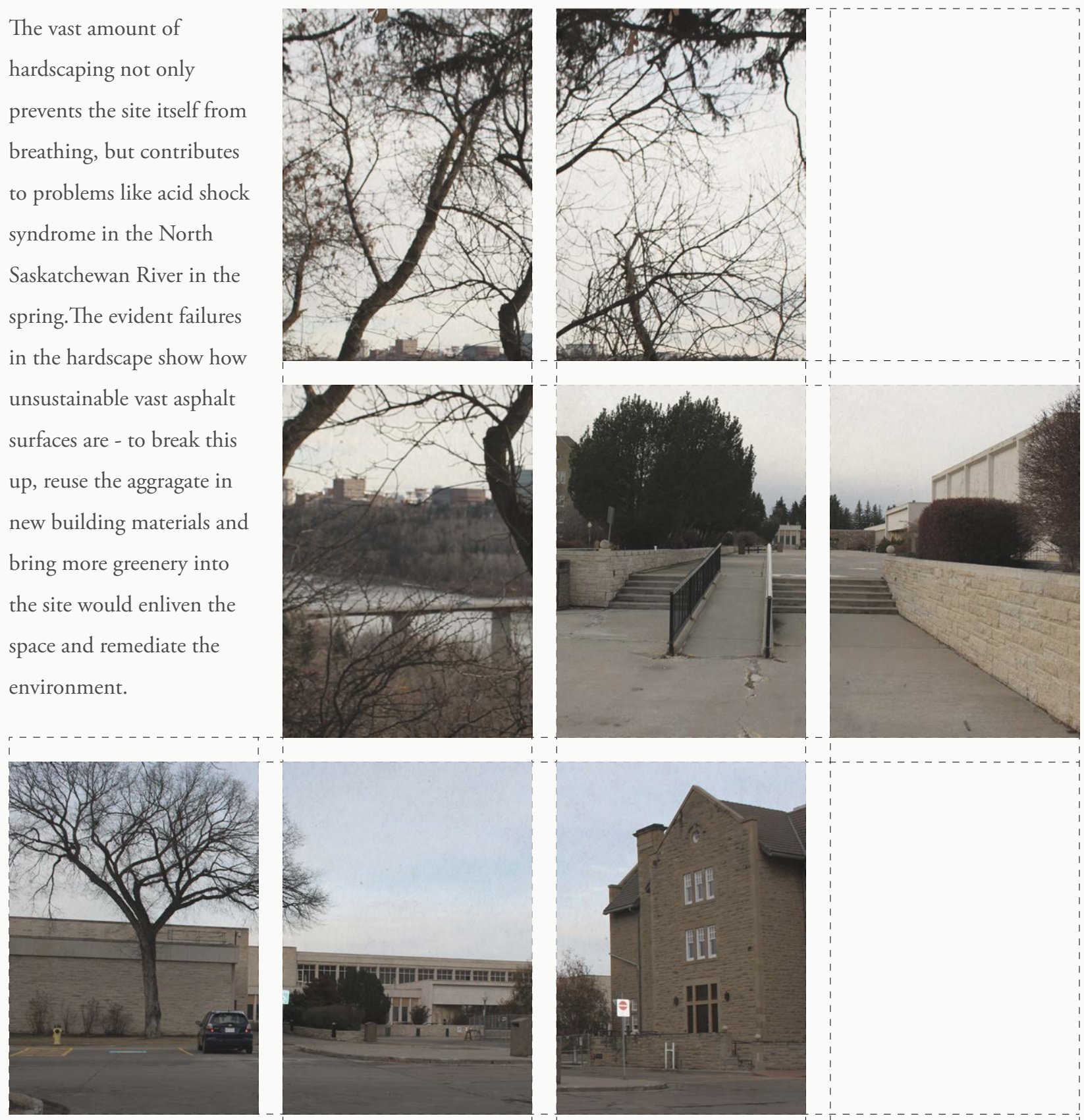

The trodden nature of the peripheries of the site express a community interest in having an outlook point - a place to come and a new lens through which to view Edmonton and the North Saskatchewan River.

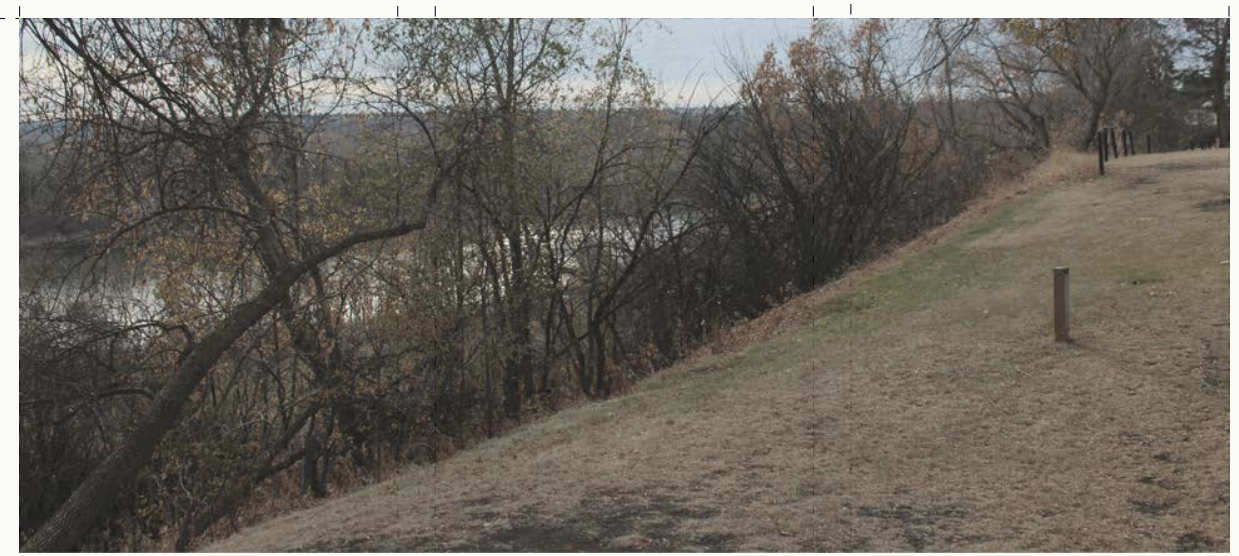

Fig. 6.10: Site Photos Contact Sheet 5 


\section{Dissecting the Site \\ LAYERING MATERIALITY}
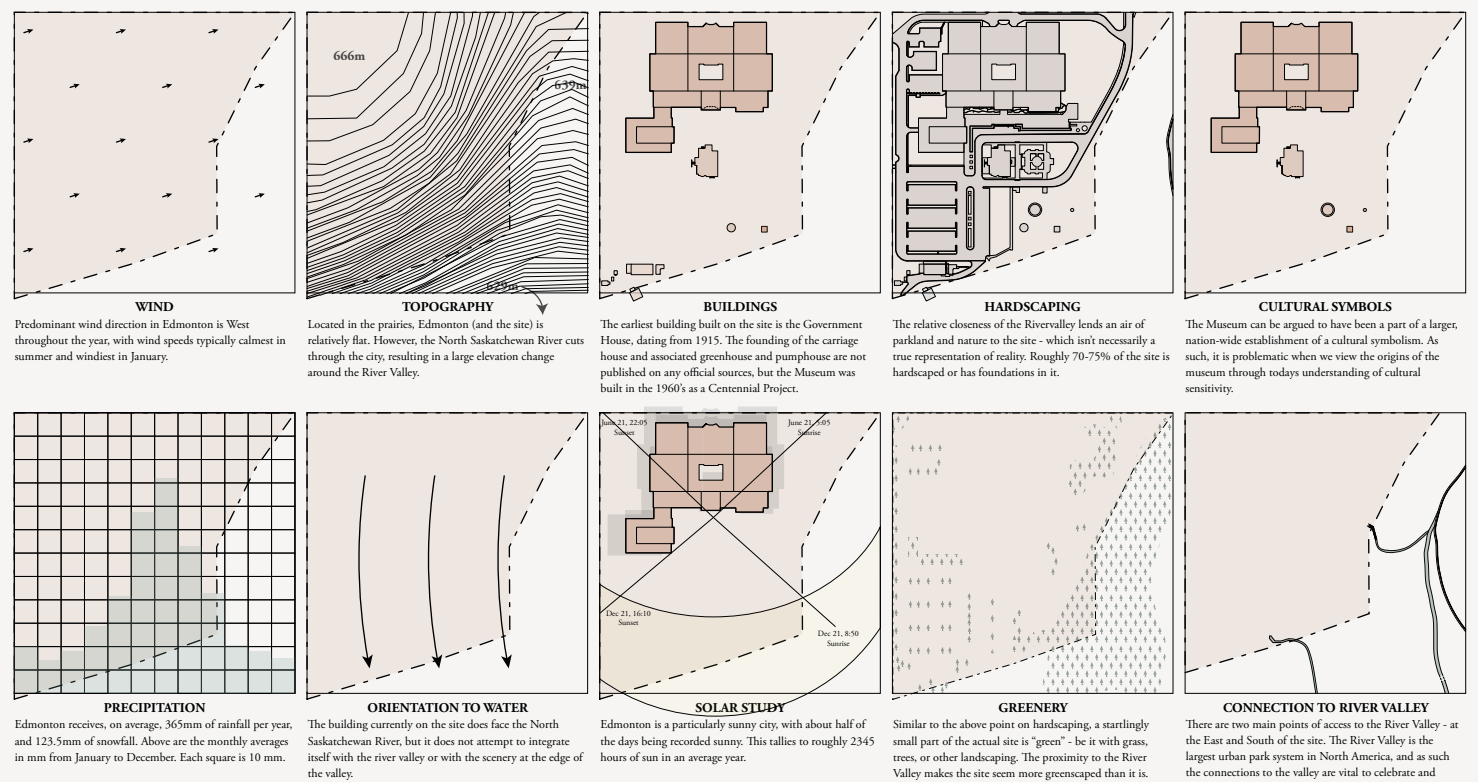

and $123.5 \mathrm{~mm}$ of snowfill. Above are the monthly yeverager
in $\mathrm{mm}$ from January to Decerber. Each square is $10 \mathrm{~mm}$.

ORIENTATION TO WATER

itself with
the valley.

Edmonton is a particulatly sunny city, with about half of
the days being recorded sunny. This sallis to roughly 23

trees, or orther landscaping, The proximity to the River
Valley makes hthe site secem more grecensaped than it i

CONNECTION TO RIVER VALLEY the East and Sount of the sitc. The River Valley is the largest urban park system in North America, and as such
the connections to the valley are vital to celchratc and preserve

Fig. 6.11: Taking Stock

\section{DISSECTING THE SITE}

This study was about investigating the layered reality of the site, of taking stock of particular environmental conditions in their isolation to create a nuanced and comprehensive understanding of the site. This was done to juxtapose how these aspects are usually investigated in their isolation, when in reality these factors overlap, interact, and function together to create a cohesive picture of a 'space' in our minds. Main factors were seperated into:

- predominant wind direction

- topographical data and elevation change

- buildings and built works on the site

- hardscaping coverage of the site

- cultural symbols

- annual precipitation data

- site orientation to the North Saskatchewan River

- greenery and plantings on and around the site

- points of connection to the River Valley. 


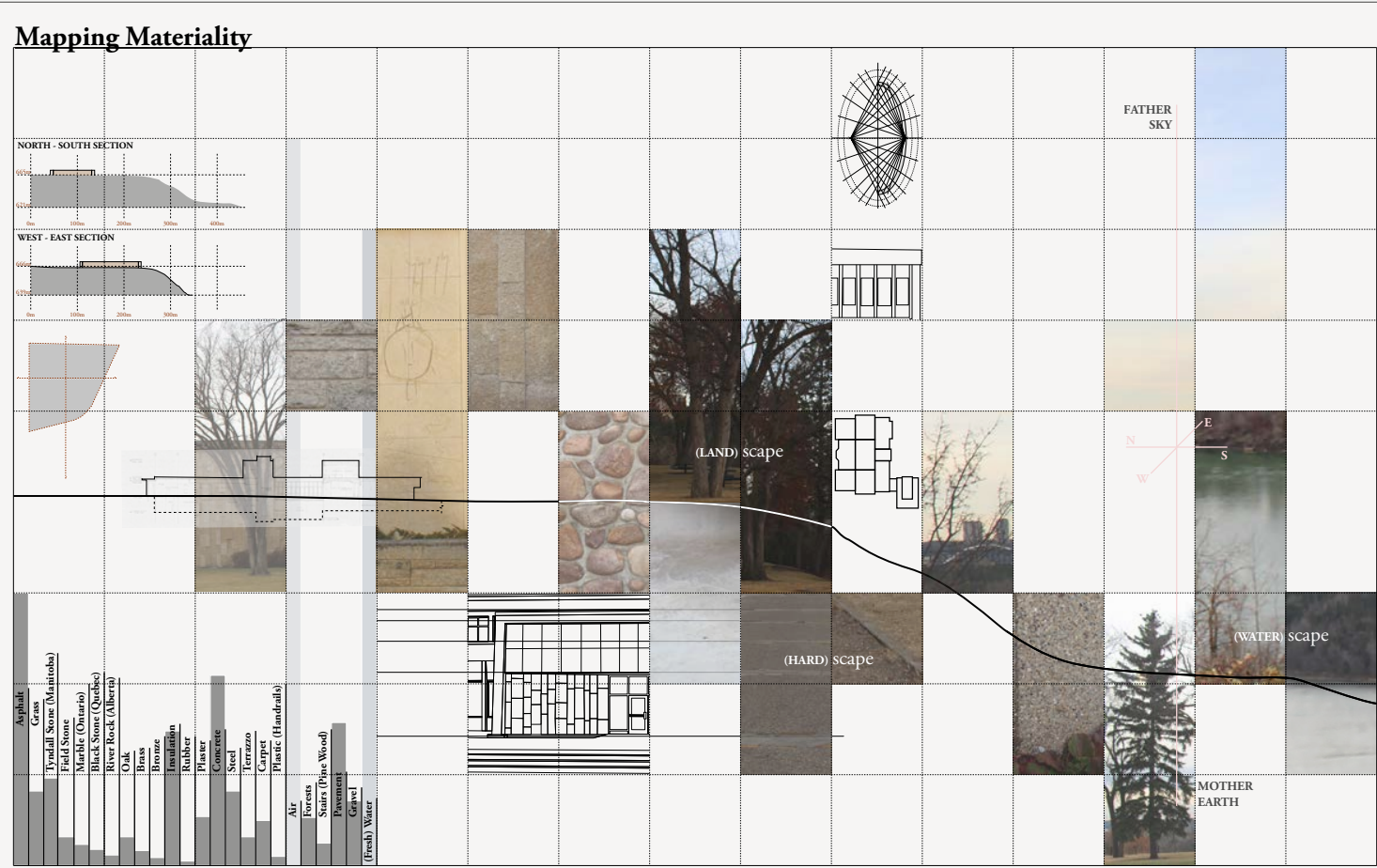

Fig. 6.12: Mapping Materiality

\section{MAPPING MATERIALITY}

This drawing was meant to break through the rigid

and meticulous quality of the last study, to show the simultaneous interplays of the material makeup on the ground plane. Existing plans of the building and a site plan were used to estimate the quantities and presence of different materials. Looking closely not only at intended and purposeful materiality, the juxtoposition of raw data with photographic snippets begins to investigate the site in terms of the less-than-tangible materials such as water, air, and surface texture.

These conditions, such as asphalt and air, moisture and stonework, and oak finishes and tree coverage co-exist on the site in their daily, monthly, seasonal and annual gentle fluctuations. Mapping them in this way creates a comprehensive inventory of materiality on the site. 


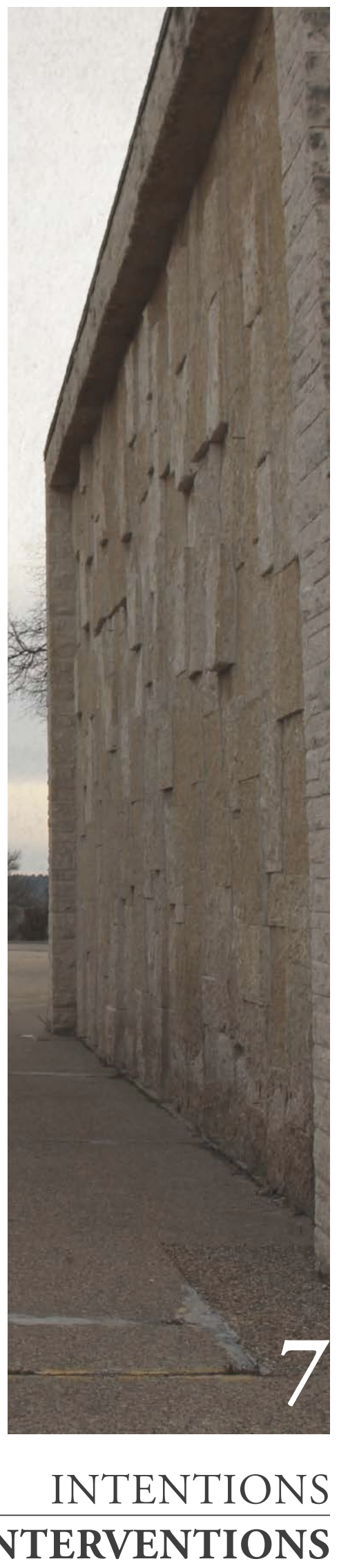

THREE INTERVENTIONS 
"I want you to dream and imagine with me what reconciliation could look like in twenty, thirty, forty years from now. When we are reconciled we will live together in harmony, be gentle with one another, we will be caring and compassionate. When we are reconciled, every person living here will live with dignity, purpose, and value."

Indigenous Relations, 154, Bob and Cynthia Joseph 


\subsection{A NEW METHODOLOGY}

Throughout Canada's history, and the longer history of colonial interactions in North America, Indigenous groups have been consistent in asserting their right to self-determination. Officially, the Truth and Reconciliation Commission "[calls] upon federal, provincial, territorial, and municipal governments to fully adopt and implement the United Nations Declaration on the Rights of Indigenous Peoples as the framework for reconciliation.," a declaration that also recognizes the right of all Indigenous peoples to "self-determination, equality, protection of their respective cultures, a collective identity, and economic and social development." ${ }^{160}$ Indigenous ways of knowing, such as the seven generations model, were "undermined and undercut" by "Westernization." 161 But the process of the seven generations model "is at the heart of sustainability." 162 It constitutes a holistic view of the progression of time and relates back to all 3 pillars of sustainability as defined by Jean Carroon. By acknowledging past mistakes, learning to listen to Indigenous voices, and incorporating Indigenous ways of knowing into construction practice, the seven generations model can provide the framework of a multigenerational timeline to ground decisions of the 'now' in relation to their effect on the future.

This speaks to a larger process of probing, as defined by Lutsky and Burkholder, in which inquiry is followed by insight, which then gives way to impression. "At the root of these operations is an expanding list of questions, which emerge from a profound respect and fascination for all that we will never know." 163 Periods of questioning ways of knowing and traditional building methods at the site of the former
160 Joseph and Joseph, Indigenous Relations. 91

161 Jojola, "Indigenous Planning: Towards a Seven Generations Model," 459-60.

162 Jojola, 458.

163 Karen Lutsky and Sean Burkholder, "Curious Methods," Places Journal, May 23, 2017, https://doi.org/10.22269/170523. 


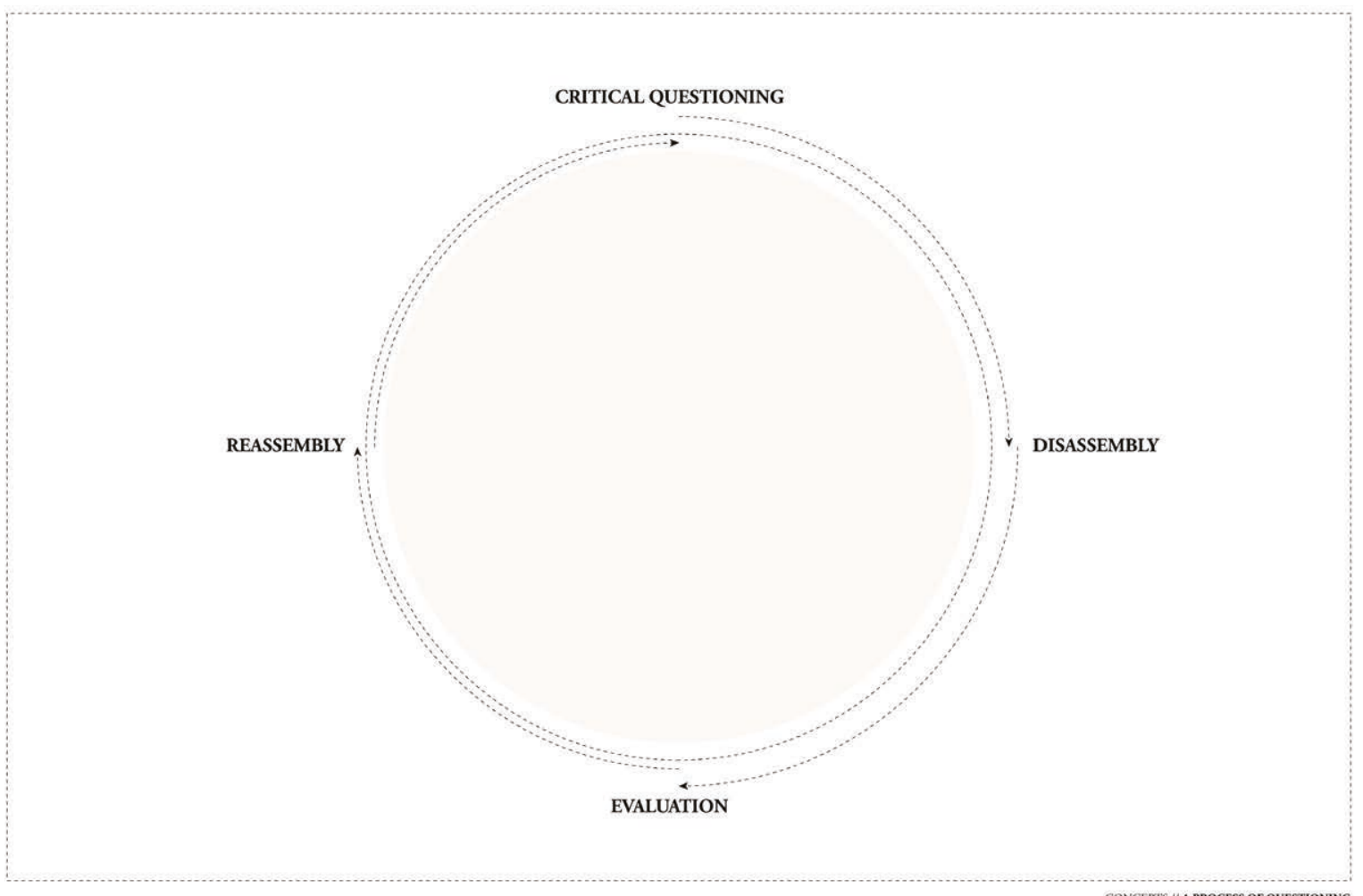

CONCEPTS // A PROCESS OF QUESTIONING

Fig. 7.1: A New Methodolgy: In contrast to current building methodologies, which focus on quick results and on current needs, each step of this cyclical process is meant to take roughly 17 years. It uses the seven generations model to anticipate what needs will have to be met three generations from now.

I use the built fabric of the former Royal Alberta Museum as an example for a new methodology, due to its complex interactions with both the built environment and with societal values. First the museum must open itself up to 164 Joseph and Joseph, Indigenous Relations, 124

165 Joseph and Joseph, Indigenous Relations, 141.

a period of critical questioning. As Bob Joseph states, "Reconciliation is not solely about policy changes and big fixes. It's also about simple gestures and small measures that add up to lasting impact." 166 The museum, through its performative role as a center for education and knowledge, had a hand in constructing the biases and stigmas of today. Simply put, the critical questioning of the role of museums in the future in Chapter 2 finds potential for them today as spaces of re-learning as well as community re-education. The former Royal Alberta Museum can be jointly used to re-educate the settler 
on a more complete version of history, and to provide spaces for the Indigenous peoples in Edmonton to create, hold meetings, or to reuse the space in whatever way is wanted.

The processes of probing, the seven generations model, and a cyclical understanding of time and of construction may be combined to move us away from "our current ecological crisis." 165 A re-learning is necessary to move towards conciliatory efforts and sustainability goals. I propose that each generation, defined by Jojola as encompassing roughly 17 years, takes one step of a cycle of critical questioning, disassembly, evaluation and reassembly to create a new construction practice that connects our reality with both our future and our past.

Critical questioning is the first step in the cycle, and opens the difficult process of questioning and re-learning. Once it begins to open up mental space and the promise of possibility, the buildings may be disassembled to begin to reconfigure physical space.

Disassembly is the second step in the cycle. This disassembly must not be a complete demolition (although it can be), nor a rupture with the past. Through the process of probing, we can honestly start to understand what no longer serves us.

The process of disassembly leaves us with a repository of new information and raw material to be evaluated - the third step in the cycle.

Only once the first three steps have been completed, can we move on to the fourth - to reassembly. The current building industry jumps right to this step, motivated by economic considerations, existing in a Western framework that prioritizes speed and efficiency, but it does not serve community needs for ecological and social renewal.

Reassembly is not a finite goal, nor a final stage to reach. It embodies just one generational spot on the proposed cycle of adaptive reuse, after which the process can then start anew.
166 Heather Davis and Zoe Todd, "On the Importance of a Date, or, Decolonizing the Anthropocene," ACME: An International Journal for Critical Geographies 16, no. 4 (December 20, 2017): 763

\section{CRITICAL QUESTIONING}
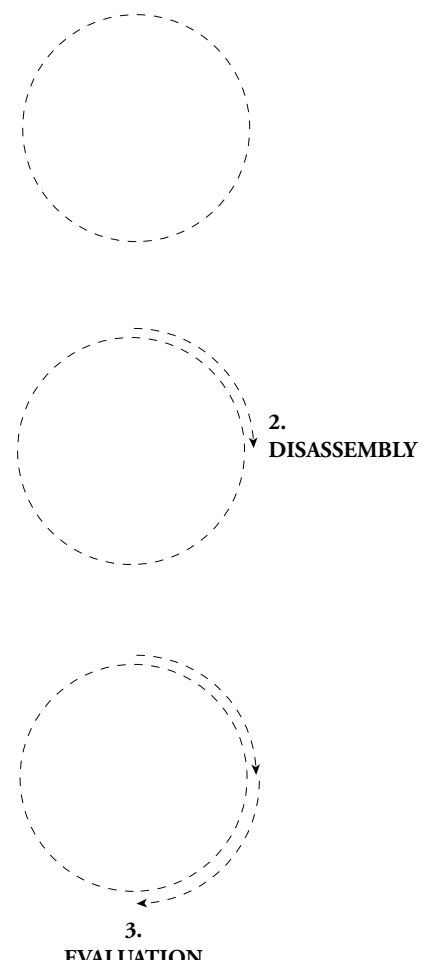

EVALUATION
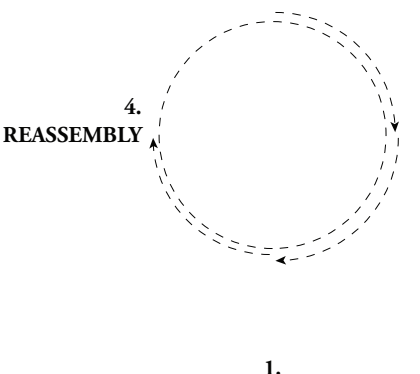

CRITICAL QUESTIONING

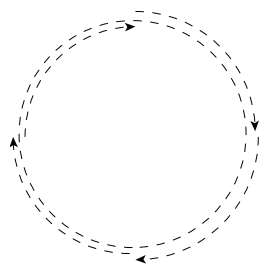

Fig. 7.2: A Cyclical Process: Each step of the process takes one generation - or 10 to 20 years. 


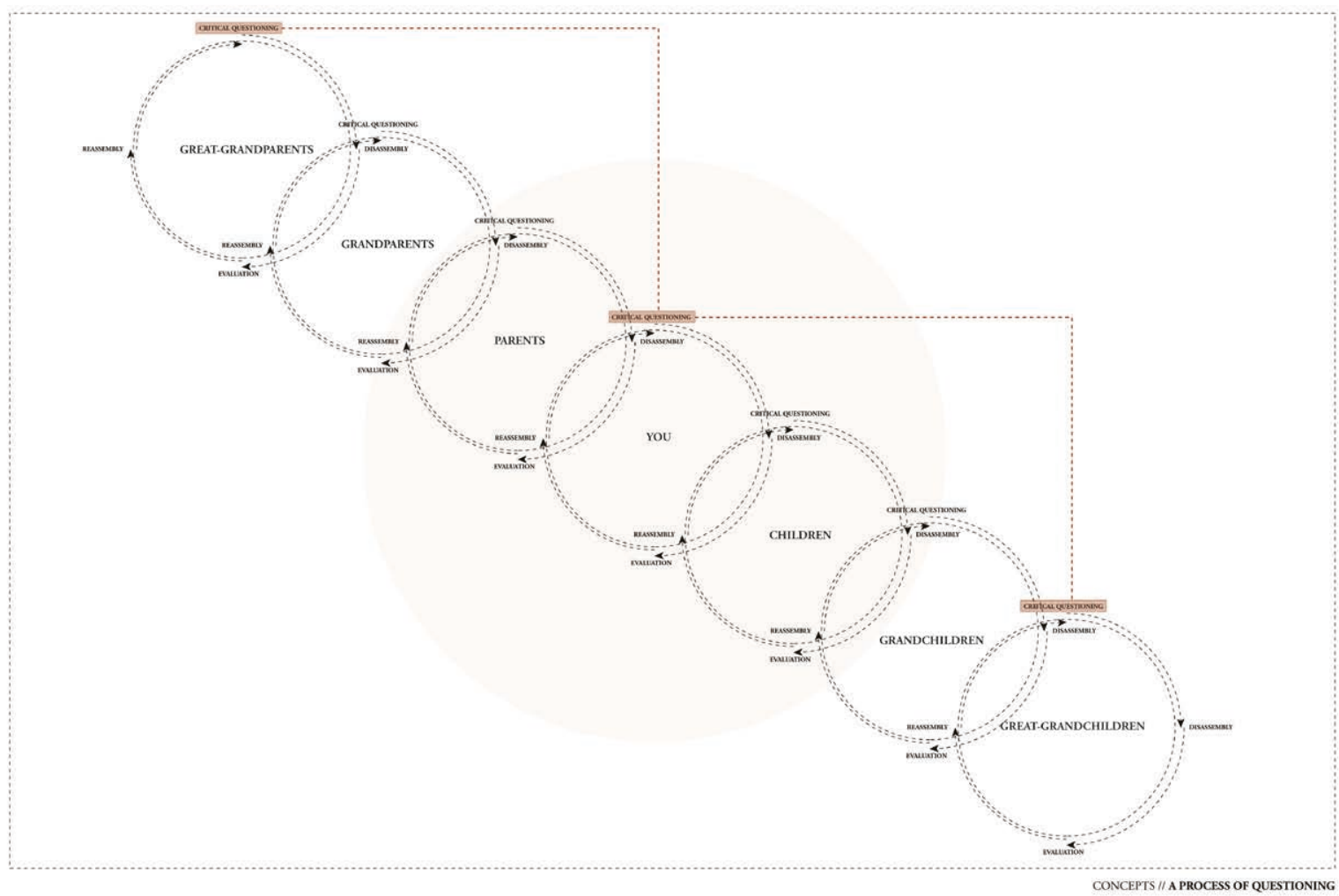

Fig. 7.3: The Link Between Generations

Assembly was chosen for this practice over a rhetoric

of de-construction/re-construction, recycling/reuse or other similar terminology because the word additionally embodies the human element. It speaks to the pulling apart and coming together of people, of the very strata of society, to reconfigure it into a space of softness and understanding through a reiterative and continual process.

Therefore, this thesis combines the strategies of disassembly and reassembly into a methodology that speaks to a larger need for conciliatory efforts from settler society in Canada. This methodology ties future adaptive reuse projects back to a history of vernacular architectural principles, in which readily available local materials are first taken apart and evaluated for their material worth and their historical implications, before being put back together to create new spatial realities. 


\subsection{INTERVENTIONS}

This methodology is framed through three interventions which come together to exemplify a new methodology for sustainable design and building practice. All three interventions are represented through past, present and future, to depict the multigenerational process of time. "Past", as represented in the drawings, is our present moment. The space in between the 'past' and the 'present' is the time in which we will probe and critically examine the colonial implications of the Anthropocene. "Present" is the generation that will come next, which can begin to disassemble the structures which no longer fully serve us. In between 'present' and 'future,' the evaluation of remaining structures and materials can take place. And lastly, "Future" speaks to the final step of the process, in which we can finally reassemble the built environment into something better, a moment of harmony before the process can repeat.

These interventions take place over a longer continuum to reflect the seven generations model. While I present the following three interventions as separate ideas, in separate sub-chapters, the themes overlap to create a sustainable narrative that views the site in terms of all three pillars of sustainability. It is also worth noting that although I present these as fixed moments in time, this is a cyclical process, in which each generation takes ownership of their own unique moment in the progression of time. These 3 interventions work together to exemplify a method that could be used to move Canada's general population towards reconciliation. 


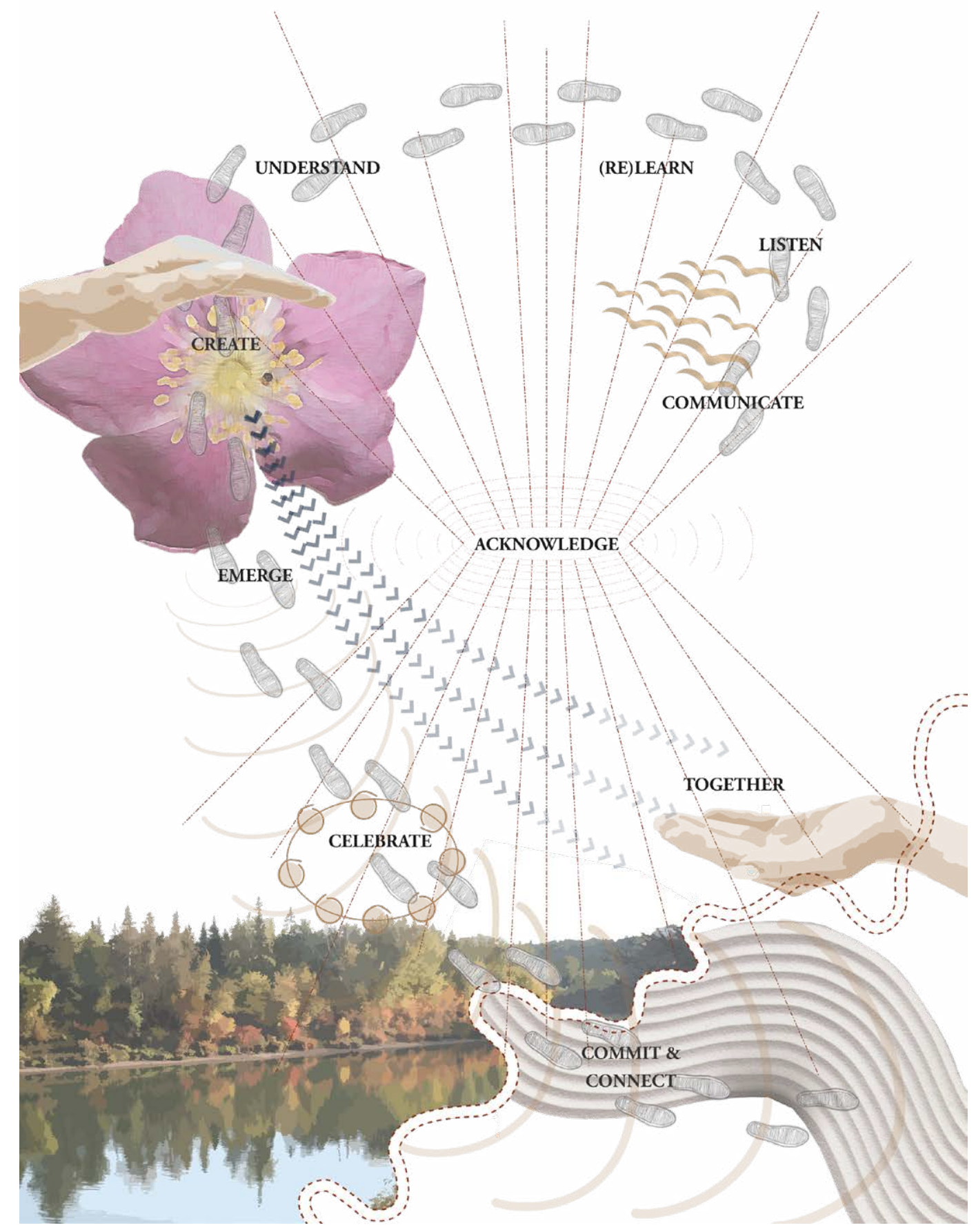

Fig. 7.4: Conceptual Programming Diagram

The programming was designed based on the verbal process of conciliation that I believe needs to happen in order to reach a point where in Indigenous voices are heard, understood and better incorporated into mainstream society. I have to state that this is not for any fault of Indigenous peoples, but rather for lack of hearing/trying from settlers 


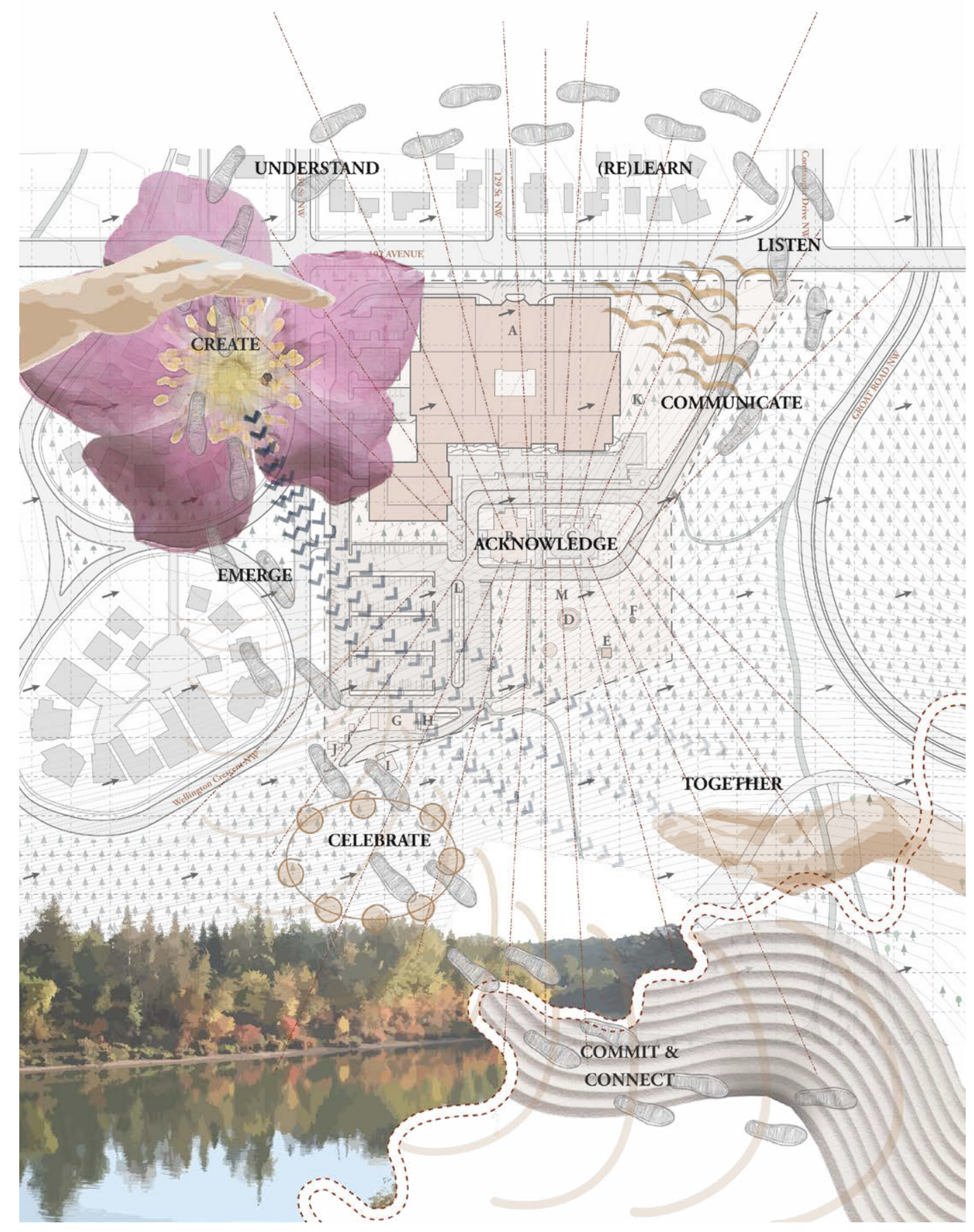

Fig. 7.5: Overlapping the Physical Realm with the Conceptual

This programmatic diagram, although not created thinking about the site literally, when overlaid over the site plan begins to show a theoretical journey towards conciliation on the

site, and the steps that could happen to move towards that. 


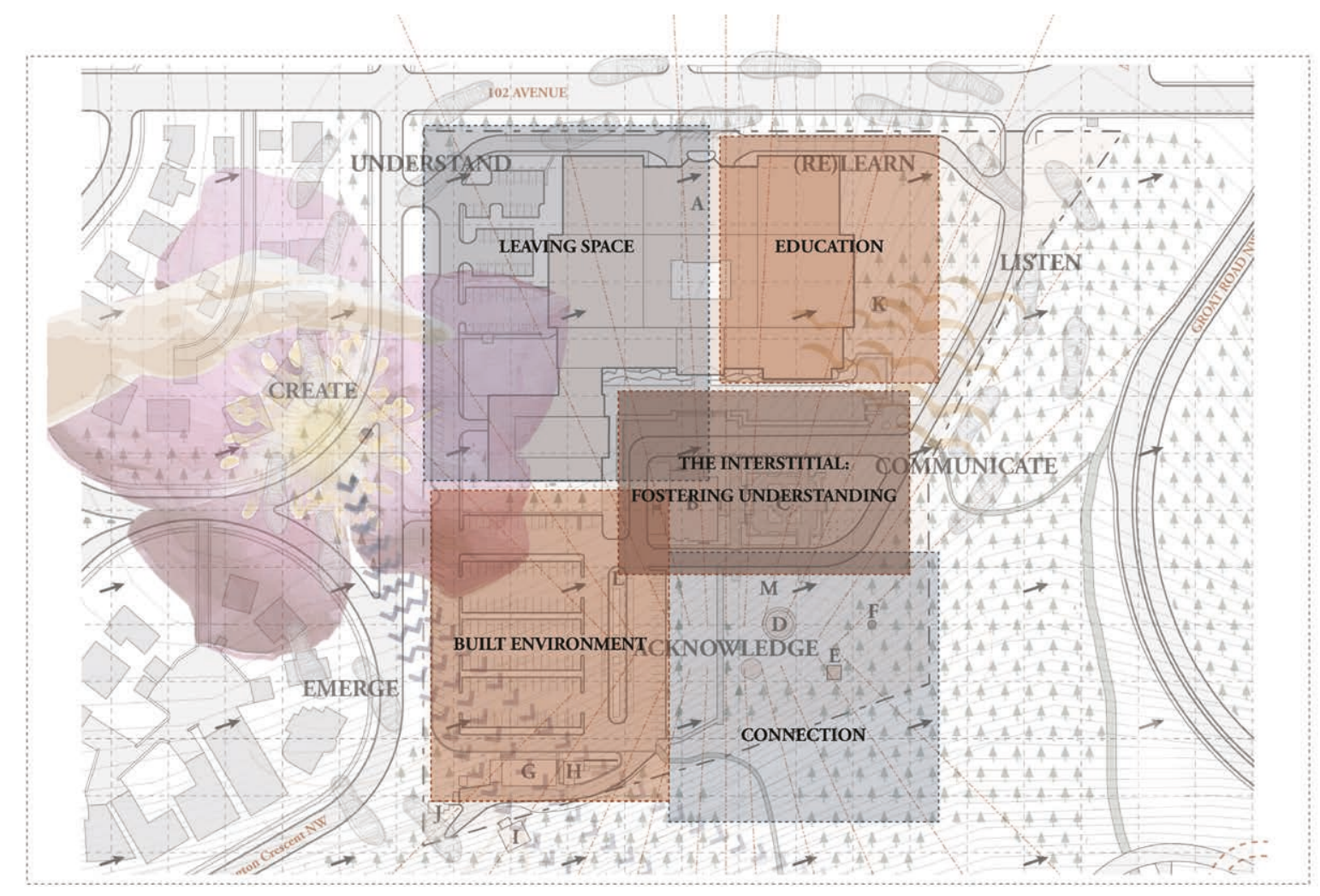

Overlapping the programming diagram with the site Fig. 7.6: Five Zones plan defined 5 different zones for the site, where different steps towards conciliation can take place. Two of the zones, marked above in blue, are areas in which it felt appropriate to leave space for Indigenous groups.

The West side of the programming diagram speaks to creation - as a museum which dictated what was 'art' and what was 'culture', this presents an opportunity for healing to happen, and for spaces in the museum to be readapted to become spaces for creation. The South-Eastern side of the site, with its view over the river valley and Edmonton also seems a pertinent space to connect outwards beyond the site.

However, as I am not Indigenous, nor does the scope or timeline of an 8 month thesis lend itself to a community design process, it would be inappropriate for me to design a building or space for a culture to which I do not belong. Those two spaces were purposefully left untouched in this thesis, to signify the need for future collaboration. 


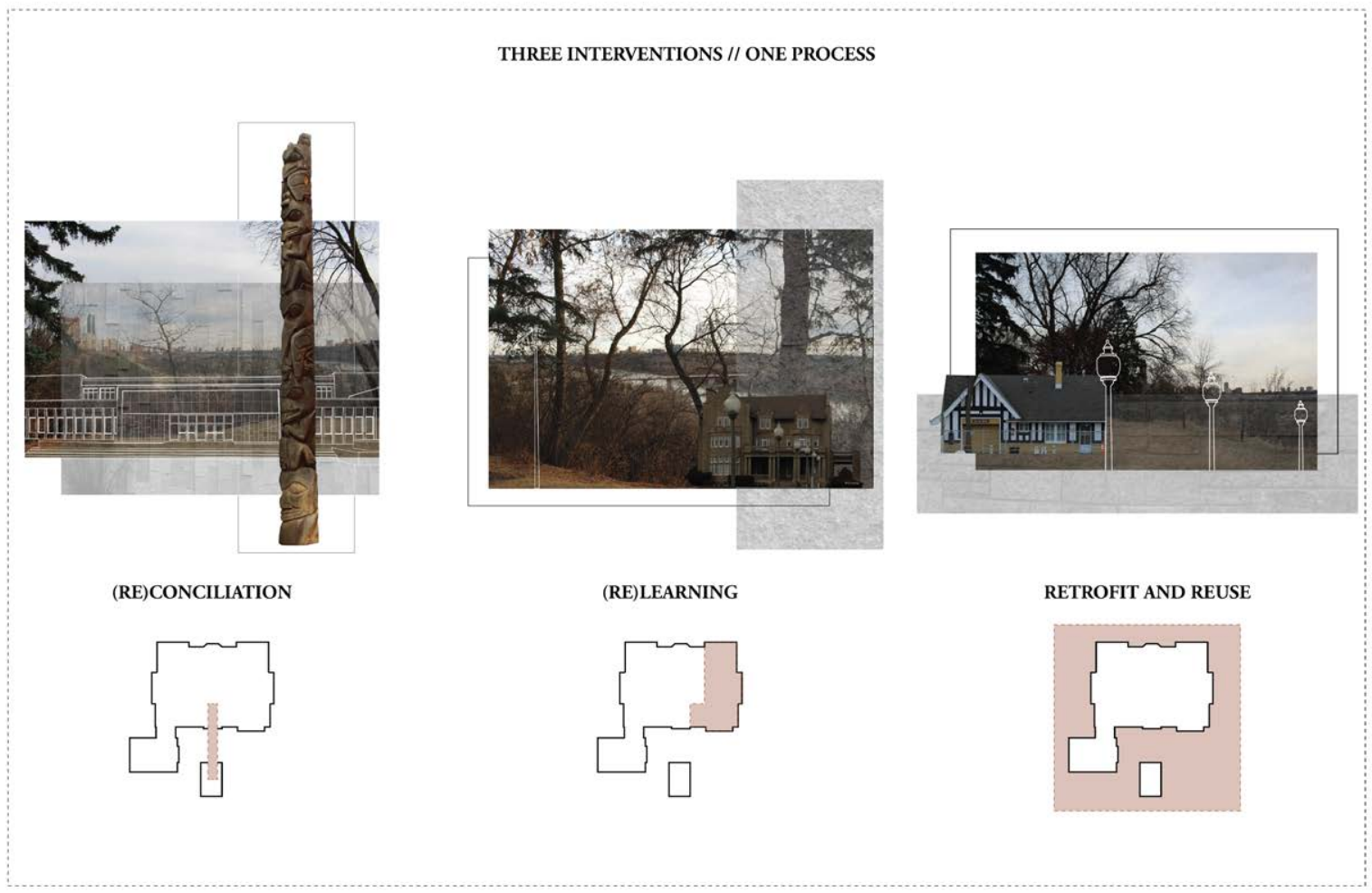

Leaving the two areas untouched results in three

Fig. 7.7: Three Interventions defined areas in which interventions will be made, using the methodology previously defined.

Intervention One // $(\mathrm{Re})$ conciliation: investigates the connection between the museum to Government house, and the goals of reconciliation.

Intervention Two // (Re)learning: addresses the educational component required in moving towards both reconciliation and sustainable design practice.

Intervention Three // Retrofit and Reuse: investigates the possibilities of adaptive reuse through the slow creation of a forest on a parking lot.

While these interventions are split into three seperate categories, each one addresses questions of conciliation, learning, and retrofit and reuse. They tend to overlap and to play different roles at different times - but that is the multifaceted reality of the site. 


\section{$7.3(\mathrm{Re})$ Conciliation}

The first intervention jumped out when looking through the archival plans of the former Royal Alberta Museum, and noticing that the museum is connected, via a small underground tunnel, to the Government House. I have been unable to uncover the original intention behind the tunnel, but viewing it through the lens of the larger colonial narrative, it began to speak to an eerie quality of observation and control. Thus the first intervention became rooted in understanding and promoting reconciliation on the site.

As Bob Joseph states in his book Indigenous Relations, "It's the next generation that is really going to carry change forward in Canada. If you have children in your life, the most important thing you can do for reconciliation is to raise informed, compassionate citizens. Talk to them about residential schools... Discuss how the Indian Act and residential schools are the root causes of many of the issues and challenges Indigenous Peoples live with daily." ${ }^{167}$

This is achieved, first and foremost, through understanding that our colonial heritage and past is not something that will go away if ignored or brushed aside, but that it needs to be brought into the open, unearthed above the ground to allow for integration into a larger narrative of healing. As seen in the following drawings, this is achieved in a number of ways. One is to, quite literally, bring the buried tunnel above ground, to visually connect the museum to the Government House. The second is to include education in the ongoing programming on site. Within the former Royal Alberta Museum itself, the East Gallery is turned into a cultural competency training center for the next generation - trying to raise
167 Joseph and Joseph, 150. 


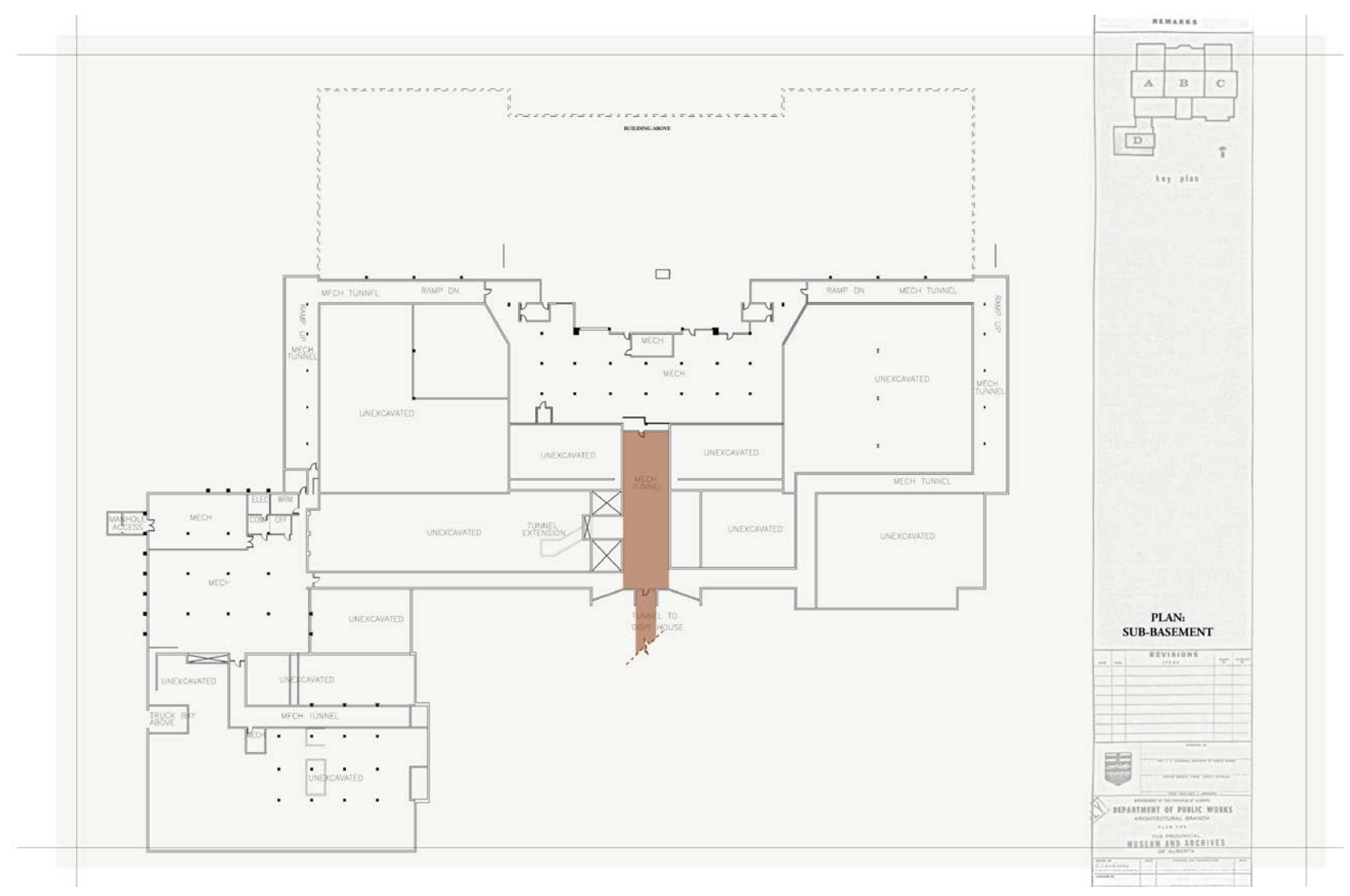

Fig. 7.9: Archival Plans: A Hidden Tunnel

the compassionate citizens that are needed to move towards reconciliation. Additionally, the Government house itself is turned into a museum, one which stands as a reminder to the settler of the residential school system, the reserve systems, and the multitude of systemic injustices which Canada has carried out towards Indigenous peoples. These two educational endeavours work together to ensure that real, tangible steps towards reconciliation continue to be made throughout the following generations.

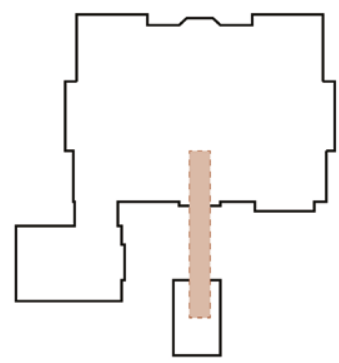

Fig. 7.8: Parti Diagram: (Re)Conciliation

The following diagrams and drawings depict how these programs and changes can be undertaken over the next 3-5 generations to create lasting change on the site. Each step of the process takes place over one generation, or 10-20 years. We start with our moment in time now, with critical inquiry, looking towards a future that is commited to reconciliation. 


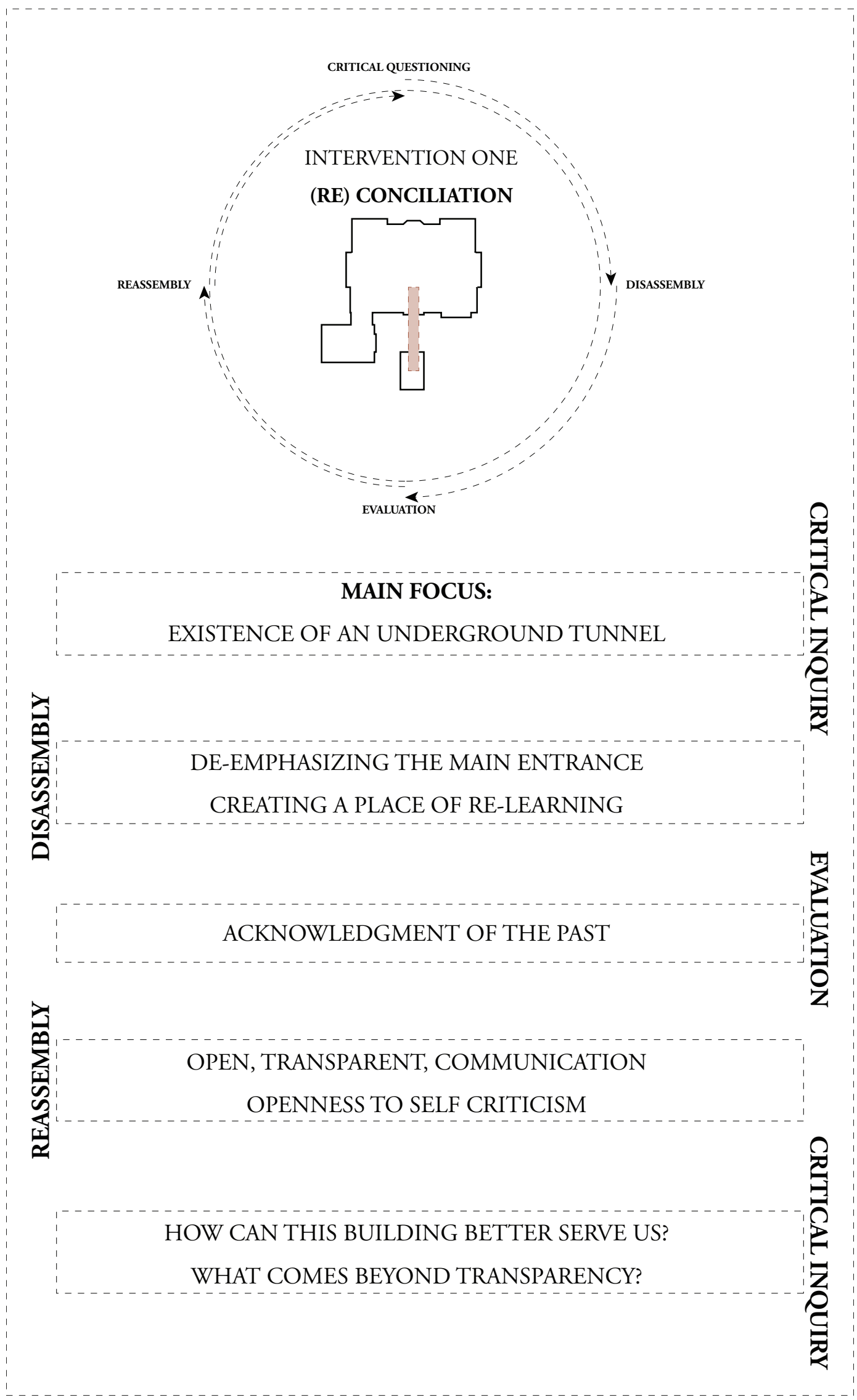

Fig. 7.10: Intervention One // Five Generations of Change 


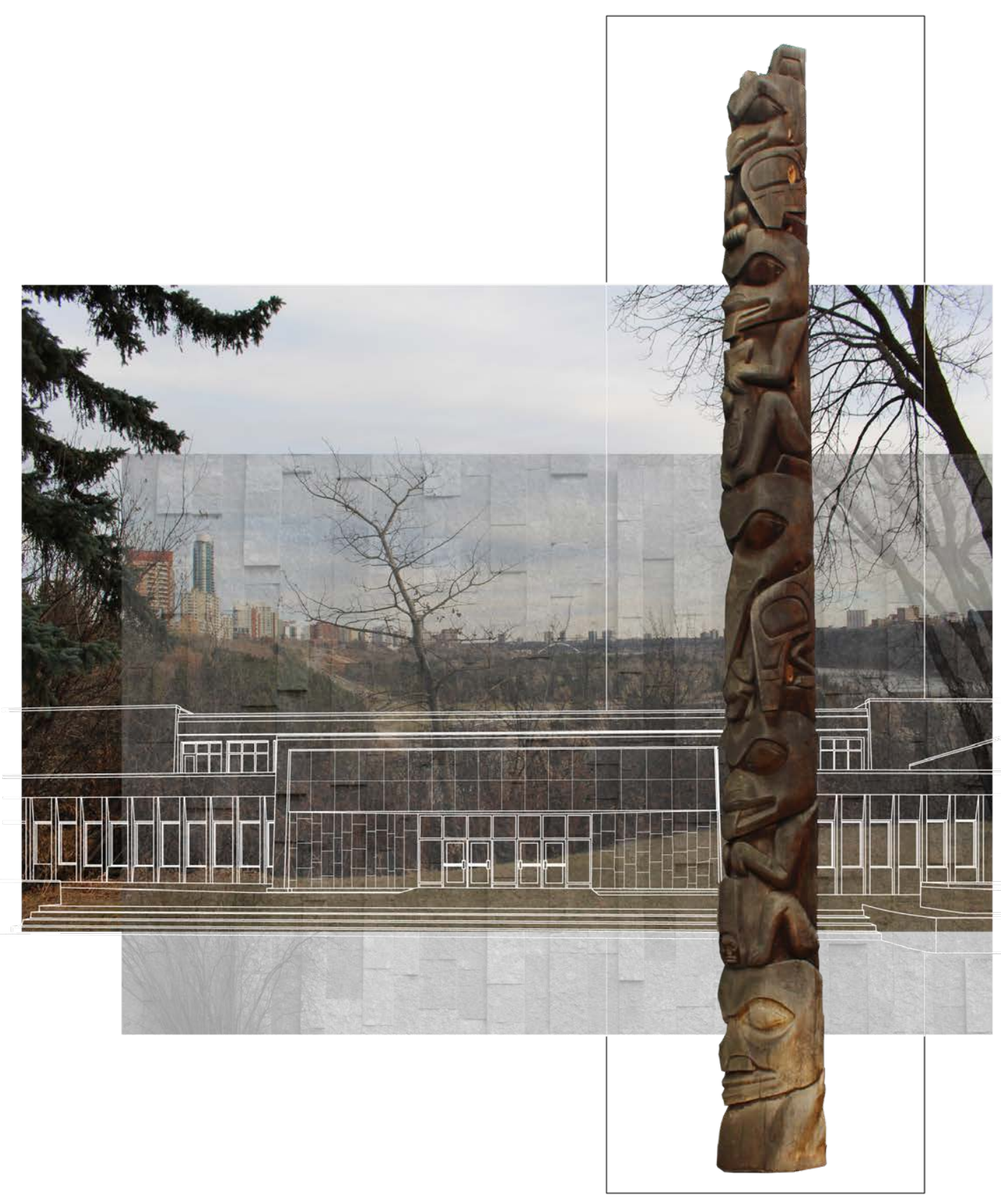

Fig. 7.11: A Story of Watching

Investigating the relationship between Indigenous peoples in Edmonton and the formal structure of a museum, this collage juxtaposes existing elements on the site to ask the question - who is watching whom? 

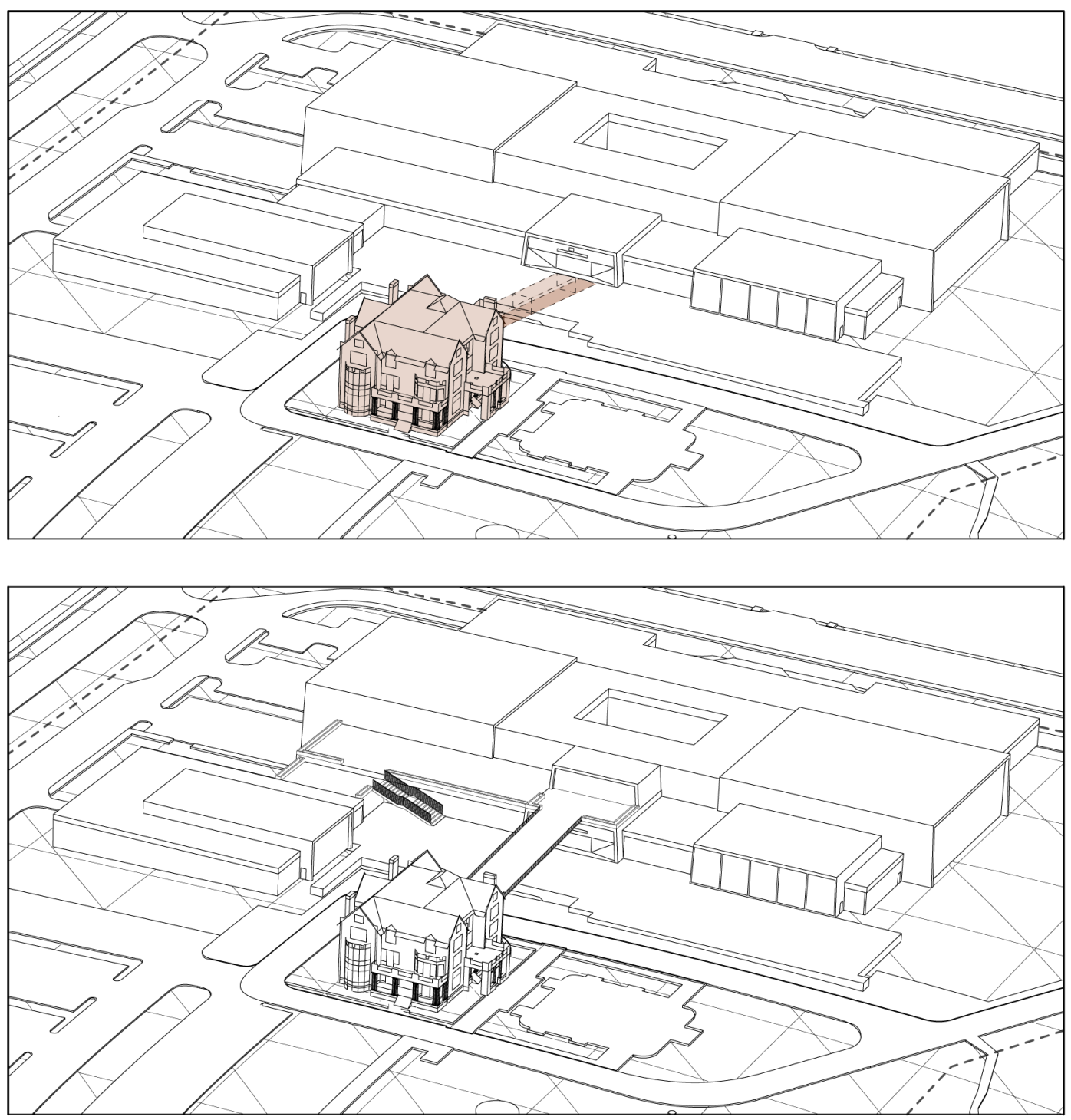

Fig. 7.12: Intervention One Site Study -

Past vs. Futue

An overview of the major physical changes of Intervention One on the site and building of the former Royal Alberta Museum. The most notable visual difference is the appearance of a bridge that connects the museum to the Government House. 


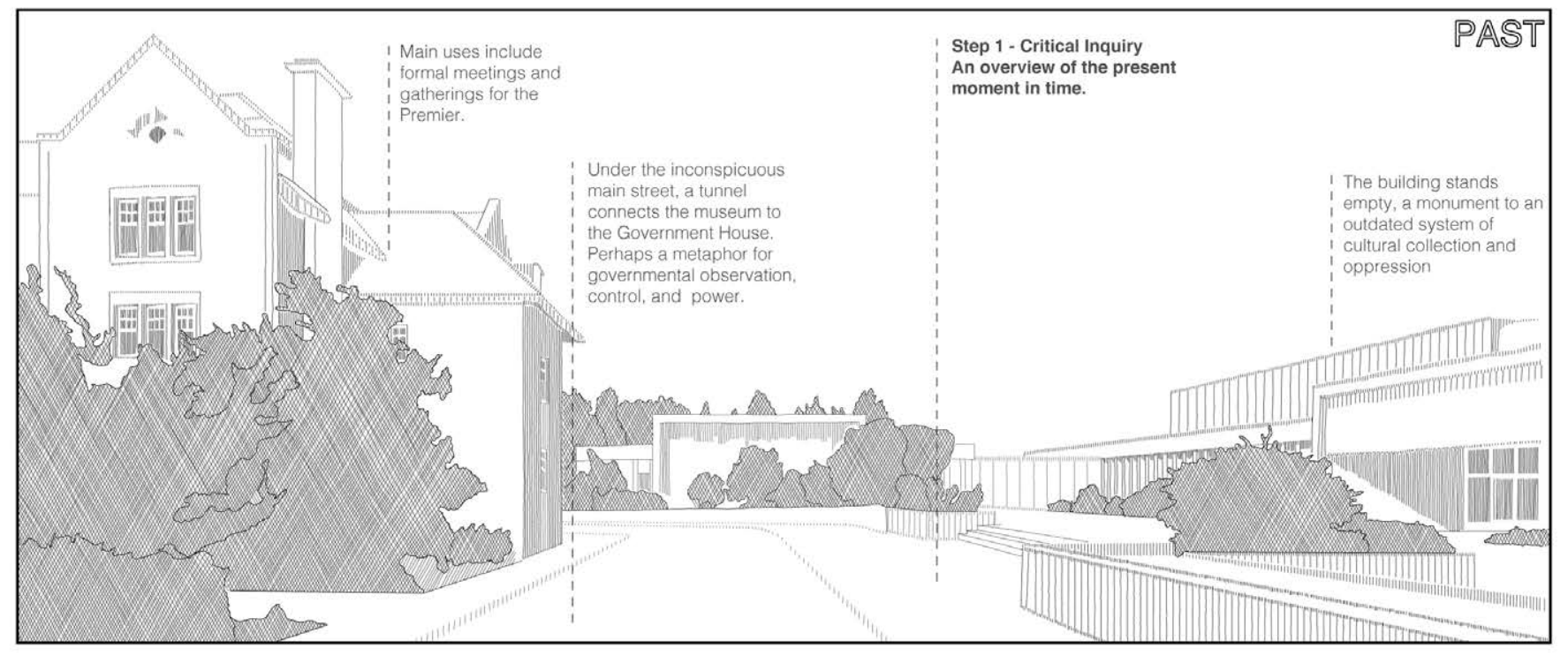

Fig. 7.13: Triptych One // The Past

1.

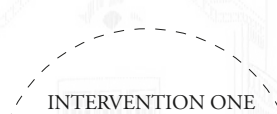

(RE) CONCILIATION

$\therefore$

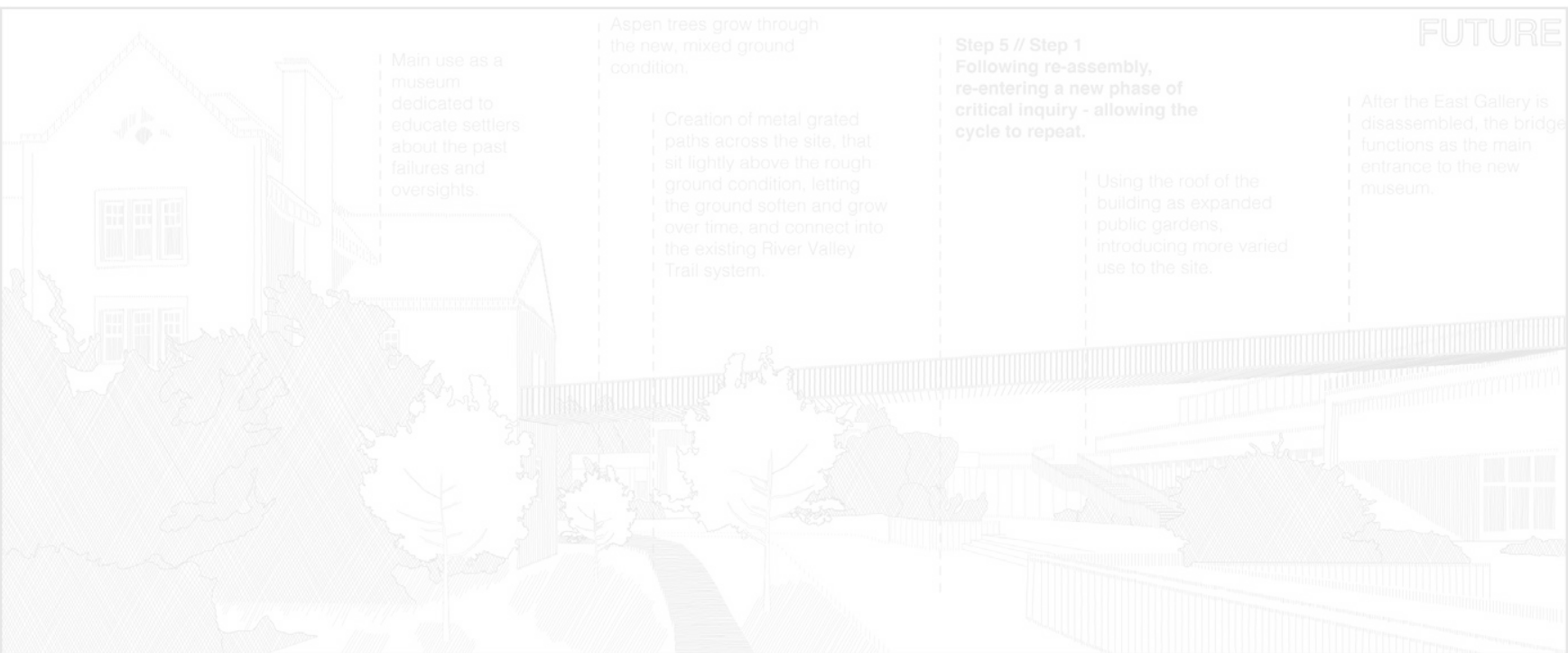




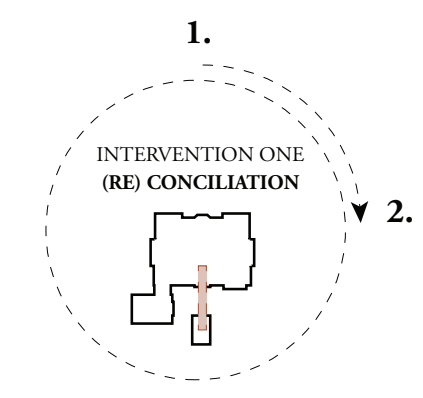

\section{DISASSEMBLY}

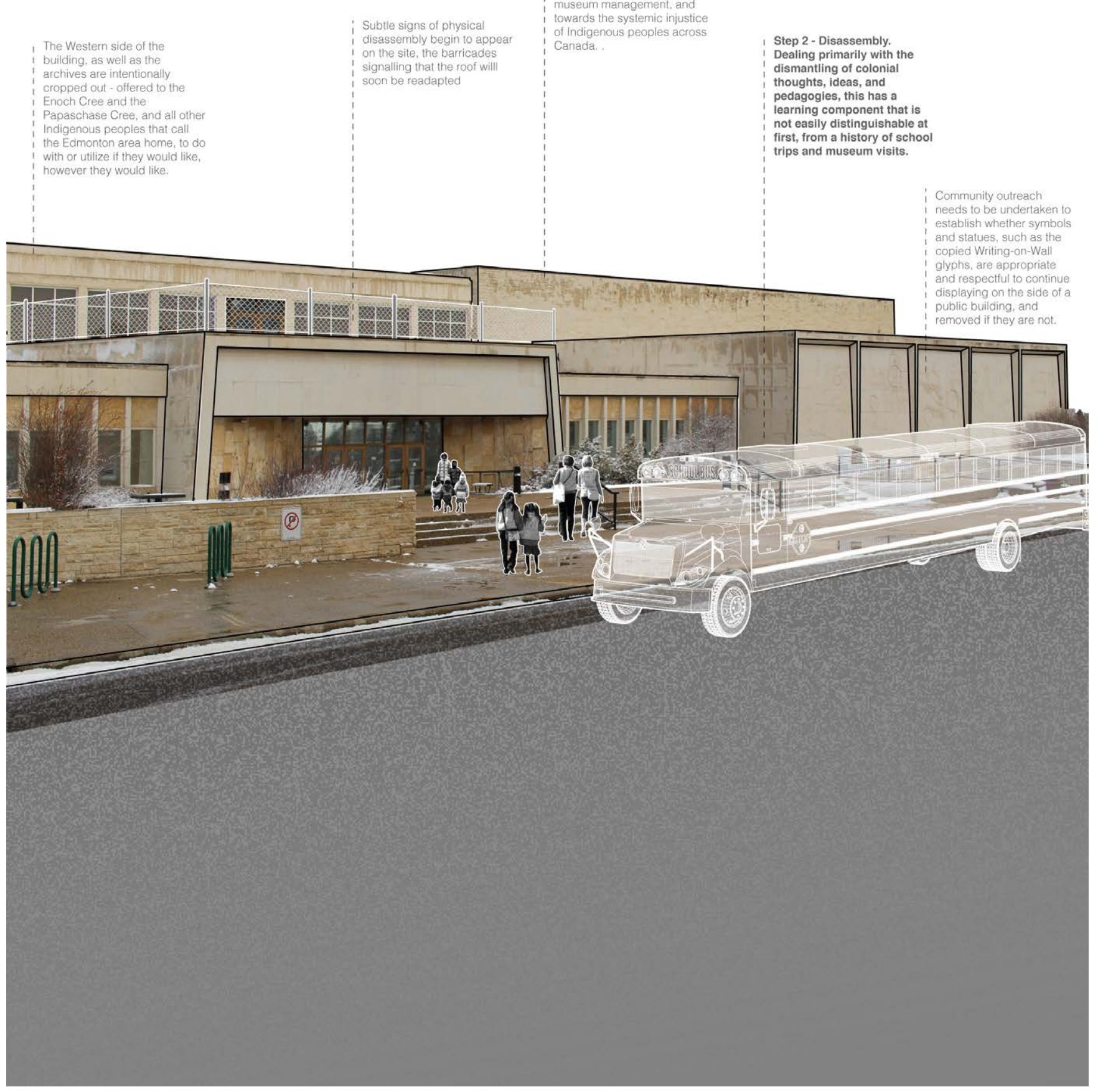

The East Galleries become initially a place of education, rather than of display. As time progresses, and the gallery is less needed, it can be

disassembled and readapted

to look outwards, rather than

inwards. It can begin to

address issues beyond

museum management, and archives are intention

cropped out - offered to the

the Edmonton area home

Fig. 7.14: Disassembly // Exhibiting Process 

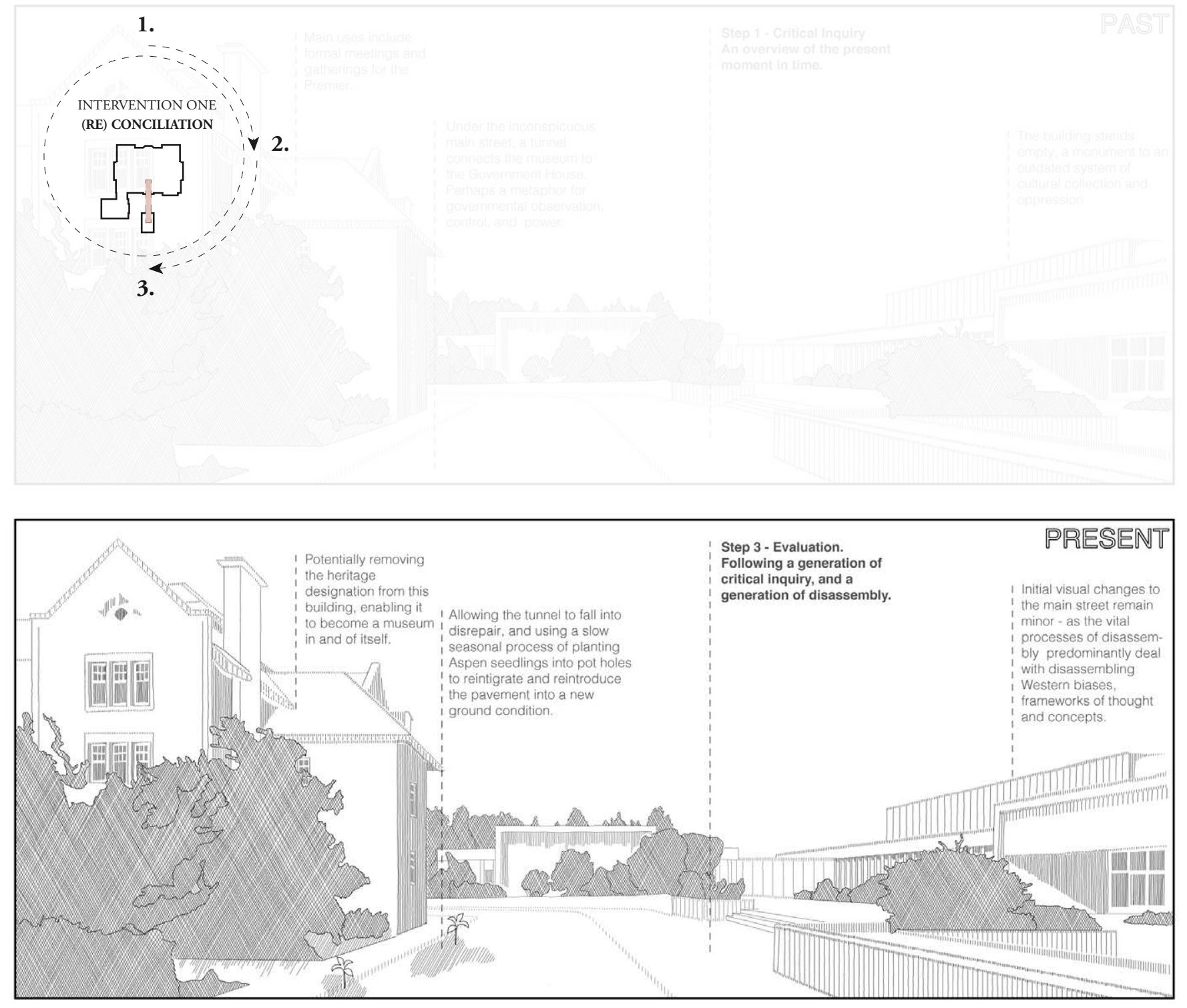

Fig. 7.15: Triptych One // The Present 


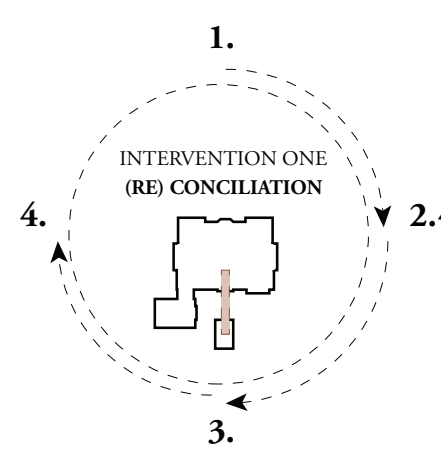

REASSEMBLY

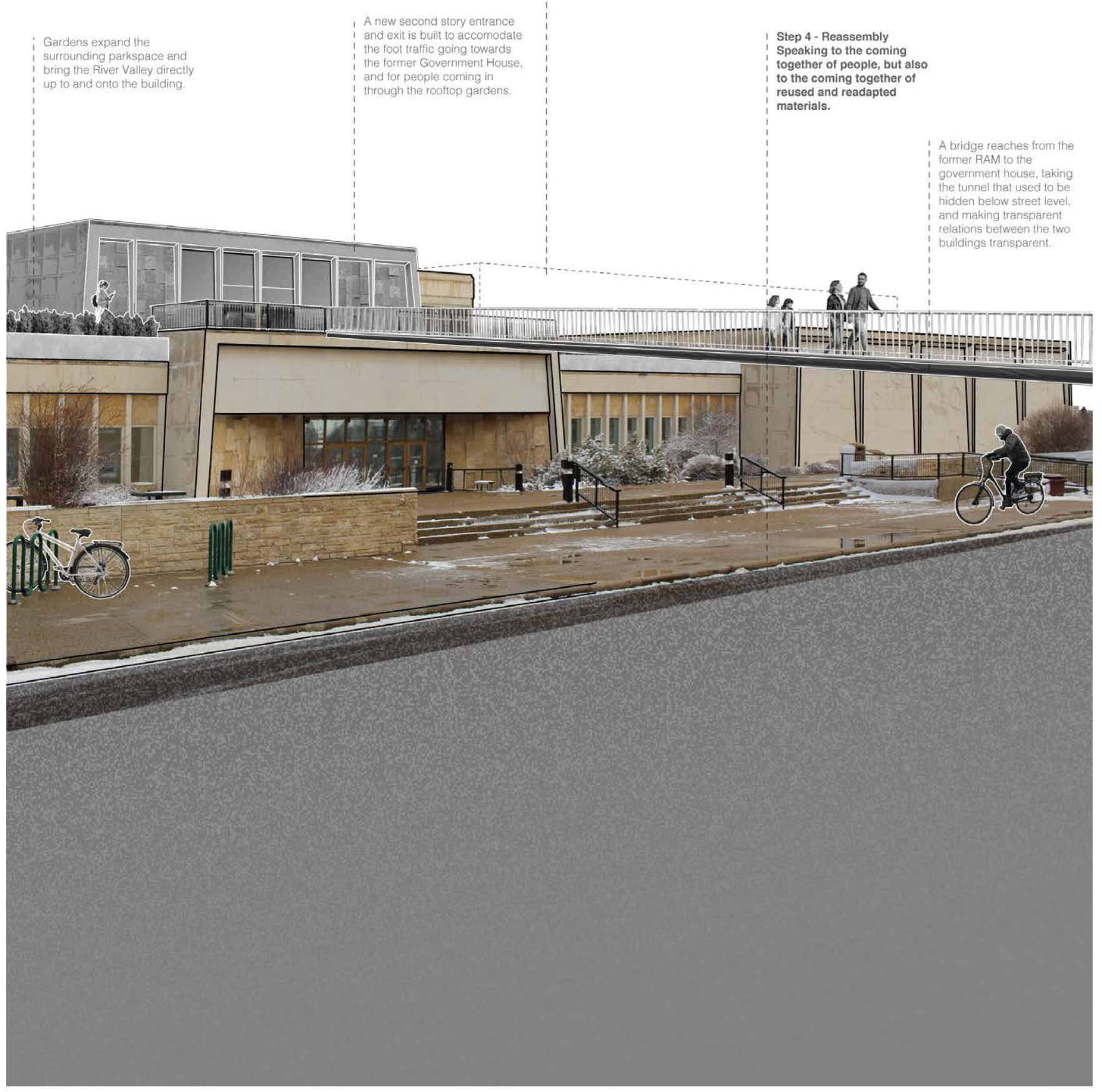

Fig. 7.16: Reassembly // Transparency 

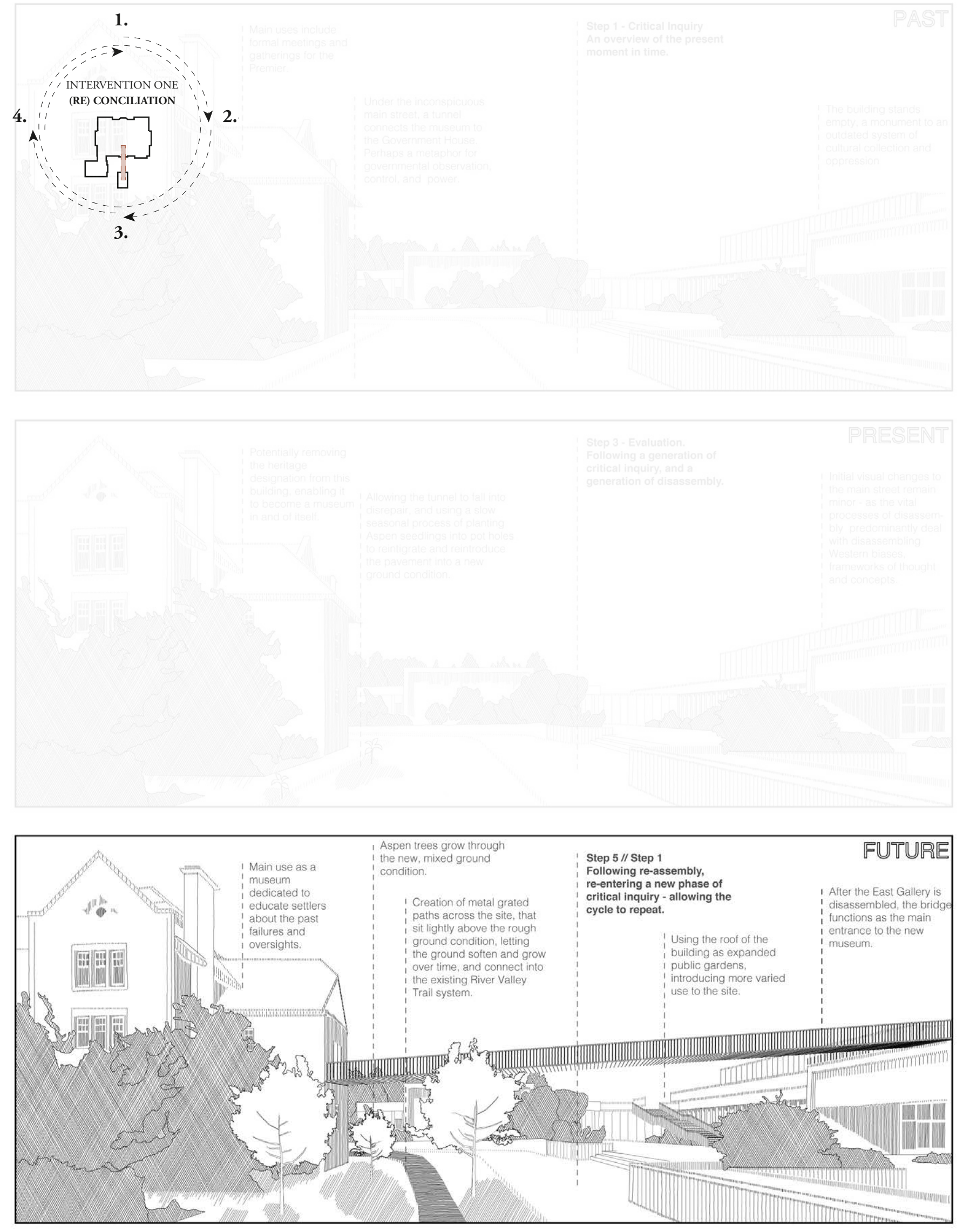

Fig. 7.17: Triptych One // The Future 

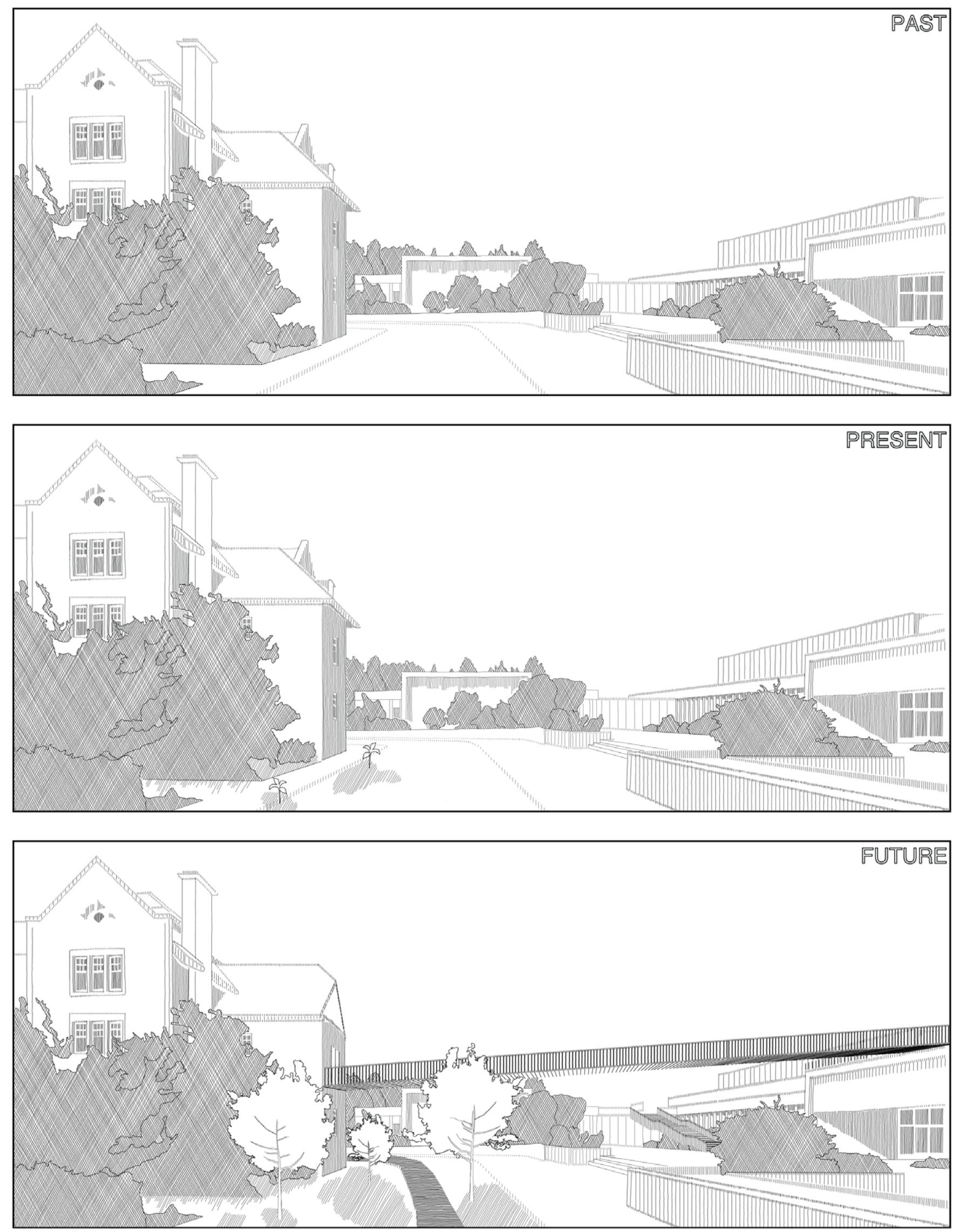

Fig. 7.18: Triptych One // The Main Entrance 


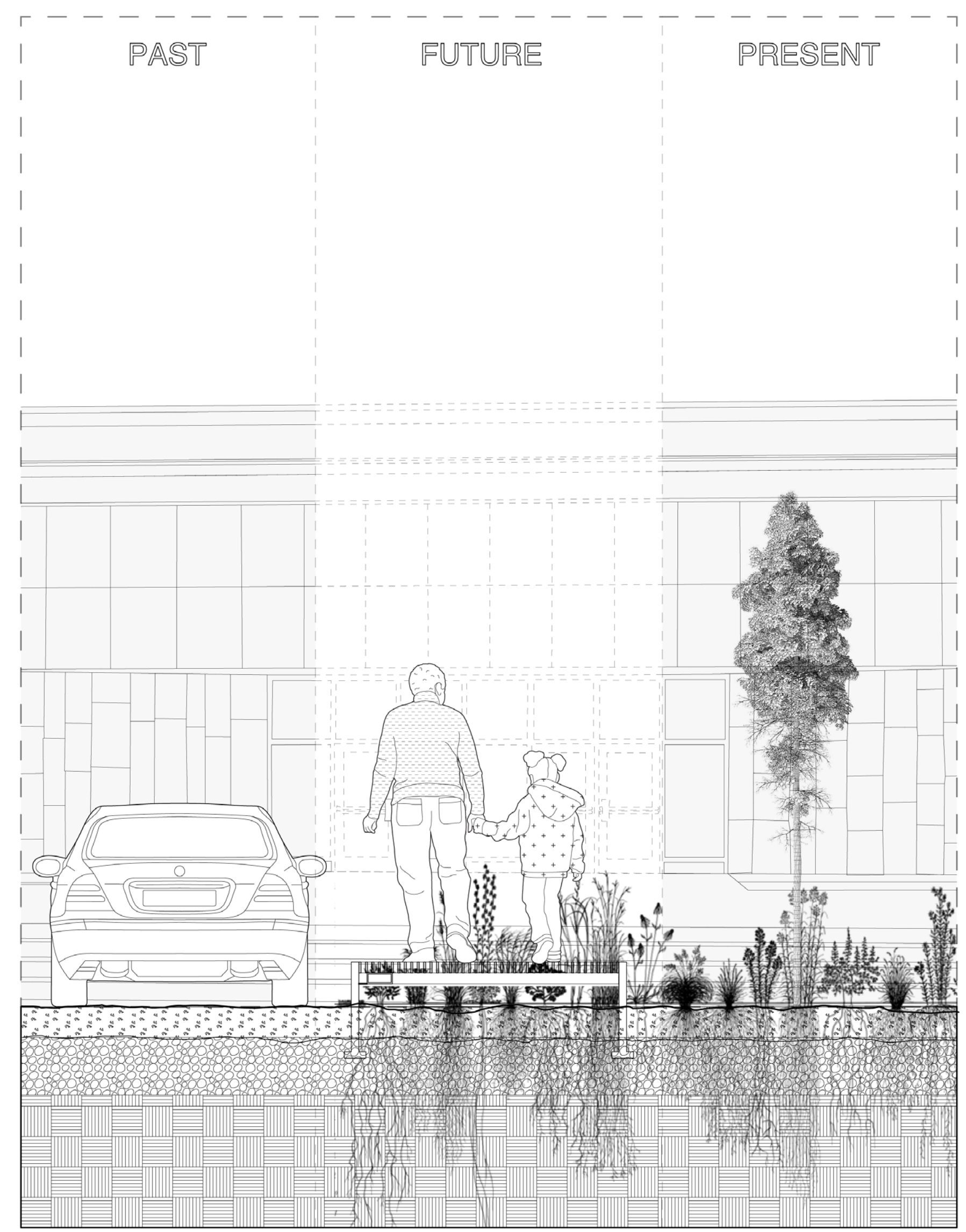

Fig. 7.19: Section One // A New Connection 


\section{4 (RE)LEARNING}

The former Royal Alberta Museum was a common location for school trips, in conjunction with different classroom curriculums - whether focusing on dinosaurs, 'human history,' or for special exhibitions. The second intervention encourages this practice to continue, welcoming the flocks of children to continue coming to the space, but instead to learn about the complete history of the land that Canada is built on, from before it had a national identity up until the present moment. An inclusive and inquisitive discourse can allow the East Wing of the museum to become, over the course of a generation, a location in Edmonton where it is encouraged to come and ask questions, and to begin to mend misunderstandings and see both sides of the story. This gallery can also potentially be a space where businesses and workplaces across Edmonton could come in order to go through cultural competency training.

This re-education takes place over the course of a generation of critical thinking, and a second generation of disassembly. This intervention is titled re-learning, but in some ways, it can also be seen as an un-learning. Not learning again, but learning to see what is truly there, evaluate it, and establish safe and secure connections. This also ties into a re-education of construction methodologies and practices. It includes the eventual disassembly and reconfiguration of this gallery space into something new through the adaptive reuse and evaluation of the materials. As seen in Chapter 5, the conservation and preservation of existing buildings and building materials is not only ecologically preferable, but is economically better long term as well. 


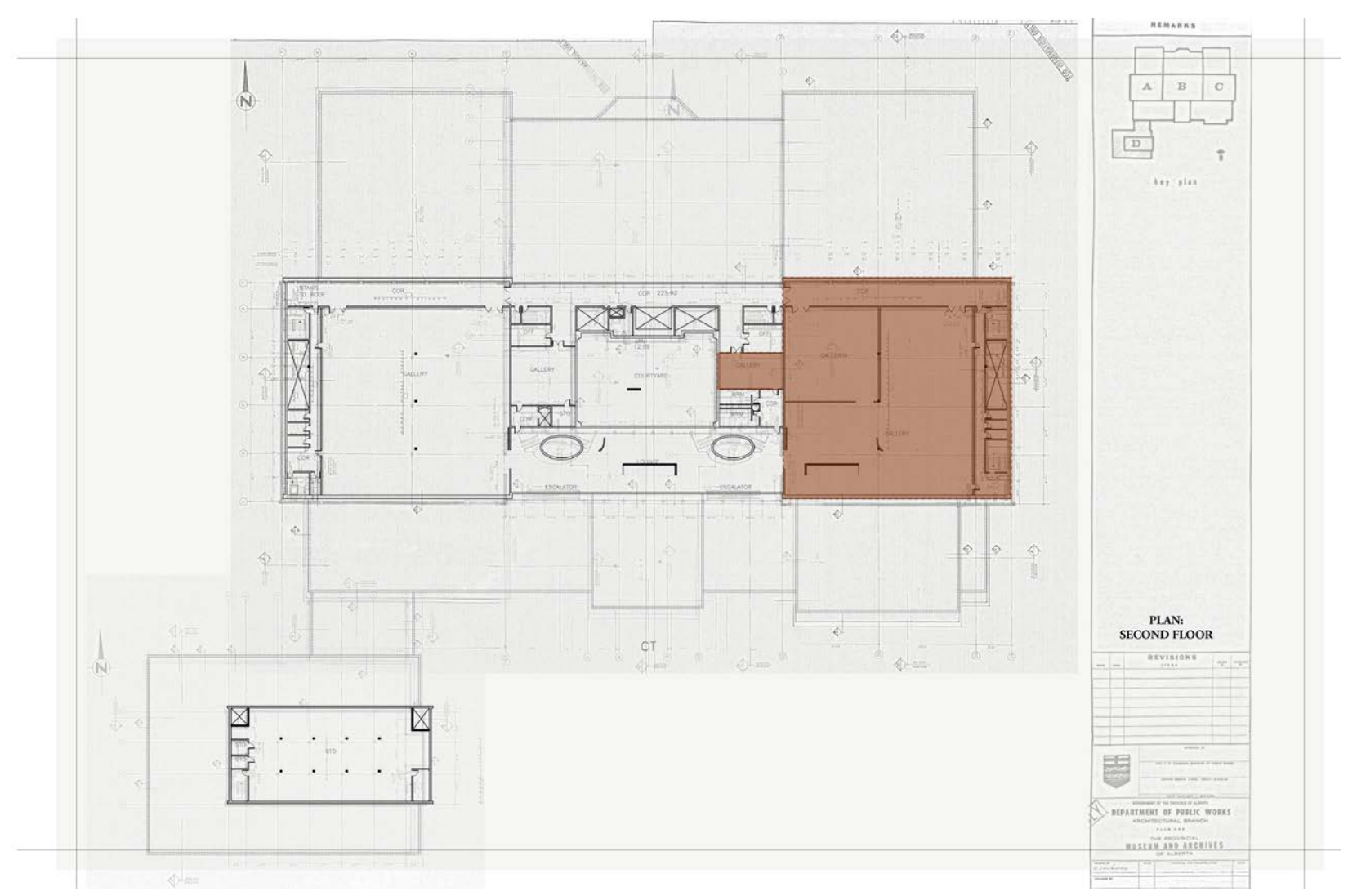

Fig. 7.21: Archival Plans: "Natural" History

The new methodology can thus be applied not only to concepts, but to place as well. As much as the conceptual disassembly of outdated colonial modes of thought can aid on the road to reconciliation, the physical disassembly and consequent reassembly of the building can help move us towards sustainability. By regularly evaluating building function and planning for future programming, changing building needs can be anticipated, and buildings can be continually adapted. This leads to a wider culture of adaptive reuse, and the con-

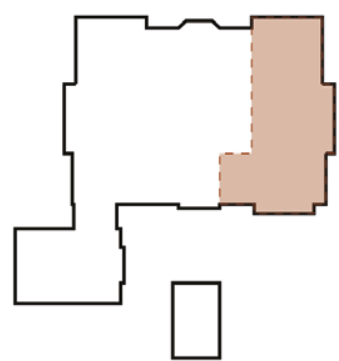

Fig. 7.20: Parti Diagram: (Re)Learning tinual renewal and repair of our building stock. 


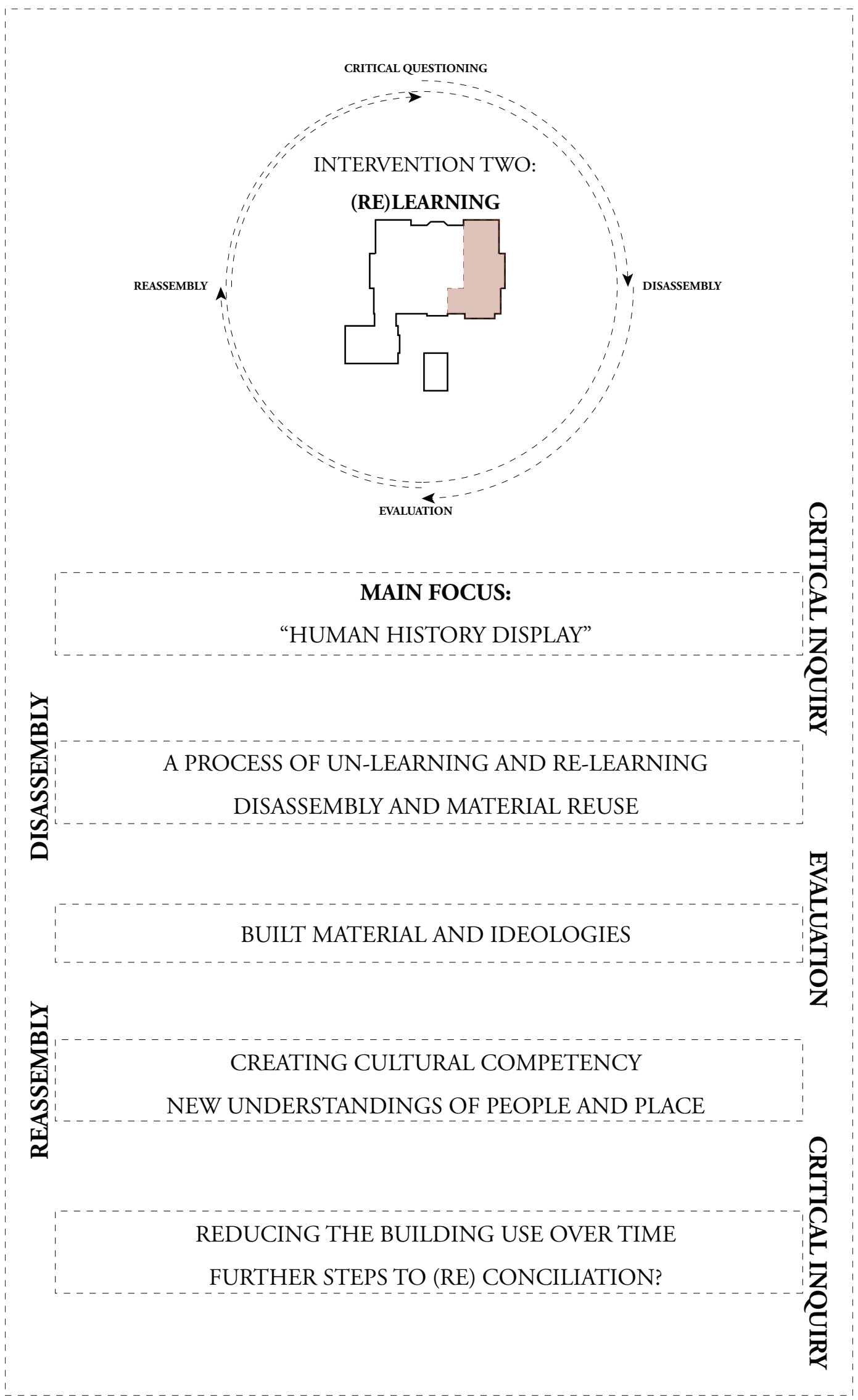

Fig. 7.22: Intervention Two // Five Generations of Change 


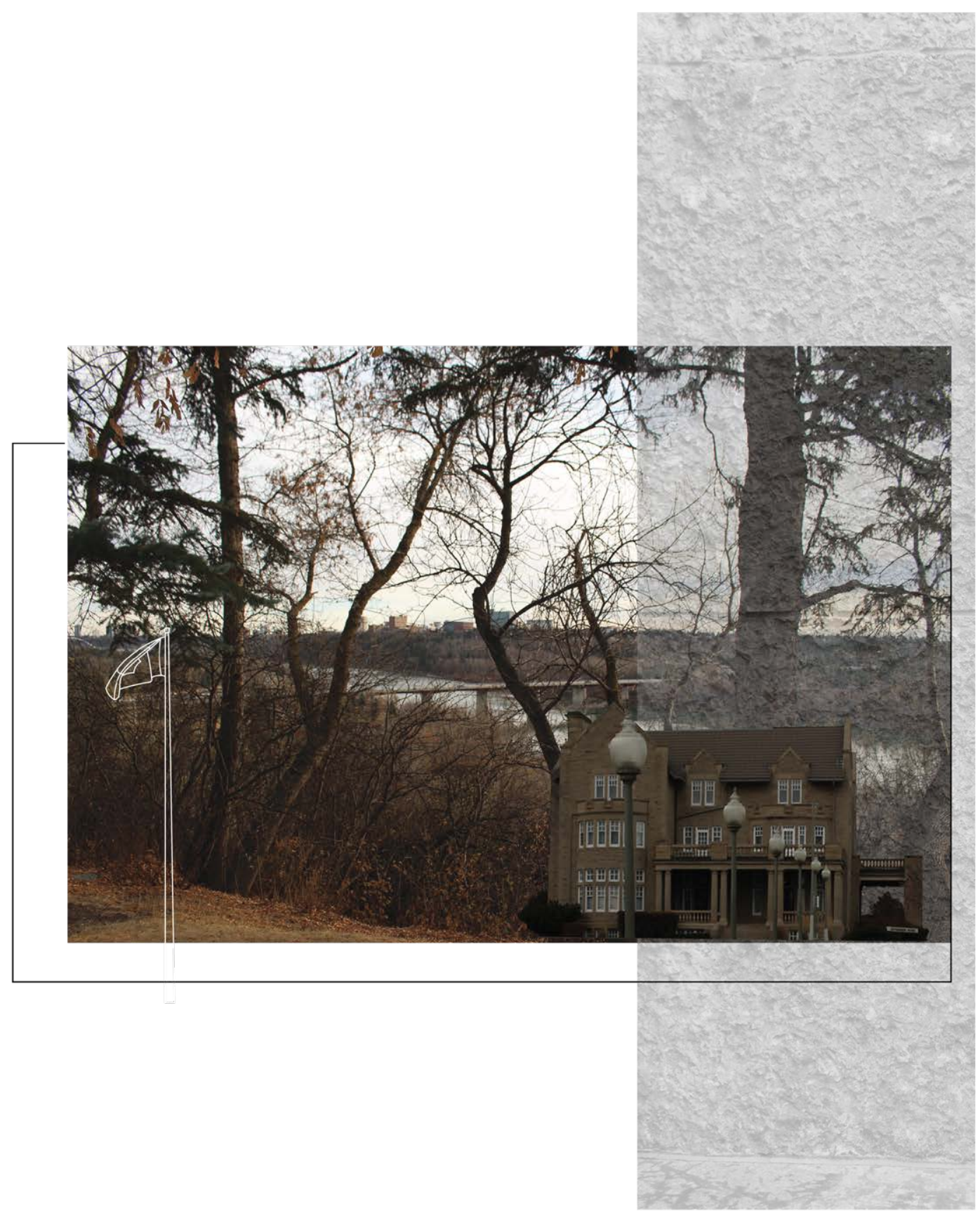

Fig. 7.23: A Whole History

In both addressing the history of the site, and of Canada, this intervention focuses on first building acceptance of what is really there, in order to move forward. This brutally honest assessment gives a clear picture of the now - but also a vision of what the future can be 

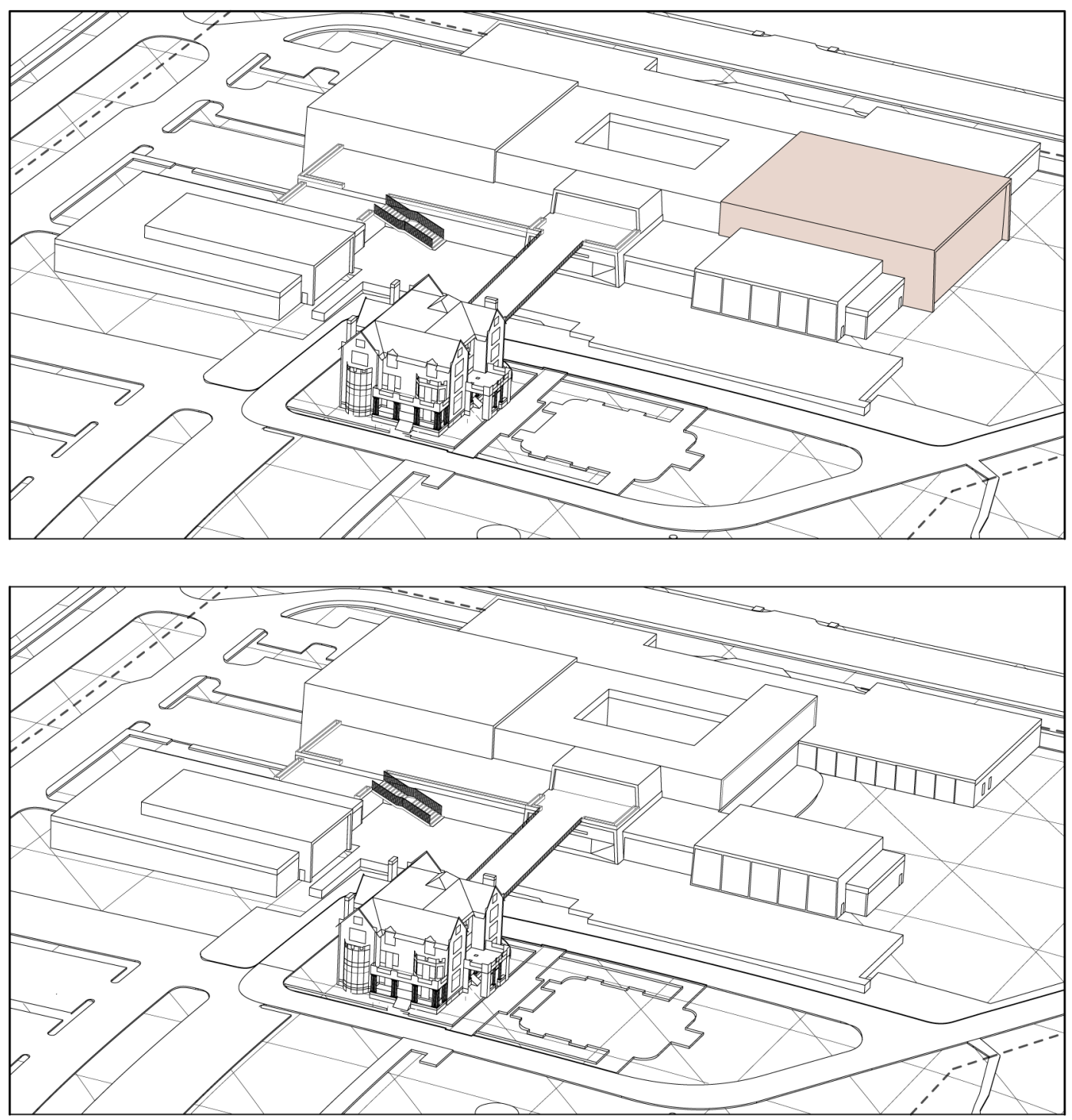

Fig. 7.24: Intervention Two Site Study -

Past vs. Futue

An overview of the major physical changes of Intervention Two on the site and building of the former Royal Alberta Museum. The most notable visual difference is the removal of the East Gallery and other minor buildings that have stood empty on site. Depicted layered on top of Intervention One. 

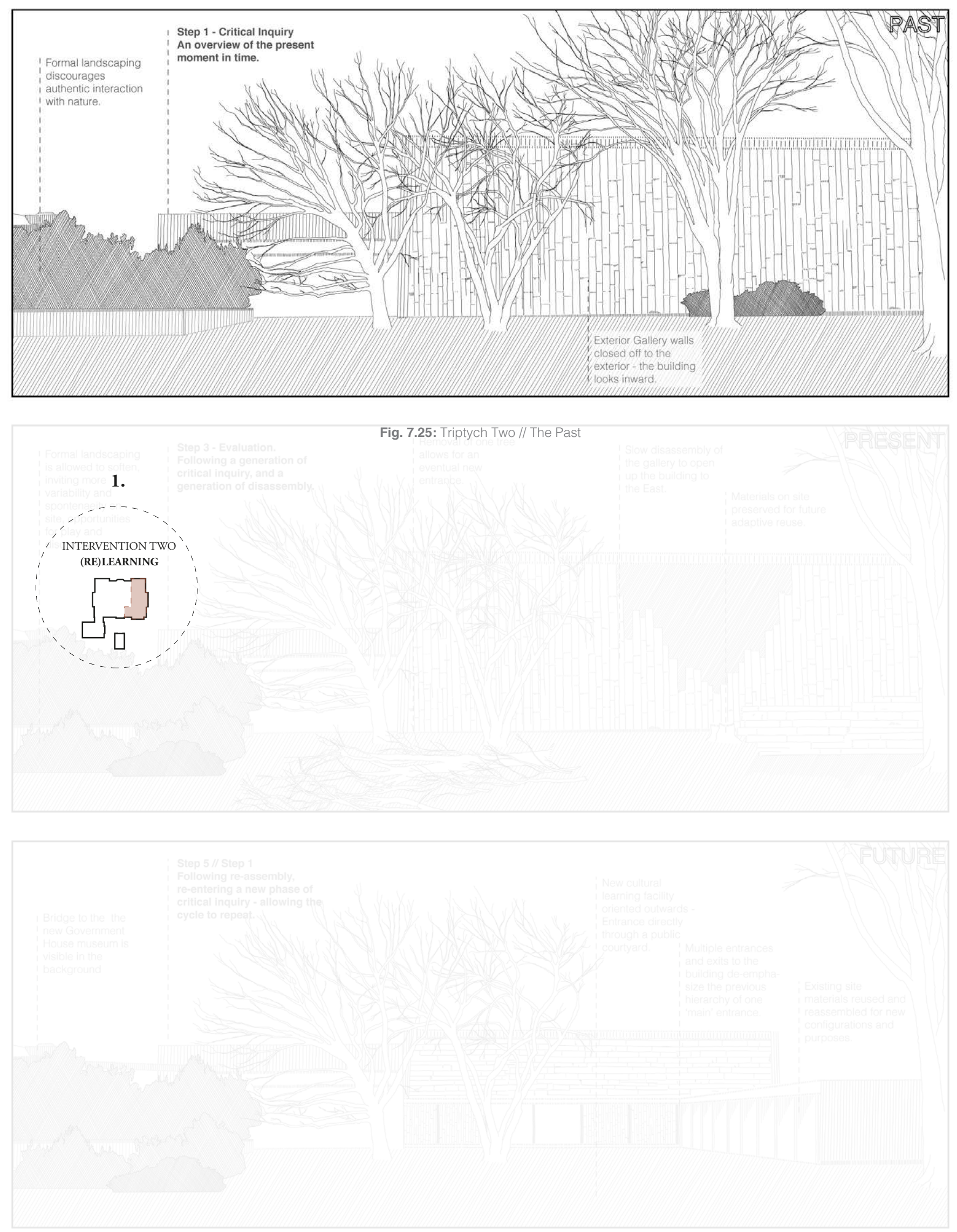


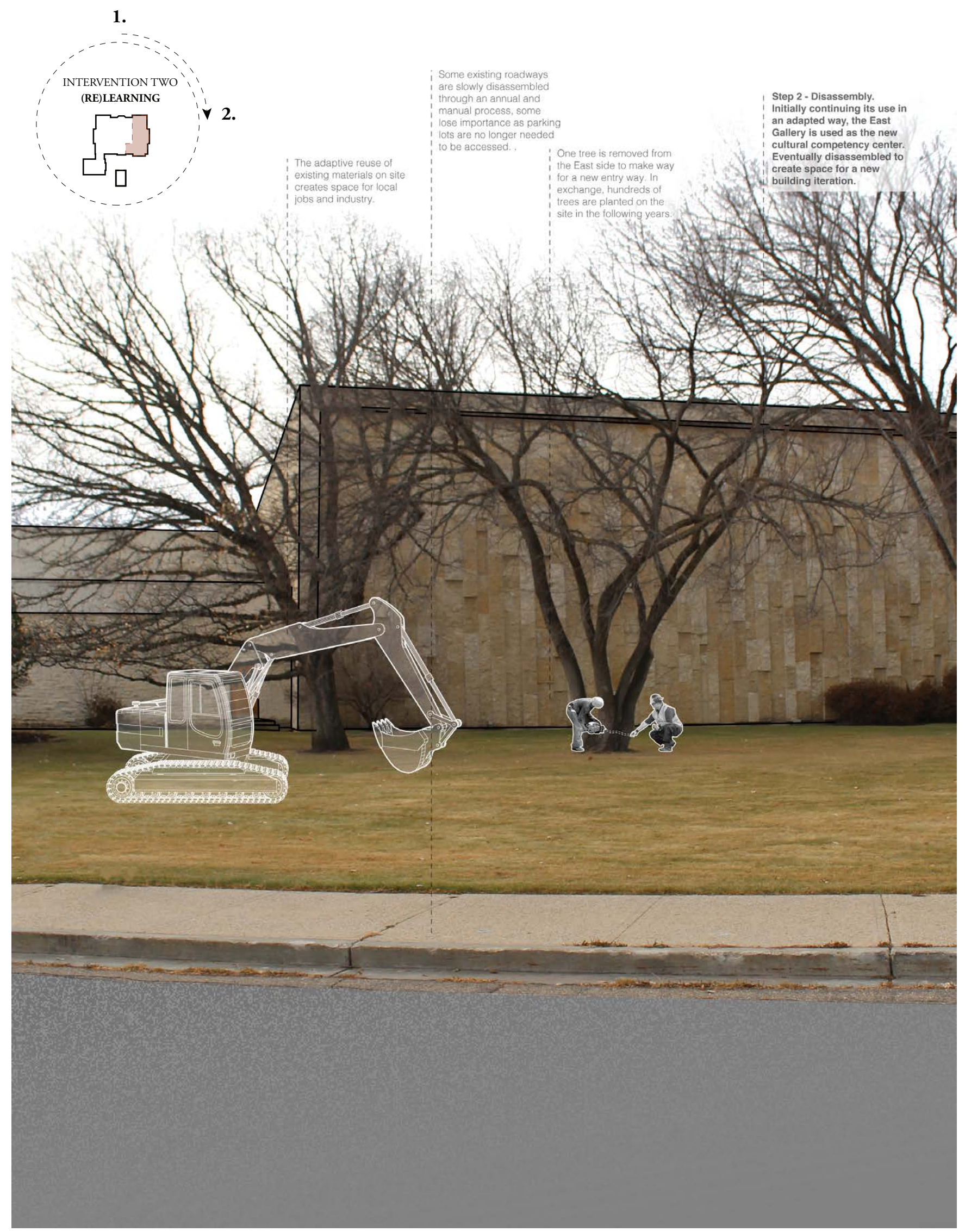




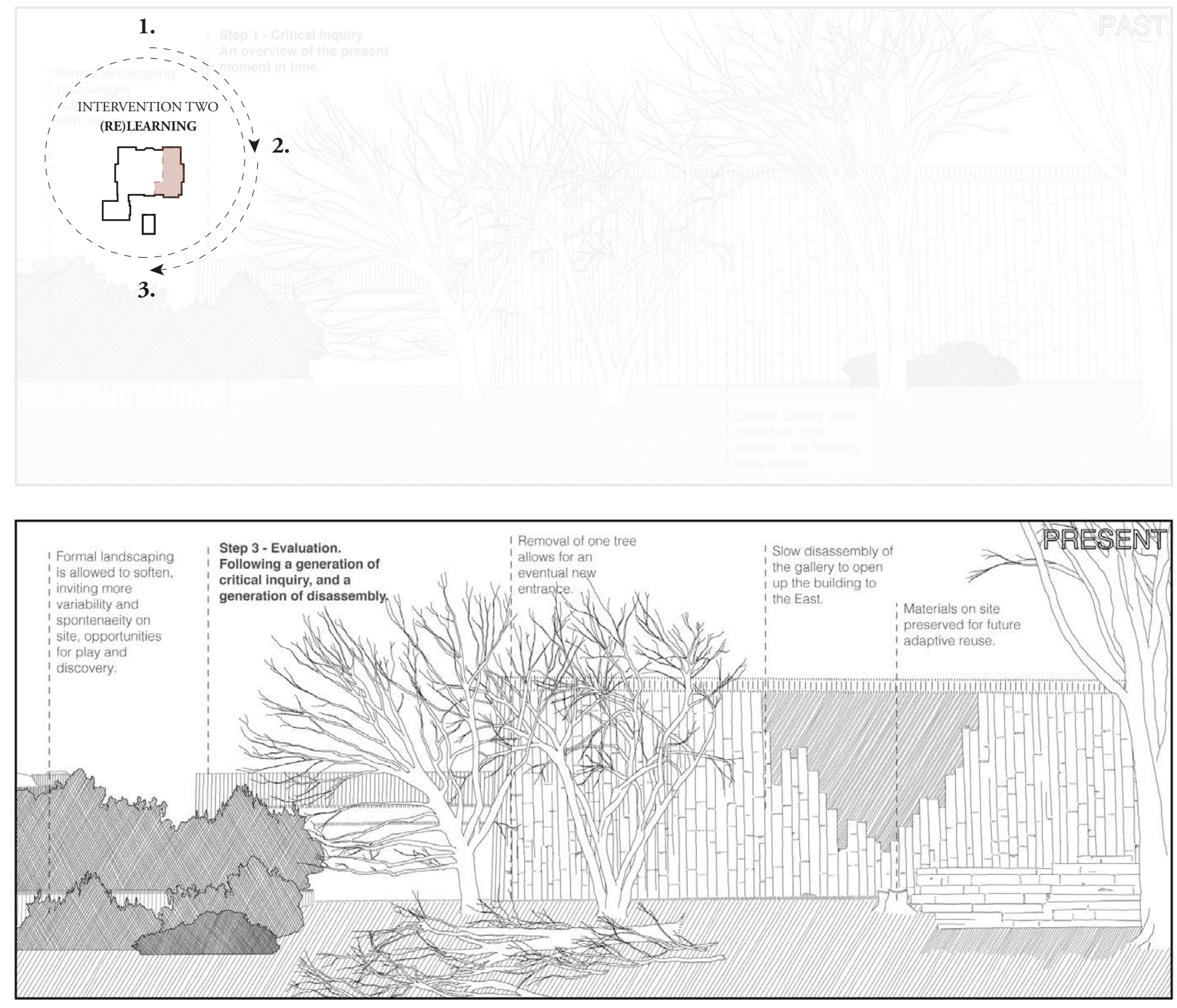

Fig. 7.27: Triptych Two // The Present 


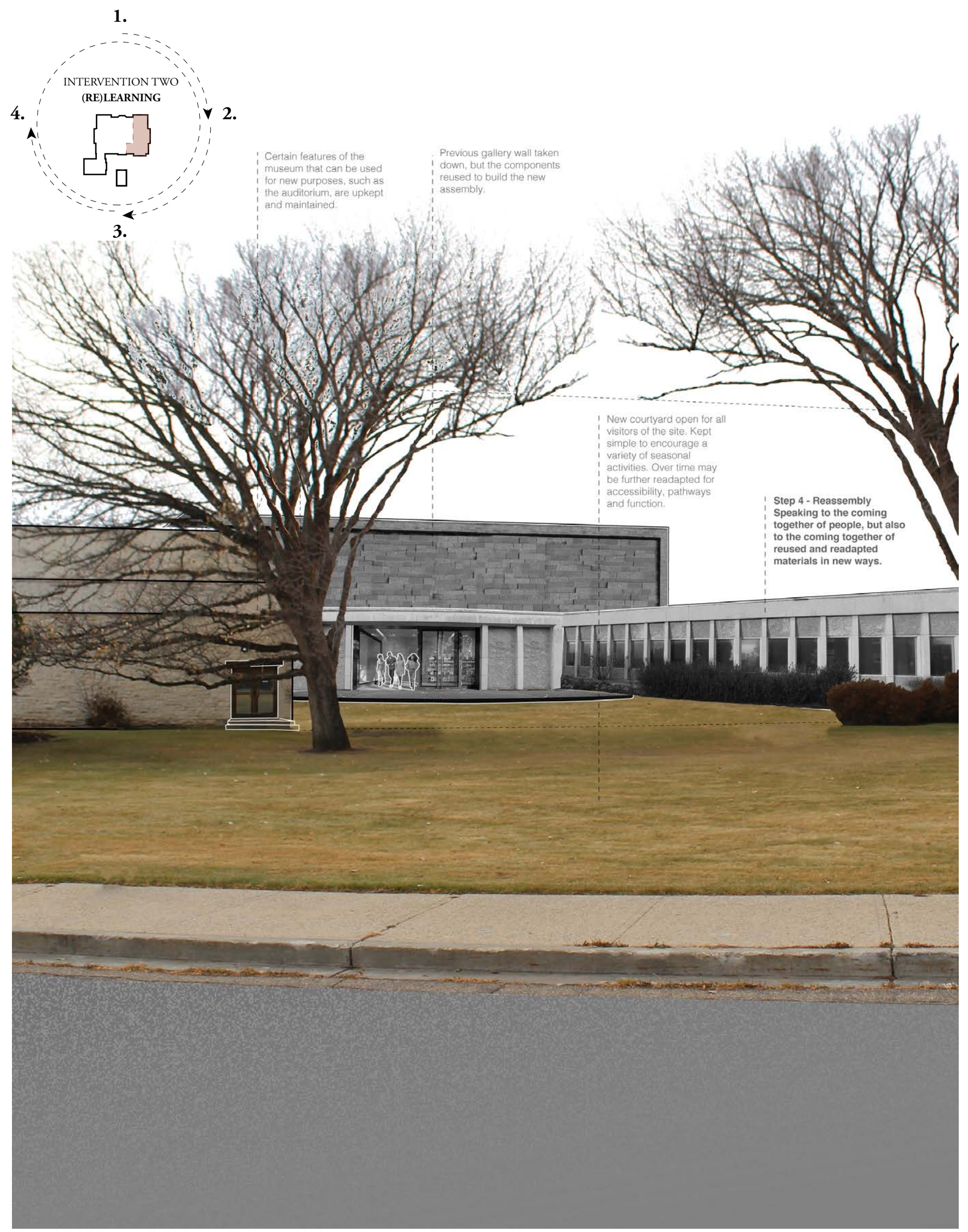

Fig. 7.28: Reassembly // Hierarchy 

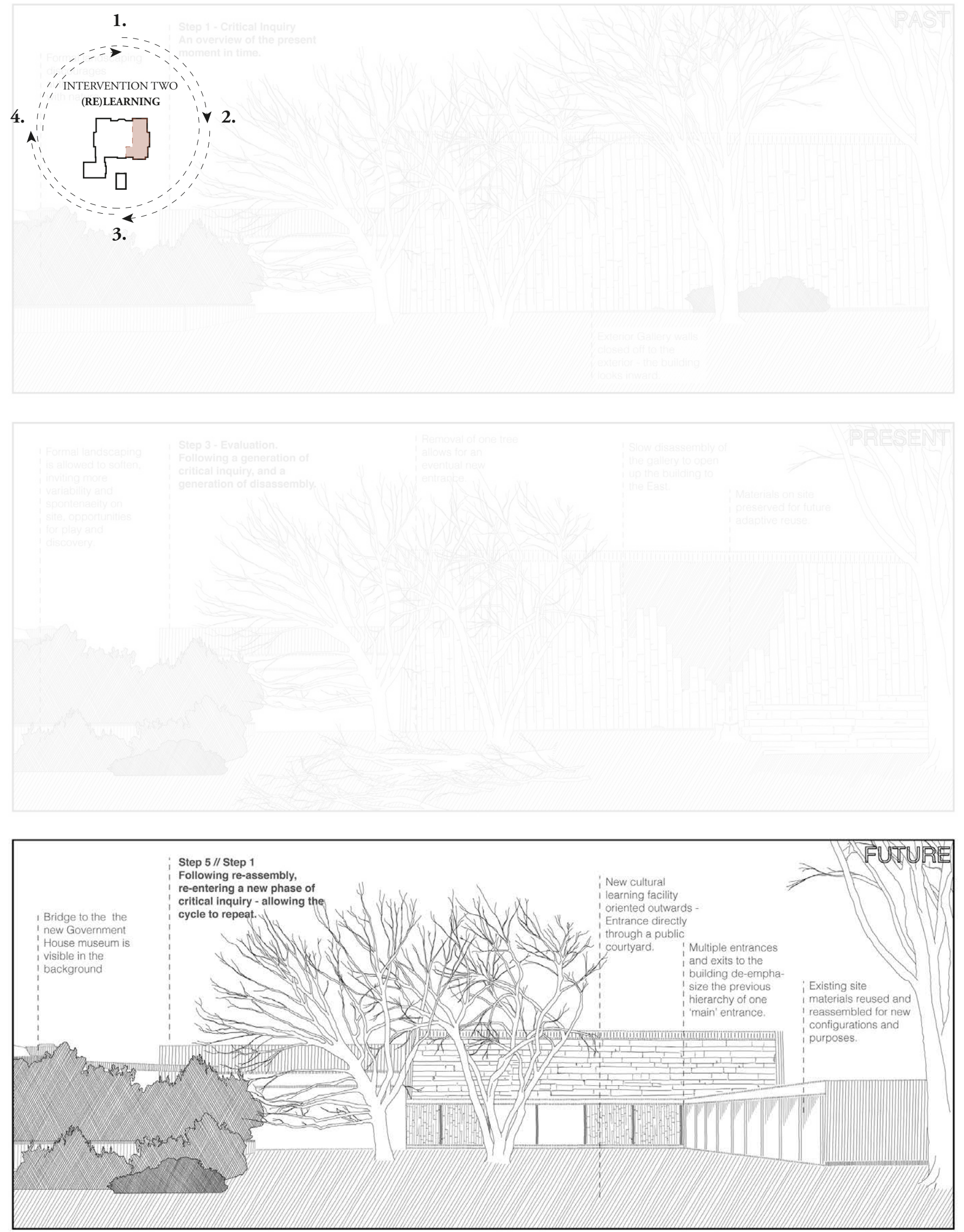

Fig. 7.29: Triptych Two // The Future 

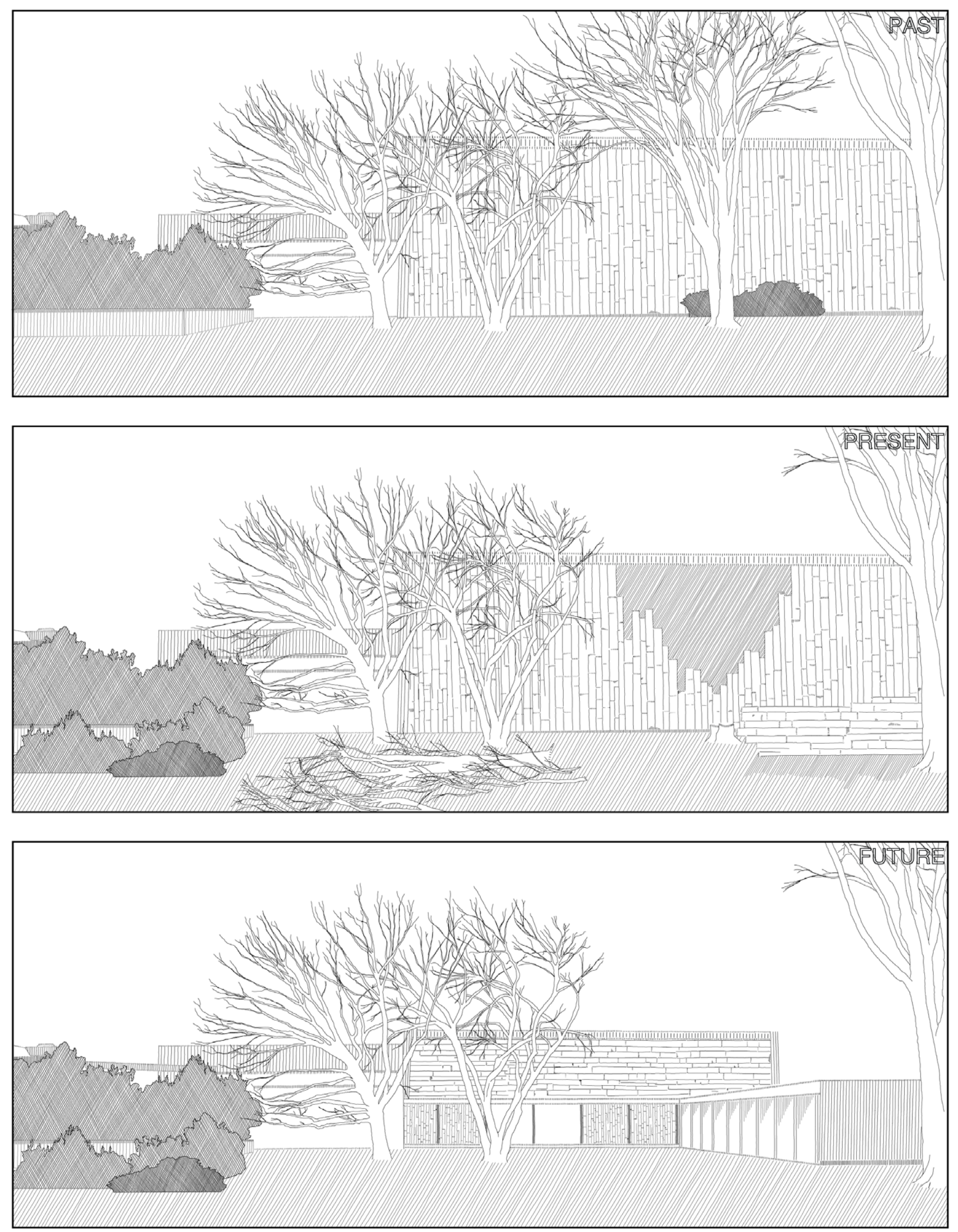

Fig. 7.30: Triptych Two // The Gallery 


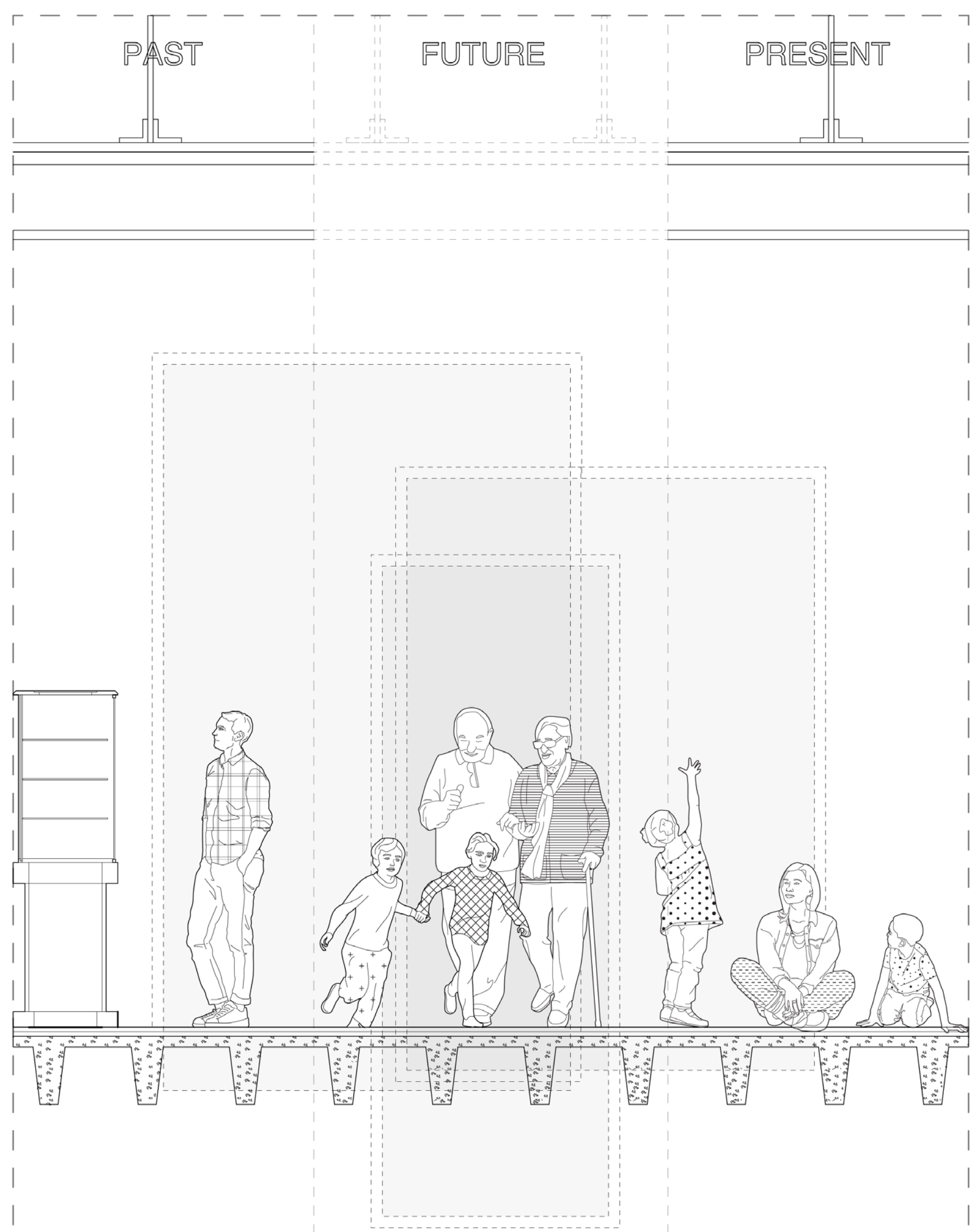




\subsection{RETROFIT AND REUSE}

The parking lot - although a mundane part of building which is easy to overlook, presents a unique problem. Over $70 \%$ of the site is hardscaped. Allowing it to stay hardscaped doesn't seem right, but Simply ripping up and removing the asphalt is not adherent with the principles of sustainability. A new parkade can be incorporated in place of existing extensive underground storage facilities to ensure that the site stays accessible by vehicle. But the removal of the asphalt, concrete and hardscaping from the site would be, in many ways, similar to ignoring difficult conversations about reconciliation. Instead, by accepting that the ground condition exists, the process of disassembly can take place through a slower, manual means.

Edmonton is a northern city, with a harsh winter climate with a high annual amount of moisture in the form of snow that expediates road deterioration in normal conditions. I propose that on the site, this process is further helped by visitors intentionally pouring water into existing cracks and breaks in the parking lot and roads during cold periods in the winter. As the water freezes, the expansion should aid in loosening hardscape and expanding existing potholes, and creating new ones.

This seasonal activity is cycled with the planting of Aspen trees into the fissures in the spring. Aspens have roots which find their way through concrete in a matter of years, and which grow relatively fast. As their roots weave and break downwards through the hardscaping, they will slowly reintroduce the surface of the earth to the ground. This symbolic connection relates to connecting the site back to the river, 


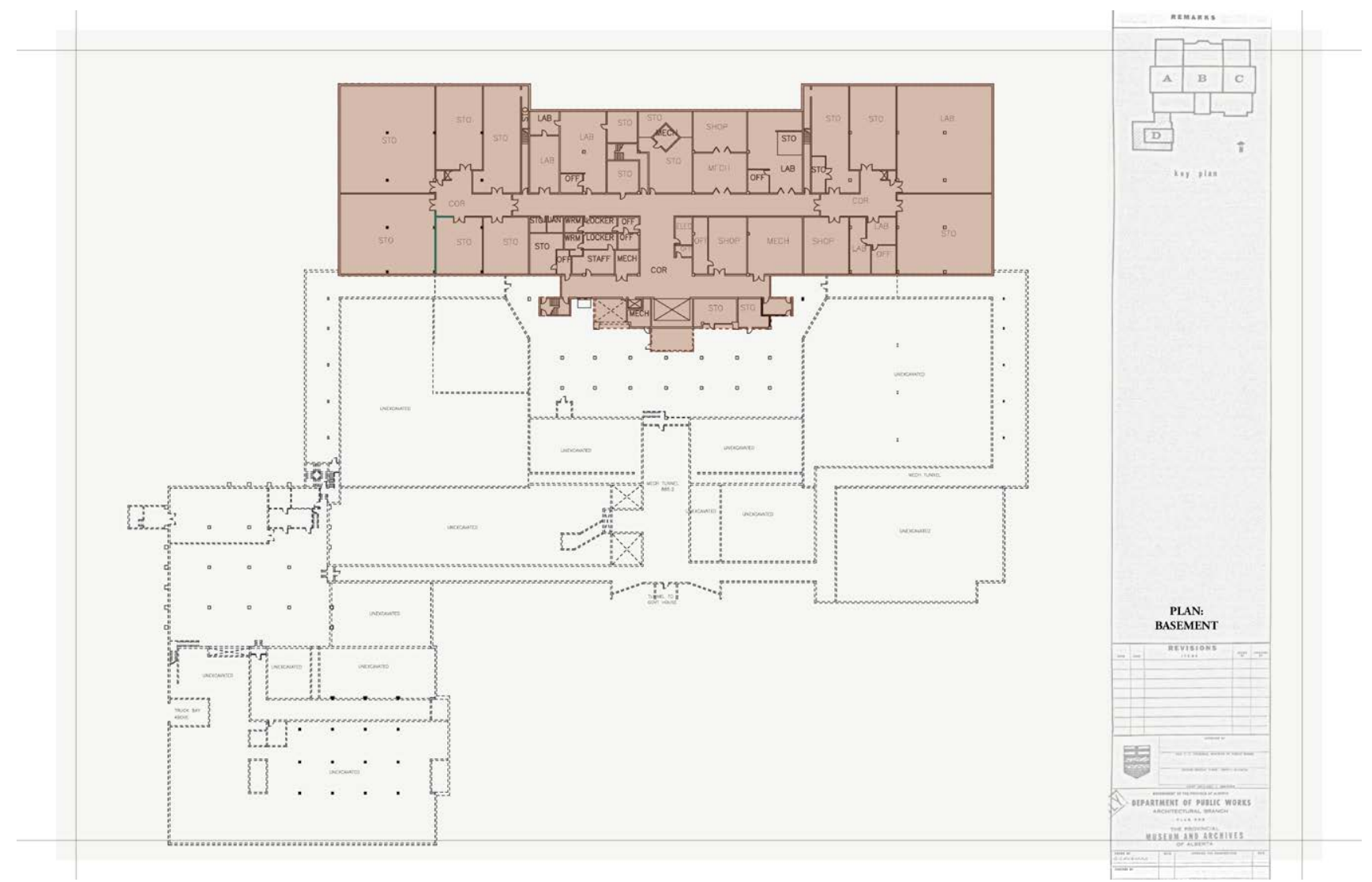

Fig. 7.32: Archival Plans: "Storage"

and connecting the site of the RAM to the other centennial sites across Canada, to propose a re-thinking of our colonial heritage.

These trees are not meant to re-green the area or for distant observation, but to be active, living players on the site, helping to break up the pavement and allow water to once again permeate down. However, it is important not to see the trees as a "museum object that is created and presented as a finished product" as that can "limit the range of expe-

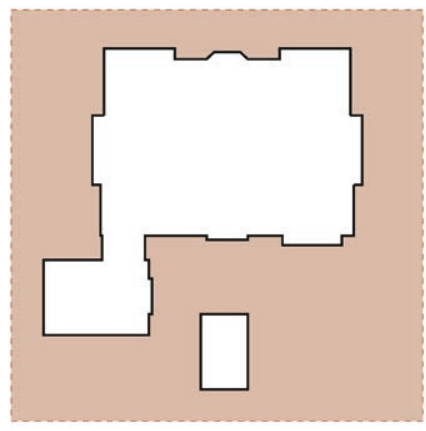

Fig. 7.33: Parti Diagram: Retrofit and Reuse riences that urban nature can provide." 168 Instead, once the cycle of breaking the pavement and growing trees has been completed, a future generation can decide how to use the trees, whether to use them as raw material for new buildings on site, or to leave them as 'nature'. 


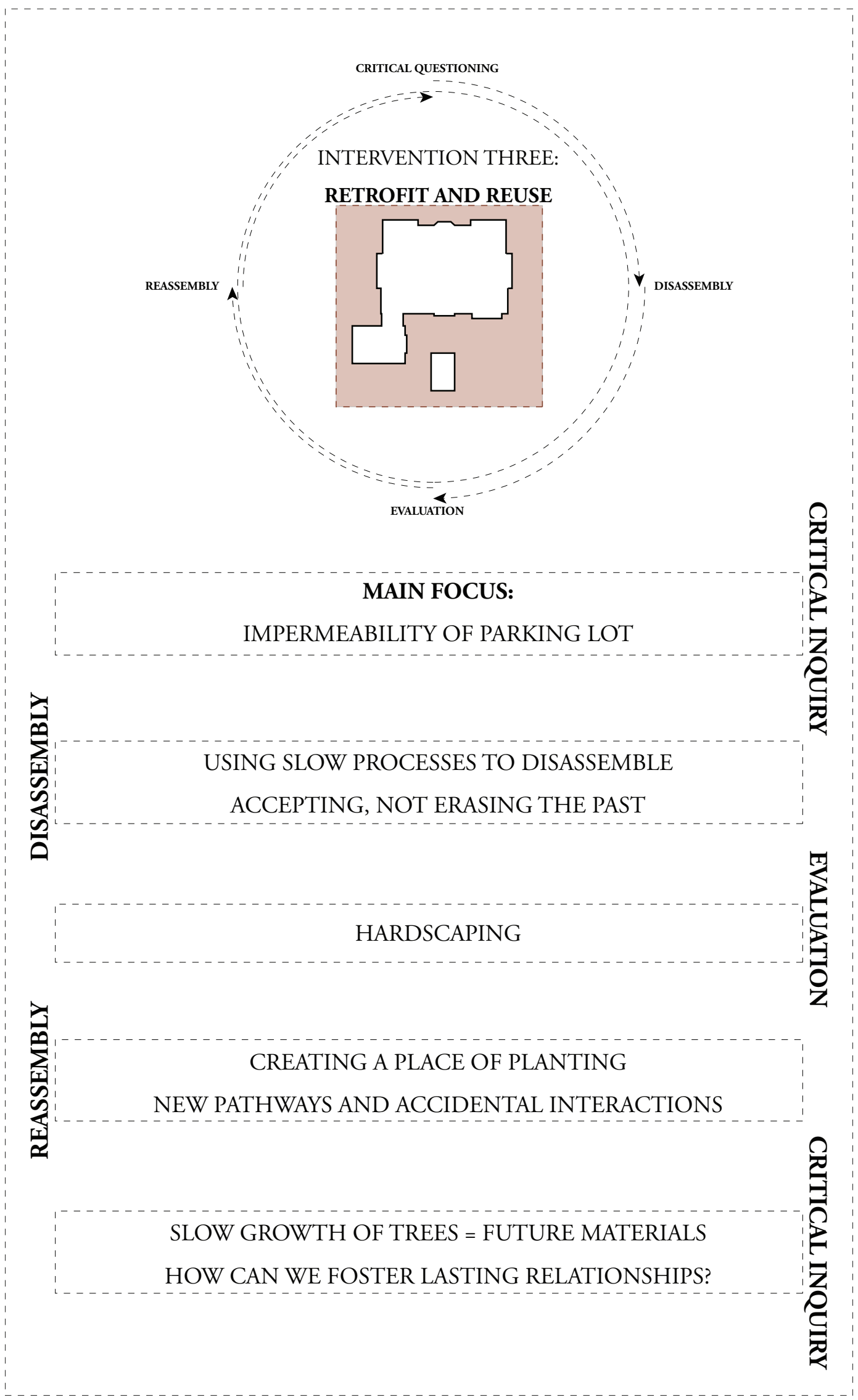

Fig. 7.34: Intervention Three // Five Generations of Change 


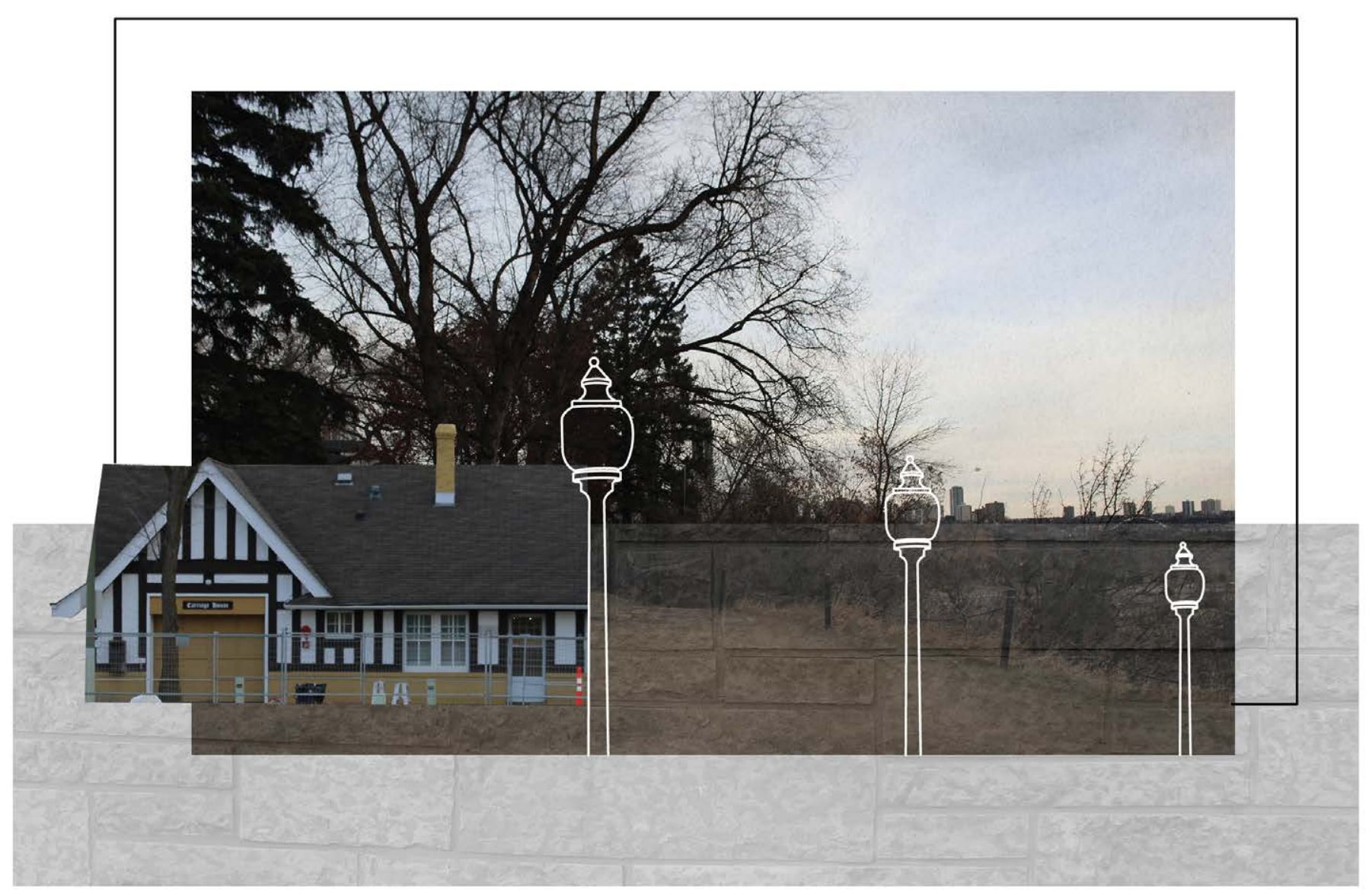

Fig. 7.35: A New Path Forward

The acceptance of the pavement into the ground condition allows for new pathways to be laid across site. Both the planting of trees and the activity of walking across the site hold potential for new, meaningful interactions between people who share space. 

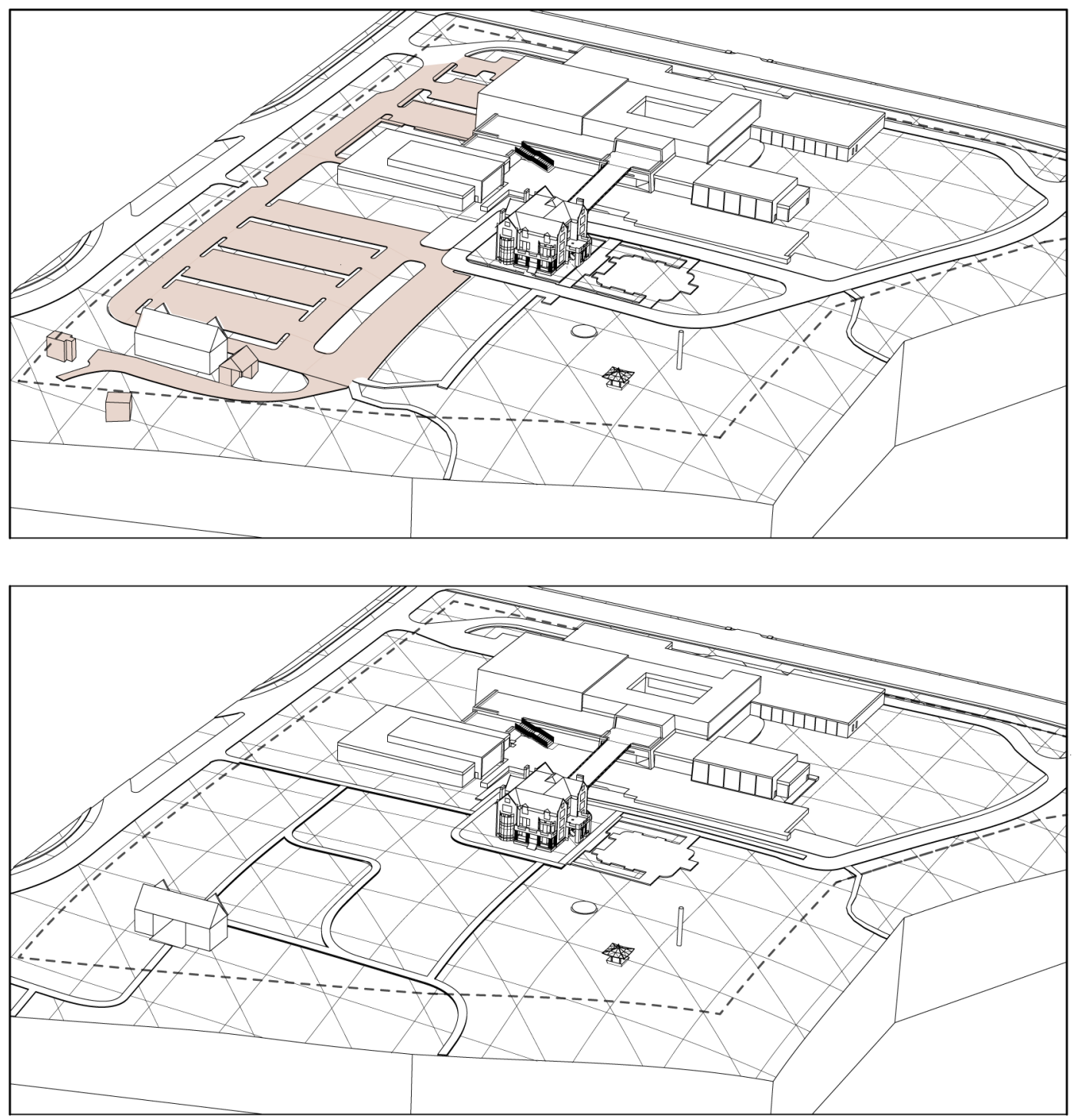

Fig. 7.36: Intervention Three Site Study -

Past vs. Futue

An overview of the major physical changes of Intervention Three on the site and building of the former Royal Alberta Museum. The most notable visual difference is the slow breaking up of the majority of hardscaped surfaces, and the introduction of new trees. Depicted layered over Intervention One and Intervention Two 


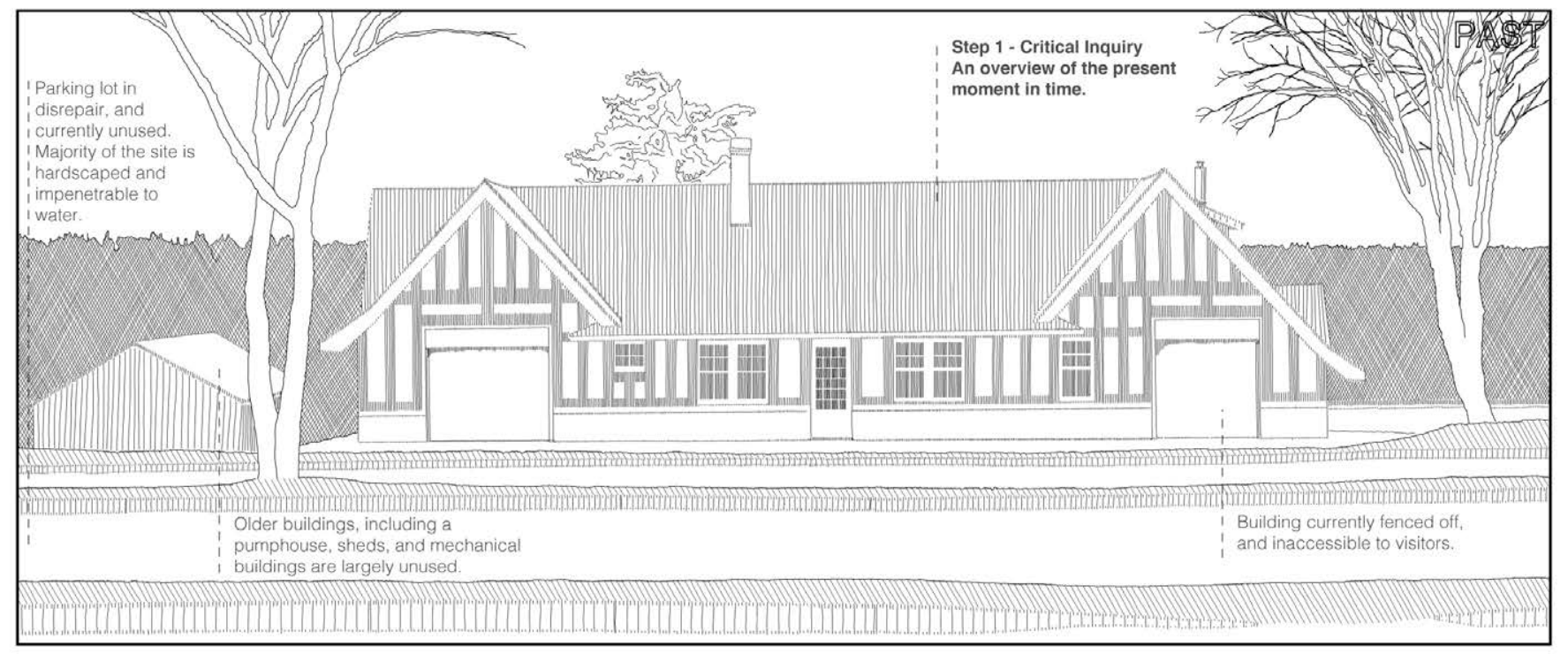

Fig. 7.37: Triptych Three // The Past

1.

INTERVENTION THREE

RETROFIT AND REUSE

$\because$ 


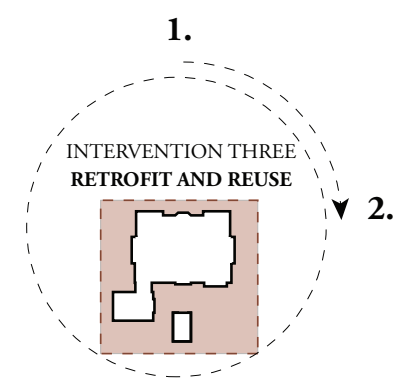

\section{DISASSEMBLY}

Regarding the slow breaking

up of the hardscaping of the

site. In winter, water is

poured into existing

potholes. The expansion of

the freezing water speeds up

the growth of the holes. In

the spring, aspen seedlings

are planted into the new

Government house is left

openings.

where it is, as time is

needed for the education

take their sfiect door
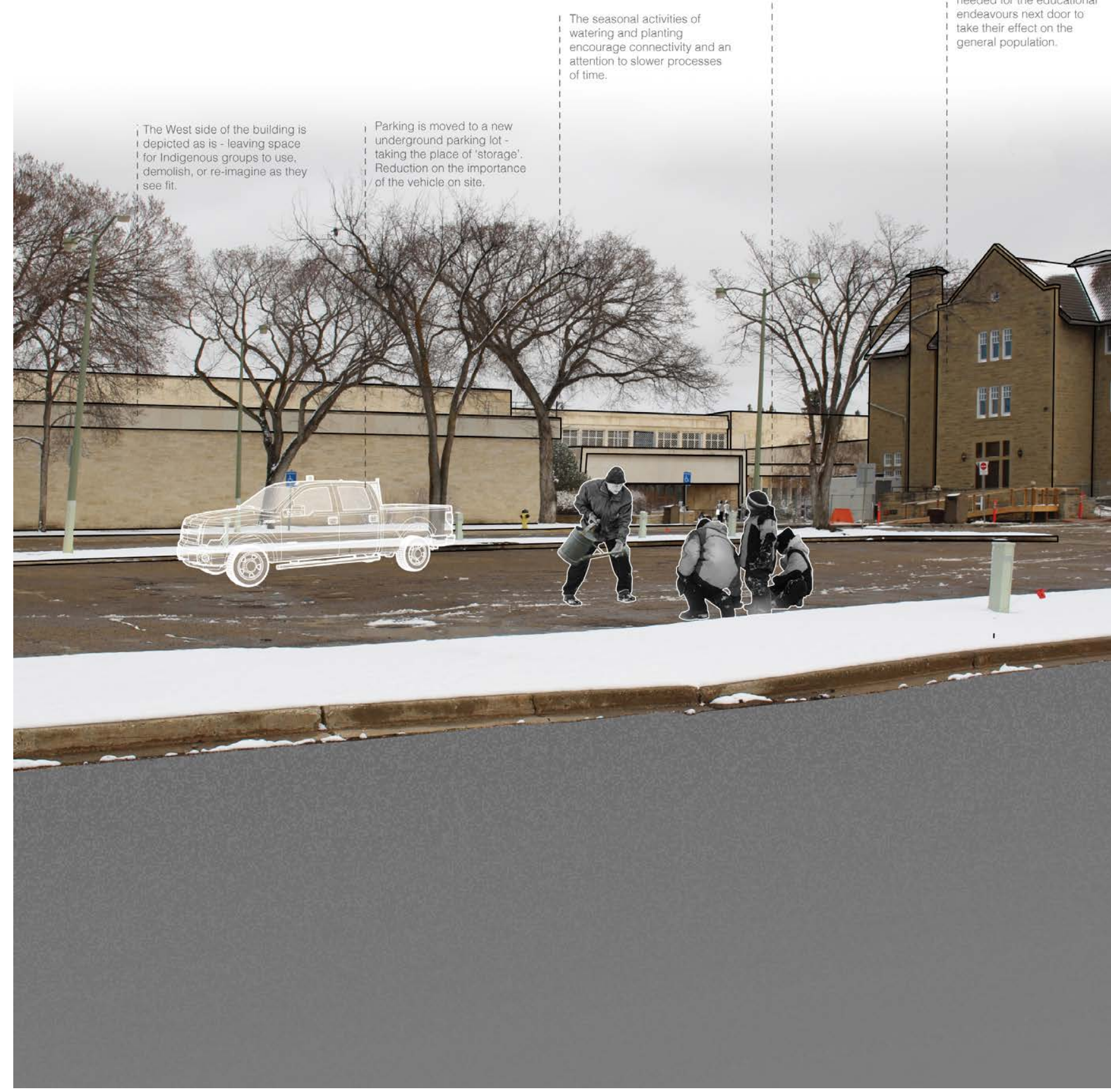

Fig. 7.38: Disassembly // Breaking Ground 


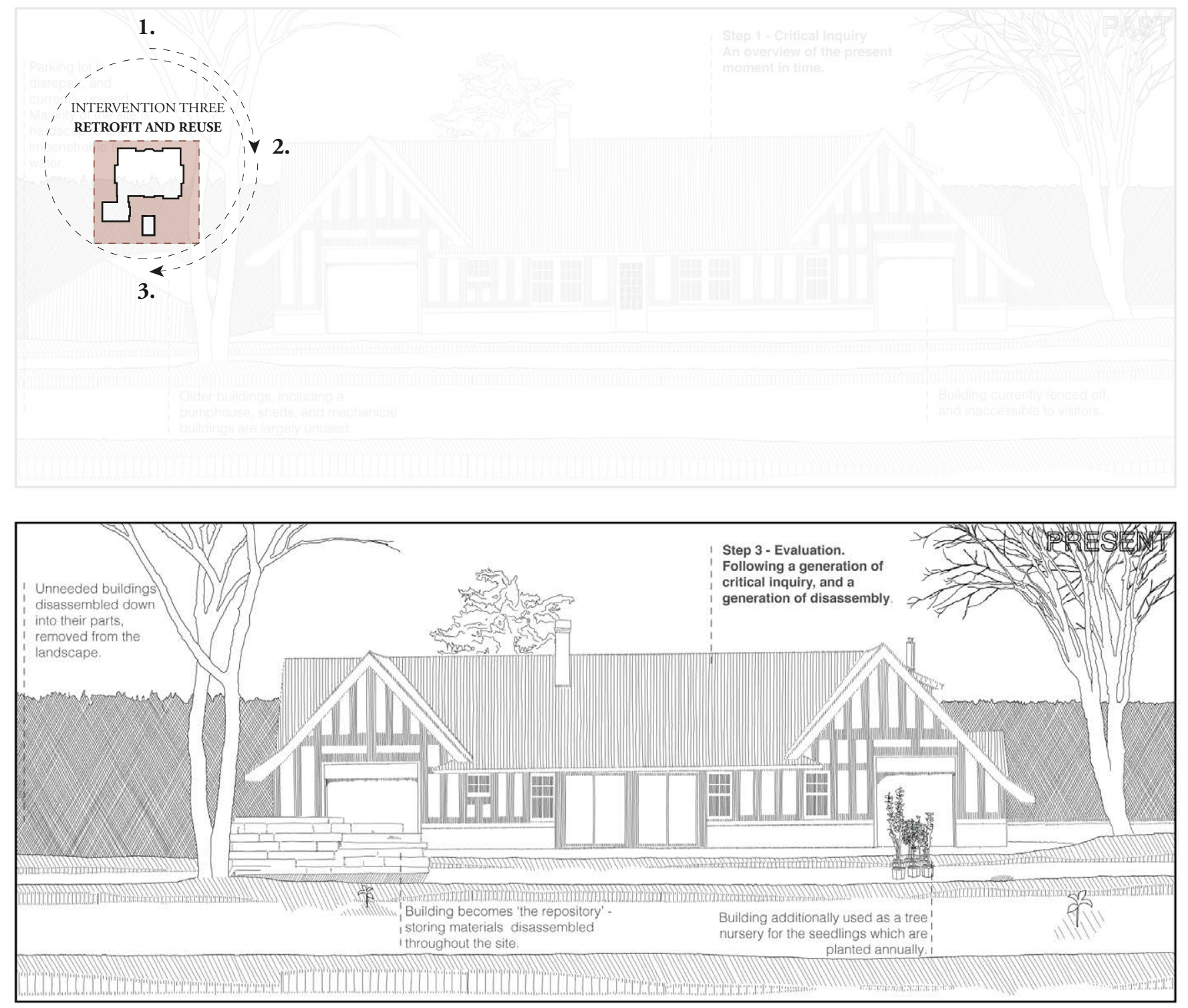

Fig. 7.39: Triptych Three // The Present 


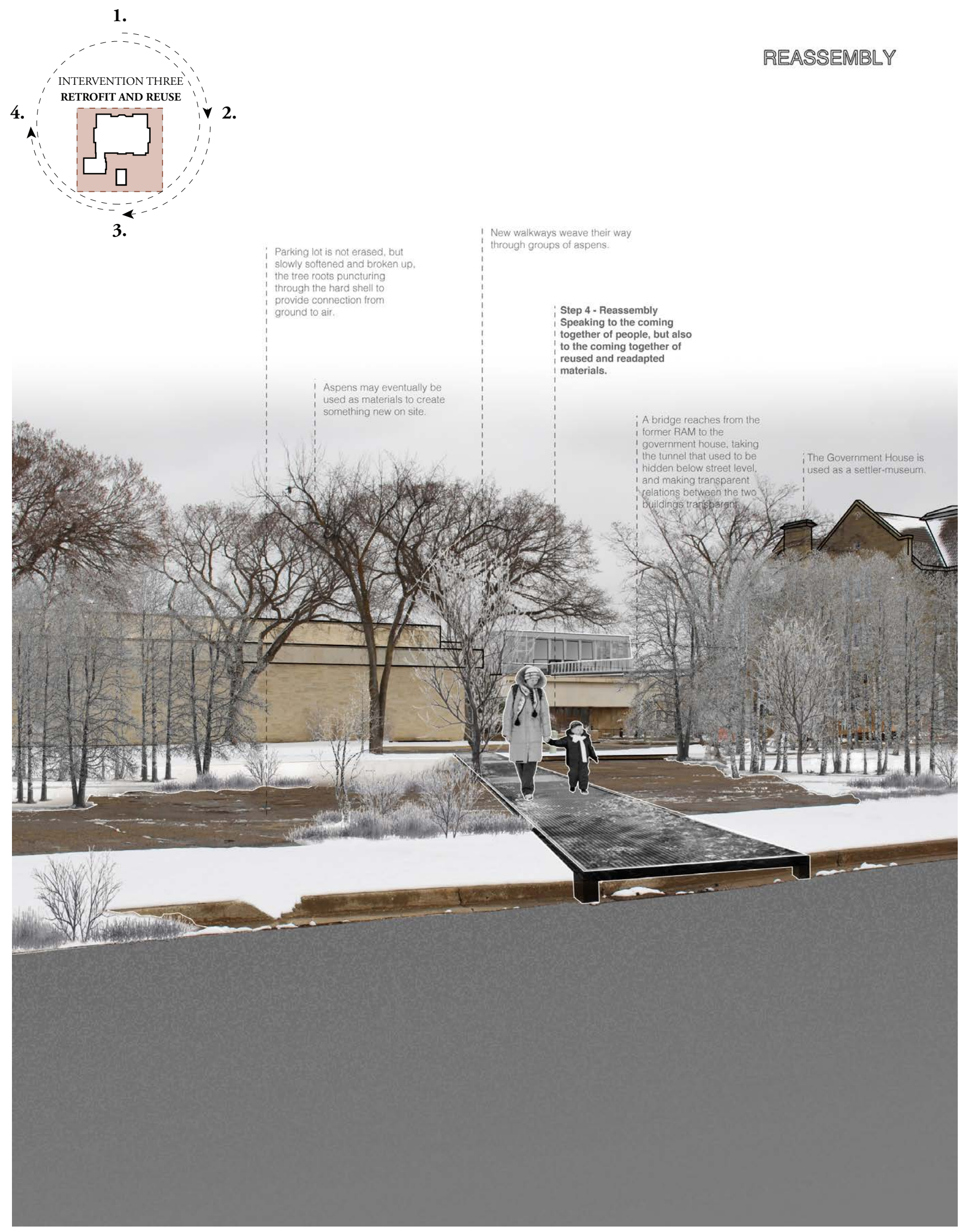

Fig. 7.40: Reassembly // A New Way Forward 

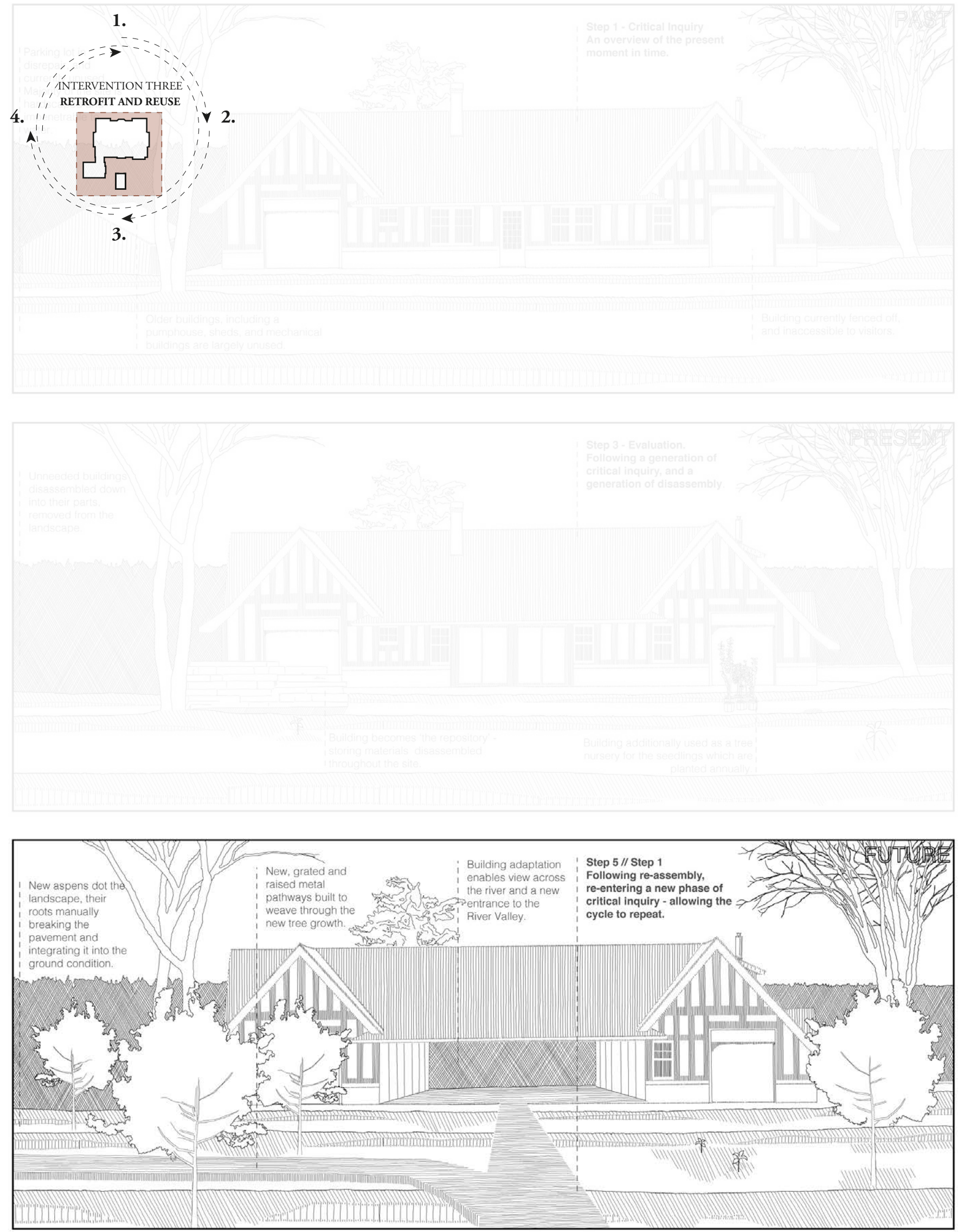

Fig. 7.41: Triptych Three // The Future 

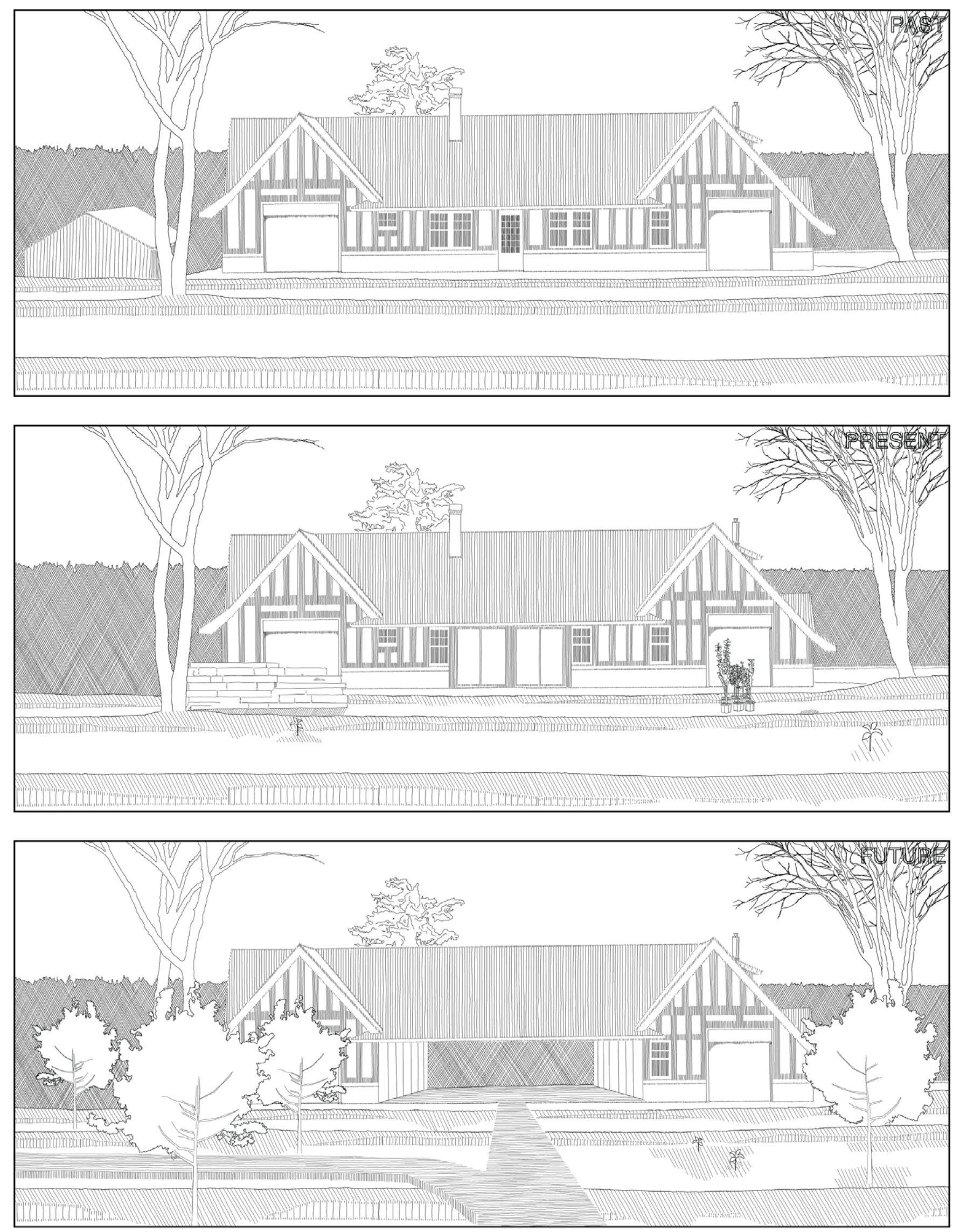

Fig. 7.42: Triptych Three // The Old Parking Lot 


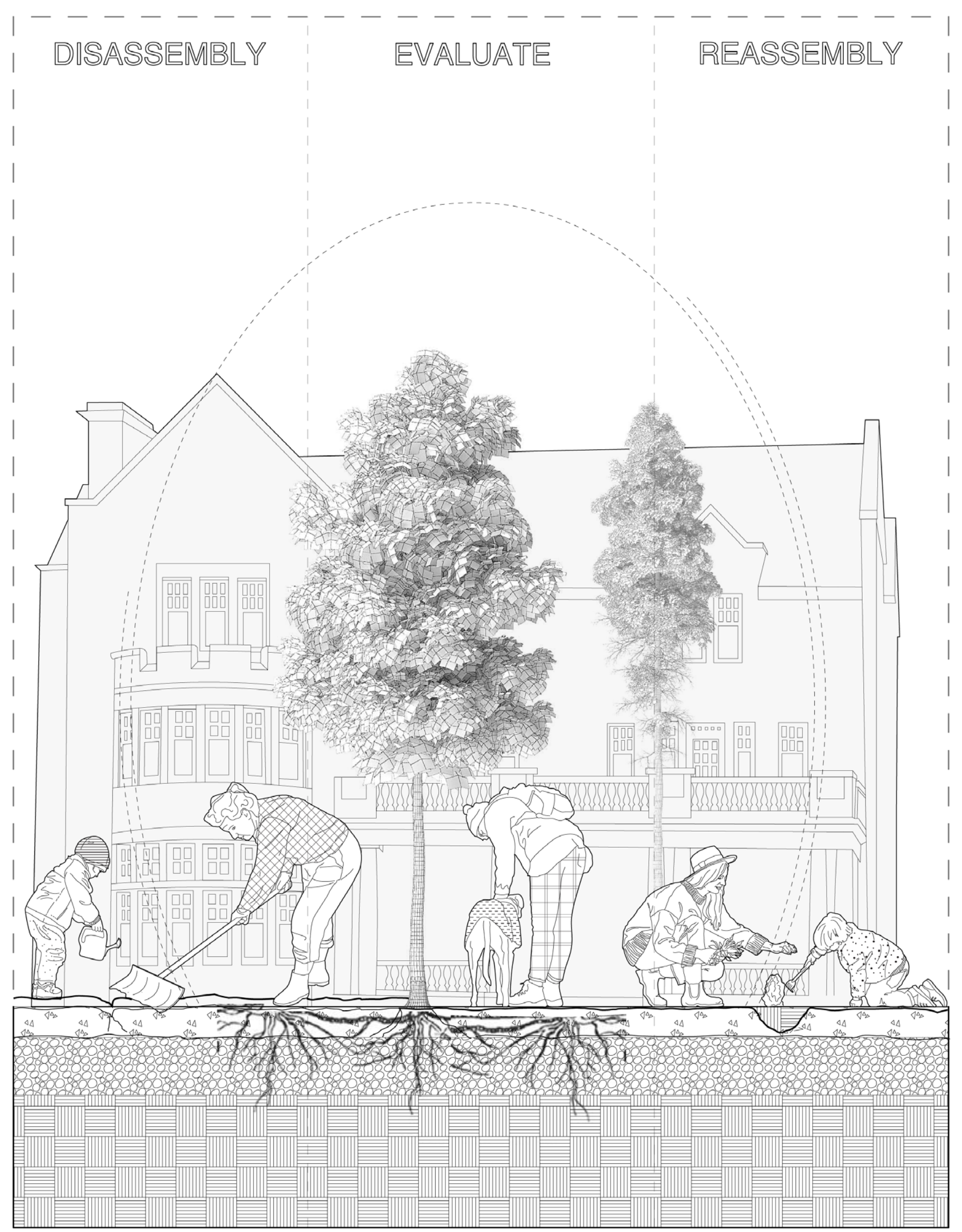

Fig. 7.43: Section Three // A New Landscape 


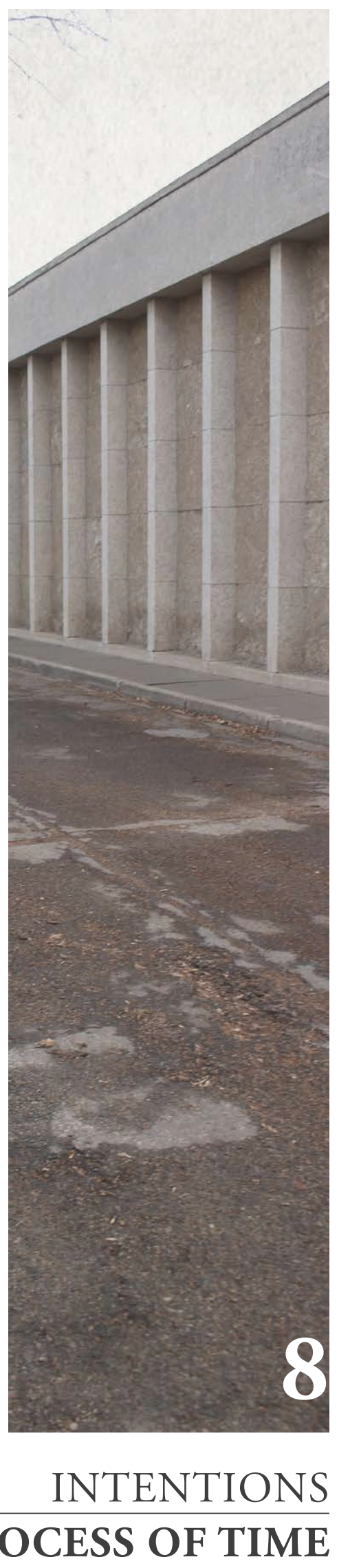




\subsection{THE PROCESS OF TIME}

This thesis began with a keen interest in sustainabilitym explored across all 3 pillars of sustainability - relating to people, planet, and profit. It became not a goal, but a multilayered process, which then extended to the exploration of architecture as process.

Looking at the former Royal Alberta Museum further layered complexity on the question of social sustainability. Conceptually, it speaks to questions of colonized space, relations between government and the Indigenous peoples in Canada, and the limited understanding Westerners have of the past.

I am not proposing a solution that revolves on capital A architecture as a framework for solving societal and ecological problems. In some ways, I do not propose solutions at all, but rather, a series of critical questions. I propose slower methodology of looking at time and place that can help reconfigure our reality through the formation of a collective vision. This methodology is centered around critically questioning surroundings, disassembling everything into their smallest parts, evaluating the raw materials right in front of us, and reassembling them into something for the future generation.

This reiterative, cyclical process speaks to seasons, to years, and to the far reach of time that lets us speak with the generations of the future and the past. While this thesis is the limited vision of only one individual, taking this methodology forward into practice has the potential to define community visions and goals. 


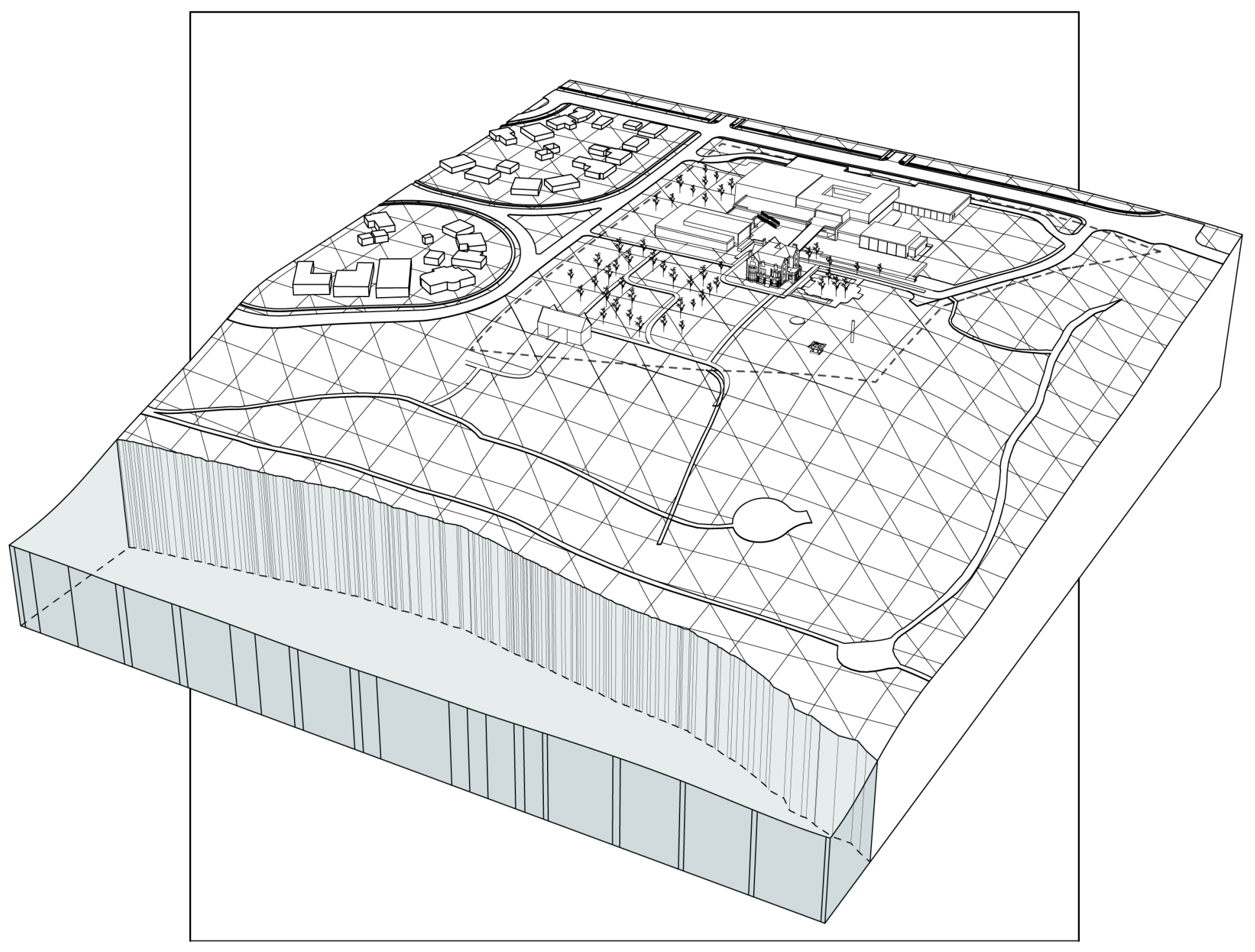

Fig. 8.1: Extending Beyond the Site

This project extends beyond the limited boundaries of the site. It embodies a

multigenerational process that can be used to create a master plan for a collective vision that moves Canadians towards reconciliation. It extends beyond the example of the former Royal Alberta Museum, and can be applied towards all centennial buildings, to move us forward towards softer connections to people and place. 


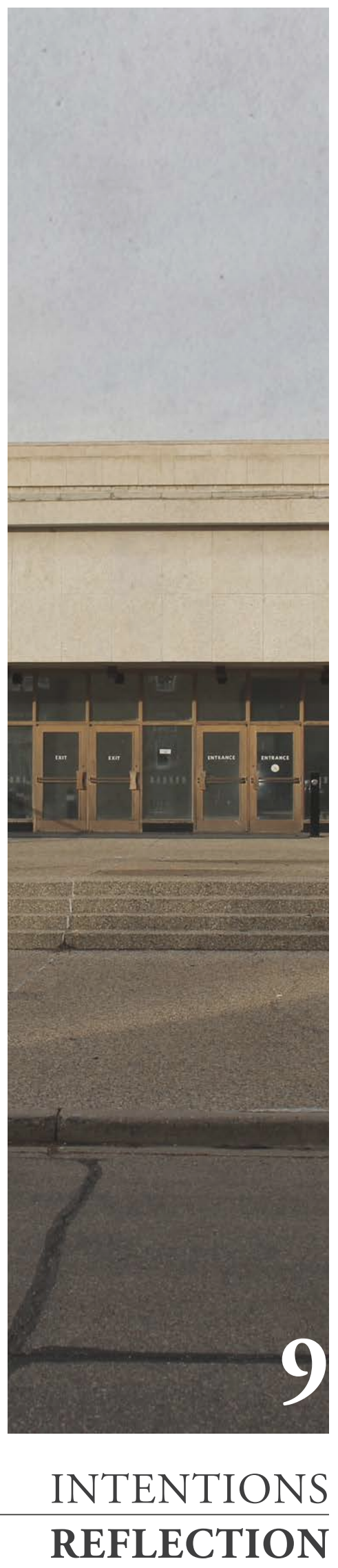




\subsection{REFLECTION}

How can the past influence the current relationship between ecological and social sustainability, to influence contemporary modes of building? In exploring that question, this thesis sought to emphasize a cohesive and holistic approach to construction and restoration. In doing so, it questions Western paradigms of social and spatial understanding, and asks us to address missing and omitted history, and to place importance on Indigenous ways of knowing.

The former Royal Alberta Museum, as one of hundreds of Canadian Centennial Buildings, is connected to a legacy of nation building on colonized land. Less than 100 years later, as many of these 'lasting' projects are coming up to the end of their life cycles, their original purposes are worth questioning and reconsidering. Anthropological museums are rooted in colonial, euro-centric traditions that subjugate and silence Indigenous voices, past and present. Conservation of the museum would perpetuate these traditions and demolition would obscure an unsightly past.

This thesis chose instead to build upon a methodology of critical questioning, disassembly, evaluation, and reassembly. This methodology can be applied to the physical treatment of the site and the adaptive reuse of materials. It can also be used to question and evaluate the conceptual basis behind what we build, who it serves, and how we can build in a way that attends to all members in a community. The Seven Generations Model underpins the research and transforms the site into a location of shared knowledge, acknowledgement and understanding. It links us to the past and the future through our unique place in time. 
This multigenerational process can assist us in addressing injustices and healing existing ruptures in society on an ecological and a social level. Altogether, this methodology relates as much to the literal disassembly of stones and foundations as it does to the disassembly of colonial spatial understandings and Western frameworks of thinking, to re-evaluate our value systems, acknowledge the past, and reassemble the pieces into something that can serve future generations. 


\section{BIBLIOGRAPHY}

Alhmidi, Maan. “The RCMP Have 'let down' Indigenous Fishers Facing Violence in Nova Scotia: Minister." News. CTV News, October 19, 2020. https://atlantic.ctvnews.ca/ the-rcmp-have-let-down-indigenous-fishers-facing-violence-in-nova-scotia-minister- 1.5151182 .

Alsayyad, Nezar. "Foreward." In Vernacular Architecture in the Twenty-First Century: Theory, Education and Practice, xvii-xviii. London: Taylor and Francis, 2006. https://www-taylorfrancis-com.proxy.library.carleton.ca/books/vernacular-architecture-21st-century-lindsay-asquith-marcel-vellinga/e/10.4324/9780203003862.

Asquith, Lindsay and Vellinga, Marcel. "Introduction.” In Vernacular Architecture in the Twenty-First Century: Theory, Education and Practice, 1-20. London: Taylor and Francis, 2006. https://www-taylorfrancis-com.proxy.library.carleton. ca/books/vernacular-architecture-21st-century-lindsay-asquith-marcel-vellinga/e/10.4324/9780203003862.

Aykroyd, Peter H. The Anniversary Compulsion: Canada's Centennial Celebration, a Model Mega-Anniversary. Toronto, Ontario: Dundurn, 1992.

Barker, John. "Going by the Book: Missionary Perspectives." In Native Art of the Northwest Coast: A History of Changing Ideas, edited by Charlotte Townsend-Gault, Jennifer Kramer, and Ki-Ke-in, 234-64. Vancouver: UBC Press, 2013.

Bennett, Tony. “The Exhibitionary Complex.” New Formations, no. 4 (1988): 73-102.

Brady, Miranda J. "Mediating Indigenous Voice in the Museum: Narratives of Place, Land, and Environment in New Exhibition Practice.” Environmental Communication 5, no. 2 (May 19, 2011): 202-20. https://doi.org/10.1080/17524032.2011.562649.

Brandt, Mark Thompson. "Buildings and Stories: Mindset, Climate Change and Mid-Century Modern.” Journal of Architectural Conservation 23, no. 1-2 (2017): 36-46. https://doi.org/10.1080/13556207.2017.1327195.

Britten, Liam. "Canada 150 Won't Leave Much of a 'concrete' Legacy, Architects Say." News. CBC News, July 3, 2017. https://www.cbc.ca/news/canada/british-columbia/canada-150-centennial-projects-1.4188658.

“Canada's 150th Anniversary in 2017." House of Commons, Canada: Parliament of Canada, September 2012. https://www.ourcommons.ca/DocumentViewer/en/41-1/CHPC/ report-4/page- 45 . 
Carroon, Jean. Sustainable Preservation: Greening Existing Buildings. 1. Aufl., 1st ed. Hoboken, N.J: Wiley, John Wiley \& Sons, Incorporated, Wiley-Blackwell, 2010.

Choi, Jong-Deok. "The Palace, the City and the Past: Controversies Surrounding the Rebuilding of the Gyeongbok Palace in Seoul, 1990-2010.” Planning Perspectives 25, no. 2 (2010): 193-213. https://doi.org/10.1080/02665431003613014.

Compton, Neil. “Expo 67.” Commentary 44, no. 1 (July 1, 1967): 32-39.

Cook, Dustin. "What's next for the Old Royal Alberta Museum? Concerned Residents Make Plea for Repurposing the Site.” News. Edmonton Journal, May 5, 2019. https:// edmontonjournal.com/news/local-news/whats-next-for-the-old-royal-alberta-museum-concerned-residents-make-plea-for-repurposing-the-site-with-its-future-up-inthe-air.

Daugherty, Richard D. "People of the Salmon." In America in 1492: The World of the Indian Peoples before the Arrival of Columbus., edited by Josephy, Alvin M. Jr., 48-83. New York: Vintage Books, a Division of Random House, Inc., 1991.

Davis, Heather, and Zoe Todd. "On the Importance of a Date, or, Decolonizing the Anthropocene.” ACME: An International Journal for Critical Geographies 16, no. 4 (December 20, 2017): 761-80.

Edmonton, City of. "Public Buildings." Government. Edmonton.ca. The City of Edmonton, March 24, 2021. Edmonton, Alberta, Canada. https://www.edmonton.ca/city_government/edmonton_archives/public-buildings.aspx.

Edmonton Historical Board. "Westmount." Accessed January 10, 2021. https://www.edmontonsarchitecturalheritage.ca/index.cfm/neighbourhoods/westmount/.

Gobster, Paul H. "Urban Park Restoration and the 'Museumification' of Nature." Nature and Culture 2, no. 2 (2007): 95-114. https://doi.org/10.3167/nc.2007.020201.

Gordon-Walker, Caitlin. Exhibiting Nation: Multicultural Nationalism (And Its Limits) in Canada’s Museums. Vancouver, Canada: UBC Press, 2016.

Government of Alberta. "Designation of Provincial Historic Resources." Government. Alberta.ca, 2021. https://www.alberta.ca/designation-provincial-historic-resources.aspx.

_ _ "Glenora Building - Former Royal Alberta Museum.” Government. Alberta.ca, June 2020. https://www.alberta.ca/glenora-building.aspx.

_ . "Glenora Building - Former Royal Alberta Museum.” Government. Alberta.ca, June 23, 2020. https://www.alberta.ca/glenora-building.aspx.

Griffith, Jane. "One Little, Two Little, Three Canadians: The Indians of Canada Pavilion and Public Pedagogy, Expo 1967.” Journal of Canadian Studies 49, no. 2 (2015): 171-204. https://doi.org/10.3138/jcs.49.2.171.

Hall, Stuart. "Constituting an Archive." Third Text 15, no. 54 (2001): 89-92. https://doi. 
org/10.1080/09528820108576903.

Hampshire, Gareth. "Indigenous History Prominent at New Royal Alberta Museum.” News. CBC News, December 26, 2017. https://www.cbc.ca/news/canada/edmonton/edmonton-indigenous-history-royal-alberta-museum-1.4449069.

Harris, Beatrice. "Indigenous Representation in the 'Moral Museum': Perspectives from Classical Ethical Theory." Museum Management and Curatorship 33, no. 2 (March 4, 2018): 195-211. https://doi.org/10.1080/09647775.2018.1442738.

Harris, R. Cole. "Native Space.” In Making Native Space: Colonialism, Resistance, and Reserves in British Columbia, 265-92. Vancouver, B.C: University of British Columbia Press, 2002.

Hendry, Joy. “Chapter 1: Museums Are Transformed.” In Reclaiming Culture: Indigenous Peoples and Self Representation, 28-55. New York: Palgrave Macmillan, 2005.

___ "Chapter 5: Arts, Archcitecture and Native Creativity." In Reclaiming Culture: Indigenous Peoples and Self Representation, 131-55. New York: Palgrave Macmillan, 2005.

Jacknis, Ira. “From Explorers to Ethnographers, 1770-1870.” In Native Art of the Northwest Coast: A History of Changing Ideas, edited by Charlotte Townsend-Gault, Jennifer Kramer, and Ki-Ke-in, 46-91. Vancouver: UBC Press, 2013.

Jarzombek, Mark. "The Great Northern Continuum - Part I.” In Architecture of First Societies: A Global Perspective, 117-90. Hoboken, New Jersey: Wiley, 2013.

Jojola, Theodore S. "Indigenous Planning: Towards a Seven Generations Model." In Reclaiming Indigenous Planning, by David C. Natcher and Ryan Christopher Walker, 457-72. McGill-Queen's Native and Northern Series 70. Montréal [Québec]: McGill-Queen's University Press, 2013.

Jonaitis, Aldona. "Museums of the Northwest Coast." In Native Art of the Northwest Coast: A History of Changing Ideas, edited by Charlotte Townsend-Gault, Jennifer Kramer, and Ki-Ke-in, 757-84. Vancouver: UBC Press, 2013.

Joseph, Bob, and Cindy Joseph. Indigenous Relations: Insights, Tips \& Suggestions to Make Reconciliation a Reality. Indigenous Relations Press, 2019.

Kim, Seulah, Dong-uk Im, Jongoh Lee, and Heejae Choi. "Utility of Digital Technologies for the Sustainability of Intangible Cultural Heritage (ICH) in Korea." Sustainability 11, no. 21 (November 2019): 19. https://doi.org/10.3390/su11216117.

Lutsky, Karen, and Sean Burkholder. "Curious Methods." Places Journal, May 23, 2017. https://doi.org/10.22269/170523.

Malnar, Joy Monice, and Frank Vodvarka. New Architecture on Indigenous Lands. Minneapolis: University of Minnesota Press, 2013. 
Mosleh, Omar. “'I'm Not Your Token': Indigenous Employee Accuses Alberta Museum of Systemic Racism.” News. The Toronto Star, June 27, 2020. https://www.thestar.com/ news/canada/2020/06/27/im-not-your-token-indigenous-employee-accuses-alberta-museum-of-systemic-racism.html.

Nicola Jones. "Redrawing the Map: How the World's Climate Zones Are Shifting - Yale E360." Yale Environment 360, October 2018. https://e360.yale.edu/features/redrawing-the-map-how-the-worlds-climate-zones-are-shifting.

Noble, Allen. Vernacular Buildings: A Global Survey. Bloomsbury Publishing, 2013.

Pender, Robyn, and Daniel Lemieux. "The Road Not Taken: Building Physics, and Returning to First Principles in Sustainable Design.” Atmosphere 11, no. 6 (June 11, 2020): 620. https://doi.org/10.3390/atmos 11060620.

Philips, Ruth B., Anderson, Janice, and Brydon, Sherry. "Arrow of Truth: The Indians of Canada Pavilion at Expo 67.” In Museum Pieces, 27-47. McGill-Queen’s University Press, 2011.

Polo, Marco, and Colin Ripley. Architecture and National Identity / Architecture et Identite Natioinal: The Centennial Projects 50 Years On / Les Projets Du Centenaire 50 Ans plus Tard. Bilingual edition. Halifax, Nova Scotia, Canada: Dalhousie Art Gallery, 2014.

Ridington, Robin. "Northern Hunters." In America in 1492: The World of the Indian Peoples before the Arrival of Columbus., edited by Josephy, Alvin M. Jr., 22-47. New York: Vintage Books, a Division of Random House, Inc., 1991.

Ross, Susan M. "Re-Evaluating Heritage Waste: Sustaining Material Values through Deconstruction and Reuse." The Historic Environment: Policy \& Practice 11, no. 2-3 (July 2, 2020): 382-408. https://doi.org/10.1080/17567505.2020.1723259.

Rubel, Franz, and Markus Kottek. "Observed and Projected Climate Shifts 1901-2100 Depicted by World Maps of the Köppen-Geiger Climate Classification.” Meteorologische Zeitschrift 19, no. 2 (April 1, 2010): 135-41. https://doi.org/10.1127/09412948/2010/0430.

Rudofsky, Bernard. Architecture Without Architects : A Short Introduction to Non-Pedigreed Architecture. Garden City, New York: Doubleday \& Company, Inc., c1964. http://hdl.handle.net/2027/mdp.39015053133032.

Rutherdale, Myra, and Jim Miller. "'It's Our Country': First Nations' Participation in the Indian Pavilion at Expo 67." Journal of the Canadian Historical Association / Revue de La Société Historique Du Canada 17, no. 2 (2006): 148-73. https://doi. org/10.7202/016594ar.

Shields, Rob, Kieran Moran, and Dianne Gillespie. "Edmonton, Amiskwaciy Wâskahikan, 
and a Papaschase Suburb for Settlers.” The Canadian Geographer / Le Géographe Canadien 64, no. 1 (March 2020): 105-19. https://doi.org/10.1111/cag.12562.

Simons, Paula. "Wanted: An Idea Good Enough to Save the Historic RAM." News. Edmonton Journal, December 20, 2017. https://edmontonjournal.com/opinion/columnists/paula-simons-wanted-an-idea-good-enough-to-save-the-historic-ram.

Whose Land? “Territories By Land.” Accessed January 10, 2021. https://www.whose.land/ en/.

Todd, Zoe. "New Plans for Historic Royal Alberta Museum Site." News. CBC News, March 4, 2016. https://www.cbc.ca/news/canada/edmonton/new-plans-for-historic-royal-alberta-museum-site-1.3475299.

Tota, Kasia. "The Old/New Neighbours - Breaking Ground in Collaborative Land Use Planning between First Nations and Local Governments." In Plan Canada, 3rd ed., 4:31-33, 2003.

United Nations. "THE 17 GOALS | Department of Economic and Social Affairs." un.org. Accessed October 5, 2020. https://sdgs.un.org/goals.

"Vernacular, Adj. and n." In OED Online. Oxford University Press. Accessed January 11, 2021. http://www.oed.com/view/Entry/222608.

Walz, Jay. “Canadian Indians' Expo Exhibit Indicts White Man.” New York Times. July 16, 1967.

Weltman-Cisneros, Talia. "'From Objects to Subjects: The Museumification of Blackness in Mexico." African and Black Diaspora: An International Journal 13, no. 1 (January 2, 2020): 80-97. https://doi.org/10.1080/17528631.2019.1637604.

Wong, Julia. "Province Seeks Ideas on How to Redevelop Royal Alberta Museum Site." News. Global News, March 5, 2016. https://globalnews.ca/news/2559879/provinceseeks-ideas-on-how-to-redevelop-royal-alberta-museum-site/. 


\section{APPENDIX}

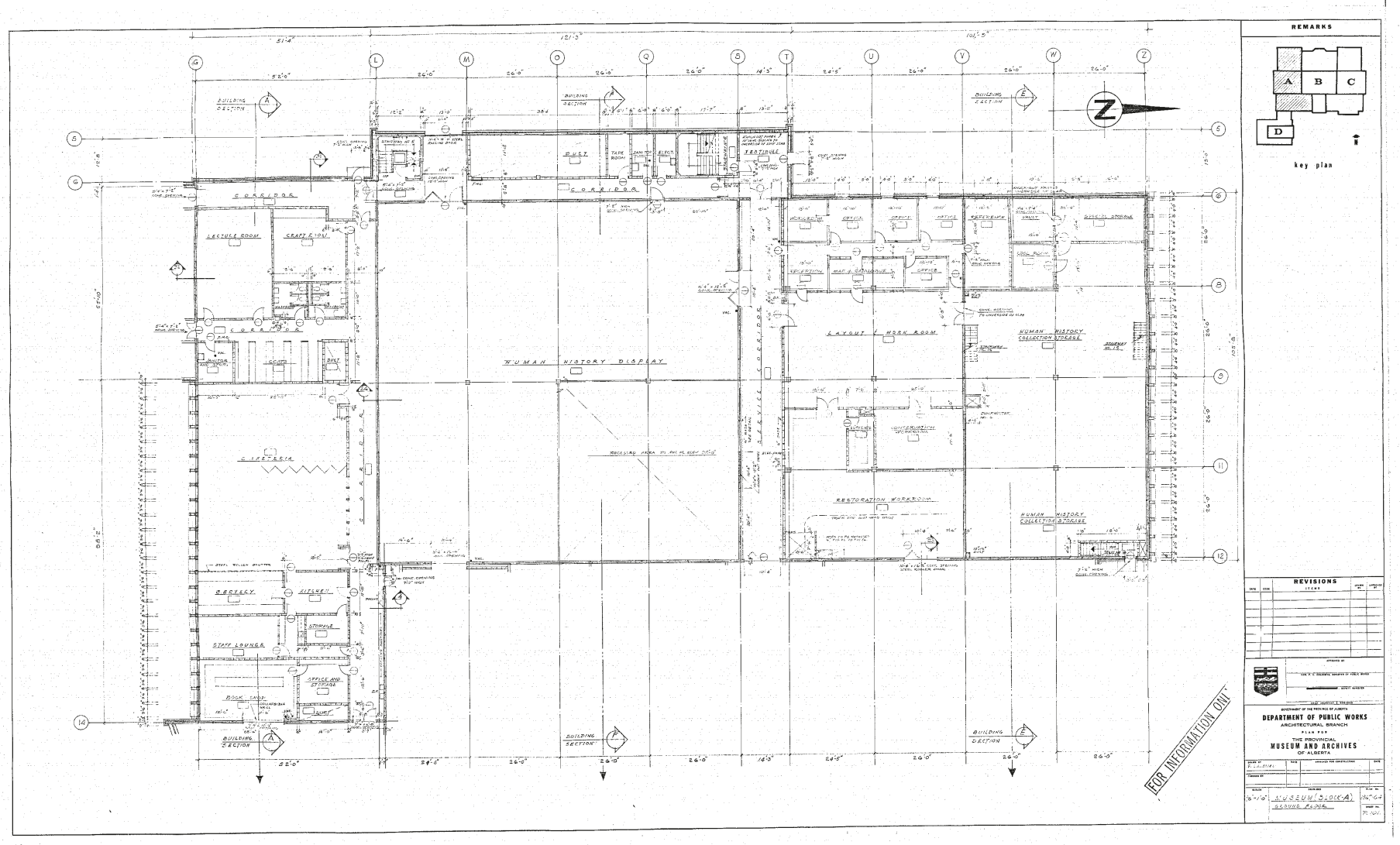

Fig. 0.2: Original Alberta Public Works Plans of the Former Royal Alberta Museum 

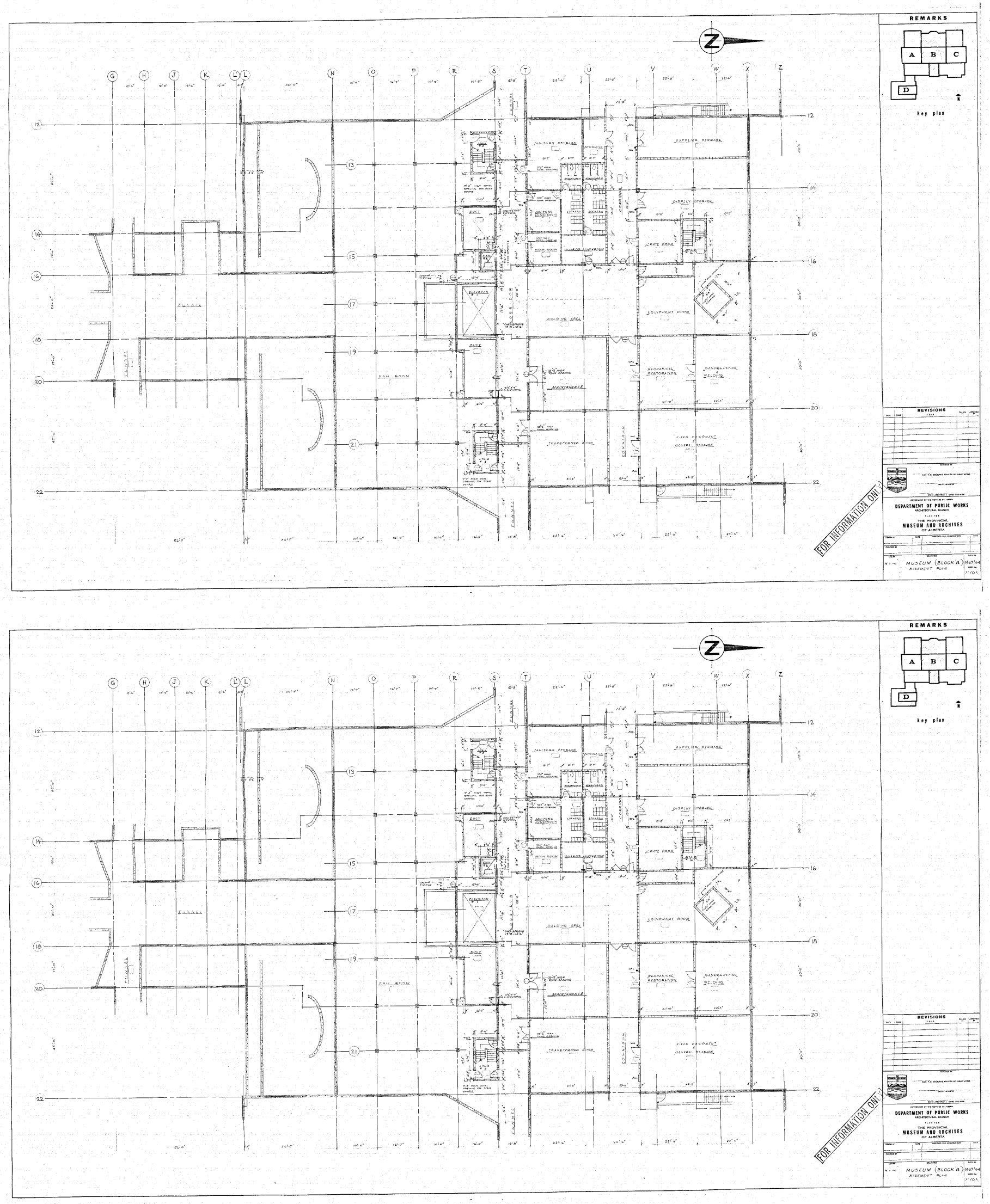

Fig. 0.3: Original Alberta Public Works Plans of the Former Royal Alberta Museum 

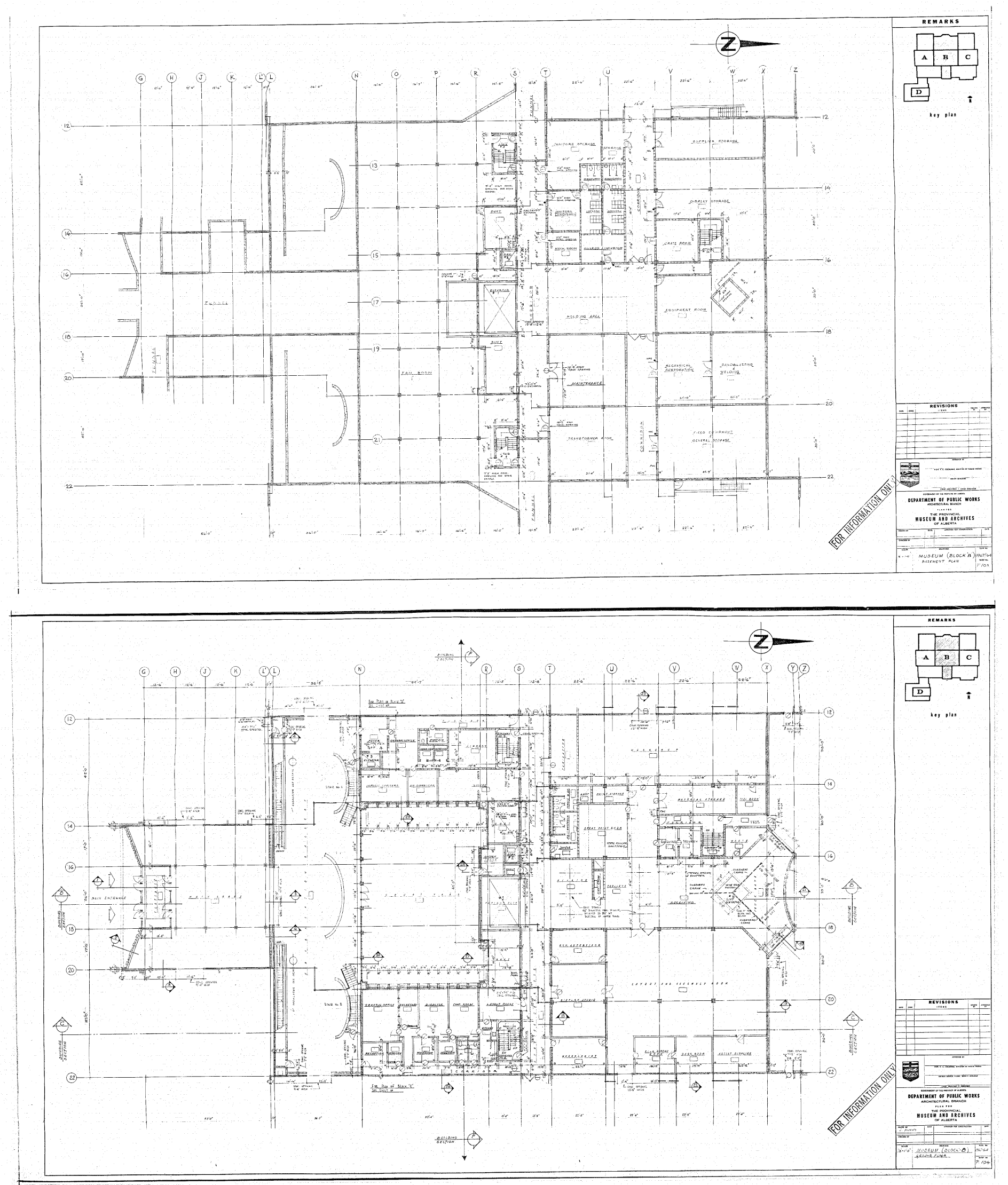

Fig. 0.4: Original Alberta Public Works Plans of the Former Royal Alberta Museum 

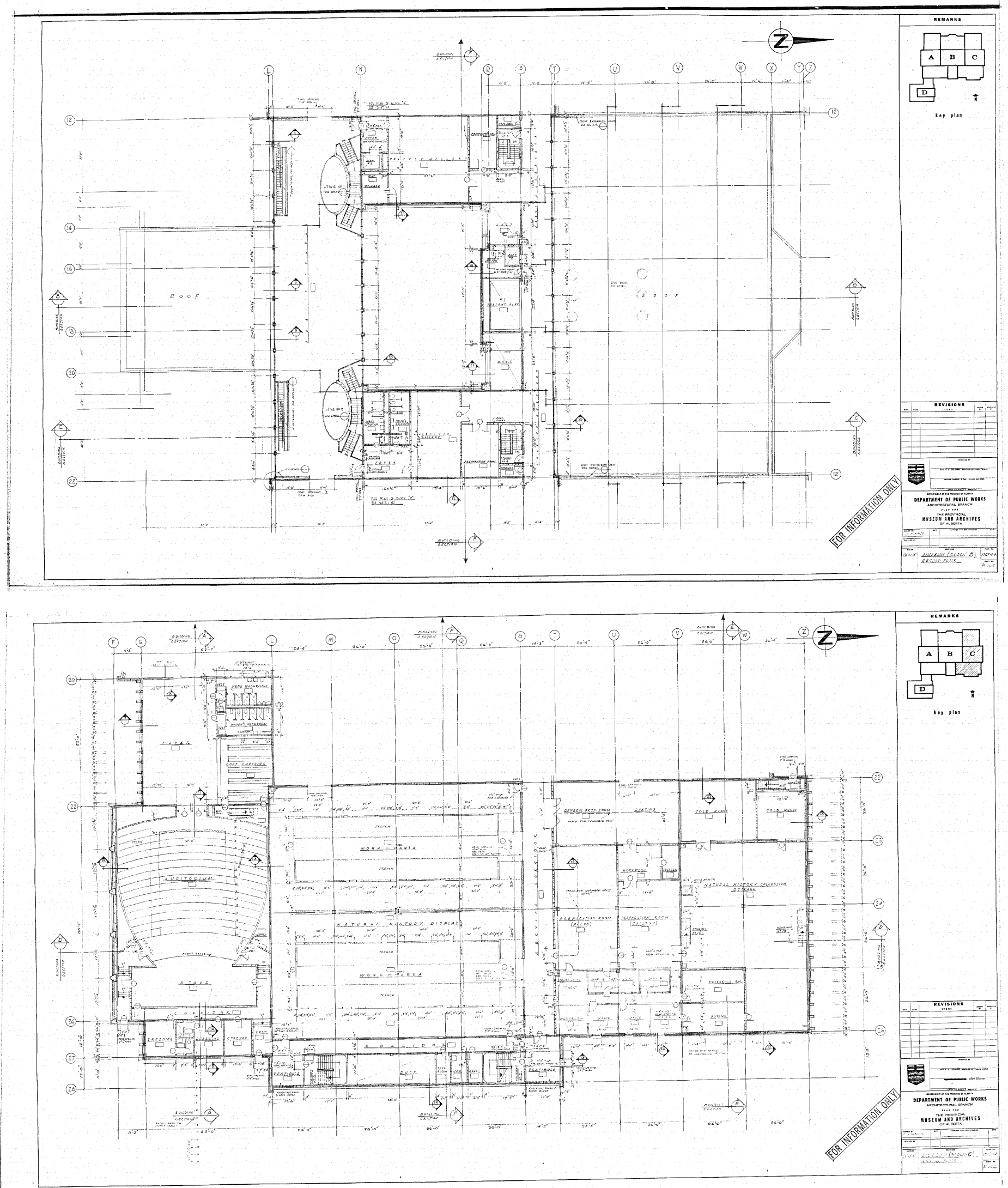

Fig. 0.5: Original Alberta Public Works Plans of the Former Royal Alberta Museum 

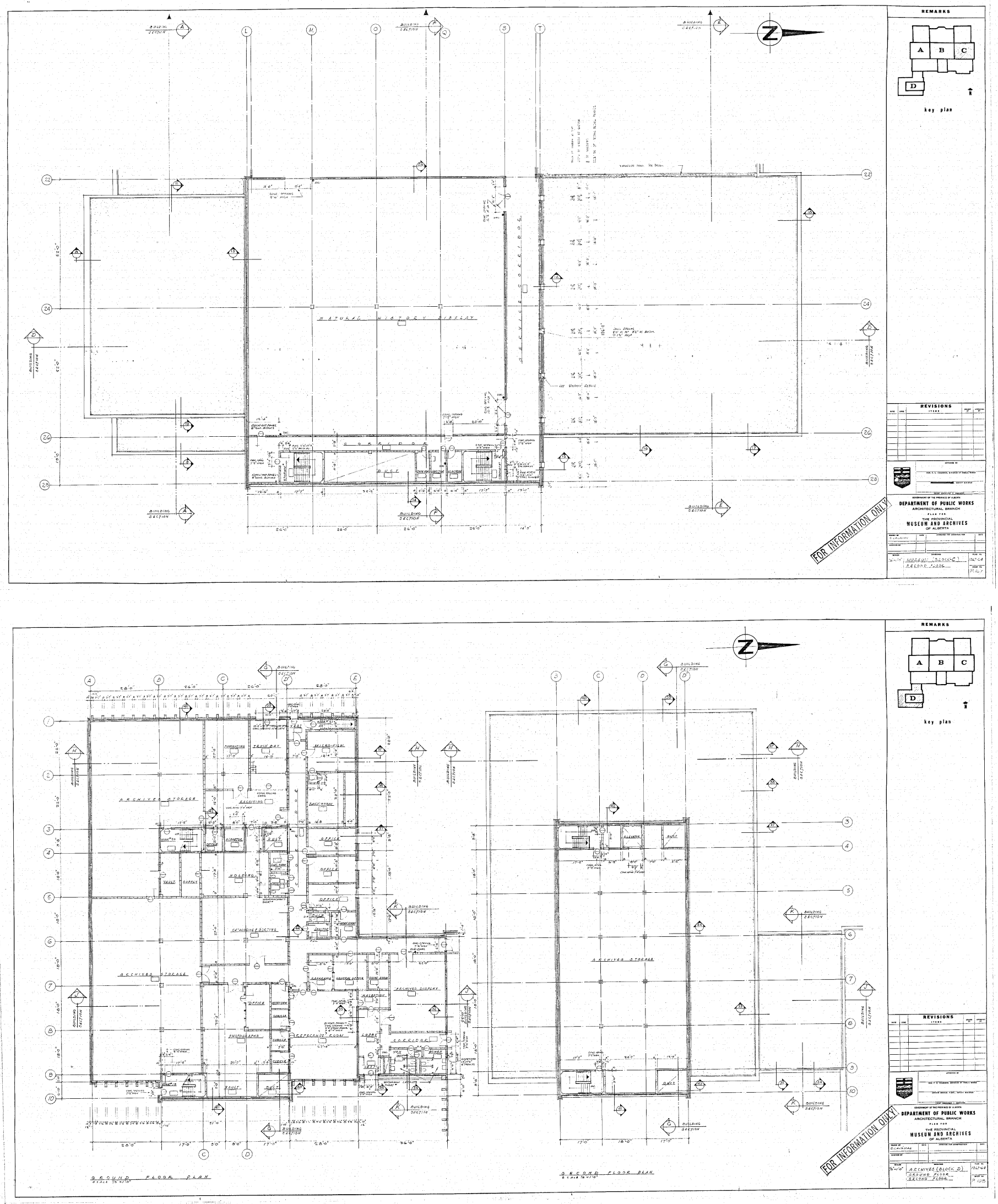

Fig. 0.6: Original Alberta Public Works Plans of the Former Royal Alberta Museum 

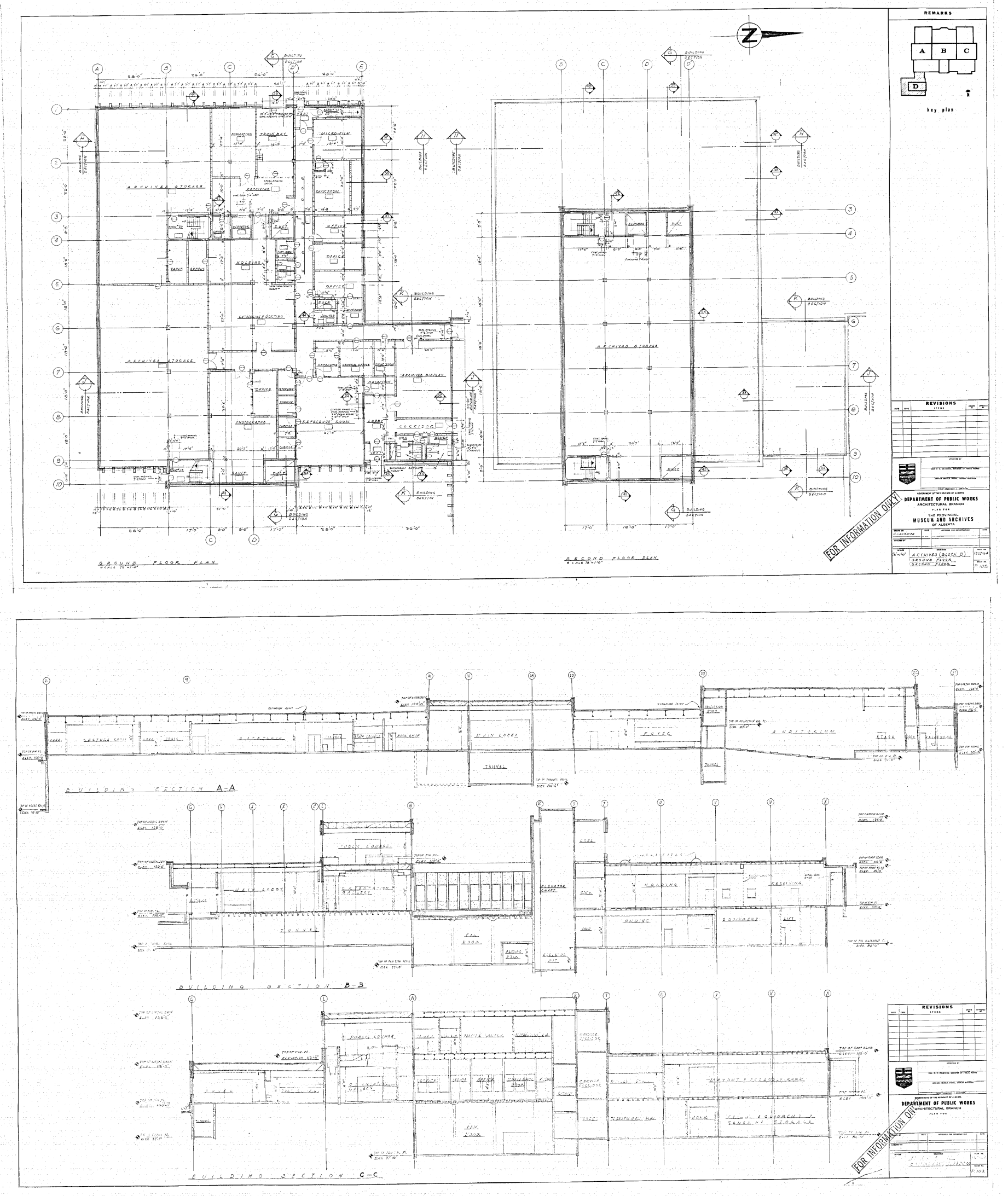

Fig. 0.7: Original Alberta Public Works Plans of the Former Royal Alberta Museum 

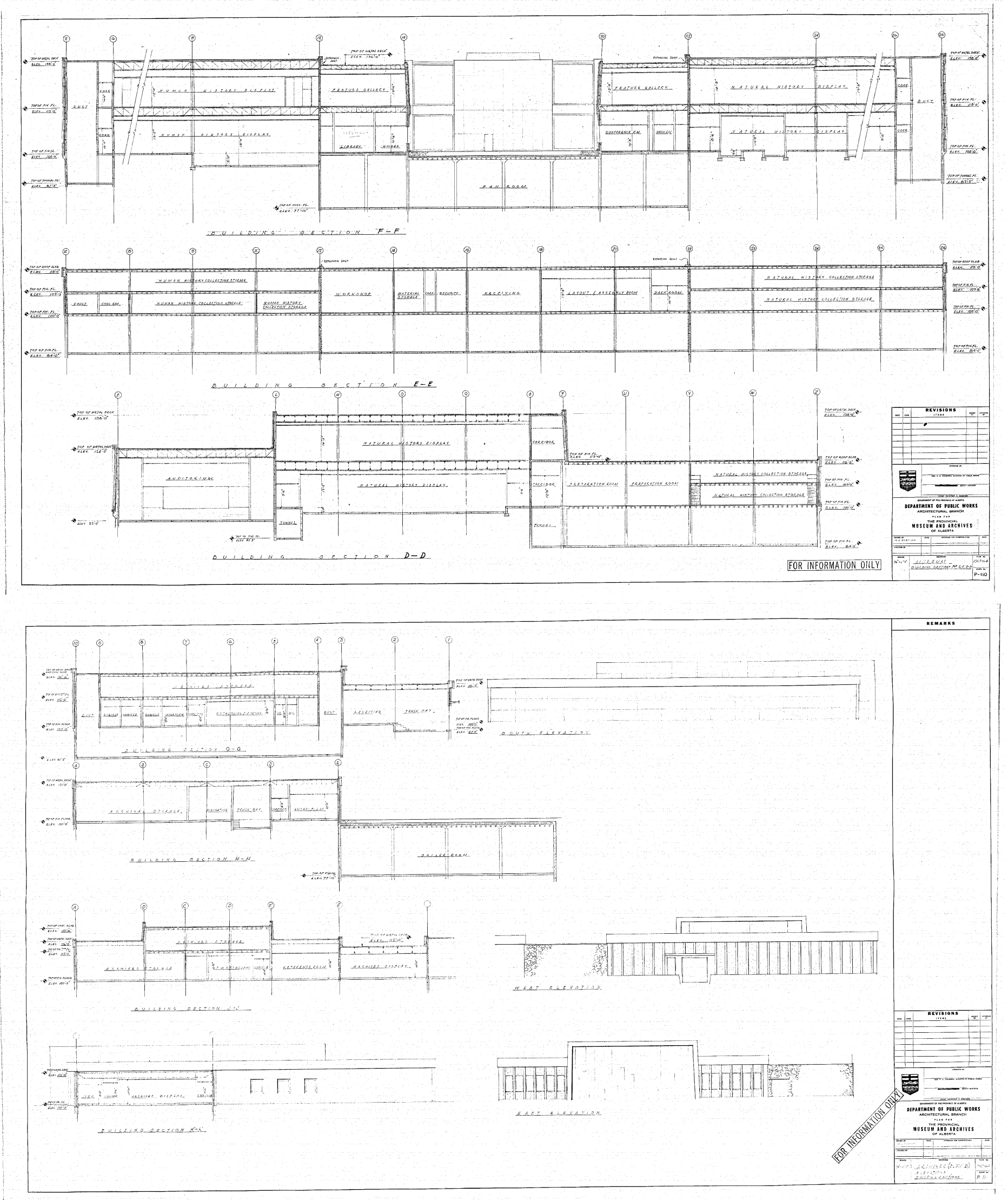

Fig. 0.8: Original Alberta Public Works Plans of the Former Royal Alberta Museum 